EMÍLIA VILLANI

\title{
AbORdAgem Híbrida PARA MOdelagem de Sistemas de AR CONDICIONADO EM EdIFÍCIOS \\ INTELIGENTES
}

Dissertação apresentada à Escola

Politécnica da Universidade de São Paulo para obtenção do título de Mestre em Engenharia 
EMÍLIA VILLANI

\section{AbORdAgem Híbrida PARA MOdelagem de Sistemas de Ar Condicionado EM Edifícios INTELIGENTES}

Dissertação apresentada à Escola Politécnica da Universidade de São Paulo para obtenção do título de Mestre em Engenharia

Área de Concentração:

Engenharia Mecânica

Orientador: Paulo Eigi Miyagi 
A meus pais Alberto $e$

Sonia e às minhas irmãs Elvira e Anita. 


\section{Agradecimentos}

Ao meu orientador Prof. Dr. Paulo Eigi Miyagi pela sua constante orientação e permanente incentivo para o desenvolvimento deste trabalho.

Ao Prof. Diolino José dos Santos Filho e ao Prof. Newton Maruyama pelas inúmeras sugestões e contribuições realizadas durante o desenvolvimento do trabalho.

Ao Prof. Alberto Hernanez Neto pelo auxílio no que se refere à parte térmica e ao sistema de ar condicionado.

Ao grupo SED-SH pelo incentivo, discussões e contribuições.

Ao Grupo de Administração dos Sistemas de Saúde da FSP-USP e a Superintendência do HC-FMUSP, por possibilitarem a utilização do PAMB como estudo de caso.

A FAPESP pela bolsa-auxílio e pelas contribuições dos revisores.

Ao $\mathrm{CNPq}$ pelo suporte complementar às atividades do projeto.

A todos os colegas e funcionários do Departamento de Engenharia Mecatrônica e de Sistemas Mecânicos e do Departamento de Engenharia Mecânica da EPUSP, que colaboraram direta ou indiretamente para este trabalho. 


\section{Índice}

Lista de Figuras ................................................................................................................................. iv

Lista de Símbolos............................................................................................................................... vi

Lista de Abreviaturas....................................................................................................................... viii

1 Introdução ............................................................................................................................. 1

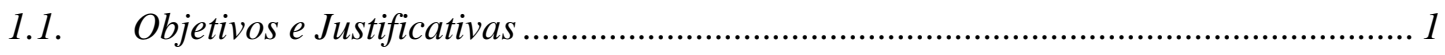

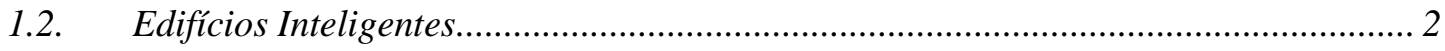

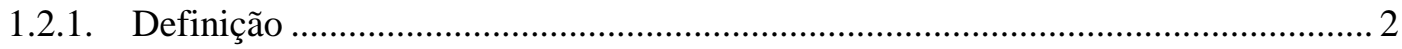

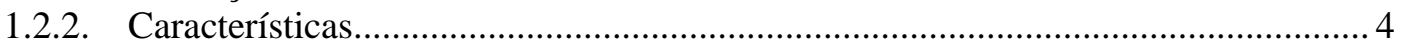

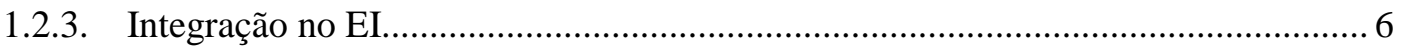

1.3. Conforto Térmico em Edificios ………………………………………………………..... 7

1.4. Organização do texto..................................................................................... 10

2 Sistemas de Ar Condicionado em Edifícios........................................................................ 12

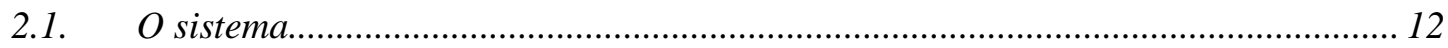

2.2. O Sistema de Ar Condicionado como Sistema Produtivo............................................ 15

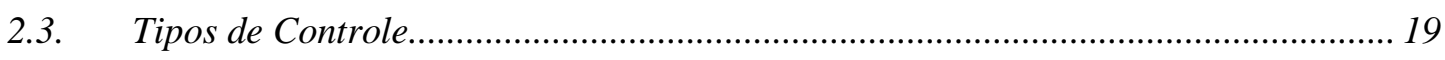

2.4. O Sistema de Controle do Ar Condicionado em Edifícios Inteligentes ...................... 21

2.4.1. Características do Sistema de Controle Programável .............................................21

2.4.2. Arquitetura do Sistema de Controle do Ar Condicionado.................................... 22

2.4.3. Controle de Zona .................................................................................................... 23

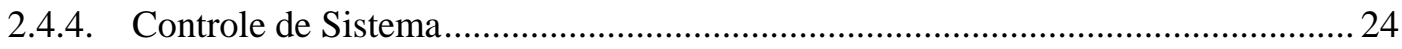

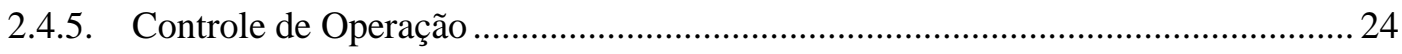

2.5. A integração em Edifícios Inteligentes ………………………………………...... 25

2.6. Tratamento de Perturbações.................................................................................... 26

3 Classificação e Modelagem de Sistemas ................................................................................. 28

3.1. Sistemas a Eventos Discretos e Sistemas de Variáveis Contínuas ............................. 28

3.2. Sistemas Híbridos ........................................................................................... 30

3.3. Sistemas de Ar Condicionado em Edifícios Inteligentes............................................. 32 


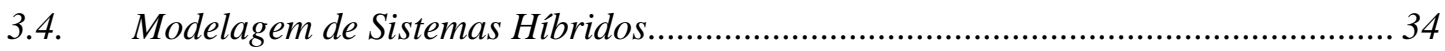

3.5. Extensões de Redes de Petri para Modelagem de Sistemas Híbridos ........................ 35

4 Metodologia para Modelagem e Simulação do Sistema de Ar Condicionado............... 42

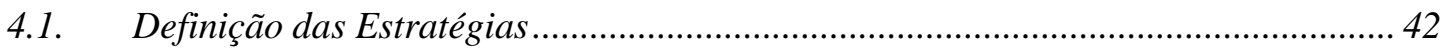

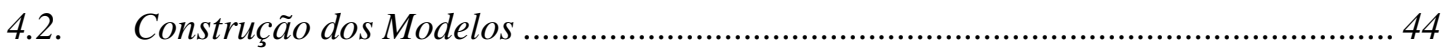

4.2.1. Modelagem do Sistema de Gerenciamento .......................................................... 45

4.2.2. Modelagem do Sistema de Ar Condicionado ......................................................5 50

4.2.3. Modelagem do Sistema de Controle Local........................................................ 56

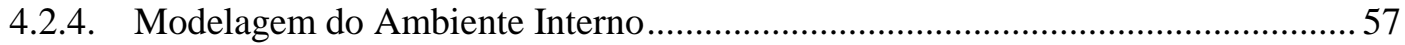

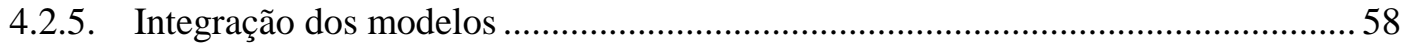

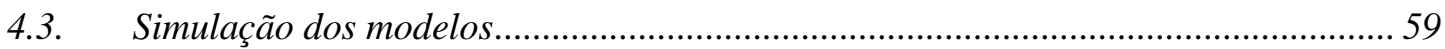

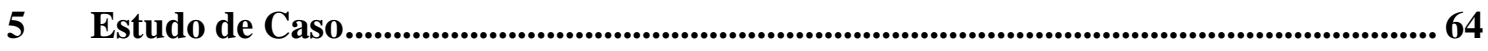

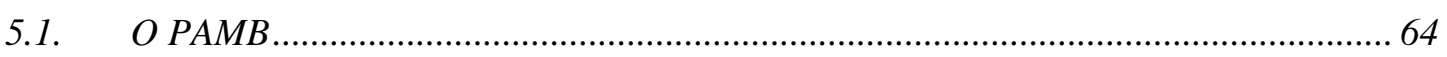

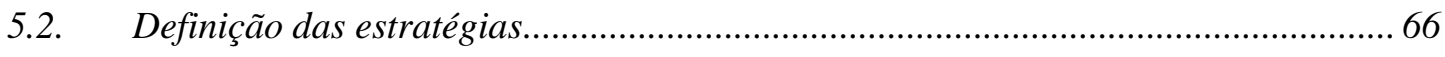

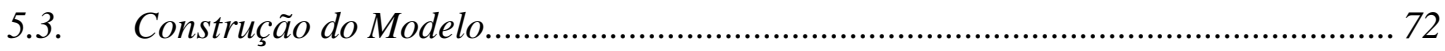

5.3.1. Modelagem do Sistema de Gerenciamento ........................................................... 72

5.3.2. Modelagem do Sistema de Ar Condicionado ....................................................... 83

5.3.3. Modelagem do Sistema de Controle Local........................................................... 109

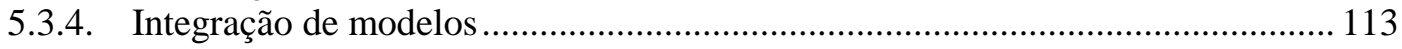

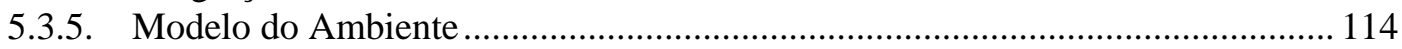

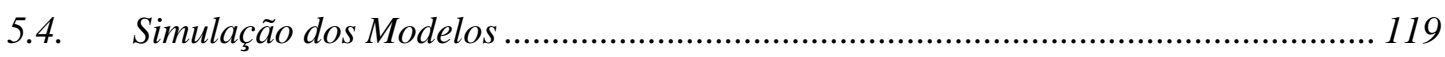

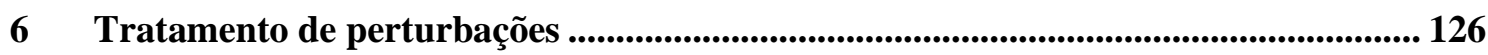

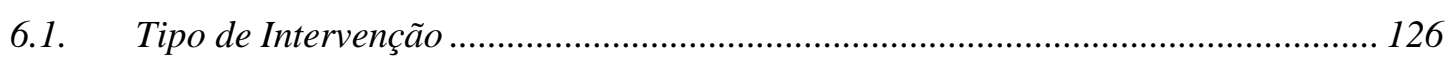

6.2. Estratégia de Controle ………………................................................................. 127

6.3. Modelagem do Tratamento de Perturbações........................................................... 128

7 Conclusões e Trabalhos Futuros ....................................................................... 136

Anexo 1 - Redes de Petri Híbridas ................................................................................... 139

Anexo 2 - Redes de Petri Diferenciais (rede RPD).............................................................. 143

Anexo 3 - Rede Híbrida Orientada a Objetos (Hybrid Object Net) .................................... 145

Anexo 4 - Rede de Petri de Alto Nível (HyNets) ......................................................................... 148

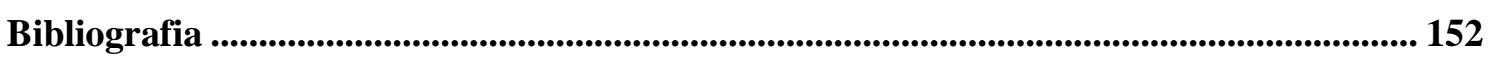

Apêndice I - Trabalhos Publicados ....................................................................................... I-1 


\section{Lista de Figuras}

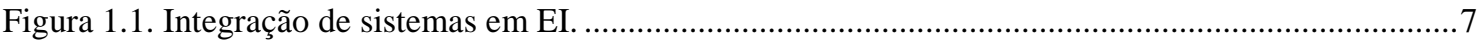

Figura 2.1. Esquema de um sistema de ar condicionado central. ........................................................ 13

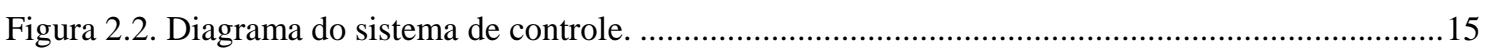

Figura 2.3. Exemplo de arranjo de pressurização para controle de fumaça num EI. .................................26

Figura 3.1. Exemplo de concepção híbrida de um sistema de ar condicionado de um EI. ........................33

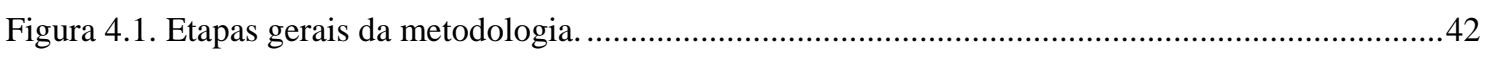

Figura 4.2. Detalhamento da etapa "Construção dos Modelos"...........................................................44

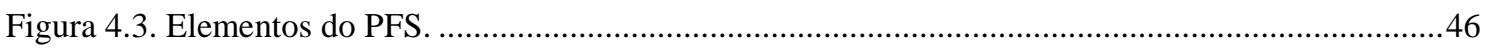

Figura 4.4. Exemplo de disparo de transição........................................................................................47

Figura 4.5. Utilização de arcos habilitadores (a) e inibidores (b) com pesos. ........................................48

Figura 4.6. Exemplos de refinamento de atividade e inter-atividade..................................................49

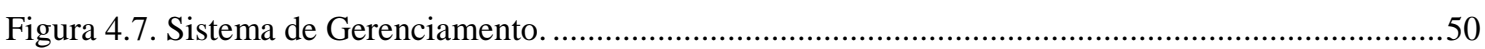

Figura 4.8. Utilização do elemento inter-atividade como elemento armazenador (a) e distribuidor (b).....51

Figura 4.9. Utilização da atividade de mistura (a) e distribuição (b) ...................................................52

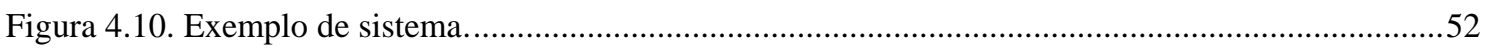

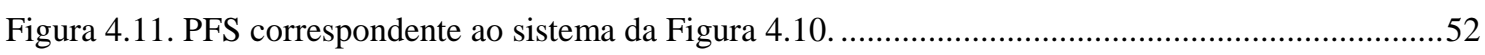

Figura 4.12. Modelo em rede PTD da atividade [Aquecimento] .........................................................55

Figura 4.13. Modelo em rede PTD de um controlador PID.................................................................56

Figura 4.14. Modelo em rede PTD de um processador de sinais contínuos. ............................................57

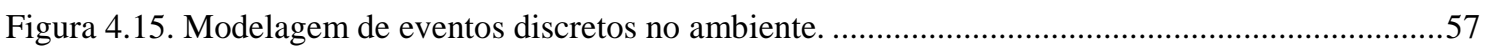

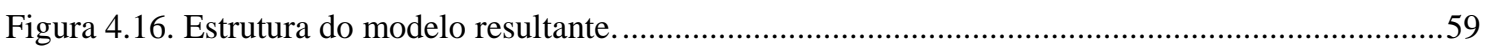

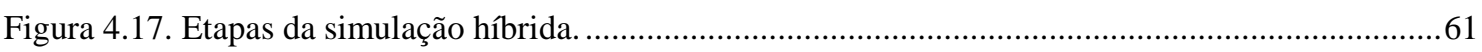

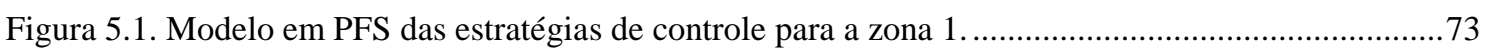

Figura 5.2. Modelo em PFS das estratégias de controle para a produção de água gelada. ........................74

Figura 5.3. Modelo em PFS das estratégias de controle para a produção de água quente.........................75

Figura 5.4. Detalhamento da atividade [Incêndio - zona 1] ...............................................................75

Figura 5.5. Detalhamento da atividade [Incêndio em zona adjacente] . ................................................76

Figura 5.6. Detalhamento da atividade [Área utilizada - zona 1] ......................................................77

Figura 5.7. Detalhamento das atividades [Aciona aquecimento na zona 1] e [Aciona resfriamento na zona

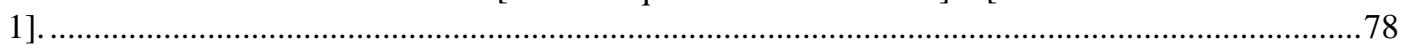

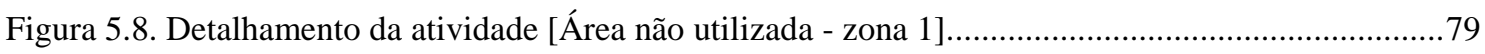

Figura 5.9. Detalhamento da atividade [Redução da produção de frio] ...................................................80

Figura 5.10. Detalhamento da atividade [Entrada em manutenção - "Chiller" 1] ...................................81

Figura 5.11. Detalhamento de atividades em Redes de Petri................................................................81

Figura 5.12. Conexão entre estratégias de controle e operações. ........................................................8 82 
Figura 5.13. Sub-sistemas do ar condicionado do PAMB..............................................................8

Figura 5.14. Detalhamento da atividade [Produção de Água Gelada]......................................................85

Figura 5.15. Detalhamento da atividade [Produção de Água Quente]....................................................85

Figura 5.16. Detalhamento da atividade [Condicionamento do $\mathrm{Ar}$ - Subsistema 1]................................86

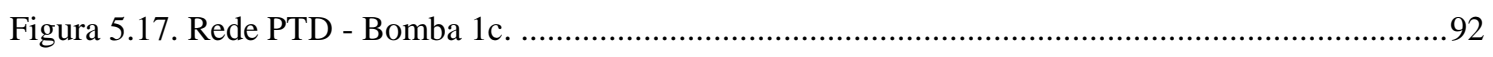

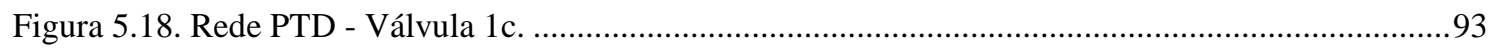

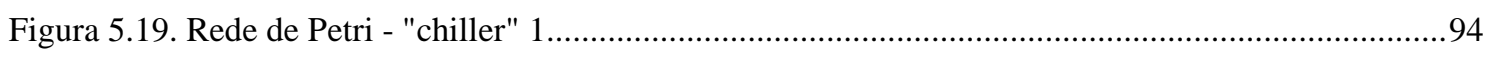

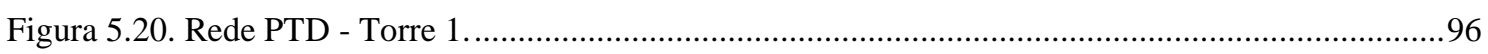

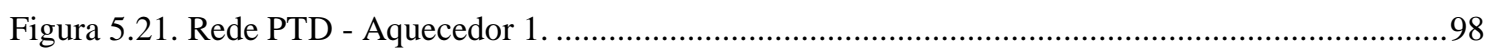

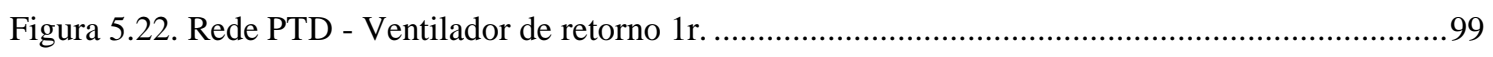

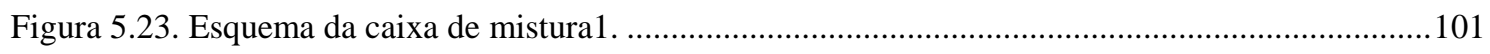

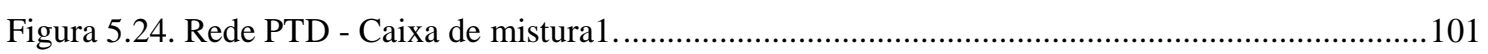

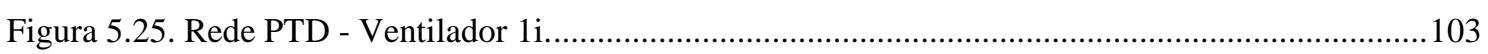

Figura 5.26. Esquema da válvula da serpentina de água fria........................................................... 104

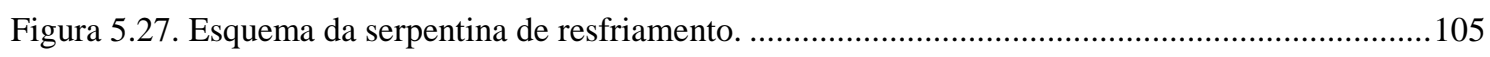

Figura 5.28. Rede PTD do controlador de resfriamento da zona 1 ........................................................110

Figura 5.29. Modelo para redução/aumento da retirada de carga térmica. .............................................111

Figura 5.30. Modelo para determinação da necessidade de chavear controladores de

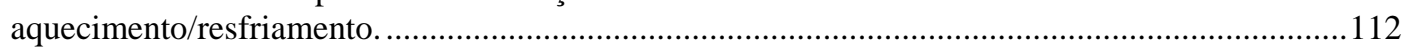

Figura 5.31. Exemplo de conexão entre modelos.................................................................................. 113

Figura 5.32. Exemplo de modelos em redes de Petri da ocorrência de eventos discretos. .......................116

Figura 5.33. Exemplo de modelo construído no simulador de Redes de Petri ......................................120

Figura 5.34. Evolução no tempo da temperatura na zona.................................................................... 123

Figura 5.35. Evolução no tempo da temperatura da água na saída da serpentina...................................124

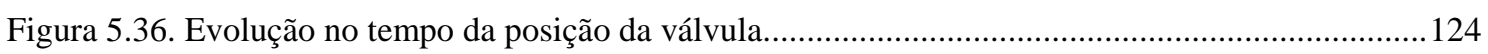

Figura 6.1. Técnica de controle proposta para tratamento de perturbações.........................................127

Figura 6.2. Modelo em rede PTD dos controladores considerando tratamento de perturbações...............129

Figura 6.3. Modelo em PFS considerando chaveamento de controladores. .......................................... 131

Figura 6.4. Detalhamento da atividade [Aumenta retirada de carga]. ...................................................132

Figura 6.5. Controle de variação da carga térmica. ................................................................................132

Figura 6.6. Evolução no tempo da temperatura no ambiente com e sem chaveamento...........................134

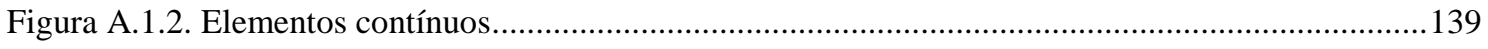

Figura A.1.3 Exemplo de modelagem de sistema contínuo..................................................................140

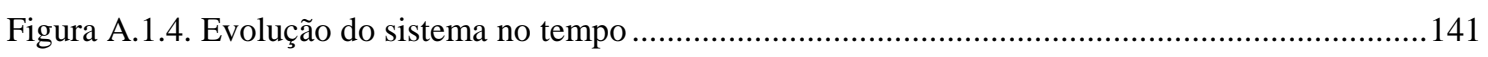

Figura A.1.5. Rede de Petri com velocidade variável........................................................................ 142

Figura A.2.2. Transição diferencial e lugar diferencial .................................................................. 143

Figura A.2. 3. Exemplo de Rede de Petri Diferencial........................................................................ 144

Figura A.3.1. Exemplo de Rede de Petri Híbrida Orientada a Objeto .................................................. 146

Figura A.4.1. Disparo de transição discreta ..............................................................................149

Figura A.4.2. Exemplo de transição contínua.................................................................................... 150 


\section{Lista de Símbolos}

A - área.

$\mathrm{Ab}_{\mathrm{f} 1}-$ abertura da válvula.

c-calor específico.

$\mathrm{c}_{\mathrm{p}}$ - calor específico a pressão constante.

e - sinal de erro.

h - entalpia da água.

HC - funções de habilitação associadas às transições.

$I_{x}$ - sinal enviado pelo BMS referente a existência de incêndio na zona $x$.

$\mathrm{K}_{\mathrm{p}}, \mathrm{K}_{\mathrm{i}}, \mathrm{K}_{\mathrm{d}}$ - ganho proporcional, integral e derivativo.

$\dot{\mathrm{m}}$ - vazão em massa.

$\mathrm{N}_{\mathrm{v}}$ - velocidade do ventilador.

$\mathbf{P}$ - lugares (Redes de Petri).

$\mathrm{P}_{\mathrm{x}}$ - sinal enviado pelo BMS referente a presença de pessoas na zona $\mathrm{x}$.

$\mathrm{Q}$ - calor, energia.

$\mathrm{S}$ - sistemas de equações diferenciais e algébricas associadas a rede.

$\mathrm{S}_{\text {caixa_x }}$ - porcentagem de renovação parcial do ar para caixa de mistura da zona $\mathrm{x}$.

$\mathrm{Si}$ - sinal de habilitação da transição para início da estratégia.

$\mathrm{Sp}$ - set-point.

Sf - sinal de habilitação da transição para inibição da estratégia.

$\mathrm{t}$ - tempo.

$\mathrm{T}$ - temperatura.

T-transições (Redes de Petri).

U - coeficiente de transferencia de calor por convecção.

UA - coeficiente global de transferência de calor. 
v - vazão.

V - saída do controlador (sinal de controle).

$\mathrm{V}_{0}$ - parâmetro de ajuste do "off-set".

vol - volume.

X - vetor de variáveis associadas a rede.

$\varepsilon$ - efetividade do trocador de calor.

$\rho$ - densidade.

$\tau$ - constante de tempo.

$\omega$ - umidade. 


\title{
Lista de Abreviaturas
}

\author{
EI Edifício Inteligente \\ BMS Building Management System \\ PFS Production Flow Schema \\ Rede PTD Rede de Petri Predicado Transição Diferencial \\ SED Sistema a Eventos Discretos \\ SVC Sistema de Variáveis Contínuas
}




\section{Resumo}

Dentro do conceito de "Edifício Inteligente", que tem como objetivo a otimização da infra-estrutura física e do ambiente em relação a aspectos de produtividade e comportamentais, este trabalho apresenta uma metodologia para modelagem e simulação de estratégias de gerenciamento de sistemas de ar condicionado onde focaliza-se a integração do ar condicionado com os demais sistemas de um edifício. Para tanto introduz-se uma abordagem híbrida onde são considerados aspectos de Sistemas a Eventos Discretos e de Sistemas de Variáveis Contínuas. Como estudo de caso apresenta-se a modelagem do sistema de ar condicionado do Prédio dos Ambulatórios do Hospital das Clínicas da Faculdade de Medicina de São Paulo, para o qual se aplica o método proposto para análise do tratamento de perturbações no sistema de ar condicionado resultantes de variações da carga térmica. 


\section{Abstract}

Considering "Intelligent Buildings", which have as one of its purpose to improve its structure and environment in order maximise the effectiveness of its occupants, this work introduce a methodology for modelling and simulation of HVAC systems. The focus is on the integration of the HVAC system with other building systems. A hybrid approach is introduced to consider both discrete and continuous aspects. As case study, we present the models for the Ambulatory Building of Hospital of the Medical School of São Paulo University. Particularly, the proposed methodology is used to analyse if the response of the HVAC system to thermal load variations can be enhanced, improving the thermal comfort, when integration between systems is considered. 


\section{Introdução}

\subsection{Objetivos e Justificativas}

Entre as diversas características dos chamados "edifícios inteligentes", encontrase a disponibilização de um ambiente próprio para o aumento da produtividade dos usuário. Uma das condições fundamentais para atender esta especificação é a garantia do conforto térmico.

Por outro lado, o sistema de ar condicionado de um edifício é responsável pela manutenção das variáveis ambientais térmicas, de modo a garantir as condições adequadas para o conforto térmico. No edifício convencional, o sistema de ar condicionado opera independentemente de outros sistemas, como o de iluminação, de controle de acesso, etc. Entretanto, considerando edifícios inteligentes, onde um sistema de gerenciamento do edifício é responsável pela integração dos diversos subsistemas, existe o acesso a informações diretamente relacionadas à operação do ar condicionado, tais como fatores relacionados à produção de calor, existência ou não de ocupação, entre outros. Através da utilização e processamento destas informações pode-se, por exemplo, determinar qual a melhor atitude a ser tomada em relação ao sistema de ar condicionado. 
Assim, o objetivo do presente trabalho é o desenvolvimento de uma metodologia ${ }^{1}$ para modelagem e simulação de estratégias de gerenciamento de sistemas de ar condicionado dentro do contexto de "edifícios inteligentes". Desta forma busca-se fornecer uma ferramenta para análise da influência das estratégias sobre o sistema de ar condicionado e sobre o condicionamento dos ambientes. Focaliza-se as estratégias onde ocorram interfaces com os demais sistemas do edifício.

Para atingir o objetivo acima proposto utiliza-se uma abordagem híbrida onde aspectos discretos e contínuos são considerados. Como aplicação da metodologia desenvolvida, propõe-se e simula-se o tratamento de perturbações no sistema de ar condicionado resultantes de variações da carga térmica.

Apresenta-se a seguir o conceito de "edifícios inteligentes", salientando-se o papel da integração de sistemas, e o conceito de conforto térmico, onde destaca-se a sua importância como elemento essencial no atendimento dos requisitos de um "edifício inteligente" e evidencia a necessidade de uma efetiva técnica de modelagem e simulação.

\subsection{Edifícios Inteligentes}

\subsubsection{Definição}

O termo "edifício inteligente" (EI) foi utilizado inicialmente no final dos anos 70 com conotação comercial e publicitária. No entanto, nos anos subseqüentes este termo adquiriu uma nova dimensão agregando conceitos de engenharia no que se refere ao projeto, construção e operação de edifícios [Arkin, 1997].

\footnotetext{
${ }^{1}$ Por metodologia entende-se um conjunto de métodos.
} 
Os EIs surgiram como o resultado de diversas transformações e evoluções ocorridas na sociedade. A chamada "era da informação" foi um dos principais direcionadores do crescimento da "inteligência dos edifícios". A globalização, o desenvolvimento e a popularização de tecnologias de comunicação e de processamento de informações deram origem a uma sociedade onde a capacidade e a habilidade de acessar e processar informações em alta velocidade têm muitas vezes um papel mais significativo que a manufatura de bens. Tornou-se, então, necessária a consideração desta nova tecnologia no projeto e operação do edifício, o que levou a introdução de requisitos como flexibilidade, produtividade e segurança [Abramson, 1995; Kujuro \& Yasuda, 1993].

De acordo com [Finley \& Kamae, 1993], o adjetivo inteligente é uma simples referência ao alto grau de automação possível através da integração dos diversos sistemas do edifício. Outros nomes utilizados para EIs são edifícios espertos, edifícios de alta tecnologia, edifícios integrados, edifícios automatizados [Kroner, 1997].

De acordo com [Becker, 1995], nos Estados Unidos, o IBI (Intelligent Building Institute) define um EI como sendo "aquele que permite a criação de ambientes produtivos, através da otimização de seus quatro elementos básicos: estrutura, sistemas, serviços e gerenciamento, assim como o inter-relacionamento entre eles, ... a única característica indispensável a todos os EIs é ter a estrutura projetada de tal modo a poder acomodar modificações convenientemente com mínimo custo.”

Segundo [Maeda, 1993], no Japão, o IBSC (Intelligent Building Study Committee) define que: “o EI deve possuir: (a) um bom ambiente para as pessoas e os equipamentos, (b) bom suporte para assegurar uma alta produtividade dos trabalhadores, (c) boa segurança contra incêndio, patrimonial e individual e, (d) operação altamente econômica". 
De acordo com [Arkin \& Paciuk, 1995], na Europa, o EIBG (European Intelligent Building Group) define um EI como sendo aquele que "cria um ambiente que permite às empresas alcançarem os seus objetivos nos negócios e maximizar a produtividade de seus ocupantes oferecendo simultaneamente uma utilização eficiente de recursos com um mínimo custo".

Para [Finley, Karakura \& Nbogni, 1991] a inteligência de um edifício reside no grau de facilidade que os ocupantes e administradores têm disponível na realização de suas tarefas. Um edifício altamente automatizado não pode ser considerado inteligente se a automação não propiciar um ambiente que favoreça a criatividade, a produtividade e a troca de informações, bem como a saúde física e mental dos usuários. Do mesmo modo, um edifício ergonomicamente projetado, mas com falta de sistemas de telecomunicação e computadores, também não pode ser chamado de "inteligente".

O EI deve ter flexibilidade e modularidade para acomodar qualquer modificação, fornecendo a base sobre a qual serão implementados outros desenvolvimentos no futuro. Assim, o EI deve permitir ao proprietário, ocupantes e administradores desfrutar de novas tecnologias, introduzindo-as com um mínimo custo e sem considerável interrupção nas atividades produtivas do ambiente de trabalho [Flax, 1991; Kroner, 1997].

\subsubsection{Características}

Os principais sistemas que compõem um EI são [Flax, 1991]:

- $\quad$ sistemas para gerenciamento e monitorização do consumo de energia;

- $\quad$ sistema de iluminação;

- $\quad$ sistemas para controle de acesso;

- $\quad$ sistemas de segurança; 
- $\quad$ sistemas de prevenção contra incêndio;

- $\quad$ sistema de telecomunicações;

- sistema de automação de escritórios;

- sistemas para gerenciamento de informações;

- $\quad$ sistemas de manutenção.

Entre as novas capacidades dos EIs, alguns exemplos são [Kroner, 1997]:

- detecção da presença humana e/ou características de ocupação em qualquer parte do edifício, visando o controle de iluminação, aquecimento, ventilação e ar condicionado, baseando-se em respostas pré programadas;

- realização de auto-diagnóstico dos componentes dos sistemas do edifício;

- ativação otimizada de elevadores, escadas rolantes e outros sistemas de locomoção;

- monitorização da segurança e acionamento do sistema de alarme de incêndio, tratando prioritariamente as localidades onde existem ocupantes, no caso de emergência;

- percepção da intensidade, ângulo da luz e radiação solar, temperatura e umidade, para ajuste das propriedades do envoltório do edifício para atingir os níveis de desempenho desejados;

- reconhecimento de digitais ou outro meio de identificação biométrica e controle de acesso ao edifício;

- detecção de odores e poluentes para o controle da ventilação;

- distribuição da energia elétrica aos equipamentos de acordo com a demanda ou de acordo com a prioridade definida e ativação automática de baterias e geradores de reserva; 
- ativação de bancos de gelo ou bancos de calor quando as tarifas de consumo de energia são menores;

\subsubsection{Integração no EI}

De acordo com [Arkin \& Paciuk, 1995] e com [Fujie \& Mikami, 1991] a chave para operação efetiva de um EI é a integração dos sistemas entre si, e entre os sistemas e a estrutura do edifício. Não existem dúvidas que integração ou inter-conexão dos sistemas, quando devidamente implementadas, melhoram a segurança e a robustez do controle dos sistemas, e, ao mesmo tempo, reduzem os custos de operação. Também é amplamente sabido que a integração dos sistemas é uma parte vital do EI.

Em um edifício convencional, o sistema de energia elétrica, de ar condicionado, de iluminação, etc. operam independentemente. Consequentemente, o gerenciamento do edifício torna-se complicado no que se refere a satisfação de demandas conflitantes. Entretanto, com a introdução de uma concepção integrada e abrangente que interrelacione os diversos sistemas, o edifício pode responder em tempo real e com melhor custo efetivo [Flax, 1991]. Pode-se então definir um EI como a integração de uma ampla gama de serviços e sistemas, cuja finalidade é criar um ambiente que conduza a uma maior criatividade, produtividade e segurança que nos edifícios convencionais [Finley \& Kamae, 1993].

De acordo com [Arkin \& Paciuk, 1995] a integração dos diversos sistemas em EIs pode ser implementada em uma estrutura onde um Sistema de Gerenciamento do Edifício (Building Management System - BMS) é responsável por compartilhar informações dos sistemas prediais em tempo real de modo a otimizar todos os controles e atender aos requisitos de conforto do usuário, de eficiência energética, entre outros (Figura 1.1). 


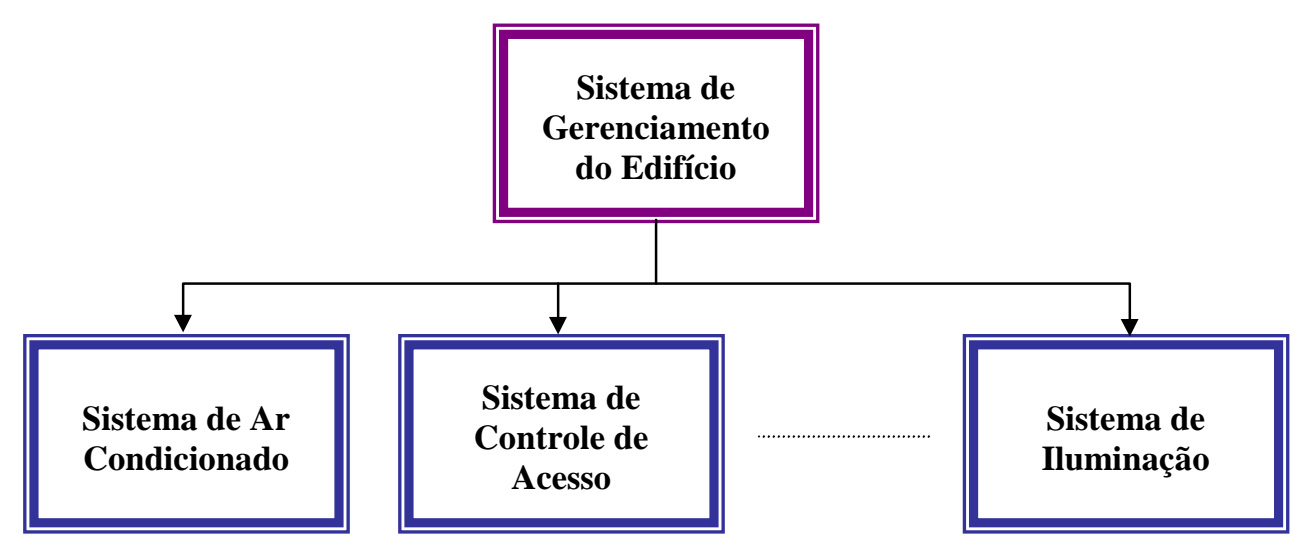

Figura 1.1. Integração de sistemas em EI.

\subsection{Conforto Térmico em Edifícios}

O homem é um animal homeotérmico. Seu organismo é mantido a uma temperatura interna aproximadamente constante, da ordem de $37^{\circ} \mathrm{C}$. A manutenção da temperatura interna relativamente constante, em ambientes cujas condições termohigrométricas são as mais variadas e variáveis, se faz por intermédio de seu aparelho termorregulador, que comanda a redução ou o aumento das perdas de calor pelo organismo através de alguns mecanismos de controle [Jabardo, 1984].

O organismo do homem gera energia através do metabolismo. Parte desta energia é transformada em trabalho e o restante é transmitido ao ambiente através dos seguintes mecanismos: convecção, radiação, evaporação por difusão e através da transpiração, e respiração [Jabardo, 1984].

O homem experimenta a sensação de conforto térmico quando, sem recorrer a nenhum mecanismo de termorregulação, está em equilíbrio térmico, ou seja, perde para o ambiente a mesma quantidade de calor produzida pelo seu metabolismo. A termorregulação, apesar de ser o meio natural de controle de perdas de calor pelo organismo, representa um esforço extra e, por conseguinte, uma queda da potencialidade de trabalho [Frota \& Schiffer, 1988]. 
De acordo com a norma ASHRAE 55-64, “conforto térmico” para uma pessoa pode ser definido como "a satisfação com o ambiente térmico onde ela se encontra", que significa que a pessoa em questão não prefere um ambiente mais frio ou mais quente [Fanger, 1972].

Nesse sentido, o desempenho durante qualquer atividade física ou mental pode ser otimizado, desde que o ambiente propicie condições de conforto, sendo esse o objetivo primeiro dos sistemas de controle ambiental [Jabardo, 1984].

O ambiente térmico é constituído principalmente pelos seguintes parâmetros:

- temperatura do ar, que influencia a troca de calor por convecção;

- temperatura radiante média (temperatura das paredes e superfícies), que influencia a troca de calor por radiação;

- velocidade relativa do ar, que influencia a troca de calor na convecção forçada;

- pressão de vapor do ambiente ou umidade, que influencia a troca de calor por respiração e por evaporação de água e suor.

Aliado a estes fatores ambientais, a troca de calor do homem com o ambiente também é influenciado por outros fatores, como por exemplo:

- metabolismo, com a produção interna de calor do corpo;

- resistência térmica das roupas, que gera uma resistência a troca de calor por convecção.

Assim, é importante determinar quais as combinações das variáveis acima que levam ao conforto térmico do homem. Dois métodos são utilizados atualmente. O primeiro método, sugerido pela [ASHRAE, 1997], é baseado em experiências onde pessoas são submetidas a diversas condições votando em relação a sua sensação térmica. O segundo método, proposto por [Fanger, 1970], consiste em equacionar a 
troca de calor do homem com o ambiente, introduzindo condições de conforto fisiológicas da temperatura da pele e da quantidade de suor e transpiração.

Resumidamente, a ASHRAE considera, para os climas mais quentes, $25^{\circ} \mathrm{C}$ como temperatura ótima, podendo variar entre 23 e $27^{\circ} \mathrm{C}$, sendo que estes valores são aplicáveis para velocidade do ar de $0,5 \mathrm{~m} / \mathrm{s}$, umidade relativa entre 40 e $60 \%$, vestimenta de meia estação, pessoa sentada, ocupação sedentária e temperatura radiante média igual a temperatura do ar.

Outro aspecto importante a respeito das condições térmicas é a salubridade do ambiente. Neste sentido os principais fatores a serem considerados são a temperatura, a umidade e a quantidade de ar exterior introduzida no ambiente. Esta preocupação é recente e causou a redução da faixa aceitável de umidade para os 40-60\% citados anteriormente [Hansen, 1991].

De acordo com outros estudos, altas temperaturas podem afetar a acuidade mental e são relacionadas ao aparecimento de alguns sintomas de SBS (Sick Building Sintomys). Aquecimento ou resfriamento inadequados ou não uniformes podem contribuir para o aumento da sensibilidade dos ocupantes a contaminantes, pois altas temperaturas e umidade aceleram a liberação de componentes orgânicos voláteis, como formaldeídos, de materiais do edifício e mobílias [Hansen, 1991].

Com a diminuição da umidade, aumenta o ressecamento interno do nariz, diminuindo a quantidade de muco, o que favorece a entrada de microorganismos. Fungos, ácaros e alguns tipos de vírus, como os da gripe, sobrevivem melhor em ambientes secos. Outros vírus, como o da poliomielite, preferem ambientes muito úmidos. Altos teores de umidade, acima de 70\%, favorecem a proliferação de bactérias. Um baixo teor de umidade causa ressecamento da pele, favorece a quebra de fibras de carpetes e móveis, aumentando o número de partículas suspensas. O teor de umidade 
mais favorável ao homem é de 50\%, onde diminui a incidência de doenças respiratórias [Hansen, 1991].

A ventilação também é um aspecto importante, pois auxilia a retirada de contaminantes expelidos por móveis e pelo próprio edifício, entretanto é necessário que o ar externo seja de boa qualidade.

As considerações acima salientam, portanto, o papel do conforto térmico como elemento importante na obtenção do bem estar dos usuários do edifícios e, conseqüentemente, no aumento da produtividade, auxiliando a atingir os objetivos propostos para o edifício inteligente.

\subsection{Organização do texto}

O Capítulo 2 apresenta as principais características do sistema de ar condicionado, bem como do seu sistema de controle, focalizando a interface com outros sistemas do edifício.

O Capítulo 3 apresenta um breve estudo sobre sistemas a eventos discretos, sistemas de variáveis contínuas e sistemas híbridos. A partir deste estudo considera-se o sistema de ar condicionado como híbrido. Apresenta-se, então, algumas técnicas de modelagem para sistemas híbridos, analisando-as no que se refere a sua adequabilidade para modelagem do sistema de ar condicionado.

O Capítulo 4 apresenta a metodologia desenvolvida para modelagem e simulação de estratégias de controle do sistema de ar condicionado.

O Capítulo 5 apresenta um estudo de caso, onde aplica-se a metodologia desenvolvida para o Prédio dos Ambulatórios do Hospital das Clínicas da Faculdade de Medicina da Universidade de São Paulo. 
O Capítulo 6 discute-se o tratamento de perturbações no sistema de ar condicionado, considerando o contexto de EI e a metodologia proposta.

O Capítulo 7 apresenta as observações finais e as principais conclusões obtidas, bem como sugestões para realização de trabalhos futuros. 


\section{Sistemas de Ar Condicionado em Edifícios}

Devido a crescente urbanização e industrialização da sociedade, as pessoas estão despendendo cada vez mais tempo em ambientes interiores, climatizados artificialmente através de sistemas de ar condicionado. Neste contexto, a principal finalidade do sistema de ar condicionado é o conforto térmico [Fanger, 1986].

Neste capítulo apresenta-se as principais características do sistema de ar condicionado, seus componentes e seu modo de operação. Aborda-se ainda seu sistema de controle, apresentando a estrutura para a sua integração com outros sistemas do EI.

\subsection{O Sistema}

As principais funções de um sistema de ar condicionado são resfriar, aquecer, umidificar, desumidificar, purificar e distribuir o ar condicionado adequadamente de modo a garantir condições de conforto e saúde para os usuários do ambiente.

Um sistema de ar condicionado pode ser divididos em três sistemas principais, o primeiro responsável pela produção de frio, o segundo responsável pela produção de calor e o último responsável pela distribuição do frio e/ou calor através do condicionamento do ar [Carrier, 1950; McQuiston \& Parker, 1994; Stocker, 1985]. Um exemplo de sistema de ar condicionado é apresentado no esquema da Figura 2.1 e seu modo de operação é apresentado a seguir. 


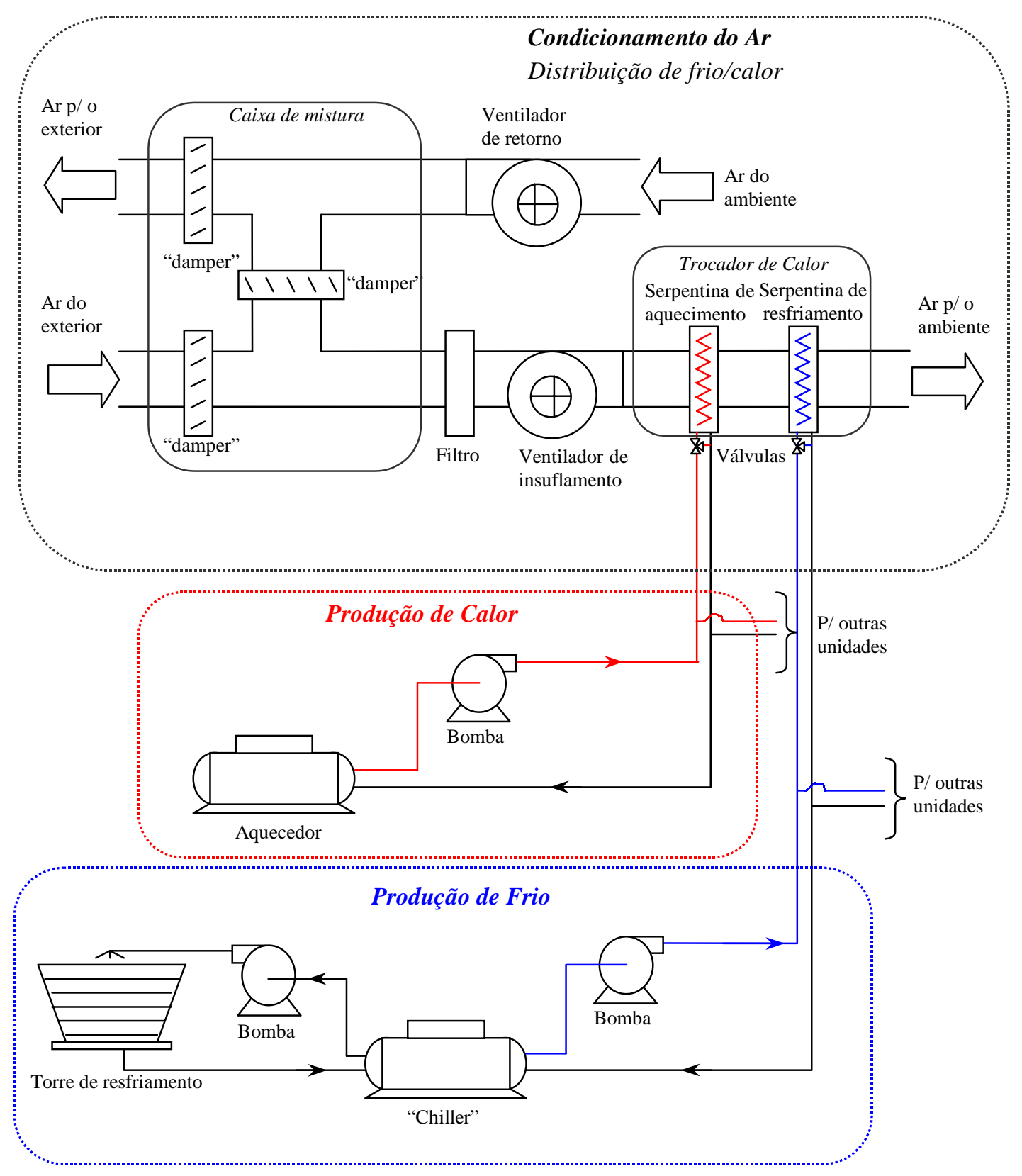

Figura 2.1. Esquema de um sistema de ar condicionado central.

\section{Produção de Frio}

A produção de frio é geralmente realizada em "chillers", onde um fluido é resfriado. Este fluido pode ser um líquido ou um gás e é comumente chamado de refrigerante. O fluido refrigerante é então bombeado até as unidades de 
condicionamento do ar onde, através de um trocador de calor, recebe o calor do ar a ser resfriado.

No "chiller" ocorre a retirada de calor do refrigerante aquecido nas unidades de condicionamento, este calor deve então ser devolvido à atmosfera. Alguns "chillers" liberam calor diretamente para o ar, outros o transmitem para água que é bombeada até as torres de resfriamento, onde o calor é liberado para a atmosfera exterior.

\section{Produção de Calor}

A produção de calor é realizada de modo semelhante. No "boiler", ou aquecedor, ocorre o aquecimento do fluido, geralmente água, que transmitirá o calor. A água quente é bombeada até as unidades de condicionamento onde trocará calor com o ar do ambiente a ser condicionado.

\section{Condicionamento do Ar}

Quanto ao condicionamento do ar, este é realizado em diversas unidades de condicionamento que podem estar espalhadas pelo edifício. Neste subsistema o ar é retirado do ambiente condicionado através de um ventilador. Uma parcela deste ar é renovada através da sua substituição por ar da atmosfera exterior. A quantidade de ar a ser renovada e a quantidade de ar exterior a ser enviada ao ambiente são determinadas na caixa de mistura. $\mathrm{O}$ ar a ser condicionado é então conduzido para a unidade de condicionamento, onde é filtrado e, posteriormente, resfriado ou aquecido, retornando então ao ambiente condicionado.

Um dos principais aspectos do sistema de ar condicionado é a disposição das zonas a serem condicionadas. Uma zona é um espaço condicionado sobre o controle de um único sensor de temperatura. Considera-se, portanto, que a temperatura no interior 
da zona é uniforme. Entretanto, edifícios comerciais geralmente não apresentam zonas com comportamento uniforme, se considerados, por exemplo, os casos onde existe produção localizada de calor causada, por exemplo, por máquinas, luminárias, etc.

Existem diversas variações para sistemas de ar condicionado em relação ao exemplo apresentado. Alguns sistemas operam controlando a temperatura do ambiente condicionado variando a quantidade de ar insuflado, são os chamados sistemas VAV (Volume de Ar Variável). Outras variações referem-se ao sistema de distribuição térmica, ao número de zonas atendidas, aos equipamentos presentes no sistema, entre outras coisas. Maiores informações podem ser encontradas em [Carrier, 1950; McQuiston \& Parker, 1994; Stocker, 1985].

\subsection{O Sistema de Ar Condicionado como Sistema Produtivo}

Considerando o sistema de ar condicionado como um sistema produtivo, onde o produto final é o ar condicionado, pode-se adotar o modelo apresentado na Figura 2.2 [Miyagi, 1996], para a classificação das diversas partes do sistema de ar condicionado.

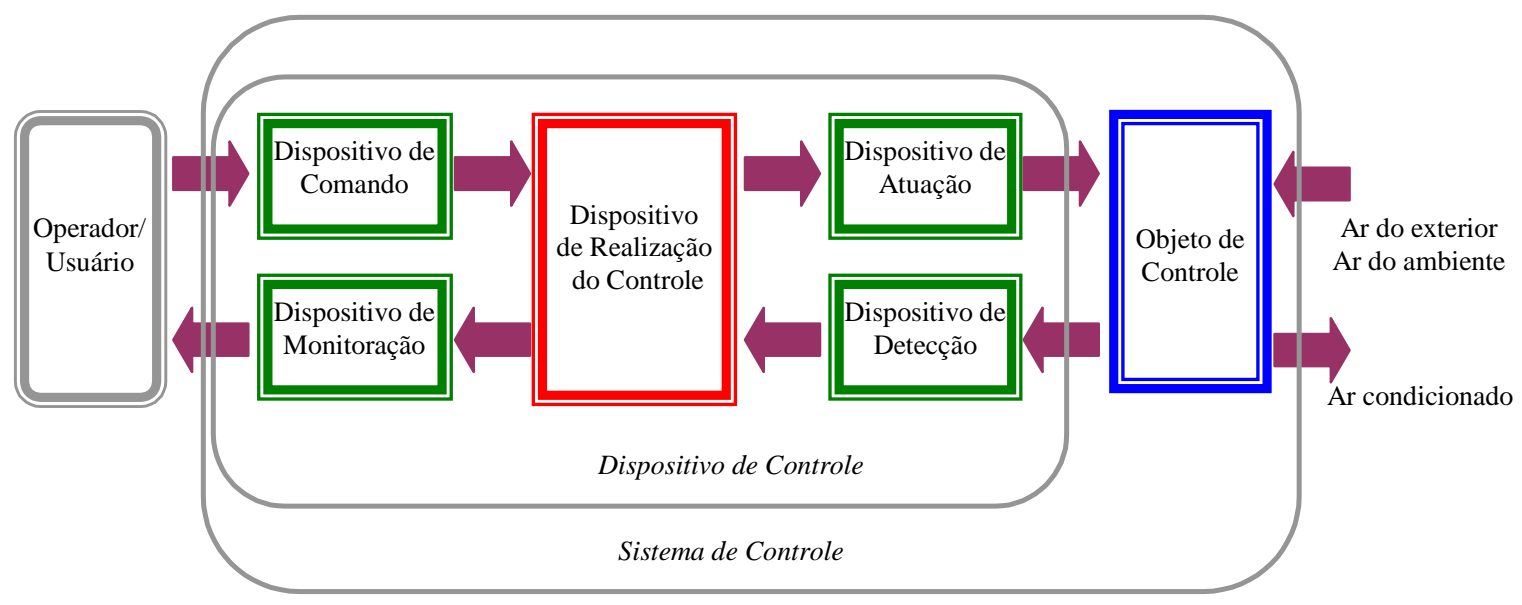

Figura 2.2. Diagrama do sistema de controle. 


\section{Objeto de Controle}

O objeto de controle no caso do ar condicionado são os fluxos de água quente e fria e o fluxo de ar enviado ao ambiente a ser condicionado, dos quais deseja-se controlar propriedades como temperatura, vazão, entre outras.

\section{Dispositivos de Atuação}

Os dispositivos de atuação são responsáveis pela modificação do estado do objeto de controle a partir do sinal recebido pelo dispositivo de realização do controle.

Os principais dispositivos de atuação do sistema de ar condicionado são:

- válvulas das serpentinas: geralmente, são do tipo de três vias e, através do desvio de parte da água quente ou fria fornecida as serpentinas, modificam a temperatura do ar que escoa através das serpentinas;

- válvulas de bloqueio: são utilizadas, entre outras coisas, para bloquear o fluxo através de "chillers" e aquecedores quando estes são desligados;

- ventiladores: são responsáveis pelo transporte do ar e pela regulagem da pressão e vazão nos dutos;

- “dampers": são registros que regulam a passagem do ar, são utilizados na caixa de mistura, onde são responsáveis pelo ajuste da proporção de ar exterior e de ar de retorno enviada às serpentinas, e para regular a quantidade de ar insuflado em sistemas VAV;

- umidificadores: aumentam a umidade do ar em sistemas com controle de umidade;

- bombas: são responsáveis pelo transporte da água através do edifício;

- aquecedores: realizam o aquecimento da água, geralmente operam com fluxo de água constante e fornecem água a uma temperatura constante pré-determinada; 
- “chillers": são responsáveis pelo resfriamento da água, geralmente operam com fluxo de água constante e fornecerem água a uma temperatura constante pré determinada;

- torres de resfriamento: são responsáveis por liberar para a atmosfera exterior o calor retirado pelos “chillers";

Dispositivos de Detecção

Os dispositivos responsáveis pela detecção do estado do sistema são os sensores e/ou transdutores. O sensor é o componente do sistema responsável pela realização da medida das variáveis de controle.

Os principais sensores utilizados no sistema de ar condicionado são:

- sensores de temperatura: podem ser utilizados para medir a temperatura do ar nas zonas, no fluxo de ar de retorno, no fluxo de ar de insuflamento, e a temperatura da água quente e da água gelada que é distribuída pelo edifício, bem como da água que retorna aos "chillers" e aquecedores;

- sensores de umidade: também chamados de higrômetros, são utilizados para medir a umidade nas zonas em sistemas com controle de umidade;

- sensores de pressão: são utilizados em sistemas do tipo VAV, para determinar a velocidade dos ventiladores;

- sensores de fluxo: são utilizados em alguns edifícios para a regulagem da velocidade dos ventiladores de retorno, principalmente em zonas próximas a portas externas.

\section{Dispositivo de Comando}

Nos sistemas de ar condicionado os dispositivos de comando geralmente se encontram espalhados nos diversos ambientes e variam de acordo com o tipo de 
sistema, englobando botões e chaves para a interface do usuário/operador com o sistema de ar condicionado.

Em sistemas automatizados, os equipamentos também podem ser comandados via interface com o computador, através de teclados, ou via aparelhos de telefone.

\section{Dispositivo de Monitorização}

A monitorização é realizada através de sinalizadores e mostradores nos equipamentos e/ou nos diferentes ambientes condicionados. Para o caso de sistemas microprocessados a interface pode ser realizada através de CRTs (Cathode Ray Tubes) e/ou monitores/mostradores digitais.

\section{Dispositivo de Realização do Controle}

Os dispositivos de realização do controle, ou controladores, recebem os sinais dos dispositivos de detecção e dos dispositivos de comando (da parte dos usuários e operadores), comparam com o valor desejado ("set point") e/ou processam os dados, e enviam os sinais de saída para os dispositivos de atuação e de monitorização (para os usuários e operadores).

No sistema de ar condicionado os controladores podem ser de diferentes tipos: eletro-mecânicos, digitais, analógicos, etc. Entretanto, no contexto de EI e em função do atual estado-da-arte da informática, considera-se aqui apenas os controladores programáveis.

Os sistemas com controladores programáveis, realizam o controle via software. Este tipo de controle também é chamado de controle digital direto (Direct Digital Control - DDC). Segundo [ASHRAE, 1991], "o controlador digital direto recebe sinais eletrônicos dos dispositivos de comando e dos dispositivos de detecção, converte os sinais eletrônicos em variáveis digitais e realiza operações lógico-matemáticas no 
processador. A saída do computador é na forma de variáveis digitais que são convertidas para sinais adequados que operam os dispositivos de atuação e os dispositivos de monitorização...”.

\subsection{Tipos de Controle em Sistemas de Ar Condicionado}

Os sistemas de controle em sistemas de ar condicionado são geralmente classificados segundo o tipo de ação corretiva gerada em resposta a uma alteração da variável de controle. Os principais tipos são apresentados a seguir.

Controle “ON-OFF”

Neste tipo de sistema de controle o dispositivo de atuação pode assumir somente duas posições, ou seja, um estado máximo e outro mínimo, ou ligado e desligado.

\section{Controle de passo ("Step Control")}

Este controladores consistem em múltiplos dispositivos de duas posições que são acionados sucessivamente de acordo com a necessidade, na tentativa de se obter um efeito mais próximo a um controle proporcional.

\section{Controle Proporcional}

Neste caso o dispositivo de controle atua proporcionalmente à diferença (erro) entre o valor medido da variável de controle e o "set point" desejado. Um controlador proporcional pode ser descrito pela Equação 1:

$$
\mathrm{V}=\mathrm{K}_{\mathrm{p}} * \mathrm{e}+\mathrm{V}_{\mathrm{o}}
$$

onde $\quad \mathrm{V}=$ saída do controlador (sinal de controle);

$\mathrm{K}_{\mathrm{p}}=$ ganho proporcional;

$\mathrm{e}=$ sinal de erro; 
$\mathrm{V}_{\mathrm{o}}=$ parâmetro de ajuste do "off-set".

Controle Proporcional e Integral (PI)

Neste tipo de controle um novo termo relacionado à integral do erro é adicionado à expressão do controle proporcional visando obtenção de melhores resultados.

O controle proporcional-integral pode ser representado pela Equação 2:

$$
\mathrm{V}=\mathrm{K}_{\mathrm{p}} * \mathrm{e}+\mathrm{K}_{\mathrm{i}} \int \mathrm{e} . \mathrm{dt}+\mathrm{V}_{\mathrm{o}}
$$

onde $\quad \mathrm{K}_{\mathrm{i}}=$ ganho integral;

$$
\mathrm{t}=\text { tempo. }
$$

Este novo termo introduzido faz com que quanto maior for o período durante o qual o erro existir, maior será o valor da saída do controlador na tentativa de eliminar o erro.

Controle Proporcional-Integral-Derivativo (PID)

Neste tipo de controle uma nova parcela é adicionada ao controle PI. A finalidade deste termo derivativo é fornecer à ação de controle um carácter antecipatório decorrente da forma de variação do erro. A expressão deste sistema é fornecida na Equação 3:

$$
\mathrm{V}=\mathrm{K}_{\mathrm{p}} * \mathrm{e}+\mathrm{K}_{\mathrm{i}} \int \mathrm{e} . \mathrm{dt}+\mathrm{K}_{\mathrm{d}} * \frac{\mathrm{de}}{\mathrm{dt}}+\mathrm{V}_{\mathrm{o}}
$$

onde $\quad \mathrm{K}_{\mathrm{d}}=$ ganho derivativo;

de/dt = derivada do erro em relação ao tempo.

No entanto, a adição do termo derivativo também faz com que o controlador seja sensível a ruídos, assim, a maioria das malhas de controle dos sistemas de ar 
condicionado obtém, na prática, resultados mais satisfatórios com um controlador do tipo PI.

\section{Controle Adaptativo}

O controle adaptativo monitora as variáveis do sistema e busca a melhoria do desempenho através do ajuste dos parâmetros do controlador. O método utilizado para a modificação dos parâmetros varia de acordo com o algoritmo do controle e com o critério de otimização. Alguns critérios são a melhoria do tempo de resposta, a diminuição do consumo de energia, entre outros.

Técnicas de controle inteligente

Além das técnicas de controle tradicional apresentadas acima, são também utilizadas em sistemas de ar condicionado técnicas de controle derivadas de inteligência artificial como fuzzy, algoritmos genéticos, redes neurais, etc.

São encontrados também exemplos de aplicação combinada destas técnicas.

\subsection{O Sistema de Controle do Ar Condicionado em Edifícios Inteligentes}

Os requisitos de EI envolvem alta flexibilidade e grande capacidade de processamento de diferentes informações, assim, os dispositivos de controle do sistema de ar condicionado são predominantemente do tipo programável

\subsubsection{Características do Sistema de Controle Programável}

Entre as principais vantagens dos sistemas de controle programável destacam-se:

- Baixo custo por função: o custo de microprocessadores, memórias e periféricos está constantemente em declínio, diminuindo o custo de hardware do sistema. Também é 
possível implementar um maior número de estratégias de controle, mais sofisticadas e eficientes.

- Flexibilidade: modificações nas seqüências de controle podem ser facilmente implementadas através de alterações no software utilizado.

- Precisão: uma maior precisão é conseguida através de algoritmos de controle mais efetivos.

- Confiabilidade: controladores digitais permitem a incorporação de subrotinas para auto-diagnóstico, de modo a aumentar a segurança e a confiabilidade do sistema.

\subsubsection{Arquitetura do Sistema de Controle do Ar Condicionado}

O sistema de controle de ar condicionado em edifícios geralmente é dividido em duas partes: controle de zona e controle de sistema.

Os controladores de zona controlam as unidades terminais que realizam o aquecimento ou resfriamento aos ambientes, como por exemplo: unidades terminais VAV, "fan-coils", equipamentos para controle da pressurização do ambiente, etc.

Os controladores de sistema são de maior capacidade de tratamento de dados. Eles são responsáveis pelo controle de equipamentos centrais como "chillers", aquecedores e unidades centrais de suprimento do ar para sistemas VAV.

Evidentemente, a automação dos edifícios envolve a integração das diversas partes do sistema de ar condicionado, assim como a integração com os demais sistemas do edifício.

Os diversos controladores devem ser integrados, compartilhando informações e atuando de modo coordenado. Esta estrutura envolve um novo nível de controle, o controle de operação, onde é realizada a interface com os operadores do sistema. 
Com a integração entre os diversos sistemas de um edifício, são introduzidas, no controle de operação, funções de integração de sistemas para permitir o interfaceamento com outros sistemas do edifício, gerenciando o sistema de ar condicionado de acordo com a ocorrência de eventos nestes sistemas. Tem-se assim, como resultado, a introdução no topo desta hierarquia do sistema de gerenciamento do edifício (BMS “Building Management System”), responsável, entre outras coisas, pela transmissão de dados entre os níveis de operação dos diversos sistemas do edifício.

\subsubsection{Controle de Zona}

O controle de zona é responsável pelo controle das propriedades da zona condicionada, como temperatura e umidade. Este sistema apresenta diversas configurações em função do tipo de sistema de ar condicionado.

Em sistemas do tipo VAV, o controle da posição dos "dampers" de insuflamento é realizado em função da temperatura do ambiente e geralmente é do tipo proporcional.

Para sistemas com volume de ar constante, o "set-point" de temperatura de insuflamento do ar é determinado através de um controlador do tipo P ou PI em função da temperatura do ambiente. Um segundo controlador controla as válvulas que regulam a vazão de água quente e fria nas serpentinas de acordo com o "set-point" desejado para temperatura de insuflamento.

Os "dampers" da caixa de mistura podem ter posições pré-definidas, neste caso é possível apenas o chaveamento entre algumas configurações. Outra opção encontrada é aquela onde a posição dos "dampers" da caixa de mistura é modificada continuamente visando o fornecimento do ar a temperatura constante. O controle realizado geralmente é do tipo PI. 
Controladores também podem ser utilizados para o controle da umidade no ambiente, através do umidificador, e para o controle da pressão nos dutos e no ambiente, através da variação da velocidade dos ventiladores.

\subsubsection{Controle de Sistema}

Em sistemas onde o ar é aquecido centralmente e distribuído para diversas zonas, a ação de aquecimento ou resfriamento do ar é realizado em função da temperatura de insuflamento, que segue um determinado "set-point". Controladores do tipo P ou PI controlam as válvulas que regulam a vazão de água quente e fria nas serpentinas. A determinação do "set-point" é realizada em função das temperaturas nas diversas zonas por um controlador do tipo proporcional.

O controle do conjunto de "chillers" e aquecedores geralmente consiste em desligar ou ligar "chillers", aquecedores e bombas de acordo com a necessidade. Em “chillers" de múltiplos compressores pode-se ainda desligar/ligar compressores, obtendo a operação do "chiller” para cargas intermediárias.

\subsubsection{Controle de Operação}

O controle de operação tem o papel de um sistema supervisor do sistema de ar condicionado. Entre suas funções encontram-se:

- funções para limitar o acesso e operação do sistema de ar condicionado somente à pessoas autorizadas;

- funções de formatação de dados, funções gráficas e funções para elaboração de relatórios;

- funções de gerenciamento de manutenção para organizar e gerar automaticamente ordens para manutenção de equipamentos baseando-se no programa de utilização do 
edifício, no histórico do equipamento ou em calendários pré-definidos pelos fornecedores;

- funções de programação para permitir aos operadores programarem remotamente os controladores de sistema e de zona;

- funções de integração para permitir o interfaceamento com outros sistemas como de segurança e de controle contra incêndio, gerenciando o sistema de ar condicionado de acordo com a ocorrência de eventos nos outros sistemas, etc.

- funções para acionar ou desligar equipamentos centrais de aquecimento ou resfriamento de água de acordo com a necessidade.

\subsection{A integração em Edifícios Inteligentes}

A integração do sistema de ar condicionado com outros sistemas visa, evidentemente, a otimização do modo de operação do edifício.

A integração deve ocorrer entre diferentes sistemas e com diversas intensidades. Um dos tipos de integração mais comumente considerado refere-se a integração com o sistema de gerenciamento contra incêndio.

Em caso de incêndio, uma vez acionado um determinado detetor de fumaça, o sistema de ar condicionado deve evitar que a fumaça seja levada a outras zonas. Para tanto o "damper" de retorno da referida zona deve ser fechado, enquanto que os "dampers" de saída de ar e entrada de ar externo devem ser abertos.

Outra medida a ser tomada é a despressurização da zona onde foi detectado fumaça e a pressurização das zonas vizinhas, de modo a evitar a difusão da fumaça.

A Figura 2.3 apresenta um exemplo de modificação da pressão nas zonas em caso de incêndio. Nesta figura cada bloco representa uma zona. As zonas com sinais negativos indicam diminuição da pressão e são aquelas onde foi detectada fumaça. As 
zonas com sinais positivos indicam aumento da pressão e são as zonas adjacentes àquelas onde foi detectada fumaça.

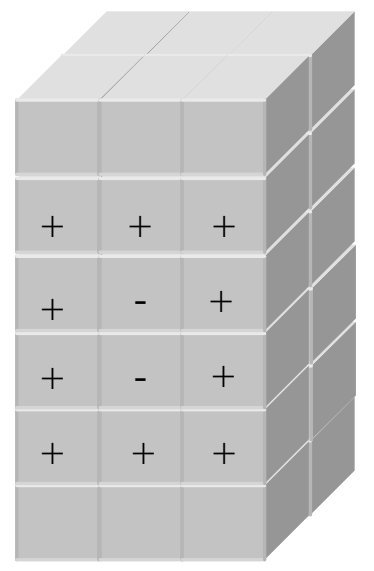

Corte vertical

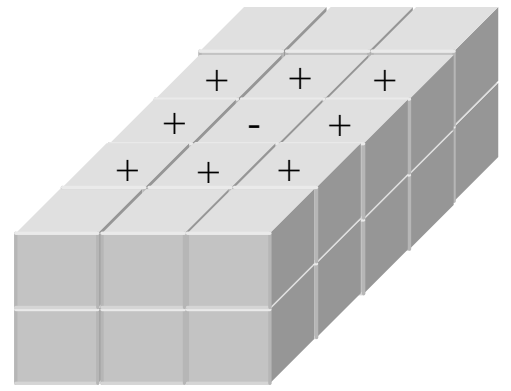

Corte horizontal

Figura 2.3. Exemplo de arranjo de pressurização para controle de fumaça num EI.

Outro exemplo de integração é aquela com o sistema de controle de presença/controle de acesso, de modo a reduzir ou desligar o ar condicionado em áreas não ocupadas, minimizando o consumo de energia.

Pode-se considerar também a integração com o sistema de manutenção, para o gerenciamento da manutenção dos equipamentos do sistema de ar condicionado, bem como com sistemas de comunicação, para obtenção de previsões do tempo que possam auxiliar no controle dos equipamentos de produção de água gelada ou quente.

Os dados referentes a outros sistemas são transmitidos através do BMS, responsável também por disponibilizar os dados do sistema de ar condicionado para outros sistemas.

\subsection{Tratamento de Perturbações}

Para o sistema de ar condicionado, modificações ou distúrbios na carga térmica correspondem a modificações na variável de controle que causam alterações no processo de condicionamento. A magnitude, a freqüência e a duração dos distúrbios 
alteram o equilíbrio entre a entrada e resposta do sistema de controle do ar condicionado. Estes distúrbios podem ser interpretados como perturbações que influem no desempenho do ar condicionado.

Em sistemas de ar condicionado observa-se que existe um atraso intrínseco entre a ocorrência da perturbação e o momento em que o sistema de ar condicionado começa a responder a esta perturbação [Honeywell, 1995]. Uma razão para este atraso no controle de sistemas de ar condicionado é que uma modificação na carga térmica não gera uma alteração instantânea das variáveis envolvidas. Ao se introduzir uma nova fonte de calor, esta aquece inicialmente o ar ao seu redor, em seguida este calor é transmitido ao restante do ambiente, até atingir o sensor. Finalmente tem-se também o atraso do próprio sensor, que demora um certo tempo para alterar suas propriedades e transmitir a informação para o sistema de controle.

Somando-se a este atraso tem-se o tempo de resposta do sistema, ou seja o tempo necessário para que o sistema retire efetivamente o calor extra introduzido e para que o ar já devidamente resfriado seja espalhado pelo ambiente.

Através da integração do sistema de ar condicionado com outros sistemas, variações de carga térmica como entrada de pessoas, início de funcionamento de equipamentos ou acionamento da iluminação, podem ser programadas, previstas e/ou detectadas e adequadamente tratadas pelo sistema de ar condicionado em tempo efetivamente menor, diminuindo o atraso do sistema e aumentando o conforto térmico do usuário. 


\section{Classificação e Modelagem de Sistemas}

Neste capítulo apresenta-se definições de Sistemas a Eventos Discretos, Sistemas a Variáveis Contínuas e Sistemas Híbridos. A partir destas definições caracteriza-se o sistema de ar condicionado em EI, considerando os objetivos deste trabalho.

Em seguida aborda-se a modelagem de sistemas híbridos, apresentando e analisando algumas das principais técnicas existentes.

\subsection{Sistemas a Eventos Discretos e Sistemas de Variáveis Contínuas}

Os sistemas podem ser classificados de acordo com diversos critérios [Blanchard \&Wolter, 81]. Uma possível dicotomia é a divisão dos sistemas em Sistemas de Variáveis Contínuas (SVC) e Sistemas a Eventos Discretos (SED) [Ho, 1987; Ho, 1989].

O principal atributo dos SVC é a continuidade no tempo. Esta característica é encontrada principalmente nos sistemas que interagem diretamente com fenômenos na natureza e cuja dinâmica é regida por leis físicas. De acordo com os especialistas das áreas de controle, este tipo de sistema sempre foi o principal objeto de estudos. Uma das principais ferramentas matemáticas utilizadas na modelagem e controle deste tipo de sistemas são os sistemas de equações diferencias que vêm sendo usados para solução de diversos problemas [Ho, 1989]. Os tipos de controle discutidos em 2.3 são basicamente para sistemas desta natureza. 
No entanto, com a evolução da tecnologia, surgiram sistemas totalmente concebidos com base em regras e procedimentos definidos pelo homem ("man-made systems"), como sistemas de manufatura integrados por computador, redes de comunicação, entre outros. A principal característica destes sistemas é que a sua dinâmica, ou seja, a modificação do seu estado ocorre principalmente em função de eventos discretos, como início do funcionamento de uma máquina, chegada de uma mensagem, etc. Estes sistemas são chamados de SED e a metodologia tradicional de equações diferenciais não é adequada para seu estudo, pois toda a sua dinâmica é caracterizada por estados discretos e eventos discretos (instantâneos), que por sua vez são definidos por regras estabelecidas pelo homem em função de algum tipo de interação discreta do sistema com a natureza [Ho, 1987].

Como evento discreto se entende aquele cuja ocorrência pode ser considerada instantânea, ou seja, de duração desprezível dentro do sistema. Por exemplo, o acendimento de uma lâmpada em uma sala pode ser considerado um evento discreto, pois o tempo entre o momento em que o usuário começou a acionar o interruptor e o momento em que a lâmpada está completamente acesa, é, geralmente, irrelevante quando se deseja avaliar a funcionalidade do ambiente.

Os SED podem, então, ser representados por uma série de estados que se mantém constante durante um certo tempo e se modificam de forma instantânea.

A classificação de um sistema em SED ou SVC depende da finalidade para qual ele é definido. A partir de um mesmo processo, pode-se definir diversos modelos de sistemas que poderão ser discretos ou contínuos, dependendo do seu uso, ou seja, das saídas que se deseja obter [Alla \& David, 1998]. 


\subsection{Sistemas Híbridos}

O termo "híbrido" em geral é utilizado para indicar heterogeneidade em relação a natureza ou composição [Antsaklis \& Nerode, 1998]. O termo híbrido, aplicado a sistemas, é interpretado como referente a existência simultânea de característica de SVC e de SED.

Existem diversas definições do que vem a ser um sistema híbrido. Estas definições caracterizam o sistema de acordo com as características da interação entre a parte com dinâmica contínua e a parte onde a evolução dos estados é dirigida por eventos discretos instantâneos.

Segundo [Alla \& David, 1998], um sistema pode ser classificado pelos tipos de variáveis que representam o estado do sistema. Assim, um sistema é SED se todas as suas variáveis são discretas e SVC se todas as suas variáveis são contínuas. Define-se, assim, um sistema híbrido como aquele contendo pelo menos uma variável discreta e pelo menos uma variável contínua.

Uma definição semelhante é adotada por [Antsaklis \& Nerode, 1998], onde um sistema híbrido é aquele onde o comportamento de interesse do sistema é determinado pela interação de dinâmicas contínuas e discretas. Os diversos sinais e variáveis podem ser dependentes do tempo, ou dirigidos por eventos, de modo assíncrono.

De acordo com [Gotesman \& Lopez-Benitez, 1996] e [Drath, 1998] um sistema híbrido corresponde a um típico sistema SVC, representado por equações diferenciais, onde eventos discretos ocorrem introduzindo modificações não-contínuas e que não podem ser representadas através de equações diferenciais.

Para [Wieting, 1996b] e [Wieting \& Sonnenschein, 1995] sistemas híbridos são sistemas onde existe uma mistura de variáveis discretas e contínuas se influenciando mutuamente em um mesmo nível hierárquico. 
Por outro lado, para alguns autores, como [Demongodin \& Koussoulas, 1998] e [Stiver, Antsaklis \& Lemmon, 1995], um sistema híbrido corresponde a uma planta contínua ou uma planta mista contínua/a eventos discretos, supervisionada por um sistema de controle que reage a eventos externos, onde existe a necessidade de uma interface híbrida para comunicação entre a planta e o sistema de controle.

Do ponto vista do sistema de controle, para [Champagnat, et all, 1998a] um sistema híbrido corresponde a interação de um sistema de controle local basicamente contínuo com um sistema supervisório a eventos discretos. [Antsaklis \& Nerode, 1998] consideram sistemas de controle híbridos aqueles resultantes da interação de um processo controlado com técnicas de controle contínuo e de acordo com um planejamento discreto. Os sistemas de controle híbridos, neste caso, contém dois tipos de componentes que interagem entre si: sub-sistemas com variáveis contínuas e subsistemas a eventos discretos. Dentro de uma organização hierárquica, a parte híbrida pode corresponder a integração de níveis superiores, onde utiliza-se abstrações de sistemas a eventos discretos, com níveis inferiores, representados por modelos de sistemas de variáveis contínuas.

Segundo [Yang, Linkens \& Banks, 1995] poucos processos, quando analisados sob o ponto de vista de integração com outros sistemas, podem ser considerados inteiramente contínuos ou discretos. A maioria dos processos contínuos sofrem modificações discretas significantes que se sobrepõem ao seu comportamento contínuo. Exemplos típicos destas interferências são falhas em equipamentos, modificações planejadas, início e conclusão de operação, operações de manutenção, etc. Situações semelhantes existem em sistemas discretos, onde eventos são influenciados pelo estado de partes contínuas. Para alguns eventos discretos são comuns pré-condições relacionadas ao estado de variáveis contínuas. Em muitos sistemas industriais, como 
plantas químicas, linhas de montagem, plantas nucleares, etc., ambas as partes, de eventos discretos e de dinâmica contínua, não são negligenciáveis. É, portanto, desejável que, em muitas situações, a modelagem, análise e controle do sistema sejam desenvolvidos de maneira híbrida.

No presente trabalho, considera-se como sistema híbrido aquele onde a não observância da parte discreta ou da parte contínua comprometem o modelo desenvolvido. Em outras palavras, é necessário a observação do sistema de um ponto de vista contínuo, considerando a sua evolução em função do tempo, mas, ao mesmo tempo, é também necessário considerar a interferência resultante de eventos discretos, que introduzem modificações discretas no sistema e que não podem ser desprezadas.

\subsection{Sistemas de Ar Condicionado em Edifícios Inteligentes}

De acordo com o apresentado anteriormente, o sistema de ar condicionado é, em geral, um sistema considerado como tipicamente contínuo, pois o processo de condicionamento do ar envolve o controle de variáveis como temperatura e umidade, que têm a propriedade de variação contínua segundo leis físicas, como a de conservação de energia e de troca de calor. A modificação do estado do sistema é, portanto, realizada continuamente em função do tempo.

Analogamente, o sistema de controle do ar condicionado tradicional também é contínuo, sendo comumente adotadas estratégias de controle automático realimentado do tipo proporcional (P) e proporcional-integral (PI).

Quando se trata o sistema de ar condicionado no contexto de edifícios inteligentes, torna-se imprescindível a interação com os demais sistemas do edifício, que apresentam características predominantemente discretas, como por exemplo: sistema de controle de acesso, sistema de iluminação, etc., o que implica em interpretar-se o sistema como 
também dirigido a eventos discretos. A ocorrência de eventos discretos gera, portanto, intervenções no sistema de controle contínuo do ar condicionado.

O sistema resultante apresenta características contínuas e discretas simultaneamente, interagindo entre si. A parte discreta do sistema é fundamental na modelagem da influência dos eventos discretos. Por outro lado, a parte contínua está intrinsecamente presente no sistema de controle do ar condicionado.

Nestes termos, o sistema deve ser representado como um sistema híbrido. A Figura 3.1 ilustra esta discussão.

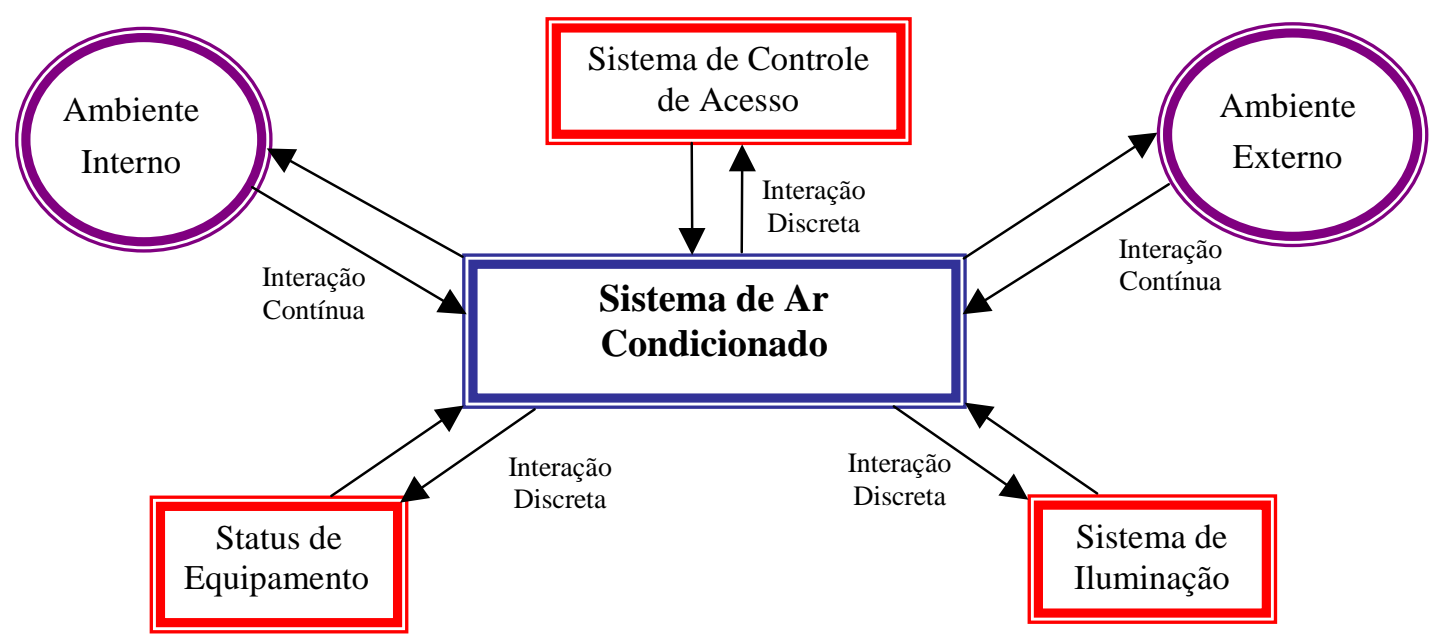

Figura 3.1. Exemplo de concepção híbrida de um sistema de ar condicionado de um EI.

No tratamento de grandes variações da carga térmica em curto espaço de tempo, uma abordagem puramente contínua não permitiria a consideração destas variações. Por outro lado, a não modelagem do comportamento contínuo implica na impossibilidade de observação dos resultados gerados pelas modificações no sistema de controle, uma vez que para tanto deve-se modelar a troca de calor que ocorre em função do tempo e em função do estado do sistema.

Adotando uma abordagem híbrida, estas perturbações podem ser devidamente tratadas e as modificações no sistema de controle podem também ser melhor 
dimensionadas para que este atue mais eficientemente, proporcionando um maior conforto ao usuário.

\subsection{Modelagem de Sistemas Híbridos}

Uma vez identificada a necessidade de utilização de uma abordagem híbrida, o passo seguinte refere-se a análise de técnicas de modelagem de sistemas híbridos considerando sua adequação para a modelagem do sistema de ar condicionado e seu sistema de controle.

Existem inúmeras abordagens genéricas para a modelagem, análise e controle de sistemas híbridos. De acordo com [Demongodin \& Koussoulas, 1998], alguns autores definem um modelo homogêneo que engloba em um único formalismo as partes de eventos discretos e de dinâmica contínua. Outros autores utilizam-se de formalismos específicos para cada parte e definem um modelo para a interface entre as duas partes.

Genericamente, as abordagens diferem entre si no que se refere à complexidade da parte continua e discreta e à finalidade do modelo, se para análise ou controle [Antsaklis \& Nerode, 1998].

Algumas abordagens consistem em extensões de modelos contínuos, descritos por equações diferenciais ordinárias nas quais são incluídas variáveis cujo valor pode ser modificado de forma descontínua no tempo. Em geral, estas abordagens têm a capacidade de trabalhar com sistemas contínuos de grande complexidade e têm como objetivo a obtenção de informações relativas a estabilidade do sistema [Antsaklis \& Nerode, 1998].

Outras abordagens consistem na modificação de técnicas de modelagem utilizadas em sistemas a eventos discretos, onde são introduzidos novos elementos que permitem a representação da dinâmica contínua do sistema. Um exemplo são as Redes de Petri 
Híbridas [Alla \& David, 1998]. Este tipo de abordagem procura enfatizar resultados de análises e simulações [Antsaklis \& Nerode, 1998].

Existem, também, abordagens intermediárias que combinam modelos de sistemas contínuos, descritos por equações diferenciais, e de sistemas discretos descritos por autômatos finitos ou Redes de Petri, onde foi introduzida uma interface para a comunicação entre os dois tipos de modelos. Um exemplo pode ser encontrado em [Valentin-Roubinet, 1998].

No escopo do presente trabalho optou-se pela utilização de técnicas derivadas das técnicas para modelagem de SED, uma vez que o objetivo do presente trabalho é a análise do sistema no nível de gerenciamento do sistema de ar condicionado, que é de caracter predominantemente discreto.

\subsection{Extensões de Redes de Petri para Modelagem de Sistemas Híbridos}

Entre os modelos para SED as Redes de Petri se destacam no que se refere a facilidade de interpretação do modelo, a representação de forma hierárquica, a facilidade de integração entre diversos sistemas e a especificação das estratégias de controle.

Esta modelagem também é apropriada para sistemas onde há interações simultâneas e paralelas entre os componentes [Matsusaki, 1998], como por exemplo em um sistema de ar condicionado multizona, onde diversas unidades operam simultaneamente sob o controle de um controlador.

O modelo básico de Redes de Petri foi proposto por Carl Adam Petri em 1962 e é também chamado de Rede de Petri Ordinária. Consiste em um grafo bipartido onde os lugares têm capacidade ilimitada de alojar marcas, as transições são conectadas aos 
lugares através de arcos direcionados formando caminhos que compõem a estrutura da rede, e uma regra estabelece o comportamento dinâmico das marcas que modelam os estados do sistema [David \& Alla, 1994].

Extensões das Redes de Petri Ordinárias incorporam regras e elementos adicionais de forma a enriquecer o poder de modelagem. Entre estas extensões destacam-se a introdução de arcos inibidores, de prioridade de disparo e de elementos temporizados [David \& Alla, 1994].

Diversas extensões também foram definidas para a modelagem de sistemas híbridos. Estas extensões variam, entre outras coisas, no que se refere a sua abrangência e complexidade. A seguir apresenta-se uma análise das extensões das Redes de Petri mais representativas encontradas na bibliografia consultada, apontando seus principais pontos positivos e negativos.

\section{Rede de Petri Híbrida}

Baseando-se na Rede de Petri Lugar/Transição, aos lugares e transições discretos são adicionados lugares contínuos, cuja marcação é um número real não negativo, e transições contínuas, as quais são associadas velocidades máximas de disparo que representam um fluxo contínuo de marcas [Alla \& David, 1998]. Esta velocidade de disparo de uma transição pode ser constante, depender da marcação dos lugares, evoluir em função do tempo, entre outras coisas. Exemplos desta rede são apresentados no Anexo 1.

O objetivo desta rede é adicionar às propriedades da rede de Petri LugarTransição a representação de um fluxo contínuo, que pode ser, por exemplo, de material ou energia. Este fluxo é representado através das transições contínuas. A marcação dos lugares contínuos representam a quantidade de material em pontos do sistema (como 
"buffers", tanques, etc.). A construção da rede híbrida é realizada principalmente a partir da observação do sistema e o modelo obtido tem um forte relacionamento físico com a estrutura do sistema, conservando a característica das Redes de Petri de fornecer uma ferramenta gráfica efetiva para análise e simulação. Em [Petterson \& Lennartson, 1996] um paralelo é realizado entre Redes de Petri Híbridas e os "Bonds Graphs" (técnica de modelagem proposta para SVC), destacando a semelhança entre a representação da parte contínua do modelo em Redes de Petri e o "Bond Graph" correspondente, sendo que as Redes de Petri Híbridas oferecem como vantagem adicional a possibilidade de modelagem dos elementos discretos.

No caso do modelagem do sistema de ar condicionado tem-se um fluxo contínuo através do sistema que poderia ser modelado através de transições. No entanto, as variáveis contínuas a serem representadas nos lugares referem-se as propriedades deste fluxo em diversos pontos do sistema, como temperatura do ar, vazão da água, etc., e não ao volume de ar ou água em pontos do sistema. Esta característica do sistema a ser modelado faz com que o modelo deva ser construído a partir da determinação das relações matemáticas entre as propriedades dos fluxos, obtidas a partir da consideração de leis físicas como troca de calor, o que restringe a utilização desta rede para o presente trabalho, uma vez que existem dificuldades intrínsecas para a modelagem precisa das relações matemáticas entre os elementos do sistema de ar condicionado.

\section{Redes de Petri Diferenciais (RPD)}

Este modelo visa unir as vantagens de uma representação gráfica com as vantagens da modelagem através de relações matemáticas entre os diversos elementos do sistema. A partir da hipótese de que um sistema contínuo pode ser representado por um número finito de equações de estado diferenciais de primeira ordem, foram 
definidas as Redes de Petri Diferenciais (RDP). Uma descrição formal das RDP pode ser encontrada em [Demongodin \& Koussoulas, 1998].

Nesta rede são introduzidos lugares diferenciais, cuja marcação é um número real, e transições diferenciais, as quais são associadas velocidades de disparo que podem ser constantes ou funções dependentes da marcação dos lugares diferenciais. Uma descrição mais detalhada e um exemplo desta rede é apresentada no Anexo 2.

Como observado anteriormente, esta rede visa apresentar maior flexibilidade pois permite a sua construção a partir da modelagem matemática do sistema, onde cada par transição-lugar representa uma equação diferencial de primeira ordem. A representação de uma equação de ordem superior deve ser feita através da partição do sistema em diversas equações, de forma semelhante ao realizado na abordagem de espaço de estados. Assim, verifica-se que a rede proposta é adequada para representação de sistemas onde a variação das variáveis contínuas representadas corresponde a somatória de diversas parcelas que são consideradas ou não de acordo com a ocorrência de eventos discretos. A representação da equação através de elementos gráficos não adiciona informações ao modelo sobre a parte contínua do sistema, em relação a representação da equação na forma de expressão matemática, uma vez que a possibilidade de adicionar funções às transições implica na não explicitação das relações entre os diversos elementos.

Quanto a sua utilização para a modelagem do sistema de ar condicionado, observa-se que ela não é adequada para representar um estado ao qual não esteja associado uma dinâmica e que seja uma combinação direta de outros estados, como por exemplo a vazão na saída de uma válvula de três vias, que é resultado direto da multiplicação da variável que representa a posição da válvula e do fluxo na entrada da válvula. 


\section{Rede Hibrida Orientada a Objetos (Hybrid Object Net)}

Este tipo de rede visa a utilização do conceito de orientação a objetos na modelagem de sistemas híbridos com grande número de componentes, baseando-se em uma rede de Petri semelhante a Rede de Petri Diferencial. Esta rede é definida em [Drath, Engmann \& Schwuchow, 1998] e une as vantagens de uma abordagem hierárquica e modular, possibilitando ainda a incorporação de conceitos como reutilização e encapsulamento de informações.

Resumidamente, os conceitos referentes a modelagem orientada a objetos são aplicados considerando-se que, nos "objetos", a marcação dos lugares são "atributos" e a estrutura da rede representa "métodos". Uma descrição mais detalhada e um exemplo são apresentados no Anexo 3.

Esta abordagem tem como vantagem sobre as Redes de Petri Diferenciais a facilidade de modelagem de sistemas complexos. Esta característica é de grande utilidade na modelagem do sistema de ar condicionado, no entanto, persiste aqui os problemas identificados nas Redes Diferenciais no que se refere a utilização dos elementos diferenciais quando da definição dos objetos.

\section{Rede de Petri de Alto Nível (HyNets)}

Este modelo utiliza redes de Petri de alto nível e equações diferenciais algébricas para descrever o comportamento de sistemas contínuos.

Esta rede foi desenvolvida a partir de uma classe especial de redes de Petri de alto nível orientada a objetos chamada Thorns (Timed Hierarchical Object-Related Nets) definida em [Schof, Sonnenschein \& Wieting, 1995].

Nesta rede, marcas são “objetos”. A linguagem utilizada na definição de “objetos” e classes é baseada em C++. Os "atributos" são variáveis do tipo "int”, "bool”, "char", 
etc., e os "métodos" são definidos através de operações matemáticas. Os elementos presentes na rede são transições (discretas e contínuas) e lugares. Às transições são associadas funções de habilitação que habilitam o disparo em função dos "atributos" dos "objetos" e funções de ação que determinam os "atributos" dos "objetos" após o disparo. Uma descrição mais detalhada e um exemplo são apresentados no Anexo 4.

Esta rede apresenta bastante flexibilidade para a modelagem de diferentes tipos de sistemas, em relação às demais redes apresentadas. No entanto a sua utilização, simulação e interpretação gráfica não é trivial, o que compromete sua aplicação prática para o presente caso.

\section{Redes de Petri Predicado/Transição Diferenciais (redes PTD)}

Este modelo combina as Redes de Petri Predicado/Transição [Genrich, 1987] com equações diferenciais algébricas. O objetivo deste modelo é o de modelar um fluxo contínuo de material que é processado em diversos equipamentos e cuja configuração é alterada de forma discreta. As Redes de Petri representam as diversas configurações discretas possíveis para os diferentes equipamentos enquanto o sistema de equações diferenciais algébricas, associados aos lugares que representam as diferentes configurações, modela a evolução contínua do estado do sistema quando em uma determinada configuração [Champagnat, 1998 e Champagnat et all, 1998 a, b e c].

Este modelo apresenta maior flexibilidade em relação às Redes de Petri Híbridas e às Redes de Petri Diferenciais no que se refere a modelagem da parte contínua, uma vez que esta parte é derivada diretamente do equacionamento matemático do sistema. Entre as desvantagens deste sistema se encontra a necessidade, durante a simulação, da coexistência de dois ambientes distintos: um responsável pela evolução da rede de Petri discreta e outro responsável pela resolução do sistema de equações diferenciais. Outra 
desvantagem é a ausência de uma representação gráfica da parte contínua que auxilie na visualização da evolução da parte contínua do sistema em função dos eventos discretos ocorridos. Esta característica faz com que o modelo seja composto por uma série de sub-redes de Petri não conectadas entre si graficamente.

Apresar das desvantagens apresentadas considerou-se esta rede como a mais adequada para a modelagem do sistema de ar condicionado principalmente devido a facilidade de construção do modelo híbrido a partir da definição das relações matemáticas entre as propriedades dos fluxos em diferentes pontos do sistema. 


\section{Metodologia para Modelagem e Simulação do Sistema de Ar Condicionado}

Este capítulo apresenta a metodologia proposta para análise por simulação de técnicas de gerenciamento do sistema de ar condicionado e foi desenvolvida através de estudos de caso. As suas principais etapas são apresentadas na Figura 4.1. O detalhamento de cada etapa é apresentado a seguir.

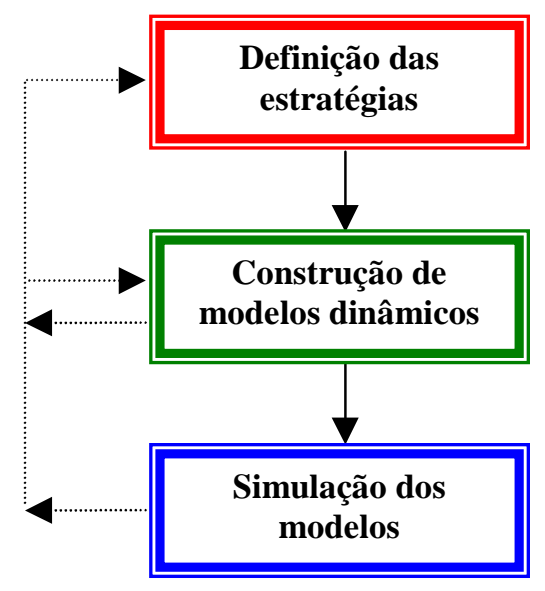

Figura 4.1. Etapas gerais da metodologia.

Observa-se que, apesar de não encontrar-se ilustrado na Figura 4.1, o retorno às etapas anteriores são considerados no decorrer da metodologia sempre que necessários.

\subsection{Definição das Estratégias}

Inicialmente devem ser definidas as estratégias a serem analisadas. Esta definição é realizada de forma descritiva e deve conter: 
- a seqüência de eventos e ações da estratégia;

- sobre quais equipamentos do sistema de ar condicionado ela atua;

- em que condições é realizada;

- em que condições deixa de ser realizada;

- etc.

Após a definição das estratégias deve-se definir quais dos seguintes aspectos deseja-se analisar:

- Influência da estratégia sobre o ambiente, ou seja, como evoluem as propriedades relacionadas ao conforto térmico, como temperatura, umidade, etc., uma vez que a estratégia é inserida no sistema de gerenciamento do ar condicionado.

- Influência da estratégia sobre o ar condicionado, ou seja, como evoluem as propriedades dos fluxos de ar e/ou água, como vazão, temperatura, etc. e/ou como evoluem os estados dos equipamentos uma vez que a estratégia é inserida no sistema de gerenciamento do ar condicionado.

- Influência da estratégia sobre o sistema de gerenciamento, ou seja, como evolui o sistema de gerenciamento do ar condicionado quando a estratégia é inserida.

- Influência da estratégia sobre outros sistemas do edifício, ou seja, qual o efeito sobre outros sistemas das modificações do ambiente e do sistema de ar condicionado geradas pela estratégia no sistema de gerenciamento do ar condicionado.

A partir dos aspectos a serem analisados define-se a abrangência do modelo a ser desenvolvido: se englobará todo o sistema de ar condicionado ou algumas zonas, se é necessário modelar o ambiente, se é necessário modelar a relação entre as diversas estratégias de controle, quais as propriedades do ambiente a serem modeladas, quais as propriedades dos fluxos de água e ar a serem modeladas, etc. 
Observa-se que o último aspecto apresentado, referente a interação com outros sistemas do edifício, engloba a modelagem de outros sistemas, o que não faz parte do escopo do presente trabalho.

\subsection{Construção dos Modelos}

A modelagem do sistema de ar condicionado, do ambiente e das estratégias de controle é realizada paralelamente. A Figura 4.2 apresenta as principais atividade desta etapa da metodologia proposta.

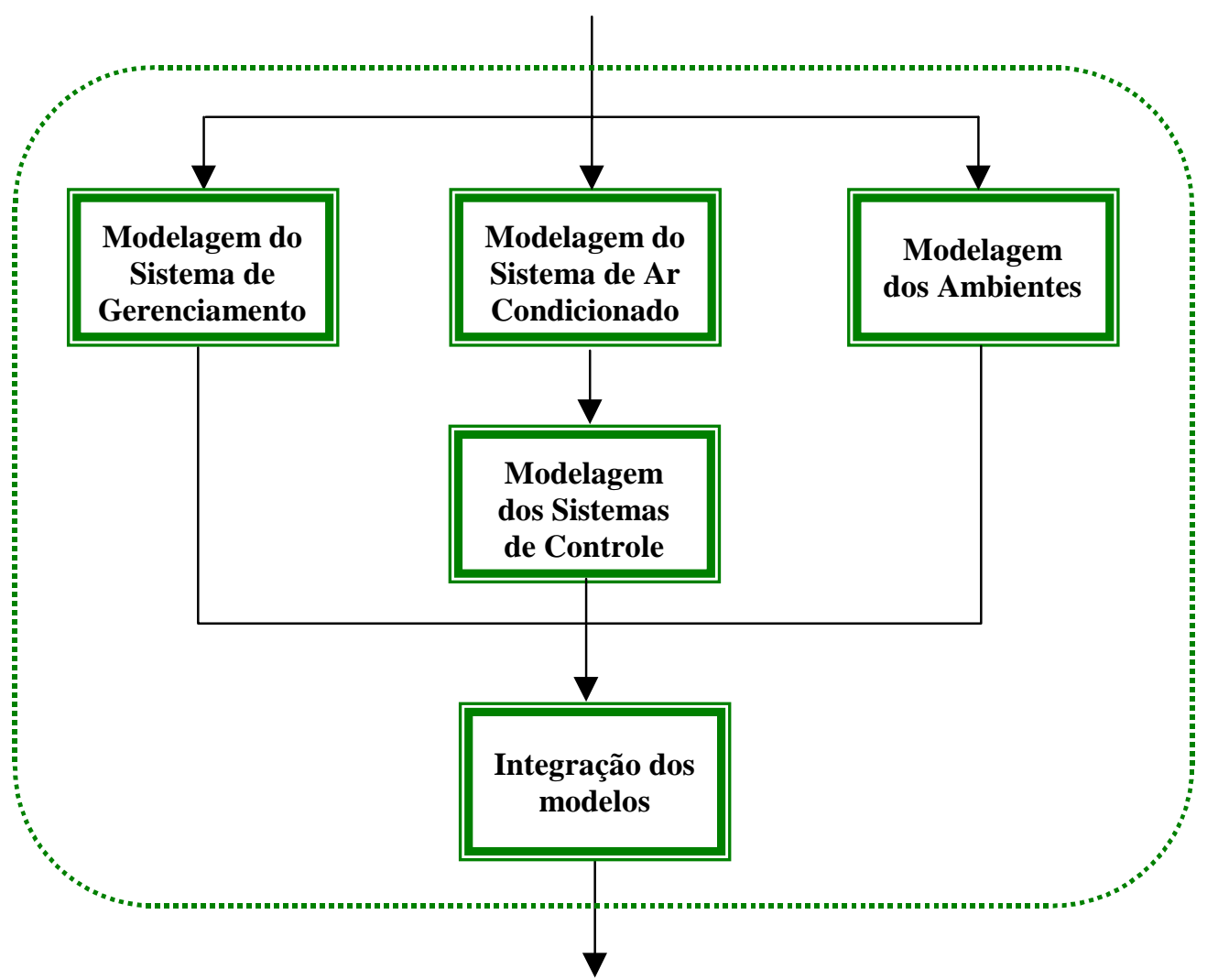

Figura 4.2. Detalhamento da etapa "Construção dos Modelos". 


\subsubsection{Modelagem do Sistema de Gerenciamento}

O sistema de gerenciamento a ser modelado pode ser considerado como um SED, pois a evolução do sistema é determinada pela ocorrência de eventos discretos como recebimento de um sinal de incêndio, detecção do estado de um equipamento, etc.

A ferramenta utilizada para a modelagem do sistema de gerenciamento são as Redes de Petri.

Dentro da abordagem através de Redes de Petri, destaca-se a Metodologia PFS/MFG, proposta em [Miyagi, 1988] para modelagem, análise e controle de sistemas. Esta metodologia baseia-se em dois tipos de redes: o PFS (Production Flow Schema) e o MFG (Mark Flow Graph), que são redes apropriadas para aplicação em diferentes níveis de modelagem, análise e controle de SED. Adota-se uma abordagem hierárquica na qual o sistema modelado em um nível macro, em PFS, é gradativamente refinado, gerando um modelo em MFG, que pode ser definido como uma rede de Petri CondiçãoEvento interpretada para especificações de controle de sistemas [Matsusaki, 1998]. No modelo resultante, as informações estruturais de todo o sistema e dos detalhes de cada elemento se encontram explicitamente descritas.

Baseando-se nesta metodologia, propõe-se neste trabalho a utilização de uma abordagem semelhante para geração de modelos em redes de Petri do sistema de gerenciamento do sistema de ar condicionado.

\subsubsection{O PFS ("Production Flow Schema")}

Para construção dos modelos, utiliza-se, inicialmente, o PFS [Miyagi, 1988].

O objetivo do PFS é identificar as atividades realizadas sobre um fluxo de itens (informação, material, etc), bem como as relações entre estas atividades, em um nível de abstração relativamente alto. Ele é composto pelos seguintes elementos (Figura 4.3): 
1. Atividades - capazes de realizar ações e modificações nos itens.

2. Inter-atividades - não realizam transformação, mas são capazes de armazenar e distribuir os itens. Entre duas atividades deve sempre existir um elemento inter-atividade.

3. Arcos direcionados - representam as relações entre as atividades e as interatividades.

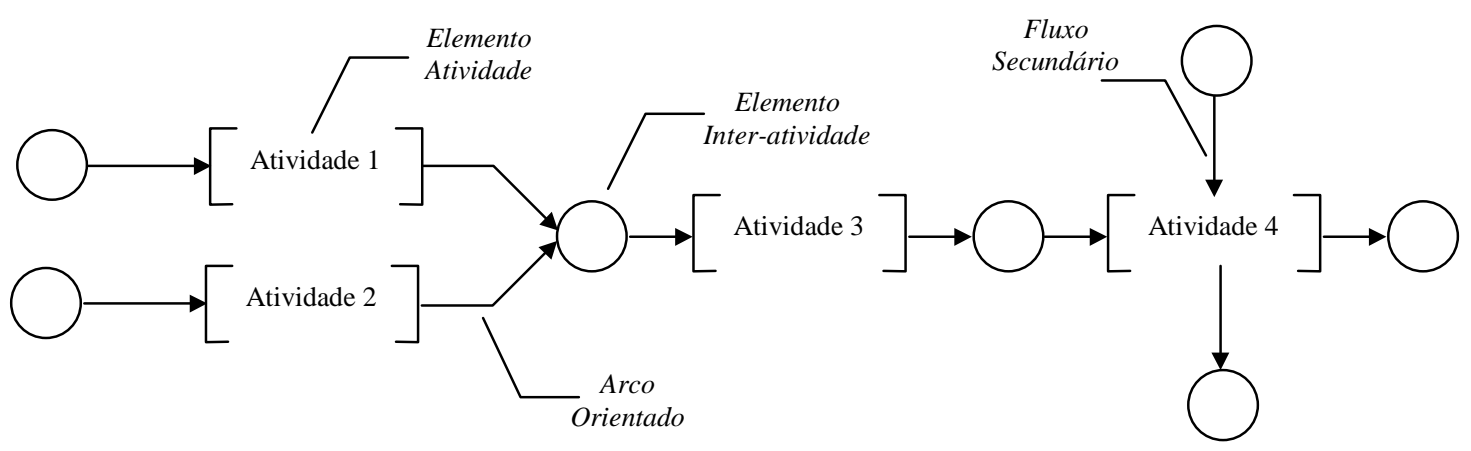

Figura 4.3. Elementos do PFS.

Em um mesmo PFS podem ser representados mais de um fluxo. Observa-se, ainda, que no PFS, distintamente das redes de Petri, não existe o conceito de marcação ou marcas, isto é, não existe a representação explícita da evolução dinâmica.

\subsubsection{2. $\quad$ Rede de Petri utilizada}

A partir do PFS deve ser gerado um modelo em redes de Petri. A rede de Petri utilizada no presente trabalho é baseada nas redes de Petri Lugar-Transição, à qual foram adicionados arcos habilitadores e inibidores, e transições temporizadas [David \& Alla, 1994]. Esta rede é composta pelos seguintes elementos:

- $\mathrm{P}=\left\{\mathrm{P}_{1}, \mathrm{P}_{2}, \mathrm{P}_{3}, \ldots, \mathrm{P}_{\mathrm{m}}\right\}$ é um conjunto finito $\left(\mathrm{m} \in \mathrm{N}^{* 2}\right)$ de lugares da rede;

- $T=\left\{T_{1}, T_{2}, T_{3}, \ldots, T_{n}\right\}$ é um conjunto finito $\left(m \in N^{*}\right)$ de transições da rede;

\footnotetext{
${ }^{2} \mathrm{~N}^{*}$ corresponde aos números naturais diferentes de zero
} 
- $\mathrm{F} \subseteq\{\mathrm{P} \times \mathrm{T}\} \cup\{\mathrm{T} \times \mathrm{P}\}$ é o conjunto de arcos direcionados;

- $\mathrm{I} \subseteq\{\mathrm{P} \times \mathrm{T}\}$ é o conjunto de arcos inibidores;

- $\mathrm{H} \subseteq\{\mathrm{P} \times \mathrm{T}\}$ é o conjunto de arcos habilitadores;

- $\mathrm{W}:\{\mathrm{F}, \mathrm{I}, \mathrm{H}\} \rightarrow \mathrm{N}^{*}$ é uma função peso associada aos arcos;

- $\mathrm{Tm}=\left\{\mathrm{Tm}_{1}, \mathrm{Tm}_{2}, \mathrm{Tm}_{3}, \ldots, \mathrm{Tm}_{\mathrm{n}}\right\}$ conjunto de tempos associados as transições;

- $\mathrm{M}_{0}$ é a marcação inicial da rede.

Observa-se que:

- a omissão do tempo associado a transição indica tempo nulo;

- a omissão de peso associado aos arcos indica peso unitário;

Os diversos estados do sistema são representados através da associação de um número de marcas a cada lugar. Diferentes marcações da rede correspondem a diferentes estados do sistema.

A evolução dinâmica da rede ocorre através do disparo de transições que alteram a marcação da rede. Quando uma transição dispara os lugares de entrada e saída da transição tem sua marcação reduzida e aumentada, respectivamente, do peso do arco que conecta o lugar a transição. Um exemplo é apresentado na Figura 4.4.

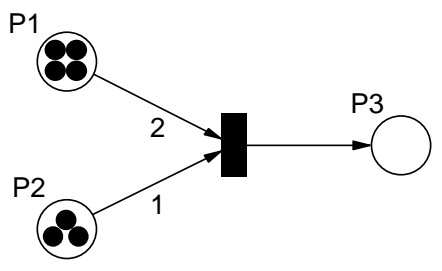

a) Antes do disparo

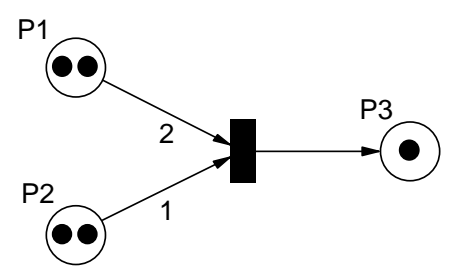

b) Após o disparo

Figura 4.4. Exemplo de disparo de transição.

Uma transição está habilitada para disparo quando:

- os lugares de entrada possuem um número de marcas igual ou superior ao peso do arco que o conecta a transição; 
- os lugares de saída possuem uma número de marcas igual ou inferior a capacidade do lugar subtraída do peso do arco que o conecta a transição;

- os arcos habilitadores e inibidores conectados à transição se encontram habilitados;

- sendo $\theta$ o tempo associado a esta transição, ela está habilitada se todas as condições para seu disparo permanecerem satisfeitas por um tempo igual ou superior a $\theta$.

A associação de pesos a arcos habilitadores e inibidores obedece as seguintes regras (Figura 4.5):

- a transição $\mathrm{T} 1$ é habilitada se $\mathrm{P} 1$ contém $\mathrm{N}$ ou mais marcas;

- a transição T2 é habilitada se $\mathrm{P} 2$ contém menos de $\mathrm{N}$ marcas;

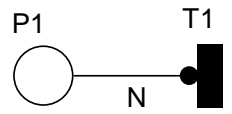

a)

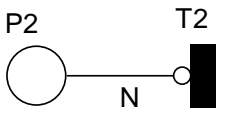

b)

Figura 4.5. Utilização de arcos habilitadores (a) e inibidores (b) com pesos.

\subsubsection{Refinamento do PFS}

O refinamento do PFS é realizado substituindo-se atividades e inter-atividades por uma nova rede PFS mais detalhada, por uma rede híbrida PFS/Rede de Petri com elementos de ambos os tipos de rede, ou por uma Rede de Petri.

No detalhamento de uma atividade deve-se considerar que:

- o início de uma atividade representa um evento que pode ser representado como uma transição ou como o início de uma atividade;

- o fim de uma atividade representa um evento que pode ser representado como uma transição ou como o fim de uma atividade;

- entre duas atividades ou entre uma atividade e uma transição deve existir um elemento inter-atividade ou um lugar; 
No detalhamento de um elemento inter-atividade deve-se considerar que:

- o início e o fim de um elemento inter-atividade são estados representados na forma de elementos inter-atividades ou de lugares;

- entre dois elementos inter-atividades ou entre um elemento inter-atividade e um lugar deve sempre existir uma atividade ou uma transição;

A Figura 4.6 apresenta alguns exemplos de refinamento:
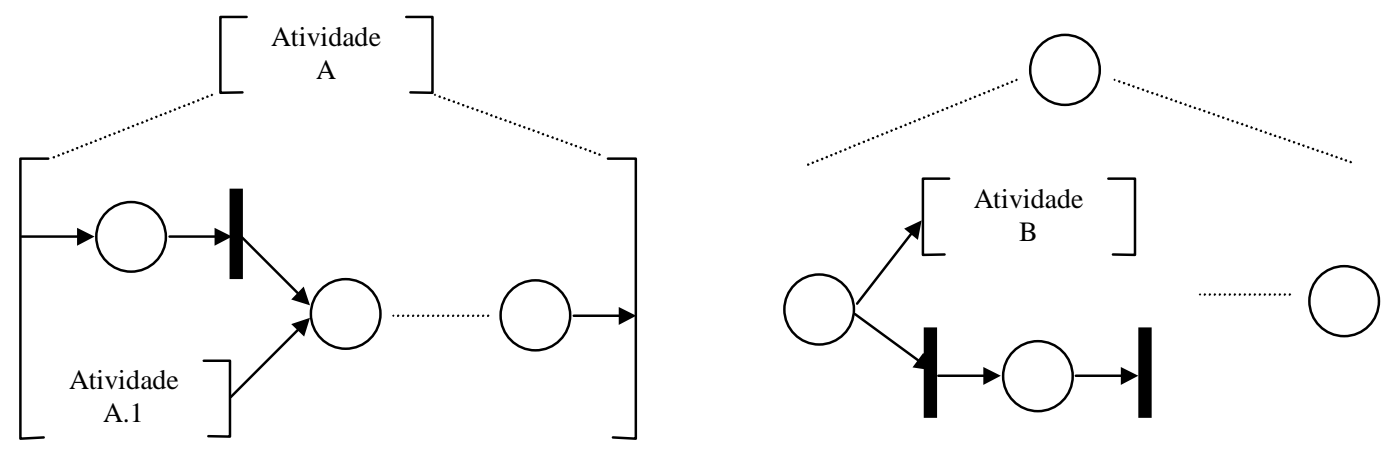

Figura 4.6. Exemplos de refinamento de atividade e inter-atividade.

\subsubsection{O Modelo do Sistema de Gerenciamento}

O modelo do sistema de gerenciamento é decomposto em duas partes. A primeira é formada pelas diversas estratégias de controle. Estas estratégias podem ser específicas para cada zona, como por exemplo: "estratégia em caso de incêndio", "estratégia de préaquecimento", etc., ou podem ainda envolver todo o edifício, como por exemplo: “manutenção de equipamentos" e "redução de carga térmica".

A segunda parte do sistema de gerenciamento é formada pelo conjunto das operações que são realizadas sobre o sistema de ar condicionado. Exemplos são: "ligar bomba", "abrir válvula", etc. Através destas operações é realizada a interface com os atuadores, que são equipamentos do sistema de ar condicionado, e com sistemas de controle local. 
Quando as diversas estratégias são executadas, estas são responsáveis por realizar as operações do sistema de ar condicionado. A interface entre as estratégias e as operações e entre as operações e o objeto de controle é realizada através de arcos habilitadores e inibidores, quando se considera modelos de redes de Petri.

O diagrama da Figura 4.7 representa a estrutura do sistema de gerenciamento descrito.

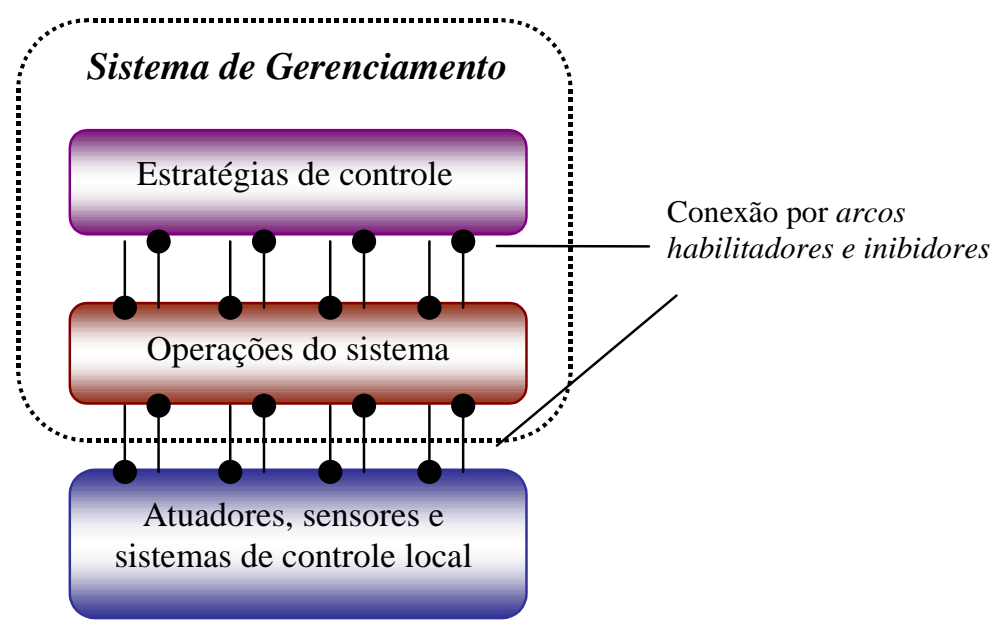

Figura 4.7. Sistema de Gerenciamento.

\subsubsection{Modelagem do Sistema de Ar Condicionado}

De acordo com o apresentado no Capítulo 3 o sistema de ar condicionado deve ser considerado híbrido. Assim, a partir da análise das técnicas de modelagem de sistemas híbridos (Capítulo 3) selecionou-se como ferramenta para a modelagem do sistema de ar condicionado, as Redes de Petri Predicado Transição Diferenciais (redes PTD), cuja definição formal é apresentada adiante.

Para a construção do modelo híbrido propõe-se também, no presente trabalho, a extensão do PFS, inicialmente definido apenas para SED, para utilização em sistemas contínuos e híbridos onde haja interesse na modelagem de eventos discretos e de fluxos contínuos através do sistema. 


\subsubsection{Utilização do PFS para Sistemas Contínuos e Híbridos}

Para a construção do PFS para sistemas contínuos considera-se o fluxo contínuo como um fluxo discreto de pacotes infinitamente pequenos. Assim, uma atividade pode ser definida como a realização de uma transformação nestes pacotes.

No caso da modelagem de fluxos contínuos define-se, para cada caso, quais as principais propriedades a serem modeladas. Define-se, então, como atividade, qualquer modificação realizada pelo sistema sobre estas propriedades do processo.

O PFS contínuo é construído a partir da estrutura do sistema, onde o sentido dos arcos indica o sentido do fluxo contínuo. Assim, as atividades do PFS podem representar graficamente a funcionalidade do sistema.

Considera-se ainda que os elementos inter-atividade também representam o tempo entre duas atividade consecutivas, ou seja, o tempo transcorrido entre uma variação nas propriedades na saída de uma atividade e a correspondente variação na entrada da atividade seguinte.

Observa-se que, em sistemas contínuos, o elemento inter-atividade pode ser utilizado para representar um elemento distribuidor ou armazenador (Figura 4.8) apenas se as propriedades do fluxo a serem modeladas não se modificarem, ao contrário do que ocorre, por exemplo, quando a vazão está entre estas propriedades. Neste caso armazenar ou distribuir torna-se uma atividade (Figura 4.9), uma vez que existe modificação da propriedade de vazão do fluxo.

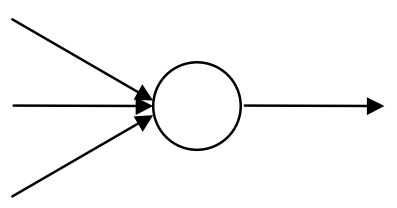

a)

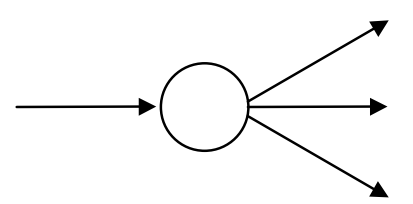

b)

Figura 4.8. Utilização do elemento inter-atividade como elemento armazenador (a) e distribuidor (b). 


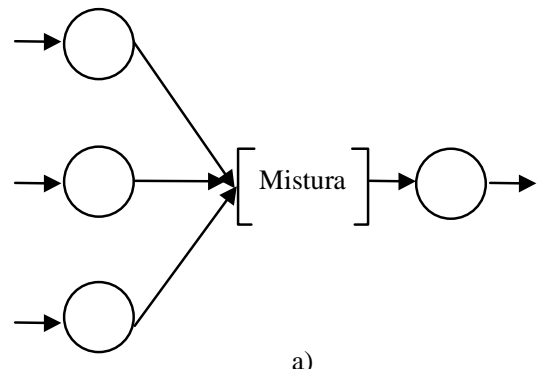

a)

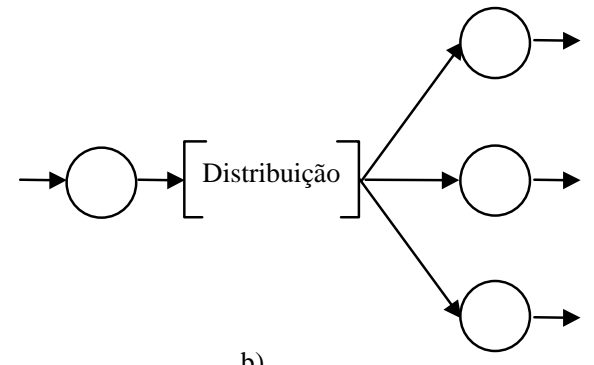

b)

Figura 4.9. Utilização da atividade de mistura (a) e distribuição (b).

Como exemplo, apresenta-se um sistema composto por um aquecedor e três serpentinas. (Figura 4.10). A água aquecida atravessa as serpentinas, onde cede calor para o ambiente.

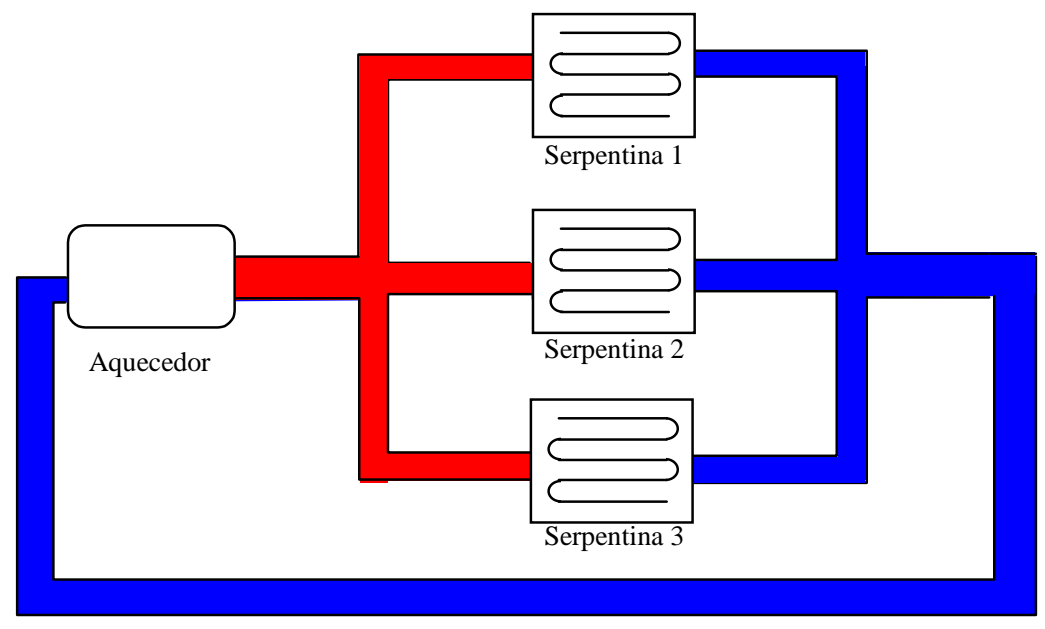

Figura 4.10. Exemplo de sistema.

Considerando que as variáveis a serem modeladas deste fluxo são temperatura e vazão, o PFS correspondente a este sistema é apresentado na Figura 4.11.

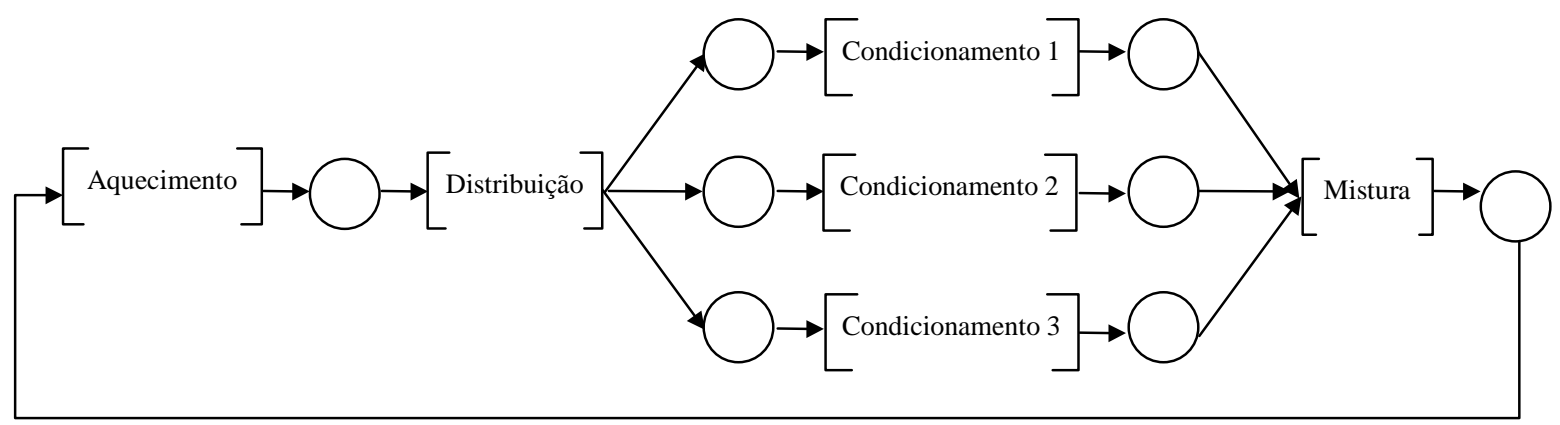

Figura 4.11. PFS correspondente ao sistema da Figura 4.10. 
Observa-se ainda que perdas ao longo da tubulação representam modificações nas propriedades do fluxo e, portanto, são associadas às atividades.

\subsubsection{O refinamento do PFS para Sistema Contínuos}

O PFS permite um refinamento sucessivo de uma atividade em um novo PFS mais detalhado, gerando um modelo hierárquico do sistema.

Assim, cada atividade do PFS pode também ser convertida em um sistema de equações diferenciais ou em uma rede PTD que representa a transformação realizada por aquela atividade nas propriedades do fluxo. Para cada atividade define-se um vetor de variáveis que contém as propriedades do fluxo após aquela atividade. O cálculo destas variáveis é realizado em função das propriedades em outros pontos do sistema, de constantes pré-definidas, de sinais externos e/ou do tempo.

Para os elementos inter-atividades, define-se a relação dinâmica entre a saída de uma atividade e a entrada da atividade seguinte em um determinado instante. Esta relação deve ser expressa na forma de equações diferenciais. Quando o tempo decorrido entre duas atividades for suficientemente pequeno frente a dinâmica do sistema, pode se consideradar que não existe diferença entre as propriedades do fluxo na saída de uma atividade e na entrada da atividade seguinte.

Observa-se que uma atividade pode realizar modificações no fluxo de material que influenciam tanto as atividades a jusante quanto as atividades a montante.

\subsubsection{Redes de Petri Predicado-Transição Diferenciais}

As redes PTD combinam as Redes de Petri Predicado/Transição [Genrich, 1987] com equações diferenciais algébricas.

Esta rede é definida como uma 9-úpla $=\left\{P, T, F, X, S, H c, J, M_{0}, V_{0}\right\}$, onde:

- $\mathrm{P}=\left\{\mathrm{P}_{1}, \mathrm{P}_{2}, \mathrm{P}_{3}, \ldots, \mathrm{P}_{\mathrm{m}}\right\}$ é um conjunto finito $\left(\mathrm{m} \in \mathrm{N}^{*}\right)$ de lugares da rede; 
- $T=\left\{T_{1}, T_{2}, T_{3}, \ldots, T_{n}\right\}$ é um conjunto finito $\left(m \in N^{*}\right)$ de transições da rede;

- $\mathrm{F} \subseteq\{\mathrm{P} \times \mathrm{T}\} \cup\{\mathrm{T} \times \mathrm{P}\}$ é o conjunto de arcos direcionados;

- $\mathrm{X}=\left\{\mathrm{x}_{1}, \mathrm{x}_{2}, \mathrm{x}_{3}, \ldots, \mathrm{x}_{\mathrm{x}}\right\}$, onde $\mathrm{x}_{\mathrm{i}} \in \mathrm{R}$, é o vetor de variáveis contínuas associado à rede.

- $\mathrm{S}=\left\{\mathrm{S}_{1}, \mathrm{~S}_{2}, \mathrm{~S}_{3}, \ldots, \mathrm{S}_{\mathrm{m}}\right\}$ é o conjunto de sistemas de equações diferenciais associadas aos lugares.

- $\mathrm{Hc}=\left\{\mathrm{Hc}_{1}, \mathrm{Hc}_{2}, \mathrm{Hc}_{3}, \ldots, \mathrm{Hc}_{\mathrm{n}}\right\}$ é o conjunto de expressões booleanas associadas as funções de habilitação das transições.

- $\mathrm{J}=\left\{\mathrm{J}_{1}, \mathrm{~J}_{2}, \mathrm{~J}_{3}, \ldots, \mathrm{J}_{\mathrm{n}}\right\}$ é o conjunto de funções de junção associadas às transições.

- $\mathrm{M}_{0}$ é a marcação inicial da rede.

- $\mathrm{X}_{0}$ é o valor inicial das variáveis pertencentes a $\mathrm{X}$.

A modelagem em redes PTD é baseada em módulos onde cada módulo eqüivale a uma máquina de estado finito, representada por uma Rede de Petri. A combinação de todas as máquinas de estado resultam no modelo do sistema.

Cada atividade do PFS pode então ser detalhada em uma rede PTD onde os sistemas de equações associados aos lugares representam as transformações realizadas sobre o fluxo nas diferentes configurações do sistema.

Para ilustrar a utilização das redes PTD no detalhamento do PFS apresenta-se um possível modelo relacionado a atividade [Aquecimento] da Figura 4.11. Esta atividade pode ser representada por sistemas de equações diferenciais e algébricas, relacionados ao estado do aquecedor.

Considerando que o aquecedor pode assumir 3 estados discretos (desligado, ligado na potência 1 e ligado na potência 2), tem-se o seguinte modelo em rede PTD para a atividade [Aquecimento]: 


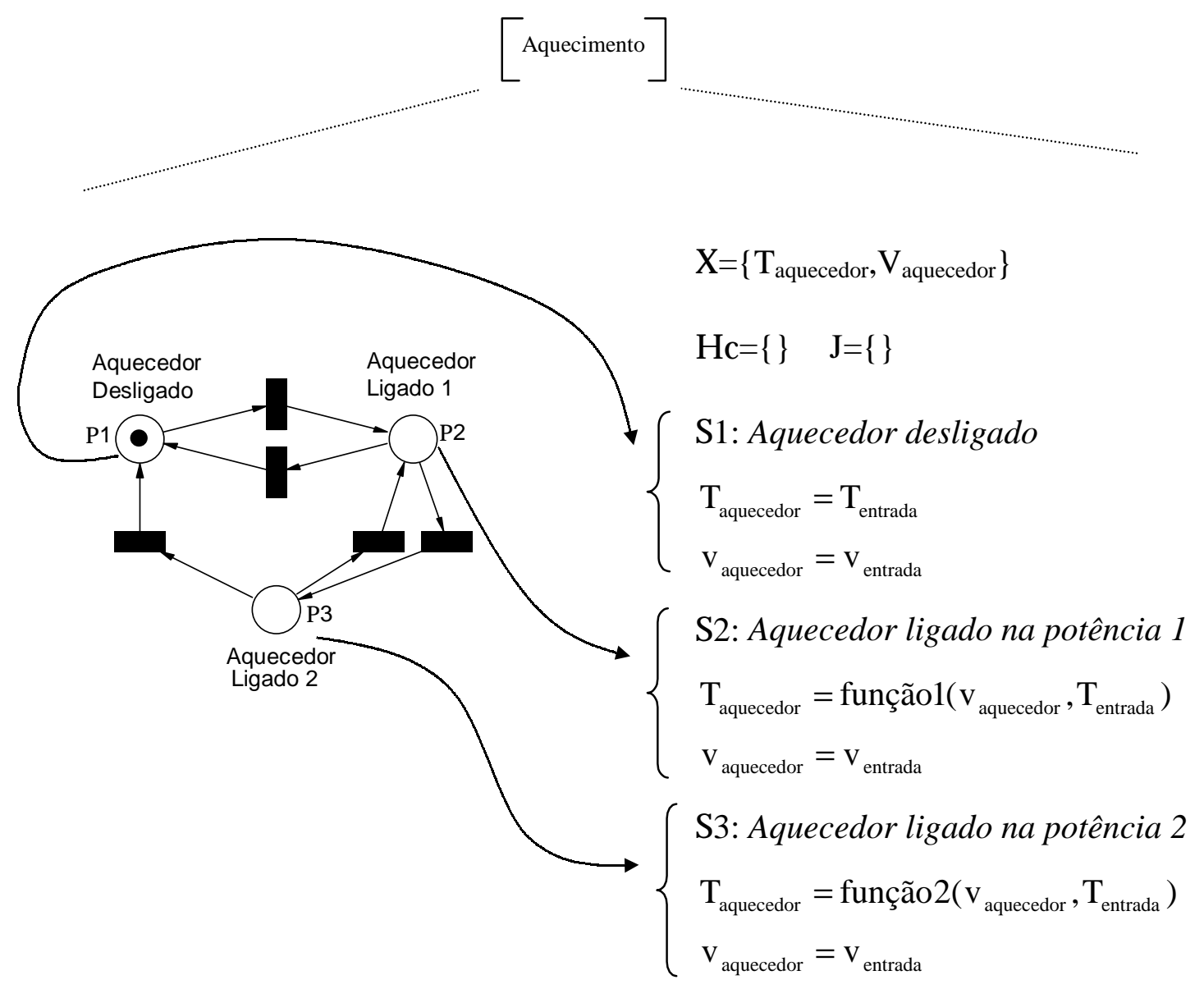

Figura 4.12. Modelo em rede PTD da atividade [Aquecimento].

onde $\quad \mathrm{T}_{\text {aquecedor }}=$ temperatura na saída do aquecedor;

$\mathrm{v}_{\text {aquecedor }}=$ vazão de água na saída do aquecedor;

$\mathrm{T}_{\text {entrada }}=$ temperatura na entrada do aquecedor;

$\mathrm{v}_{\text {entrada }}=$ vazão de água na entrada do aquecedor;

função $_{1}$ e função ${ }_{2}=$ equações algébricas diferenciais.

As funções de habilitação são utilizadas para habilitar ou desabilitar transições em função dos valores das variáveis.

As funções de junção são utilizadas para possibilitar saltos discretos nas variáveis contínuas após o disparo de uma transição. Na omissão de funções de junção, o valor das variáveis não é modificado quando ocorre um disparo. 


\subsubsection{Modelagem do Sistema de Controle Local}

Uma vez modelado o sistema de ar condicionado, o passo seguinte refere-se a modelagem do sistema de controle local.

O sistema de controle local é dividido em duas partes: aquela formada por controladores, por exemplo do tipo P, PI, PID, e aquela formada por processadores responsáveis por transformar informações provenientes de sensores sobre os valores das variáveis contínuas em sinais de habilitação e inibição de transições do sistema de gerenciamento.

O sistema de controle local também é modelado através de redes PTD.

Como exemplo apresenta-se a modelagem de um controlador PID. Este controlador pode assumir dois estados discretos: ligado ou desligado. Tem-se, então, o seguinte modelo em rede PTD (Figura 4.13).

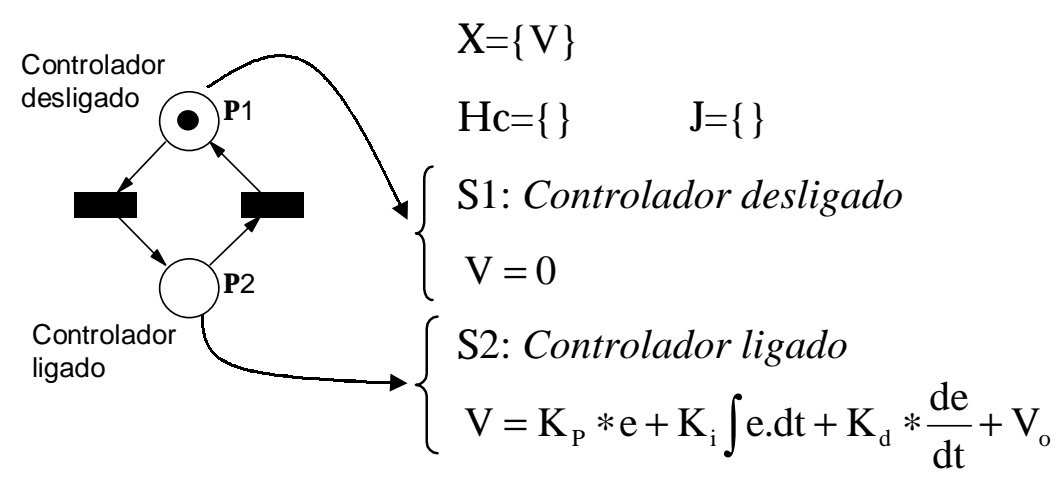

Figura 4.13. Modelo em rede PTD de um controlador PID.

A conexão do controlador com o modelo do sistema de ar condicionado se faz através do erro (e) que é calculado através da variável do sistema de ar condicionado a ser controlada e da variável $\mathrm{V}$ que é o sinal de controle enviado ao sistema de ar condicionado. 
A segunda parte do sistema de controle local é exemplificada na Figura 4.14, onde tem-se uma rede responsável por habilitar ou inibir uma transição de acordo com o valor da temperatura na entrada do aquecedor:

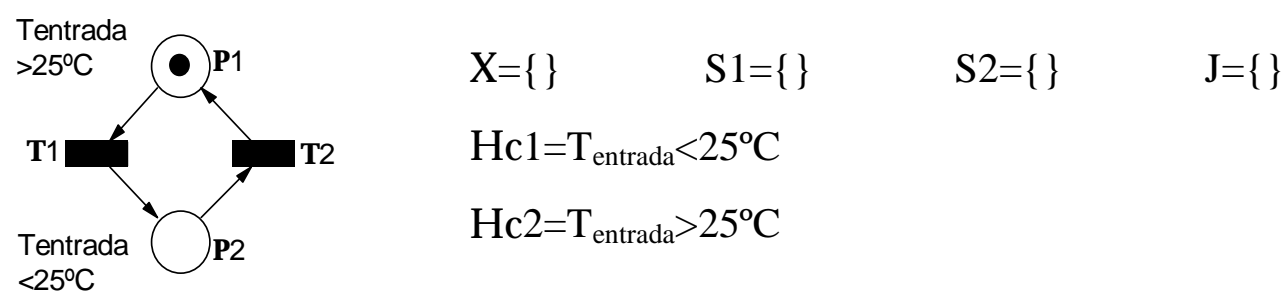

Figura 4.14. Modelo em rede PTD de um processador de sinais contínuos.

\subsubsection{Modelagem do Ambiente Interno}

A modelagem do ambiente é dividida em duas partes. A primeira, modelada na forma de redes de Petri, representa a ocorrência de eventos discretos no ambiente. A segunda, na forma de equações algébricas diferenciais, representa a evolução no tempo das propriedades de interesse do ambiente interno.

Um exemplo de modelagem dos eventos discretos que interferem na carga térmica do ambiente é apresentado na Figura 4.15.
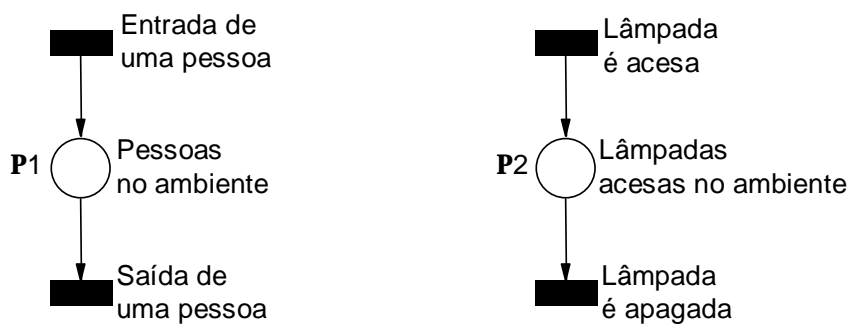

Figura 4.15. Modelagem de eventos discretos no ambiente.

A variação das propriedades do ambiente em função da carga térmica recebida é modelada através de equações diferenciais onde tem-se como parâmetro a marcação dos lugares da rede da Figura 4.15 e variáveis do modelo do sistema de ar condicionado. 


\subsubsection{Integração dos Modelos}

A integração entre o modelo do sistema de gerenciamento e o modelo do ar condicionado e do sistema de controle local é realizada através de arcos habilitadores e inibidores.

A integração do sistema de ar condicionado com o ambiente é realizada através de variáveis contínuas que influenciam no cálculo da carga térmica inserida/retirada do ambiente pelo sistema de ar condicionado.

A Figura 4.16 apresenta um esquema geral do modelo resultante através da aplicação da metodologia. Comparando o modelo obtido com o diagrama do sistema de controle apresentado na Figura 2.2, observa-se que:

- o objeto de controle é representado por equações dos diversos sistemas e das redes PTD dos blocos "Instalações do Sistema de Ar Condicionado" e "Ambiente Interno i”;

- os "Dispositivos de Atuação" são representados pela estrutura em rede de Petri das redes PTD;

- os "Dispositivos de Detecção" são representados por equações dos diversos sistemas e das redes PTD dos blocos "Instalações do Sistema de Ar Condicionado" e "Ambiente Interno i";

- os "Dispositivos de Realização do Controle" são representados pelo "BMS", pelo "Sistema de Gerenciamento" e pelo "Sistema de Controle Local", sendo que a relação entre eles é realizada de acordo com a Figura 4.16;

- não são representados de forma explícita a interface com o usuário/operador, pois considera-se que em EI o sistema de ar condicionado opera sem necessidade de interferências. 


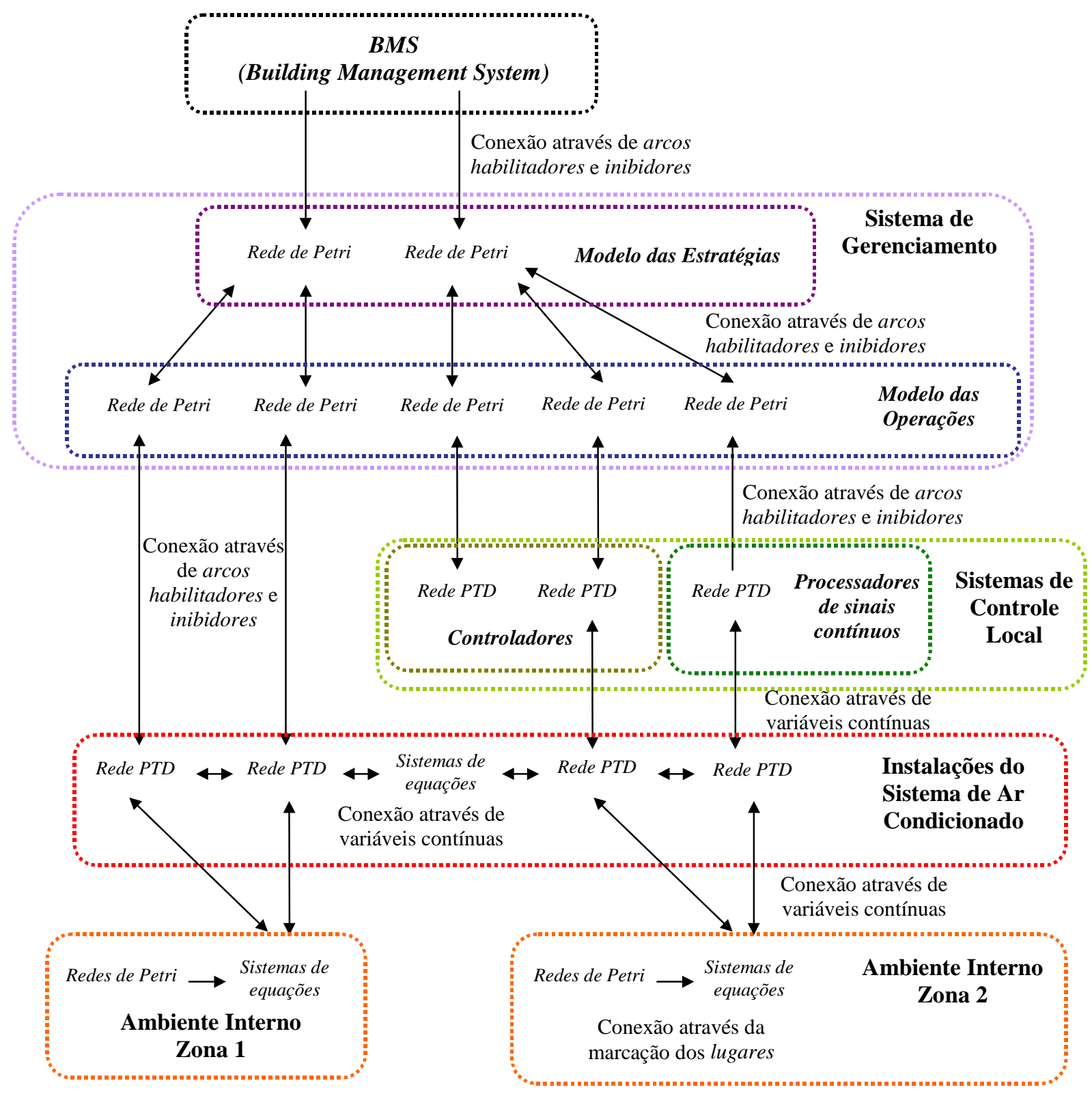

Figura 4.16. Estrutura do modelo resultante.

\subsection{Simulação dos Modelos}

A simulação do modelo é dividida em três partes: discreta, contínua e híbrida.

\section{Simulação Discreta}

Uma vez construído o modelo, elimina-se deste a parte referente às equações algébricas diferenciais. O modelo resultante é constituído apenas de redes de Petri e 
engloba o modelo completo do sistema de gerenciamento, a parte do modelo do sistema de controle local referente aos estados discretos dos controladores e aos estados de processadores responsáveis pela habilitação/inibição de transições, e a parte do modelo do sistema de ar condicionado referente ao estado dos equipamentos do sistema de ar condicionado.

A simulação pode ser realizada em softwares para simulação de redes de Petri que comportem redes de Petri Lugar/Transição com arcos habilitadores e inibidores. Em [Storrle, 98] é apresentada uma análise dos principais softwares de simulação disponíveis atualmente, apresentando suas características, restrições e qualidades.

A partir da simulação do modelo em redes de Petri é possível confirmar o funcionamento lógico do sistema e detectar se o modelo construído alcança estados não desejáveis do sistema, como, por exemplo, uma zona sendo aquecida e resfriada simultaneamente, um "chiller" em funcionamento com a respectiva válvula que permite o fluxo através do "chiller" fechada, etc.

\section{Simulação Contínua}

Esta etapa consiste em, a partir do modelo construído, adotar-se algumas configurações para os estados discretos das redes PTD e com base nisto, simular numericamente as equações resultantes. $\mathrm{O}$ modelo resultante engloba uma série de sistemas de equações que representam o sistema de ar condicionado, os controladores do sistema de controle local e o ambiente.

O objetivo desta etapa é verificar e confirmar o conjunto de equações adotadas apresenta um comportamento adequado quando simulado para algumas situações prédeterminadas. 


\section{Simulação Híbrida}

A simulação do modelo global do sistema implica no acoplamento de dois simuladores: o primeiro de redes de Petri e o segundo de equações diferenciais. Assim, os simuladores evoluem de forma intercalada sendo sincronizados pelos eventos. Observa-se que não se trata de executar dois simuladores paralelamente, mas sim executar um simulador até a ocorrência de um evento e, então, trocar-se de simulador.

A Figura 4.17 apresenta as principais etapas de simulação:

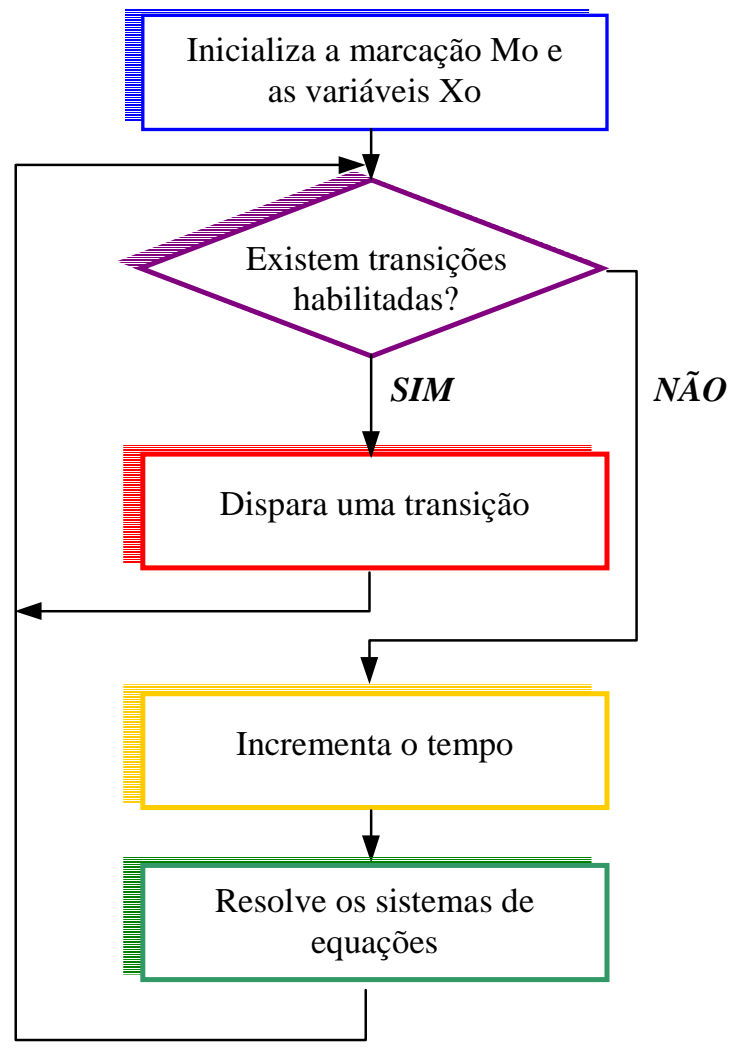

Figura 4.17. Etapas da simulação híbrida.

O primeiro passo para o início da simulação é definir o estado inicial do sistema, isto é, a marcação inicial dos modelos em redes de Petri e em redes PTD, e o valor inicial de todas as variáveis contínuas do sistema.

A segunda etapa consiste em verificar a existência ou não de transições habilitadas. Devem ser verificadas tanto as transições dos modelos em redes de Petri 
como dos modelos em redes PTD. Para cada transição deve-se verificar as seguintes condições de disparo:

- $\quad$ se as pré-condições estão satisfeitas, ou seja, se a marcação dos lugares de entrada é igual ou superior ao peso dos arcos;

- $\quad$ se os arcos habilitadores e inibidores estão habilitados;

- caso a transição seja temporal, se as condições acima já se encontram satisfeitas por um tempo igual ou superior ao tempo associado a transição;

- caso a transição seja de uma rede PTD, se a função de habilitação se encontra satisfeita.

Uma vez determinada quais são as transições habilitadas passa-se a etapa seguinte.

A etapa seguinte é o disparo de uma das transições habilitadas. A escolha da transição a ser disparada é realizada aleatoriamente. O disparo da transição é constituído pelas seguintes etapas:

- atualização da marcação dos lugares de entrada e saída;

- caso a transição seja de uma rede PTD, modificação do sistema de equações responsável pela evolução das variáveis contínuas no tempo;

- caso a transição seja de uma rede PTD, modificação dos valores das variáveis do vetor de variáveis associado àquela rede de acordo com o valor das funções de junção.

Quando não houver mais transições discretas a serem disparadas, incrementa-se o tempo e realiza-se a simulação numérica dos sistemas de equações diferenciais.

Inicialmente resolve-se os sistemas de equações das redes PTD do sistema de controle local. Em seguida aborda-se o modelo do sistema de ar condicionado. Neste caso, a seqüência de resolução dos sistemas é definida pelo modelo em PFS. 
Uma vez atualizado o estado do sistema de ar condicionado, calcula-se as propriedades do ambiente. Entre cada incremento de tempo deve-se verificar a ocorrência de eventos discretos, ou seja, o disparo de transições tem prioridade em relação a evolução do tempo.

Para que a metodologia proposta seja confiável, ou seja, para que apresente dados suficientes para possibilitar a análise da estratégia, o modelo construído deve ser simulado para todas as possíveis situações, ou seja, para todas as possíveis seqüências de eventos discretos e para as mais variadas condições ambientais.

No entanto, de acordo com a complexidade e abrangência do sistema modelado tal simulação é inviável no que se refere ao tempo de execução e processamento. Assim, sugere-se a adoção de alguns casos representativos, como condições com maior probabilidade de ocorrência e condições extremas.

De acordo com a objetivo da análise a ser realizada, os dados da simulação são utilizados como entrada para critérios de comparação de desempenho. Um exemplo é a utilização de métodos como o proposto por [Fanger, 1972] para a determinação de índices como o PMV (voto estimado médio) e o PPD (porcentagem de pessoas insatisfeitas). 


\section{Estudo de Caso}

Neste capítulo aplica-se a metodologia proposta no Capítulo 4 para o Prédio dos Ambulatórios (PAMB) do Hospital das Clínicas da Faculdade de Medicina da Universidade de São Paulo (HC - FMUSP).

O PAMB não é um EI e atualmente, seu sistema de controle de ar condicionado vem atuando de forma pouco eficaz, devido à ausência de um sistema de controle que interaja com os demais sistemas do edifício. Assim uma solução para este problema baseia-se na introdução da tecnologia de EI, ou seja, em desenvolver módulos que controlem eficazmente cada um dos seus sistemas e que possibilitem a interação dos diversos sistemas entre si. Considerando estas hipótese, o PAMB foi escolhido como estudo de caso devido a grande variedade de ambientes apresentados e a particular importância da manutenção do conforto térmico em um hospital.

\subsection{O PAMB}

O HC-FMUSP é um complexo hospitalar de atendimento terciário, isto é, que atende à todas as especialidades médicas, formado por um conjunto de 5 institutos (Central, Coração, Pediatria, Ortopedia, Psiquiatria), 2 Hospitais Auxiliares e 1 Divisão de Reabilitação. O PAMB e o Instituto de Radiologia fazem parte do Instituto Central do HC.

O PAMB tem aproximadamente $100.000 \mathrm{~m}^{2}$ de área construída, 10 andares (e mais 7 pisos intermediários entre andares) e inclui ambulatórios, centro cirúrgico, farmácia 
industrial, entre outras instalações. Por ele circulam diariamente cerca de 2.300 pacientes e 5.000 funcionários.

Quanto ao seu sistema de ar condicionado, ele possibilita resfriamento e aquecimento do ambiente.

A produção de água gelada no PAMB é realizada através de 4 “chillers". Fazem parte também do sistema 8 torres de resfriamento. Para o transporte da água entre os “chillers", localizados no subsolo, e as torres de resfriamento no último andar, e entre os "chillers" e os locais de condicionamento do ar, existem 8 bombas. Válvulas de bloqueio impedem o fluxo de água através do "chiller" quando este é desligado. A água gelada é fornecida a uma temperatura de $7^{\circ} \mathrm{C}$.

São necessárias duas torres de resfriamento para resfriar a água produzida por cada "chiller".

A água quente do PAMB é produzida por 2 aquecedores à vapor e é fornecida às unidades de condicionamento a uma temperatura de $75^{\circ} \mathrm{C}$. Para o transporte de água quente tem-se 2 bombas.

O condicionamento do ar é realizado em “fan-coils". No PAMB, existem 370 "fan-coils" de diversas dimensões. Estes "fan-coils" estão distribuídos de acordo com a utilização das áreas por ele atendidas. Alguns andares possuem apenas 12 "fan-coils", outros até 36. Alguns atendem apenas uma pequena sala, outros atendem diversas salas.

A renovação do ar é de cerca de $40 \%$ para a maioria das áreas do PAMB. São exceções o centro cirúrgico, banheiros, refeitório, vestiário, laboratório e farmácia, onde a renovação é de $100 \%$.

As exigências de condicionamento do ar dentro de um hospital variam de acordo com a utilização que é feita da área. Algumas áreas exigem condicionamento apenas para fins de conforto, como salas administrativas, quartos de internação, cozinhas, 
lavanderias e áreas de circulação, entre outros. Alguns setores necessitam de condicionamento não apenas para o conforto mas também para assepsia, tais como salas de cirurgias, UTI, berçário, etc. No atendimento destes recintos devem ser tomados os devidos cuidados no que se refere aos sistemas de filtragens e renovação do ar, principalmente por envolver trabalhos e tratamentos destinados à análise e erradicação de doenças infecciosas [Normas, 1985].

$\mathrm{Na}$ Tabela 5.1 apresenta-se exemplos de algumas exigências básicas que se referem a temperatura mínima, temperatura máxima, umidade relativa e número mínimo de trocas de ar por hora de alguns ambientes.

Tabela 5.1. Exigências básicas para algumas áreas de hospitais [Normas,1985].

\begin{tabular}{l||c||c||c||c} 
& Tmín & Tmáx & \% Umidade & N. trocas \\
\hline \hline Centro Cirúrgico & 19 & 24 & $45-60$ & 25 \\
\hline Consultórios & 20 & 26 & $40-60$ & 6 \\
\hline Laboratórios & 20 & 26 & $40-60$ & 6 \\
\hline Áreas de circulação & 20 & 26 & $40-60$ & 4
\end{tabular}

Observa-se, no entanto que, apesar de a umidade ser fator importante para a garantia da qualidade do ar, no hospital analisado não existe controle de umidade.

\subsection{Definição das Estratégias}

A seguir apresenta-se as estratégias consideradas para o PAMB. Na aplicação da metodologia considerou-se a existência de um sistema de gerenciamento do edifício (o BMS) responsável pela integração e compartilhamento de informações entre os diversos sistemas do edifício. Observa-se, no entanto, que tal sistema atualmente não se encontra em operação e que muitas destas estratégias não se encontram automatizadas, sendo, de fato, realizadas por técnicos e operadores responsáveis pela manutenção do ar condicionado. 


\section{Estratégia em caso de incêndio}

Esta estratégia é adotada para cada zona em caso de detecção de incêndio na zona. Devem ser tomadas as seguintes medidas:

- para a zona onde foi detectada fumaça e para as zonas anexas renova-se $100 \%$ do ar;

- a pressão na zona afetada é diminuída através do aumento da velocidade dos ventiladores de retorno das zonas afetadas;

- para as zonas anexas a zona afetada, caso não haja incêndio nestas zonas, as velocidades dos ventiladores de retorno são reduzidas de modo a aumentar a pressão nestas zonas e a impedir a difusão do ar.

Esta estratégia é realizada quando o BMS (Building Management System) informa a presença de fumaça na zona.

\section{Estratégia para Áreas Não Utilizadas}

No PAMB algumas áreas devem ser condicionadas constantemente, como o centro cirúrgico. Outras, como alguns ambulatórios, são utilizadas apenas durante o período da manhã. Assim, de acordo com as características da zona, pode-se desligar o condicionamento da área durante estes períodos.

A tomada de decisão de quando modificar a estratégia de condicionamento da zona pode variar de acordo com a necessidade de cada zona. Algumas opções são:

- depois de um determinado horário;

- quando a iluminação é desligada;

- quando não existem pessoas na sala;

- quando todos os equipamentos são desligados;

- combinações das opções acima.

Durante o período de não utilização das zonas são tomadas as seguintes medidas: 
- a caixa de mistura é posicionada para renovação $0 \%$;

- os ventiladores de insuflamento e de retorno são desligados;

- o condicionamento do ambiente é desligado.

Esta estratégia só é realizada se não existe sinal de presença de fumaça na zona e nas zonas anexas.

\section{Estratégia para Áreas Utilizadas}

Durante o período de utilização das zonas são tomadas as seguintes medidas:

- a caixa de mistura é posicionada para renovação parcial, ou total, de acordo com a zona;

- os ventiladores de insuflamento e de retorno são ligados a velocidade média;

- o condicionamento do ambiente é acionado.

A estratégia de condicionamento de áreas utilizadas é realizada quando é detectada a presença de pessoas na zona e se não existe sinal de presença de fumaça na zona e nas zonas anexas.

O chaveamento entre aquecimento e resfriamento é realizado em função da temperatura no ambiente. Se o sistema está sendo resfriado e a temperatura no ambiente decresce abaixo de um determinado limite inferior, desliga-se o resfriamento e inicia-se o aquecimento. Se o sistema está sendo aquecido e a temperatura é elevada acima de um determinado limite superior, desliga-se o aquecimento e inicia-se o resfriamento.

\section{Estratégia de pré-aquecimento/resfriamento}

Para as zonas onde o condicionamento não é realizado durante longos períodos, por exemplo à noite, uma estratégia muito utilizada é o condicionamento do ambiente antes do início da sua ocupação.

Esta estratégia consiste em: 
- colocar a caixa de mistura para renovação $0 \%$, de modo a não utilizar ar exterior;

- acionar os ventiladores de retorno e de insuflamento a velocidade média;

- condicionar o ambiente.

Esta estratégia é executada em um horário pré-determinado quando a zona não está sendo utilizada e quando não existe sinal de incêndio na zona em questão ou nas zonas anexas. A presença de ocupação na sala é detectada pelo sistema de controle de acesso e o BMS realiza a transmissão desta informação ao sistema de ar condicionado.

\section{Estratégia para ventilação noturna}

Este tipo de estratégia é utilizada para resfriar ambientes preparando-os para o dia seguinte. Através da ventilação visa-se retirar do ambiente o calor armazenado na estrutura do edifício e em móveis e equipamentos que é liberado no período noturno quando a temperatura do ambiente torna-se inferior a temperatura da estrutura e dos móveis, diminuindo assim a necessidade de condicionamento no dia seguinte. Outro motivo para a utilização de ventilação noturna é a retirada de odores, fumaças e outros contaminantes.

O procedimento adotado consiste em:

- modificar a posição da caixa de mistura para renovação $100 \%$;

- acionar o ventilador de retorno e de insuflamento a velocidade média;

- desligar o condicionamento da zona.

A realização ou não da ventilação noturna é determinada em função da temperatura máxima atingida na zona no dia anterior. A ventilação é realizada em um determinado horário se não existe ocupação na zona e se não é detectado fumaça na zona e nas zonas anexas. 
Alguns autores sugerem também o super-condicionamento noturno, buscando a utilização da capacidade térmica de móveis e da estrutura civil como armazenadores de frio. Durante o super-condicionamento não é realizada a renovação do ar, ao contrário de quando é adotada a ventilação noturna [Meyer \& Emery, 95]. Neste caso a temperatura de condicionamento do ambiente é ajustada para uma temperatura inferior àquela utilizada durante o funcionamento normal. Um certo tempo antes da utilização do ambiente, o super-resfriamento é desativado de modo a atingir a temperatura de condicionamento normal no início da ocupação.

\section{Estratégia para operação baseada na carga térmica}

Como neste caso existem múltiplos "chillers" ou/e aquecedores, existe a possibilidade de desligar-se alguns equipamentos de modo a minimizar a operação em carga parcial, obtendo assim maior economia a medida que a carga térmica produzida no edifício se afasta da carga máxima para a qual o sistema foi projetado.

A decisão sobre colocar ou retirar um "chiller" ou aquecedor de operação é realizada em função da temperatura da água que retorna do sistema.

Para que um "chiller" possa ser desligado, o calor retirado por ele deverá ser distribuído entre os demais "chillers" em funcionamento sem ultrapassar a capacidade destes equipamentos. A Equação 4 determina a temperatura limite para a retirada de operação de um “chiller”:

$$
\mathrm{Q}=\dot{\mathrm{m}}_{\text {água }} *\left(\mathrm{~h}\left(\mathrm{~T}_{\text {entrada }}\right)-\mathrm{h}\left(\mathrm{T}_{\text {saída }}\right)\right)<(\mathrm{n}-1) * \mathrm{C}_{\text {chiller }}
$$

onde $\quad \mathrm{Q}=$ calor total retirado da água pelos "chillers" em operação;

$$
\begin{aligned}
& \mathrm{T}_{\text {entrada }}=\text { temperatura da água na entrada dos "chillers"; } \\
& \mathrm{T}_{\text {saída }}=\text { temperatura da água na saída dos "chillers"; } \\
& \dot{\mathrm{m}}_{\text {agua }}=\text { vazão em massa de água através dos "chillers"; }
\end{aligned}
$$


$\mathrm{h}=$ entalpia da água;

n = número de "chillers" em operação;

$\mathrm{C}_{\text {chiller }}=$ capacidade de um "chiller", considera-se que todos os "chillers" possuem a mesma capacidade.

Considera-se o cálculo da entalpia como uma aproximação linear de acordo com a equação sugerida por [Taube, 97], onde T é a temperatura em graus Kelvin (Equação 5):

$$
\mathrm{h}_{\text {agua }}(\mathrm{T})=4,187 * \mathrm{~T}+7,72
$$

Tem-se que:

$$
\begin{aligned}
& \mathrm{Q}=\mathrm{v}_{\text {água }} * \mathrm{~K}^{*}\left(\mathrm{~T}_{\text {entrada }}-\mathrm{T}_{\text {saída }}\right)<(\mathrm{n}-1) * \mathrm{C}_{\text {chiller }} \\
& \mathrm{T}_{\text {entrada }}<\left[\frac{(\mathrm{n}-1) * \mathrm{C}_{\text {chiller }}}{\mathrm{v}_{\text {água }} * \mathrm{~K}}+\mathrm{T}_{\text {sá́da }}\right]
\end{aligned}
$$

onde $\quad \mathrm{K}=$ constante;

$$
\text { Vágua = vazão da água; }
$$

Para que um “chiller” seja acionado, o calor a ser retirado da água deve ser maior que a capacidade total dos "chillers" ligados, ou seja:

$$
\begin{aligned}
& \mathrm{Q}=\mathrm{v}_{\text {agua }} * \mathrm{~K} *\left(\mathrm{~T}_{\text {entrada }}-\mathrm{T}_{\text {sáda }}\right)>\mathrm{n} * \mathrm{C}_{\text {chiller }} \\
& \mathrm{T}_{\text {entrada }}>\left[\frac{\mathrm{n} * \mathrm{C}_{\text {chiller }}}{\mathrm{v}_{\text {agua }} * \mathrm{~K}}+\mathrm{T}_{\text {saída }}\right]
\end{aligned}
$$

Uma vez detectada a retirada de operação um "chiller", desliga-se também duas torres de resfriamento e as bombas correspondentes.

Em "chillers" de múltiplos compressores pode-se ainda considerar a possibilidade de desligar um ou mais compressores.

Para os aquecedores o procedimento realizado é semelhante. 
Estratégia para manutenção.

Um sistema responsável pelo gerenciamento global da manutenção dos equipamentos dos diversos sistemas do edifício é responsável pela comunicação da necessidade de manutenção e supervisão da sua realização.

Ao se detectar a necessidade de colocação de um determinado "chiller" em manutenção, deve-se:

- caso o "chiller" esteja desligado, ele é imediatamente colocado em manutenção;

- caso o "chiller" esteja ligado, verifica-se a existência de um "chiller" com capacidade semelhante desligado para ser colocado em operação;

- caso o "chiller" esteja ligado e não exista um "chiller" desligado para ser acionado no seu lugar, desliga-se o "chiller", duas torres de resfriamento e as bombas correspondentes.

\subsection{Construção do Modelo}

\subsubsection{Modelagem do Sistema de Gerenciamento}

Uma vez definidas as estratégias do sistema de gerenciamento, desenvolveu-se, então, um modelo em PFS.

Inicialmente identifica-se, para cada zona, quais são as estratégias de controle que atuam sobre os equipamentos relativos ao controle do condicionamento da zona, ou seja, sobre os controladores das válvulas de água quente e fria, sobre os ventiladores e sobre as caixas de mistura.

No caso das estratégias apresentadas no item 4.1, as que devem ser consideradas para estes equipamentos são:

- Estratégia em caso de incêndio; 
- Estratégia para zona não utilizada;

- Estratégia para zona utilizada.

- Estratégia de pré-condicionamento;

- Estratégia de ventilação noturna;

Cada estratégia corresponde a execução de uma sequiência de operações que colocam o sistema em uma determinada configuração para os ventiladores, caixas de mistura e válvulas das serpentinas. Constrói-se, então, para cada zona, um modelo em PFS representando estas estratégias. A Figura 5.1 apresenta este modelo para uma determinada zona chamada de "zona 1":

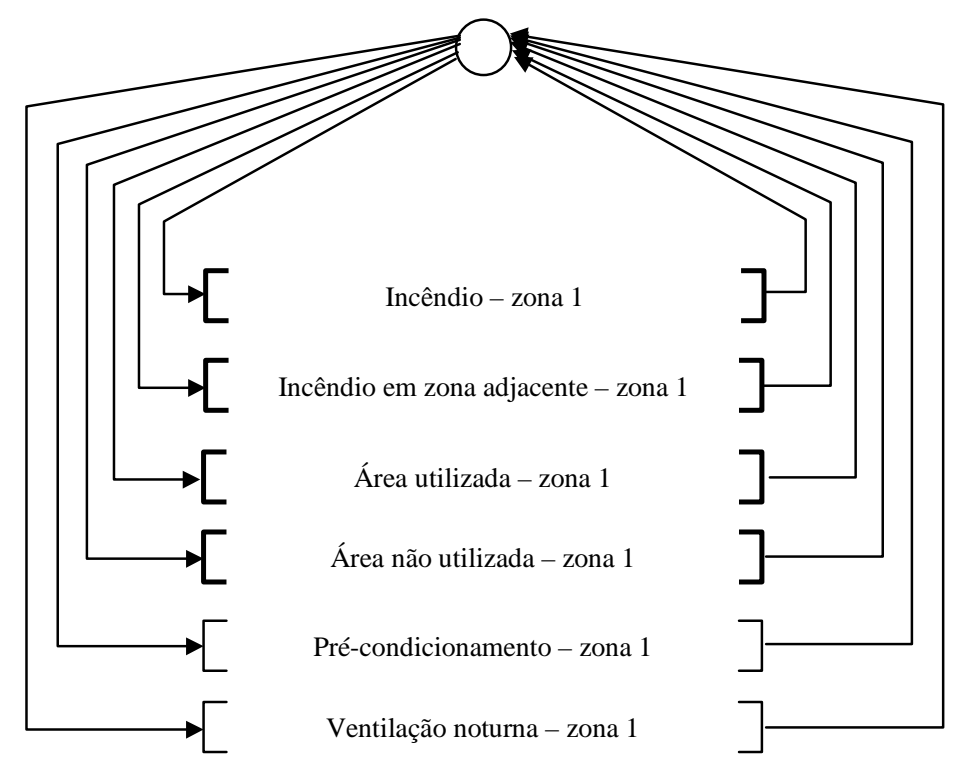

Figura 5.1. Modelo em PFS das estratégias de controle para a zona 1.

Na Figura 5.1 a estratégia em caso de incêndio foi dividida em duas atividades: "Incêndio" e "Incêndio em zona adjacente". A primeira corresponde as atividades realizadas nos equipamentos da zona 1 quando é detectado a presença de fumaça nesta zona. A última corresponde as atividades realizadas nos equipamentos da zona 1 quando é detectado a presença de fumaça em uma zona adjacente a esta zona.

Para as demais zonas é construído um modelo semelhante ao apresentado na Figura 5.1. 
Para os equipamentos responsáveis pela produção do frio e do calor o procedimento é semelhante. As estratégias que envolvem atuação sobre os equipamentos responsáveis pela produção de água gelada são:

- Estratégia de operação baseada na carga térmica;

- Estratégia para manutenção de equipamentos.

A "estratégia de operação baseada na carga térmica" é dividida em duas atividades: "aumento da produção de frio" e "redução da produção de frio". A "estratégia de manutenção de equipamentos" foi dividida em diversas atividades referentes a colocação e retirada de manutenção de cada equipamento.

O modelo em PFS para estas estratégias é apresentado na Figura 5.2.

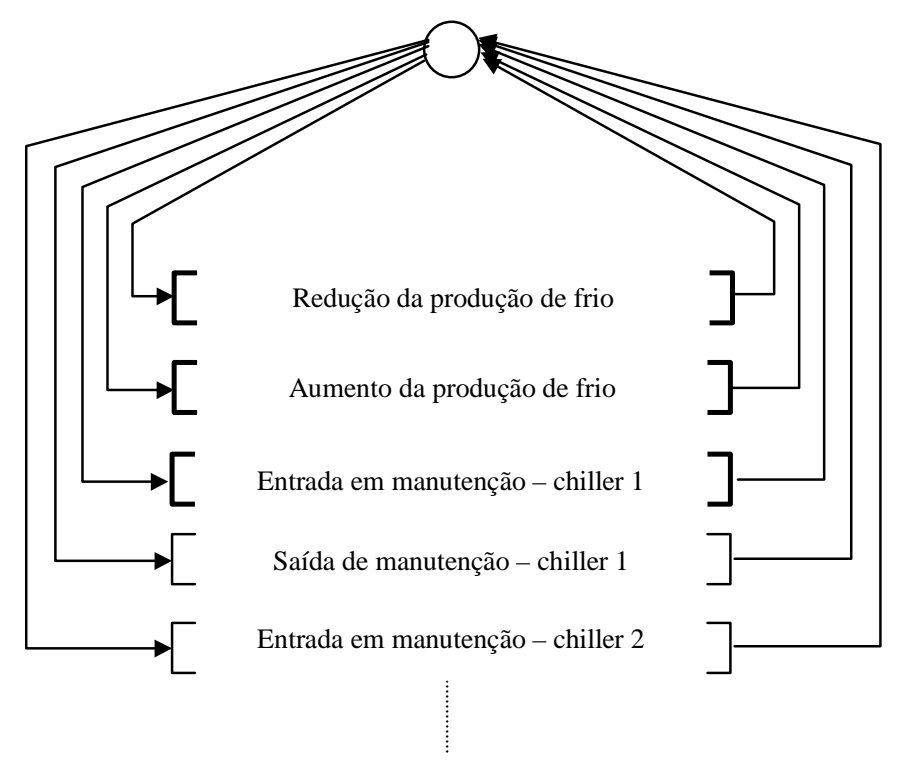

Figura 5.2. Modelo em PFS das estratégias de controle para a produção de água gelada.

Um modelo em PFS semelhante é construído para o sub-sistema de produção de água quente (Figura 5.3):

A seguir apresenta-se o detalhamento das atividades da Figura 5.1 e da Figura 5.2 representadas por colchetes em negrito. Observa-se que as atividades da Figura 5.3 são detalhadas de modo semelhante as da Figura 5.2. 


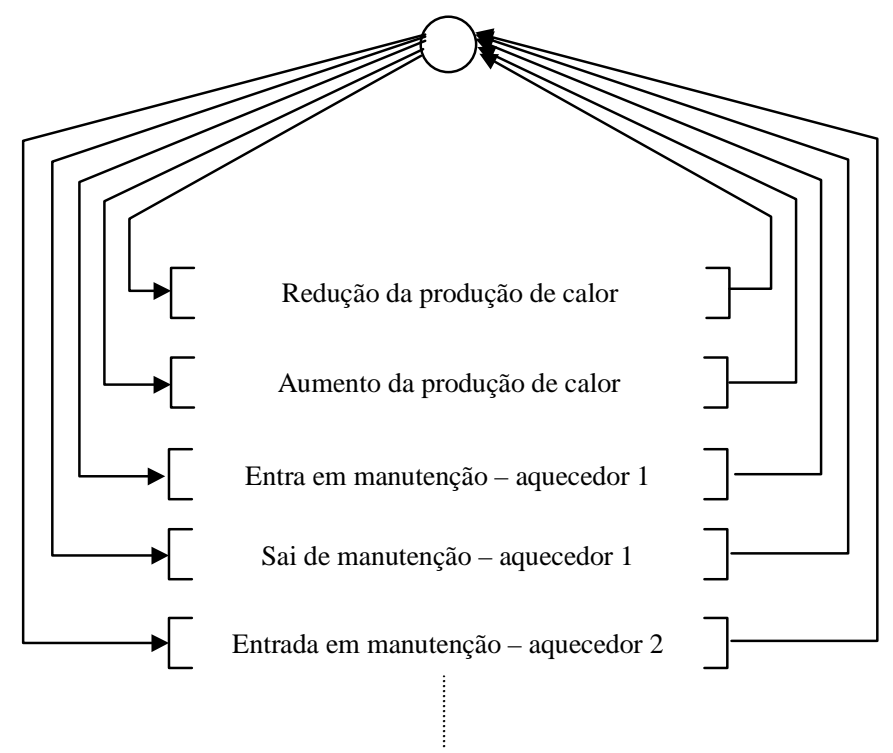

Figura 5.3. Modelo em PFS das estratégias de controle para a produção de água quente.

\section{Atividade [Incêndio - zona 1]}

De acordo com o apresentado no item 5.2, a Figura 5.4 apresenta o detalhamento para esta estratégia. O início da atividade é habilitado por um sinal proveniente do "sistema de controle de incêndio" e transmitido através do BMS.

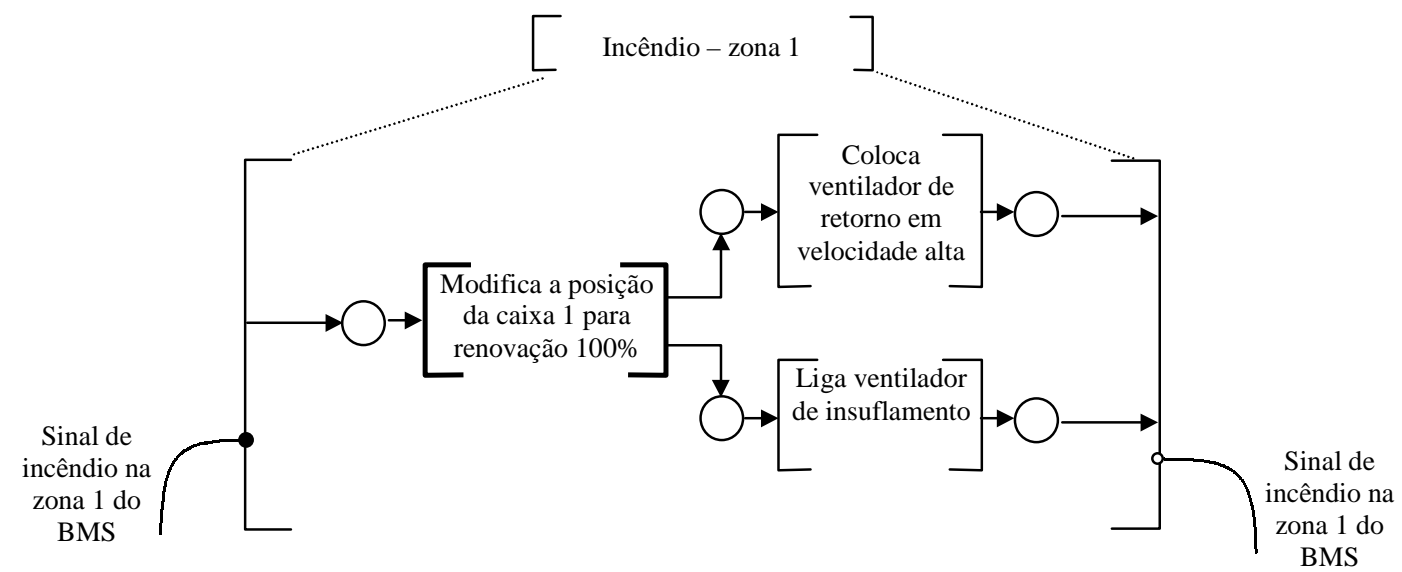

Figura 5.4. Detalhamento da atividade [Incêndio - zona 1]. 
Atividade [Incêndio em zona vizinha - zona 1]

Quando é detectada fumaça em uma zona, o condicionamento das zonas vizinhas também é modificado de acordo com o apresentado no item 5.2. A habilitação desta atividade também é realizada por sinais provenientes do "sistema de controle de incêndio", transmitidos através do BMS. A Figura 5.5 apresenta o detalhamento desta atividade.

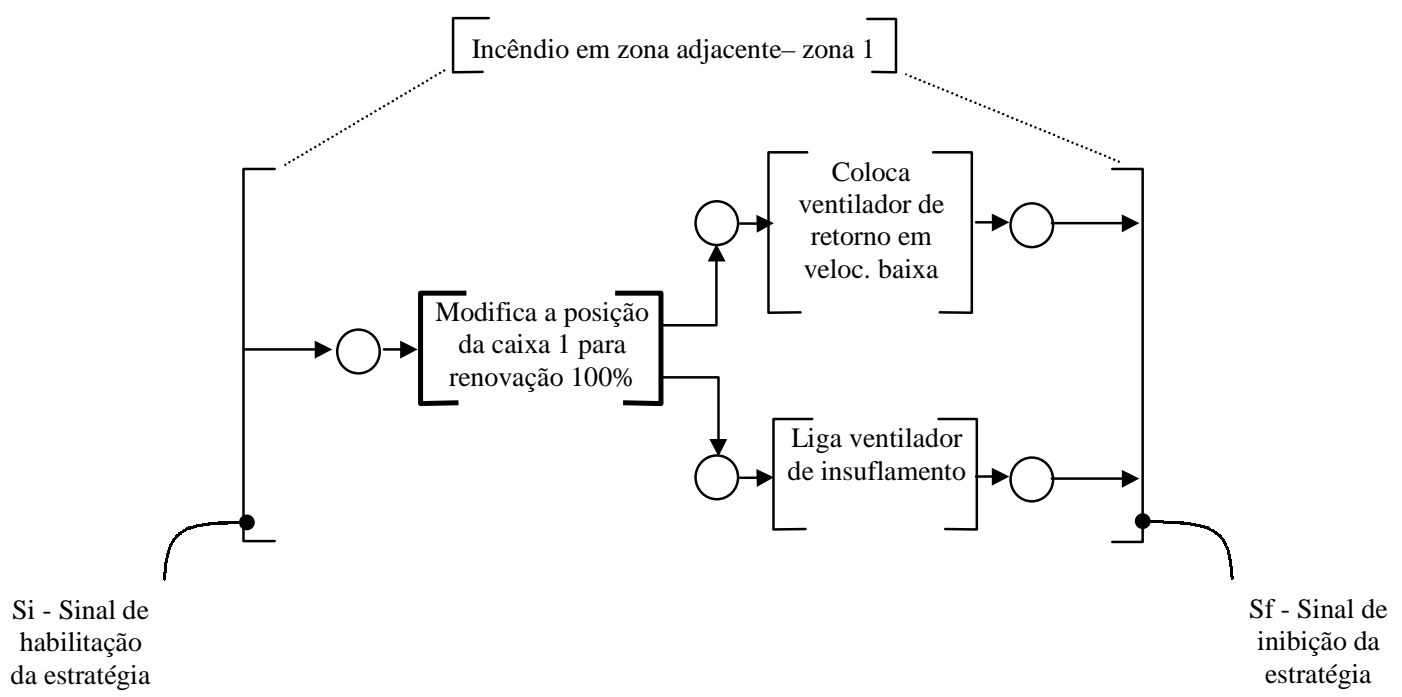

Figura 5.5. Detalhamento da atividade [Incêndio em zona adjacente].

Observa-se que esta atividade só é iniciada se não existe detecção de fumaça na zona 1.

Para a zona 1 considerou-se como zona adjacente as zonas 2 e 3 . O sinal de habilitação das estratégias é uma combinação lógica dos sinais de detecção de fumaça nas zonas 1,2 e 3.

A expressão booleana 8 indica a condição para habilitação da estratégia.

$$
\mathrm{Si}=\overline{\mathrm{I}}_{1} \cdot\left(\mathrm{I}_{2}+\mathrm{I}_{3}\right)
$$

onde $\quad \mathrm{Si}=$ sinal de habilitação da transição para início da estratégia;

$\mathrm{I}_{1}=$ sinal enviado pelo BMS referente a existência de incêndio na zona 1;

$\mathrm{I}_{2}=$ sinal enviado pelo BMS referente a existência de incêndio na zona 2; 
$\mathrm{I}_{3}=$ sinal enviado pelo BMS referente a existência de incêndio na zona 3.

A condição para que esta estratégia não seja mais executada é :

$$
\mathrm{Sf}=\mathrm{I}_{1}+\left(\overline{\mathrm{I}}_{2} \cdot \overline{\mathrm{I}}_{3}\right)
$$

onde $\quad$ Sf $=$ sinal de habilitação da transição para inibição da estratégia.

De modo correspondente, as atividades [Incêndio em zona adjacente - zona 2] e [Incêndio em zona adjacente - zona 3] serão habilitadas pelo sinal de incêndio na zona 1.

Atividade [Área utilizada - zona 1]

Esta atividade é realizada durante o período ocupação do edifício. A Figura 5.6 apresenta o PFS desta estratégia.

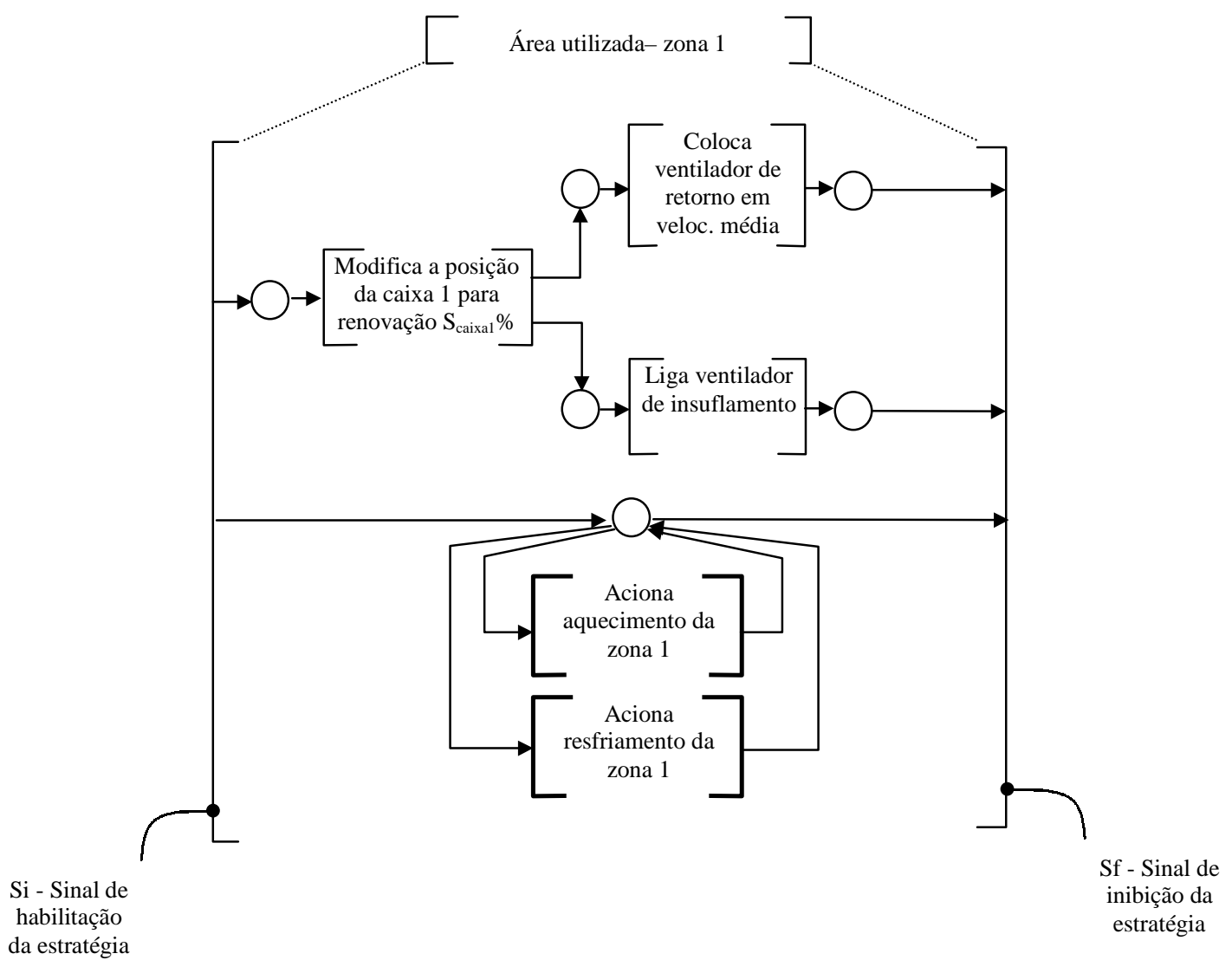

Figura 5.6. Detalhamento da atividade [Área utilizada - zona 1]. 
Considerou-se como condição para o início do condicionamento a detecção de pessoas na zona, bem como ausência de incêndio tanto nas zonas adjacentes como na própria zona. Assim, tem-se as seguintes expressões para os sinais de habilitação e inibição da estratégia:

$$
\begin{aligned}
& \mathrm{Si}=\overline{\mathrm{I}}_{1} \cdot \overline{\mathrm{I}}_{2} \cdot \overline{\mathrm{I}}_{3} \cdot \mathrm{P}_{1} \\
& \mathrm{Sf}=\mathrm{I}_{1}+\mathrm{I}_{2}+\mathrm{I}_{3}+\overline{\mathrm{P}}_{1}
\end{aligned}
$$

onde $\quad \mathrm{P}_{1}=$ sinal enviado pelo BMS referente a presença de pessoas na zona 1 ;

As atividades [Aciona aquecimento da zona 1] e [Aciona resfriamento da zona 1] são responsáveis por acionar/desligar os controladores das válvulas de água quente e fria de acordo com a temperatura no ambiente. O detalhamento destas atividades é apresentado na Figura 5.7.
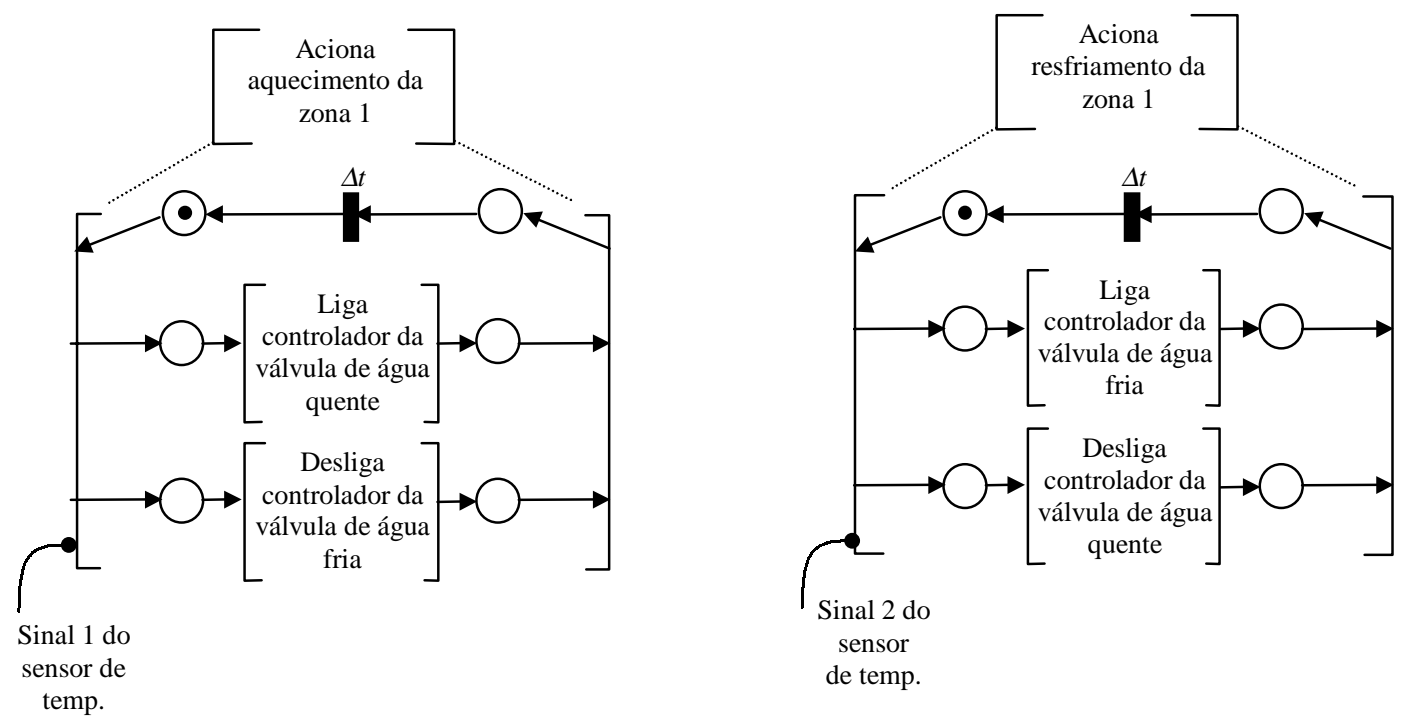

Figura 5.7. Detalhamento das atividades [Aciona aquecimento na zona 1] e [Aciona resfriamento na zona $1]$.

A transição temporizada é introduzida para que uma nova solicitação não seja realizada enquanto a temperatura na zona não sofreu as alterações devido ao acionamento do aquecimento ou resfriamento. 
A habilitação do chaveamento entre os controladores das válvulas de água quente e fria é realizada em função da temperatura na zona. Sua modelagem será apresentada adiante.

Atividade [Área não utilizada - zona 1]

O critério adotado para o início desta estratégia para o caso da zona 1 é a ausência de pessoas na zona.

O detalhamento desta atividade é apresentado na Figura 5.8.

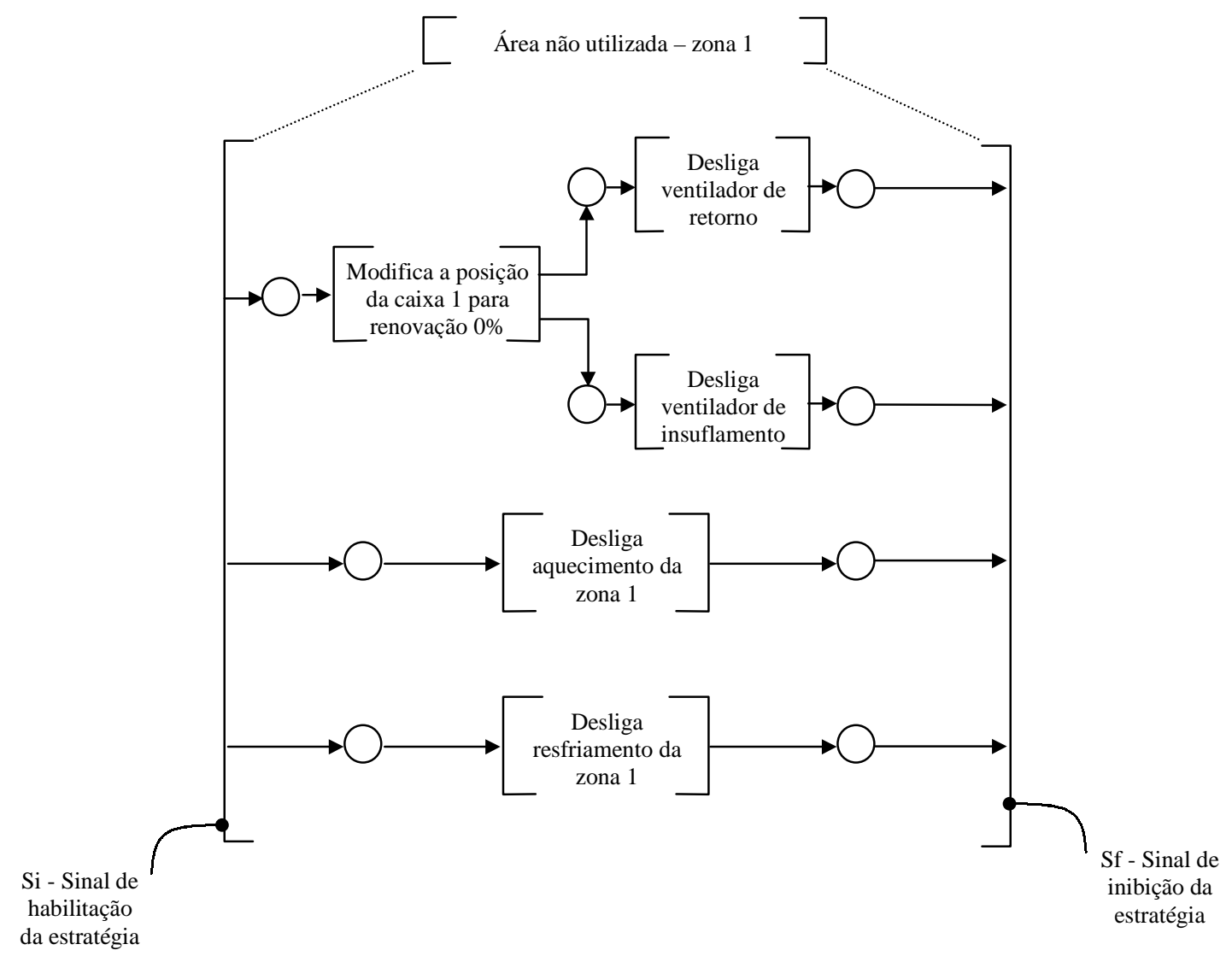

Figura 5.8. Detalhamento da atividade [Área não utilizada - zona 1].

Os sinais de habilitação e inibição da estratégia são:

$$
\begin{aligned}
& \mathrm{Si}=\overline{\mathrm{I}}_{1} \cdot \overline{\mathrm{I}}_{2} \cdot \overline{\mathrm{I}}_{3} \cdot \overline{\mathrm{P}}_{1} \\
& \mathrm{Sf}=\mathrm{I}_{1}+\mathrm{I}_{2}+\mathrm{I}_{3}+\mathrm{P}_{1}
\end{aligned}
$$




\section{Atividade [Redução da produção de frio]}

Esta atividade liga e desliga os diversos "chiller" de acordo com a temperatura da água de retorno. Ela é habilitada por um sinal proveniente de um sensor que detecta a temperatura da água de retorno, e que é modelado no item 5.3.3.

Após a retirada de operação de um "chiller" aguarda-se um determinado tempo até a habilitação da retirada de operação de um novo "chiller", para que o sistema se estabilize e o efeito da retirada de operação do "chiller" seja refletido na temperatura da água na entrada dos "chillers", este tempo é representado pela transição temporizada $\mathrm{T}_{1}$.

O detalhamento desta atividade é apresentado na Figura 5.9. Observa-se que, nesta figura, os índices t e c associados as bombas referem-se as bombas responsáveis pelo fluxo da água que circula entre os "chillers" e as torres de resfriamento, e entre os "chillers" e as serpentinas, respectivamente.

Um modelo semelhante é construído para o aumento da produção de frio.

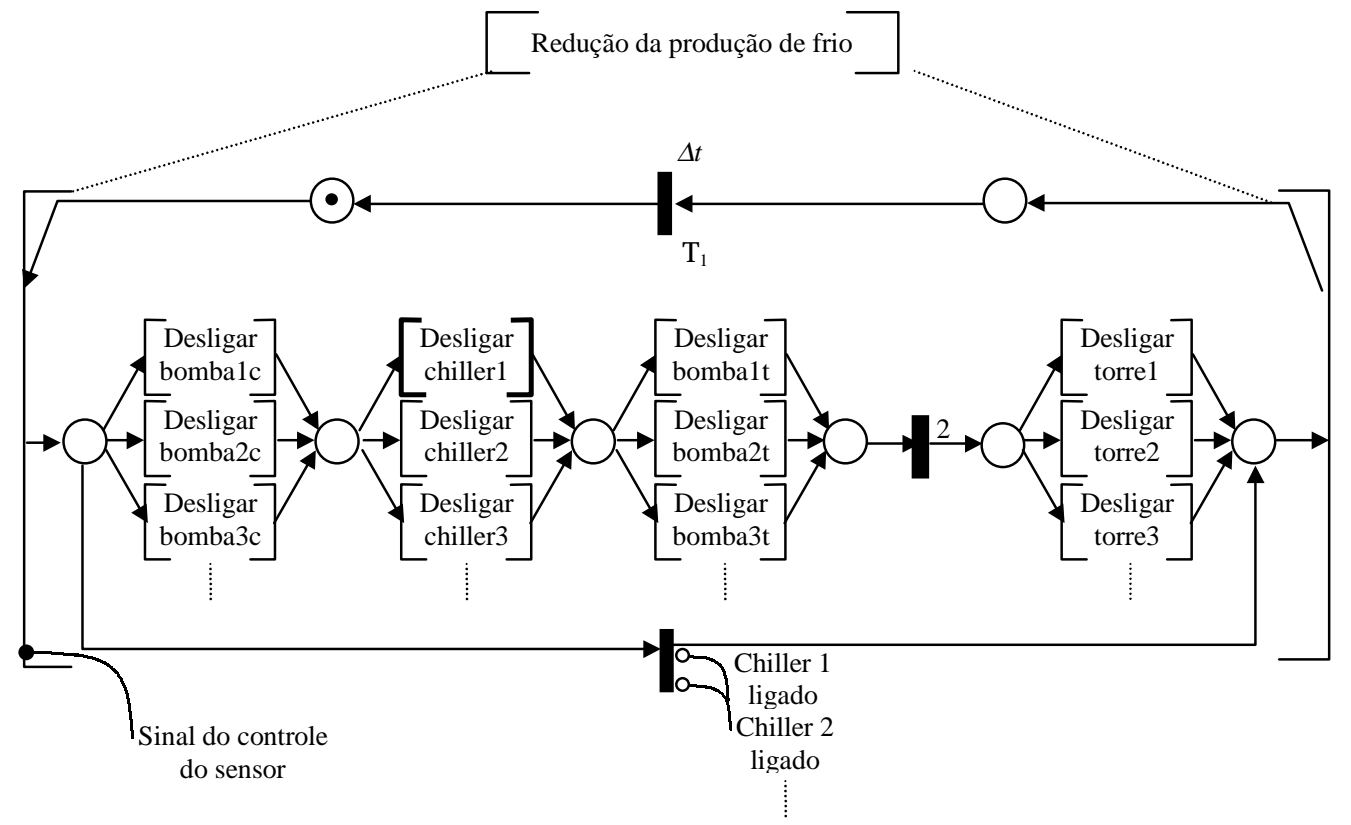

Figura 5.9. Detalhamento da atividade [Redução da produção de frio]. 
Atividade [Entra em manutenção - chiller 1]

Esta atividade é iniciada quando o sistema de gerenciamento de manutenção de equipamentos solicita, através do BMS, a manutenção do "chiller" 1.

O detalhamento desta atividade é apresentado na Figura 5.10.

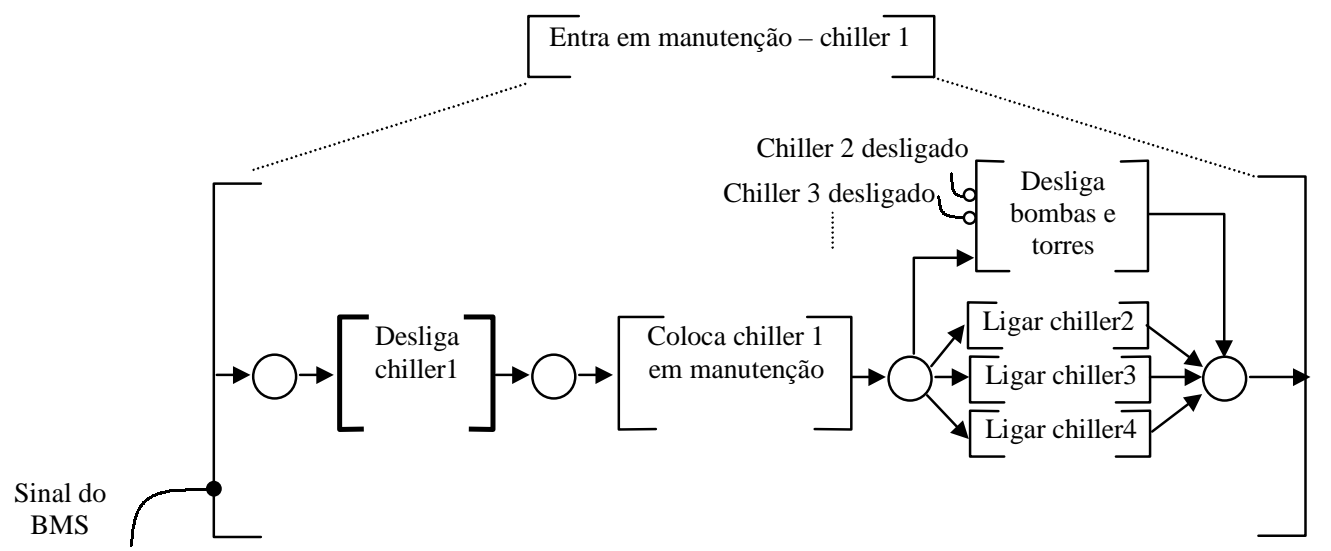

Figura 5.10. Detalhamento da atividade [Entrada em manutenção - "Chiller" 1].

Observa-se que, para os demais equipamentos envolvidos na produção de água gelada, como bombas e torres de resfriamento, existem atividades semelhantes.

Uma vez modeladas as estratégias em PFS, deriva-se o modelo em Redes de Petri de cada atividade de cada estratégia. A Figura 5.11 apresenta alguns exemplos.
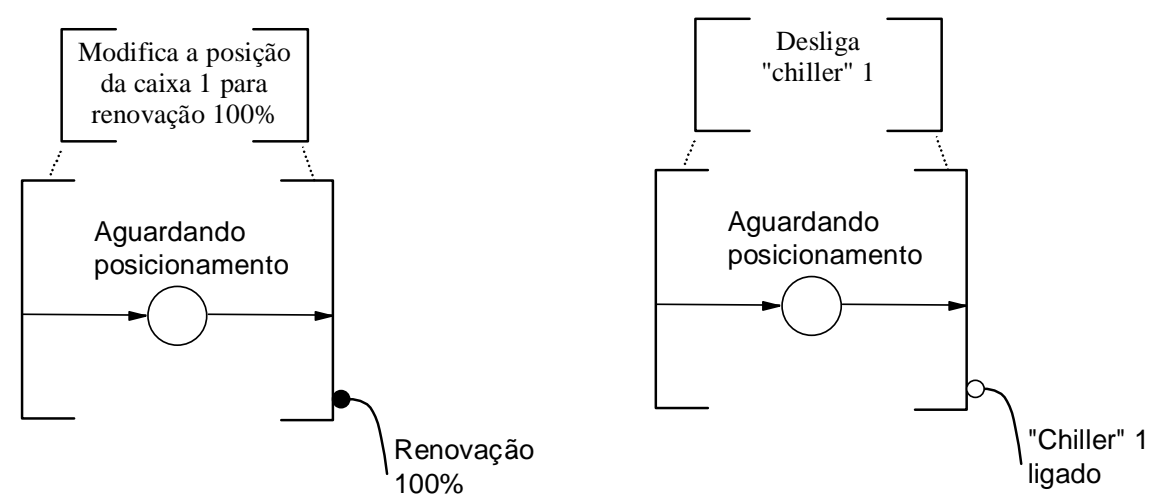

Figura 5.11. Detalhamento de atividades em Redes de Petri.

Os sinais "Renovação 100\%" e “"Chiller" 1 ligado" são provenientes do modelo do sistema de ar condicionado, que é apresentado no item 5.3.2.

Os modelos das estratégias de gerenciamento são conectados através de $\operatorname{arcos}$ habilitadores e inibidores ao sistema de gerenciamento na parte referente às "operações 
do sistema". Quando as diversas estratégias da primeira parte do sistema de gerenciamento são executadas, estas são responsáveis por acionar as operações da segunda parte, que por sua vez atuam no sistema de ar condicionado.

São exemplos de operações do sistema:

- Ligar bomba 1c

- Desligar bomba 1c

- $\quad$ Ligar "chiller" 1

- Colocar caixa de mistura 1 em $100 \%$

- Colocar caixa de mistura 1 em $0 \%$

- Colocar caixa de mistura 2 em 100\%

A Figura 5.12 apresenta-se o modelo em redes de Petri das operações "Colocar caixa de mistura em 100\%" e "Desligar "chiller" 1", bem como a conexão destas operações com as respectivas atividades das estratégias de controle.

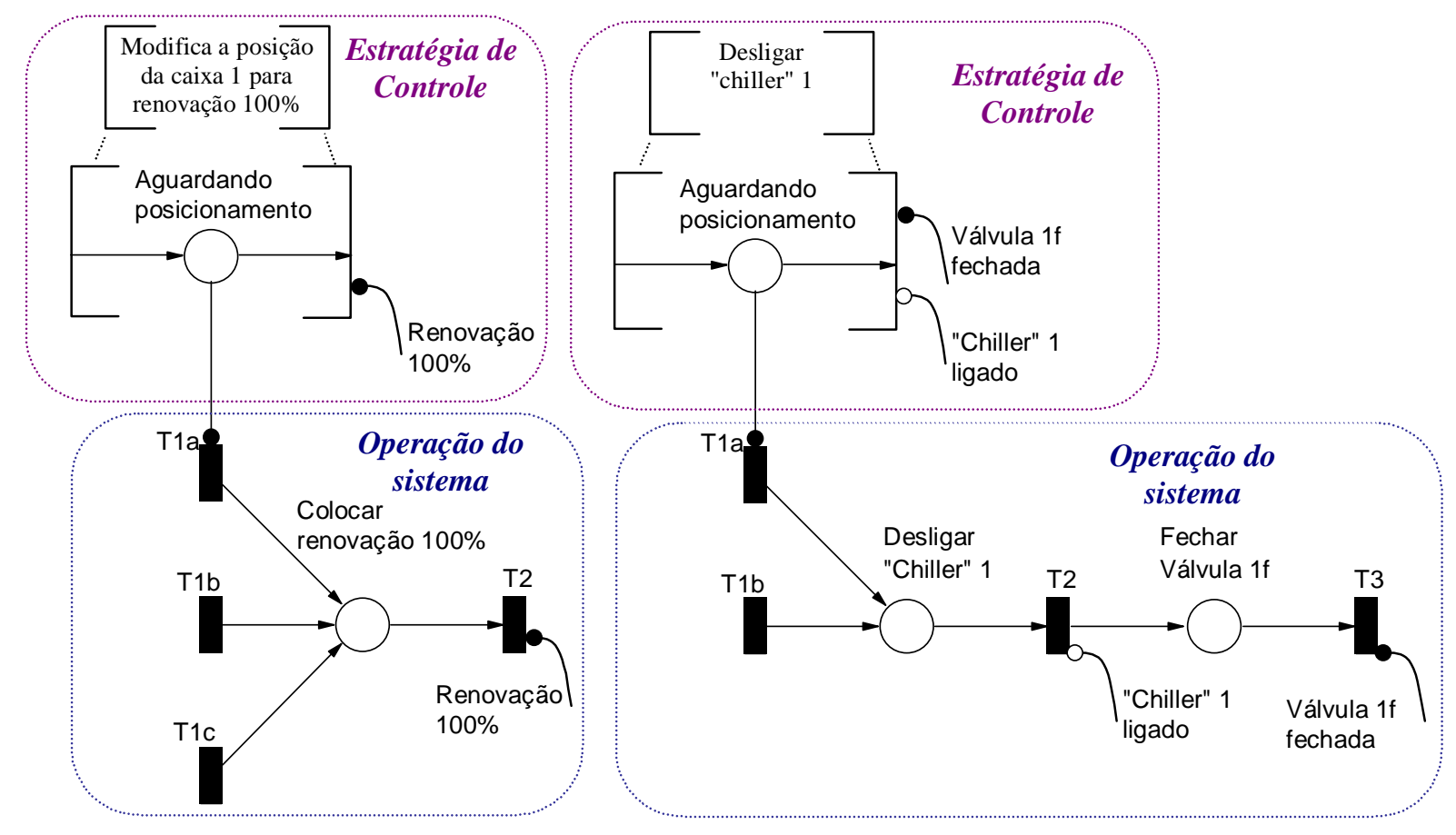

a)

b)

Figura 5.12. Conexão entre estratégias de controle e operações. 
Observa-se que, no exemplo da Figura 5.12 (a), as operações podem ser iniciadas a partir de três estratégias de controles (Estratégia A, Estratégia B e Estratégia C). Quando a atividade é inicializada a partir da Estratégia A, a transição T1a é disparadas, para a Estratégia B e C dispara-se as transições T1b e T1c, respectivamente.

\subsubsection{Modelagem do Sistema de Ar Condicionado}

Inicialmente, identificam-se os principais fluxos que ocorrem no sistema de ar condicionado do PAMB. São eles: fluxo de ar, fluxo de água quente e fluxo de água gelada. Para cada fluxo define-se quais as propriedades de interesse a serem modeladas. Para os fluxos de água quente e gelada, no presente caso, são consideradas a temperatura e a vazão. Para o fluxo de ar, não existe interesse na modelagem da pressão ou umidade, uma vez que estas propriedades não são atualmente controladas no PAMB, são modeladas, portanto, apenas a vazão e a temperatura do ar.

É construído, então, um modelo em PFS dos principais fluxos do sistema de ar condicionado do PAMB (Figura 5.13), onde as cores vermelho, azul e preto associadas aos arcos relacionados com o fluxo de água indicam água fria, água quente e água a temperatura intermediária, respectivamente.

Cada atividade [Condicionamento do Ar - Sub-sistema i] corresponde ao sistema de condicionamento do ar de uma zona i. A atividade [Produção de Água Gelada] representa a parte do sistema responsável pelo resfriamento da água. Esta água é distribuída para os diversos subsistemas de condicionamento, assim como para a água processada pela atividade [Produção de Água Quente].

Cada atividade do PFS da Figura 5.13 pode ser detalhada em um novo PFS ou em redes PTD ou em sistemas de equações diferenciais, visando representar as propriedades da vazão e temperatura em diversos pontos do sistema. 


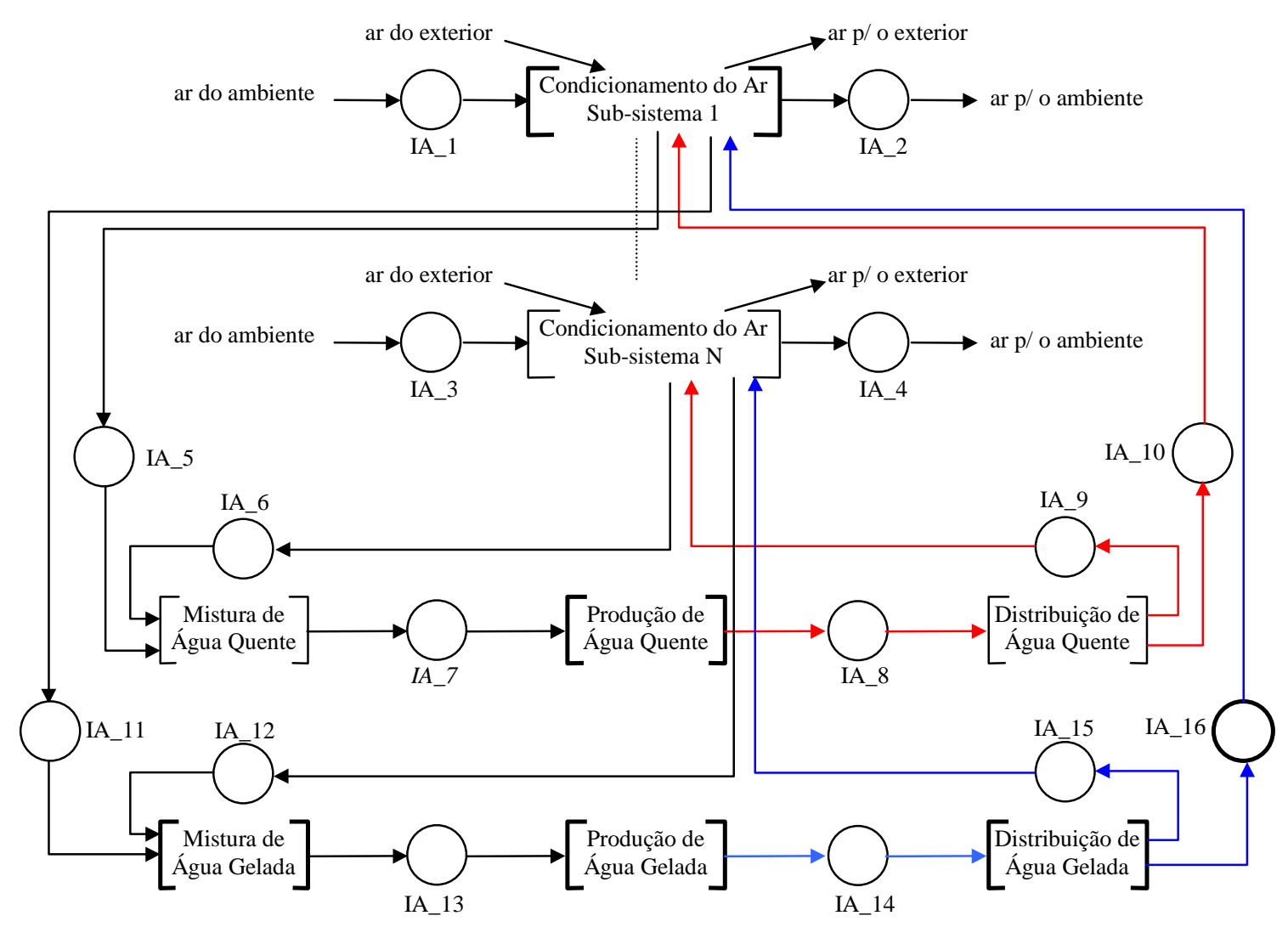

Figura 5.13. Sub-sistemas do ar condicionado do PAMB.

As atividades detalhadas em um novo modelo em PFS são [Produção de Água Gelada], [Produção de Água Quente] e [Condicionamento do Ar - Subsistema 1...N]. Os modelos em PFS para estas atividades são apresentados na Figura 5.14, na Figura 5.15 e na Figura 5.16.

Na Figura 5.15 observa-se que os índices $\mathrm{r}$ e i referem-se aos ventiladores de retorno e de insuflamento, respectivamente, e que os índices f e q referem-se aos fluxos de água fria e quente, respectivamente.

Uma vez construído o modelo em PFS do sistema de ar condicionado, cada atividade e cada elemento inter-atividade é detalhado em um sistema de equações diferenciais ou em uma rede PTD. 


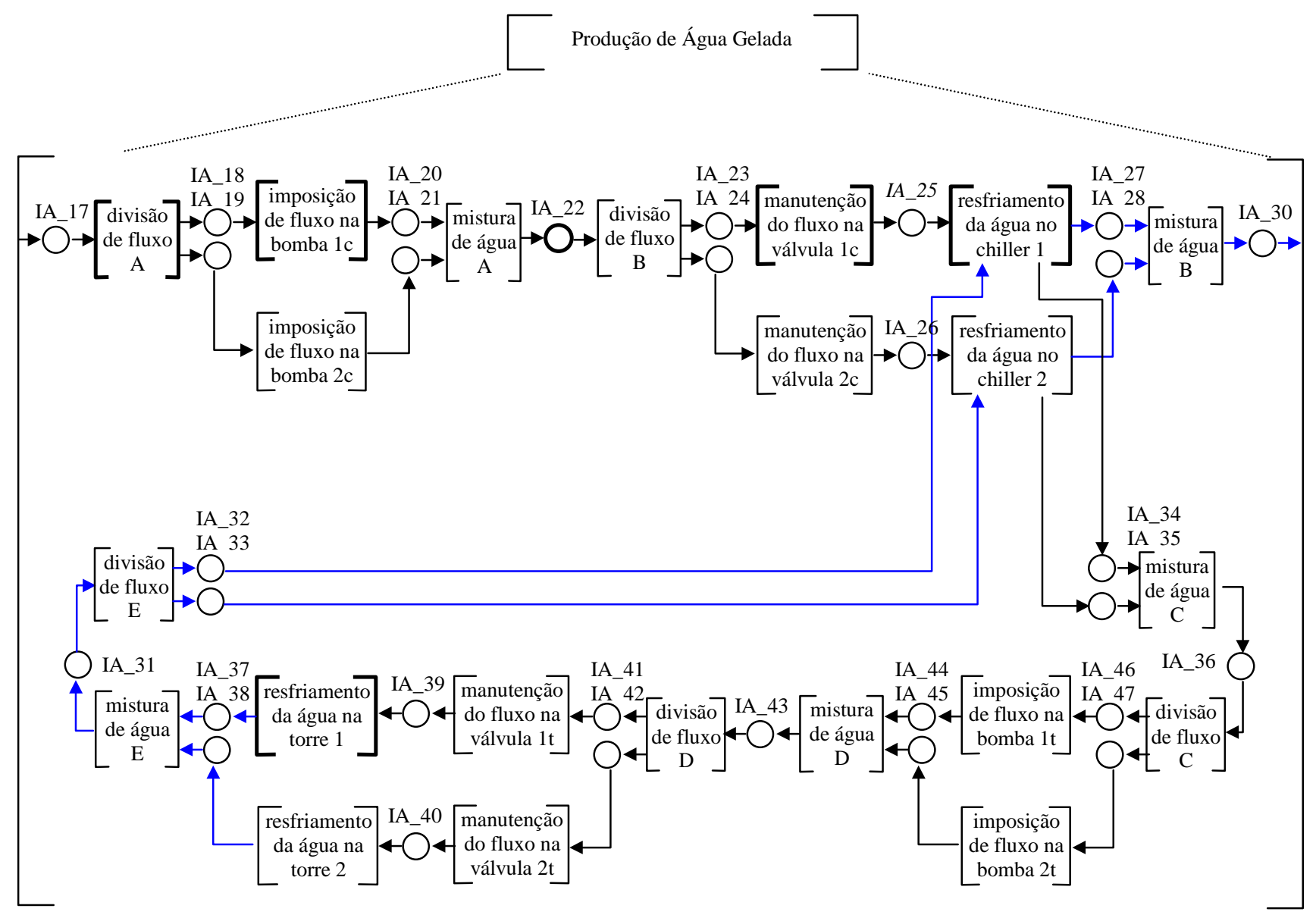

Figura 5.14. Detalhamento da atividade [Produção de Água Gelada].

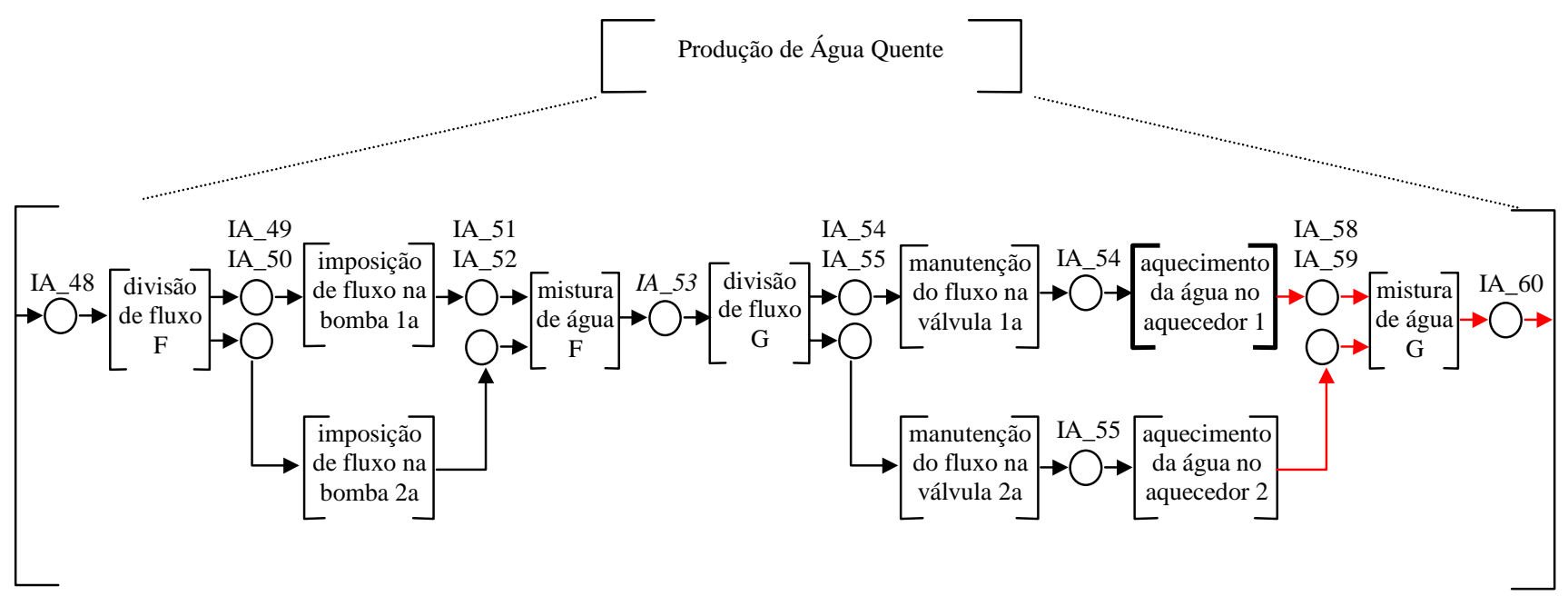

Figura 5.15. Detalhamento da atividade [Produção de Água Quente]. 


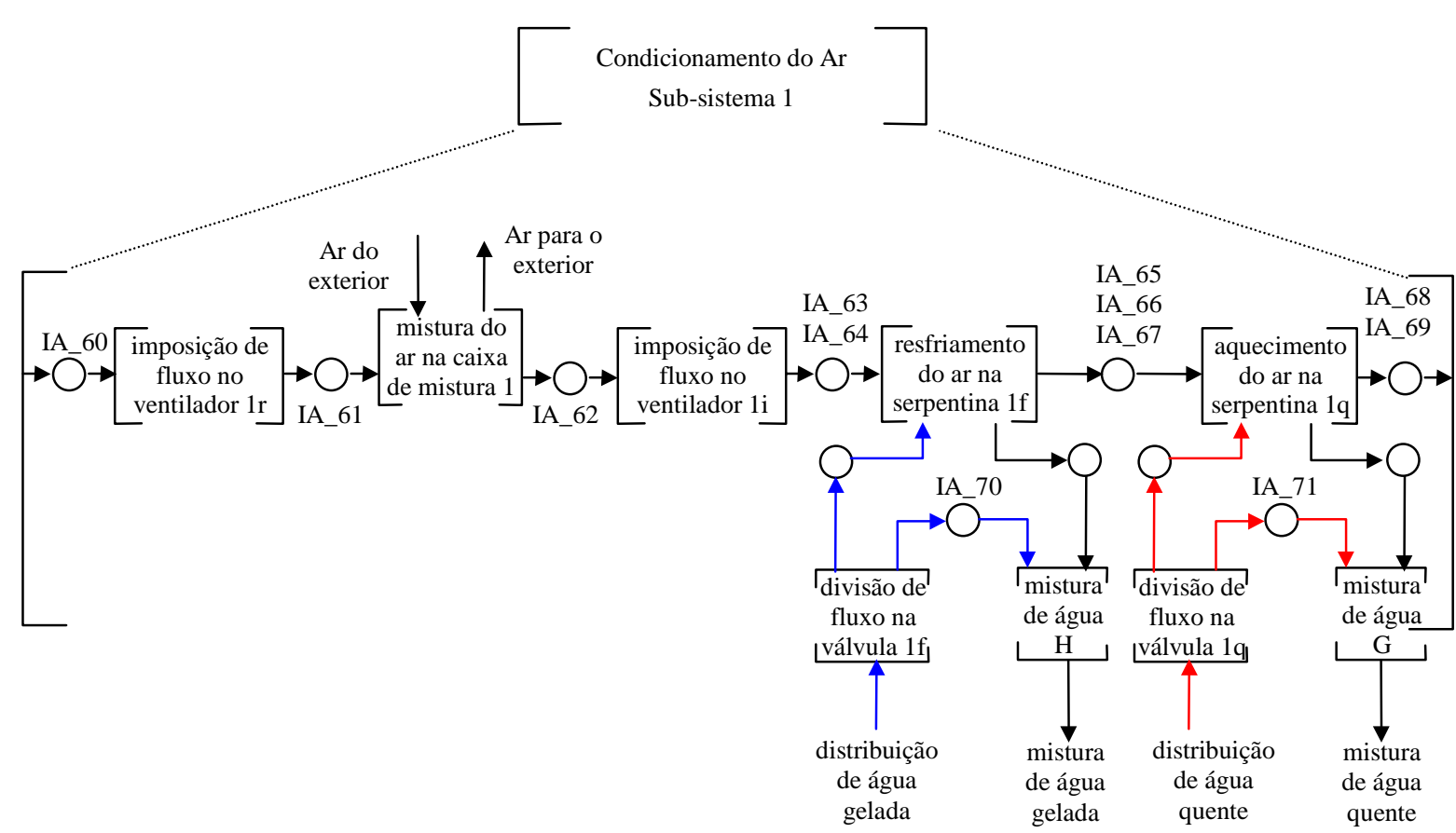

Figura 5.16. Detalhamento da atividade [Condicionamento do $\mathrm{Ar}$ - Subsistema 1].

\subsubsection{Modelagem dos elementos inter-atividade}

Cada elemento inter-atividade pode ser detalhado diretamente como uma equação diferencial ou de um sistema de equações diferenciais que representa o tempo gasto para uma variação na temperatura ou na vazão do fluxo de água ou ar na saída de uma atividade para modificar as propriedades na entrada da atividade seguinte. $\mathrm{O}$ modelo adotado para este tempo é um sistema de primeira ordem em função da constante de tempo do sistema ( $\tau$ ), dado pela Equação 14, onde "u" é a entrada, ou seja, o valor da propriedade na saída de uma atividade e "x" é a saída, ou seja, o valor da propriedade na entrada da próxima atividade:

$$
\frac{\mathrm{dx}}{\mathrm{dt}}=\frac{\mathrm{u}-\mathrm{x}}{\tau}
$$

Como exemplo, apresenta-se o detalhamento do elemento inter-atividade IA-16 da Figura 5.13 entre as atividades [Distribuição de água gelada] e [Condicionamento do 
ar - Sub-sistema 1]. Observa-se que para cada elemento inter-atividade também é definido um vetor de variáveis contendo as variáveis do fluxo de água gelada na saída do elemento.

vetor de variáveis:

$$
X_{\text {IA_16 }}=\left[T_{\text {cond_1f_in }}, V_{\text {cond_1f_in }}\right]
$$

sistema de equações: $\left\{\begin{array}{l}\frac{\mathrm{dv}_{\text {cond_1f_in }}}{\mathrm{dt}}=\frac{\mathrm{v}_{\text {dist_ag_out_1 }}-\mathrm{v}_{\text {cond_1f_in }}}{\tau_{\text {IA_16_v }}} \\ \frac{\mathrm{dT}_{\text {cond_1f_in }}}{\mathrm{dt}}=\frac{\mathrm{T}_{\text {dist_ag_out_1 }}-\mathrm{T}_{\text {cond_1f_in }}}{\tau_{\mathrm{IA} \_16 \_T}}\end{array}\right.$

onde $\quad \mathrm{X}_{\mathrm{IA} \_16}=$ vetor de variáveis da inter-atividade IA-16;

$\mathrm{v}_{\text {cond_1f_in }} \mathrm{e} \mathrm{T}_{\text {cond_1f_in }}=$ vazão e temperatura para a atividade [Condicionamento do ar - Sub-sistema 1];

$\mathrm{V}_{\text {dist_ag_out_1 }}$ e $\mathrm{T}_{\text {dist_ag_out_1 }}=$ vazão e temperatura na saída para o sub-sistema de condicionamento 1 da atividade [Distribuição de Água Gelada];

$\tau_{\mathrm{IA} \_16 \_v}$ e $\tau_{\mathrm{IA} \_16 \_\mathrm{T}}=$ constantes de tempo do sistema para vazão e temperatura, respectivamente;

$\mathrm{t}=$ tempo.

Foram adotados modelos semelhantes para as seguintes inter-atividades (Figura 5.16) :

- IA_5, IA_6, ... - representam o atraso das propriedades da água entre a saída das serpentinas e a entrada nos aquecedores;

- IA_9, IA_10, .. - representam o atraso das propriedades da água entre a saída dos aquecedores e a entrada nas serpentinas ;

- IA_11, IA_12, .. - representam o atraso das propriedades da água entre a saída das serpentinas e a entrada nos "chillers"; 
- IA_15, IA_16, ... - representam o atraso das propriedades da água entre a saída dos “chillers" e a entrada nas serpentinas ;

- IA_63 e equivalentes - representam o atraso entre as propriedades do ar exterior e do ambiente e a entrada na serpentina.

Para os demais elementos inter-atividades considerou-se não necessária a representação deste atraso de tempo. Assim, as propriedades na saída do elemento interatividade são iguais às propriedades na entrada. Como exemplo apresenta-se a modelagem do elemento IA-22 da Figura 5.14.

vetor de variáveis: $\quad \mathrm{X}_{\mathrm{IA} \_22}=\left[\mathrm{T}_{\text {div_B_in }}, \mathrm{V}_{\text {div_B_in }}\right]$

sistema de equações: $\quad\left\{\begin{array}{l}\mathrm{v}_{\text {div_B_in }}=\mathrm{v}_{\text {mist_A_out }} \\ \mathrm{T}_{\text {div_B_in }}=\mathrm{T}_{\text {mist_A_out }}\end{array}\right.$

onde $\quad \mathrm{X}_{\mathrm{IA} \_22}=$ vetor de variáveis da inter-atividade IA-22;

$\mathrm{v}_{\text {div_B_in }}$ e $\mathrm{T}_{\text {div_B_in }}=$ vazão e temperatura na entrada da atividade [Divisão de fluxo B];

$\mathrm{v}_{\text {mist_A_out }} \mathrm{e} \mathrm{T}_{\text {mist_A_out }}=$ vazão e temperatura na saída da atividade e [Mistura de água $\mathrm{A}]$;

\subsubsection{2. $\quad$ Modelagem das atividades}

Cada atividade pode ser detalhada diretamente como um sistema de equações diferenciais, como uma rede PTD ou como um PFS que é ser posteriormente detalhado.

A seguir é apresentado o detalhamento das atividades da Figura 5.13, da Figura 5.14, da Figura 5.15 e da Figura 5.16.

Mistura de Água Gelada (Figura 5.13)

Esta atividade representa a mistura da água proveniente das diversas serpentinas de água fria do sistema. 
O cálculo da vazão total na saída desta atividade ( $\left.\mathrm{v}_{\text {mist_ag_out }}\right)$ é obtido através da soma da vazão dos fluxos provenientes das diversas serpentinas $\left(\mathrm{v}_{\text {mist_ag_in_1 }}, \mathrm{v}_{\text {mist_ag_in_2 }}\right.$, ... V V mist_ag_in_N $)$.

A variável "temperatura" após a mistura ( $\left.\mathrm{T}_{\text {mist_ag_out }}\right)$ é obtida considerando o sistema em equilíbrio térmico, ou seja, a conservação de energia entre a água antes e após a mistura, conforme a Equação15.

$$
\begin{aligned}
& \sum\left[\mathrm{v}_{\text {mist_ag_in_1 }} * \rho_{\text {água }} * \mathrm{~h}_{\text {água }}\left(\mathrm{T}_{\text {mist_ag_in_1 }}\right)+\mathrm{v}_{\text {mist_ag_in_2 }} * \rho_{\text {água }} * \mathrm{~h}_{\text {aggua }}\left(\mathrm{T}_{\text {mist_ag_in_2 }}\right) \ldots\right] \\
& \quad=\mathrm{v}_{\text {mist_ag_out }} * \rho_{\text {água }} * \mathrm{~h}_{\text {água }}\left(\mathrm{T}_{\text {mist_ag_out }}\right)
\end{aligned}
$$

onde $\quad V_{\text {mist_ag_in_1 }}, T_{\text {mist_ag_in_1 }}, v_{\text {mist_ag_in_2 }}$ e $T_{\text {mist_ag_in_2 }}=$ vazão e temperatura do na entrada da atividade [Mistura de Água Gelada] dos fluxo proveniente dos "fancoils" nas atividades [Condicionamento do ar - Sub-sistemas 1], [... 2], ...; $\mathrm{v}_{\text {mist_ag_out }}, \mathrm{T}_{\text {mist_ag_out }}=$ vazão e temperatura na saída da atividade [Mistura de Água Gelada];

$\rho_{\text {água }}=$ densidade da água;

$\mathrm{h}_{\text {água }}=$ entalpia.

Na expressão acima substituiu-se o cálculo da entalpia por uma aproximação linear da equação sugerida por [Taube, 97], onde T é a temperatura em graus Kelvin (Equação 16):

$$
\mathrm{h}_{\text {agua }}(\mathrm{T})=4,187 * \mathrm{~T}+7,72
$$

Esta aproximação implica em um acréscimo no erro original da equação de no máximo $0,82 \%$ para a faixa de 0 a $50^{\circ} \mathrm{C}(273$ a $323 \mathrm{~K})$.

A Equação 12 é, então, simplificada para Equação 17.

$$
\mathrm{T}_{\text {mist_ag_out }}=\frac{\sum\left[\mathrm{v}_{\text {mist_ag_in_1 }} * \mathrm{~T}_{\text {mist_ag_in_1 }}+\mathrm{v}_{\text {mist_ag_in_2 }} * \mathrm{~T}_{\text {mist_ag_in_2 }}+\ldots\right]}{\mathrm{v}_{\text {mist_ag_out }}}
$$


O vetor de variáveis e o sistema de equações associados a esta atividade são:

vetor de variáveis: $\quad X_{\text {mist_ag }}=\left[T_{\text {mist_ag_out }}, V_{\text {mist_ag_out }}\right]$

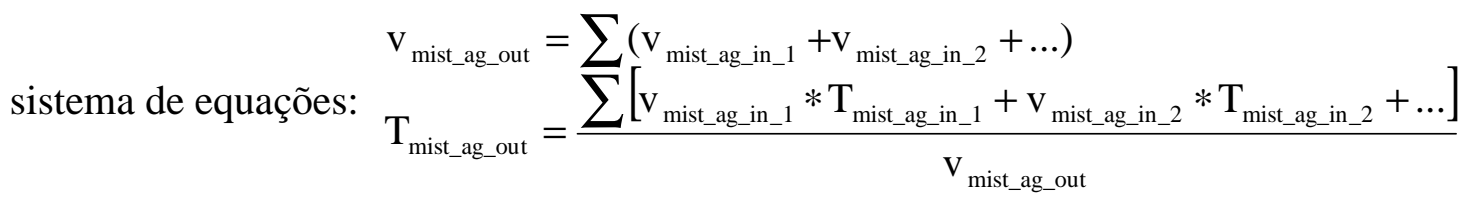

Observa-se que a atividade [Mistura de Água Quente] é modelada de modo análogo.

Distribuição de Água Gelada (Figura 5.13)

Esta atividade representa a distribuição da água gelada produzida nos "chillers" para as diversas serpentinas de água fria do sistema de ar condicionado. Considerou-se que cada serpentina de água fria recebe uma porcentagem fixa da água fria produzida, de acordo com a capacidade do "fan-coil".

Para esta atividade, tem-se o seguinte vetor de variáveis e sistema de equações:

vetor de variáveis: $\quad \mathrm{X}_{\text {distr_ag }}=\left[\mathrm{T}_{\text {distr_ag_out_1 }}, \mathrm{v}_{\text {distr_ag_out_1 }}, \mathrm{T}_{\text {distr_ag_out_2}}, \mathrm{V}_{\text {distr_ag_out_2 }}, \ldots\right]$

sistema de equações: $\left\{\begin{array}{l}\mathrm{v}_{\text {distr_ag_out_1 }}=\mathrm{x}_{1} * \mathrm{v}_{\text {distrag_in }} \\ \mathrm{T}_{\text {distr_ag_out_1 }}=\mathrm{T}_{\text {distr_ag_in }} \\ \mathrm{v}_{\text {distr_ag_out_2 }}=\mathrm{x}_{2} * \mathrm{v}_{\text {distr_ag_in }} \\ \mathrm{T}_{\text {distr_ag_out_2 }}=\mathrm{T}_{\text {distr_ag_in }}\end{array}\right.$

onde $\quad \mathrm{v}_{\text {distr_ag_out_1 }}, \mathrm{T}_{\text {distr_ag_out_1 }}, \mathrm{v}_{\text {distr_ag_out_2 }}, \mathrm{T}_{\text {distr_ag_out_2 }}=$ vazão e temperatura dos fluxos de água enviados aos "fan-coil" nas atividades [Condicionamento do ar Sub-sistemas 1], [...2], respectivamente;

$\mathrm{v}_{\text {distr_ag_in }}, \mathrm{T}_{\text {distr_ag_in }},=$ vazão e temperatura do fluxo de água na entrada da atividade [Distribuição de Água Gelada];

$\mathrm{x}_{1}$ e $\mathrm{x}_{2}=$ porcentagem do fluxo de água gelada total produzido enviado aos "fancoils" 1 e 2 , respectivamente. 
Divisão de Fluxo A (Figura 5.14)

Este elemento modela a divisão do fluxo proveniente da atividade [Mistura de Água Gelada] entre as diversas bombas. Como no caso da atividade [Distribuição de Água Gelada], a temperatura do fluxo de água não é alterada.

Observa-se que a porcentagem de vazão enviada a cada bomba depende do número de bombas que estiverem acionadas. As bombas estão relacionadas as atividades [imposição de fluxo na bomba 1c], [...2c], etc. e se encontram modeladas em redes PTD mais adiante.

O vetor de variáveis e o sistema de equações associados a esta atividade são:

vetor de variáveis: $\quad \mathrm{X}_{\text {div_A }}=\left[\mathrm{v}_{\text {div_A_out_1 }}, \mathrm{T}_{\text {div_A_out_1 }}, \mathrm{v}_{\text {div_A_out_2 }}, \mathrm{T}_{\text {div_A_out_2 }}, \ldots\right]$

sistema de equações: $\left\{\begin{array}{l}\mathrm{v}_{\text {div_A_out_1 }}=\frac{\mathrm{v}_{\text {div_A_in }}}{\sum\left[\mathrm{m}_{\mathrm{x} 1}+\mathrm{m}_{\mathrm{x} 2}+\ldots\right]} * \mathrm{~m}_{\mathrm{x} 1} \\ \mathrm{~T}_{\text {div_A_out_1 }}=\mathrm{T}_{\text {div_A_in }} \\ \mathrm{v}_{\text {div_A_out_2 }}=\frac{\mathrm{v}_{\text {div_A_in }}}{\sum\left[\mathrm{m}_{\mathrm{x} 1}+\mathrm{m}_{\mathrm{x} 2}+. . .\right]} * \mathrm{~m}_{\mathrm{x} 2} \\ \mathrm{~T}_{\text {div_A_out_2 }}=\mathrm{T}_{\text {div_A_in }}\end{array}\right.$

onde $\quad v_{\text {div_A_out_1 }}, T_{\text {div_A_out_1 }}, v_{\text {div_A_out_2 }}, T_{\text {div_A_out_2 }}=$ vazão e temperatura dos fluxos de água para as bombas do "chiller" 1 e do "chiller" 2, respectivamente;

$\mathrm{m}_{\mathrm{x} 1}$ e $\mathrm{m}_{\mathrm{x} 2}=$ marcação dos lugares "bomba 1c ligada" e "bomba 2c ligada";

$\mathrm{v}_{\text {div_A_in }}, \mathrm{T}_{\text {div_A_in }},=$ vazão e temperatura do fluxo de água na entrada da atividade resultante da mistura dos fluxos de água gelada proveniente dos diversos "fan-coils".

A modelagem das atividades [Divisão de fluxo B], [... C], etc. é semelhante. 
Imposição de fluxo na bomba 1c (Figura 5.14)

O fluxo total de água através do sistema é determinado pelo número de bombas em funcionamento. Observa-se que as bombas não modificam a temperatura da água, apenas determinam a vazão total.

A seguir apresenta-se a modelagem da bomba 1c em rede PTD, que pode assumir três estados discretos: ligada, desligada ou em manutenção (Figura 5.17).

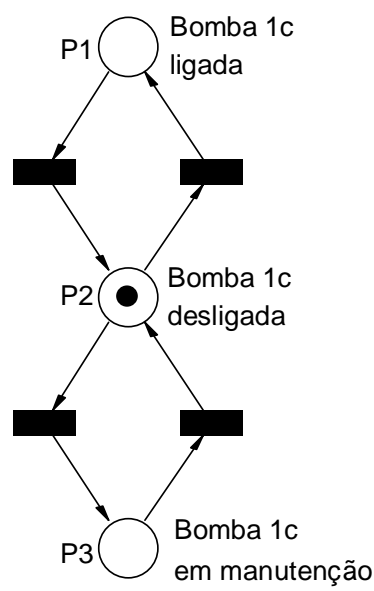

Figura 5.17. Rede PTD - Bomba 1c.

O vetor de variáveis e as equações da rede PTD associados a esta atividade são:

vetor de variáveis: $\quad \mathrm{X}_{\text {bombalc }}=\left[\mathrm{T}_{\text {bombalc_out }}, \mathrm{v}_{\text {bombalc_out }}\right]$

sistemas de equações: $\left\{\begin{array}{l}\text { Lugar: Bombalc ligada } \\ \mathrm{v}_{\text {bombalc_out }}=\mathrm{Sp}_{\text {bombalc }} \\ \mathrm{T}_{\text {bombalc_out }}=\mathrm{T}_{\text {bombalc_in }} \\ \text { Lugar: Bombalc desligada e Bombalc em manutenção } \\ \mathrm{v}_{\text {bombalc_out }}=0 \\ \frac{\mathrm{dT}_{\text {bombalc_out }}=0}{\mathrm{dt}}=0\end{array}\right.$

onde $T_{\text {bombalc_out }}, v_{\text {bombalc_out }}=$ temperatura e vazão da água na saída da bomba 1c;

$\mathrm{T}_{\text {bombalc_in }}=$ temperatura do fluxo de água na entrada da bomba $1 \mathrm{c}$;

$\mathrm{Sp}_{\text {bombalc }}=$ "set-point" da bomba 1c para quantidade de fluxo desejado. 
A modelagem das atividades [Imposição de fluxo na Bomba 2c], [... 1t], etc., realizadas pelas demais bombas do sistema, é semelhante a atividade [Imposição de fluxo na Bomba 1c].

\section{Manutenção do fluxo na válvula 1c (Figura 5.14)}

Esta atividade representa a passagem ou o bloqueio do fluxo de água através da válvula de bloqueio. No primeiro caso, as propriedades do fluxo não são alteradas. No caso da válvula estar fechada, a vazão é nula e a temperatura na saída da válvula não é alterada.

A válvula de bloqueio é modelada através de uma rede PTD, à qual se encontram associados os sistemas de equação que representam a atividade.

A rede PTD associada a válvula 1c é apresentada na Figura 5.18.

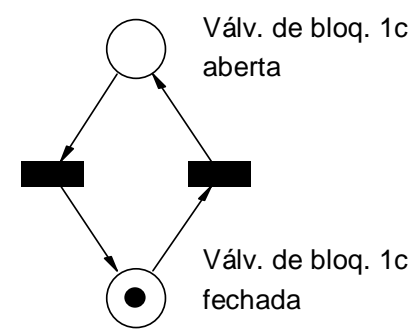

Figura 5.18. Rede PTD - Válvula 1c.

O vetor de variáveis e os sistemas de equações associados a esta atividade para cada estado da válvula são:

vetor de variáveis: $\quad \mathrm{X}_{\text {válvula1c }}=\left[\mathrm{T}_{\text {válvula1c_out }}, \mathrm{V}_{\text {válvula1c_out }}\right]$ sistemas de equações: $\left\{\begin{array}{l}\text { Lugar: Válvulalc e atuador abertos } \\ \mathrm{v}_{\text {válvulalc_out }}=\mathrm{v}_{\text {válvulalc_in }} \\ \mathrm{T}_{\text {válvulalc_out }}=\mathrm{T}_{\text {válvulalc_in }} \\ \text { Lugar: Válvulalce } \text { atuador fechados } \\ \mathrm{v}_{\text {válvulalc_out }}=0 \\ \frac{\mathrm{dT}_{\text {válvula1t_out }}}{\mathrm{dt}}=0\end{array}\right.$ 
onde $\mathrm{T}_{\text {válvula1c_out }}, \mathrm{V}_{\text {válvula1c_out }}=$ temperatura e vazão do fluxo de água na saída da válvula 1c;

$\mathrm{T}_{\text {válvula1c_in }}, \mathrm{v}_{\text {válvula1c_in }}=$ temperatura e vazão do fluxo de água na entrada da válvula 1c.

\section{Resfriamento da Água no "Chiller" 1 (Figura 5.14)}

A água proveniente das válvulas de bloqueio é então enviada ao "chiller" correspondente.

Como a bomba, o "chiller 1" pode assumir três estados discretos: ligado, desligado, em manutenção. A sua modelagem é apresentada na Figura 5.19:

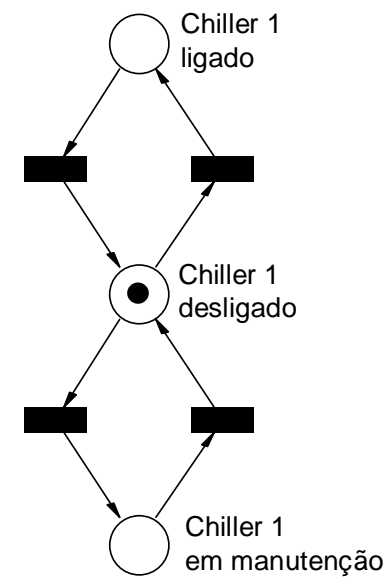

Figura 5.19. Rede de Petri - "chiller" 1.

Para a modelagem das propriedades na saída do "chiller", considerou-se que este, quando em regime, fornece água a uma temperatura fixa (set-point $=\mathrm{Sp}_{\text {chiller1 }}$ ). No entanto, quando ligado, o "chiller" gasta um determinado tempo para entrar em regime. Este tempo é representado pela constante $\tau_{\text {chiller_1 }}$. Quando desligado o "chiller" não altera a temperatura da água.

Para a determinação das propriedades da água de condensação na saída do "chiller", considerou-se que esta absorve todo o calor liberado pela água de 
resfriamento ( $\left.\mathrm{v}_{\text {chiller1_out, }} \mathrm{T}_{\text {chiller1_out }}\right)$, proveniente das serpentinas de resfriamento. A Equação 18 apresenta este balanço energético.

$$
\begin{aligned}
& \mathrm{Q}_{\text {trocado }}=\mathrm{v}_{\text {chiller1_out }} * \rho_{\text {água }} *\left(\mathrm{~h}_{\text {água }}\left(\mathrm{T}_{\text {chiller1_in }}\right)-\mathrm{h}_{\text {água }}\left(\mathrm{T}_{\text {chiller1_out }}\right)\right)= \\
& \mathrm{V}_{\text {chiller1_cond_out }} * \rho_{\text {água }} *\left(\mathrm{~h}_{\text {água }}\left(\mathrm{T}_{\text {chiller1_cond_out }}\right)-\mathrm{h}_{\text {água }}\left(\mathrm{T}_{\text {chiller1_cond_in }}\right)\right)
\end{aligned}
$$

onde $v_{\text {chiller1_out }}, T_{\text {chiller1_out }}=$ vazão e temperatura do fluxo de água de resfriamento (fluxo principal) na saída do "chiller"1;

$\mathrm{V}_{\text {chiller1_cond_out, }} \mathrm{T}_{\text {chiller1_cond_out }}=$ vazão e temperatura do fluxo de água de condensação (fluxo secundário) na saída do “chiller"1;

$\mathrm{V}_{\text {chiller1_in }}, \mathrm{T}_{\text {chiller1_in }}, \mathrm{V}_{\text {chiller1_cond_in }}, \mathrm{T}_{\text {chiller1_cond_in }}=$ vazão e temperatura dos fluxos de água de resfriamento e de condensação na entrada do "chiller"1.

Considerando a simplificação apresentada pela Equação 19, tem-se que:

$$
\mathrm{T}_{\text {chiller1_cond_out }}=\frac{\mathrm{V}_{\text {chiller1_out }}\left(\mathrm{T}_{\text {chiller1_in }}-\mathrm{T}_{\text {chiller1_out }}\right)}{\mathrm{V}_{\text {chiller1_cond_out }}}+\mathrm{T}_{\text {chiller1_cond_in }}
$$

O vetor de variáveis e as equações associados a esta atividade para os diferentes estados do "chiller 1" são:

vetor de variáveis:

$$
\text { sistema de equações: }\left\{\begin{array}{l}
\quad \mathrm{X}_{\text {chiller1 }}=\left[\mathrm{T}_{\text {chiller1_out }}, \mathrm{v}_{\text {chiller1_out }}, \mathrm{T}_{\text {chiller1_cond_out }}, \mathrm{v}_{\text {chiller1_cond_out }}\right] \\
\frac{\mathrm{dT}_{\text {chiller1_out }}}{\mathrm{dt}}=\frac{\mathrm{Sp}_{\text {chiller1 }}-\mathrm{T}_{\text {chiller1_out }}}{\tau_{\text {chiller1 }}} \\
\mathrm{v}_{\text {chiller1_out }}=\mathrm{v}_{\text {chiller1_in }} \\
\mathrm{T}_{\text {chiller1_cond_out }}=\frac{\mathrm{v}_{\text {chiller1_out }}\left(\mathrm{T}_{\text {chiller1_in }}-\mathrm{T}_{\text {chiller1_out }}\right)}{\mathrm{v}_{\text {chiller1_cond_out }}}+\mathrm{T}_{\text {chiller1_cond_in }} \\
\mathrm{v}_{\text {chiller1_cond_out }}=\mathrm{v}_{\text {chiller1_cond_in }} \\
\text { Lugar: “Chiller”1 desligado e “Chiller”1 em manutenção }
\end{array}\right.
$$


sistema de equações: $\left\{\begin{array}{l}\mathrm{T}_{\text {chiller1_out }}=\mathrm{T}_{\text {chiller1_in }} \\ \mathrm{v}_{\text {chiller1_out }}=\mathrm{v}_{\text {chiller1_in }} \\ \frac{\mathrm{dT}_{\text {chiller1_cond_out }}}{\mathrm{dt}}=0 \\ \mathrm{v}_{\text {chiller1_cond_out }}=\mathrm{v}_{\text {chiller1_cond_n }}\end{array}\right.$

onde $\mathrm{T}_{\text {chiller1_out }}, \mathrm{V}_{\text {chiller1_out }}, \mathrm{T}_{\text {chiller1_cond_out, }} \mathrm{v}_{\text {chiller1_cond_out }}=$ temperatura e vazão dos fluxos de água gelada (fluxo principal) e de água de condensação (fluxo secundário), respectivamente.

$\mathrm{Sp}_{\text {chiller1 }}=$ "set-point" do "chiller" para temperatura de fornecimento da água.

$\tau_{\text {chiller1 }}=$ constante de tempo referente a variação da temperatura;

Resfriamento da Água na Torre 1 (Figura 5.14)

Como os "chillers", a torre pode assumir três estados discretos: ligado, desligado, em manutenção (Figura 5.20).

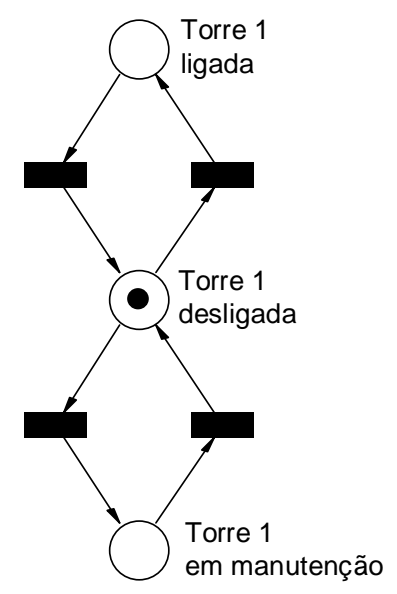

Figura 5.20. Rede PTD - Torre 1.

A temperatura na saída da torre de resfriamento foi aproximada por uma função (Equação 20), onde define-se a temperatura da água na saída da torre de resfriamento em função da temperatura do ar exterior e da temperatura da água na entrada da torre, para regime permanente. 


$$
\begin{aligned}
\mathrm{T}_{\text {torre1_out_aux }}= & \mathrm{C}_{1}+\mathrm{C}_{2} * \mathrm{~T}_{\text {ext }}+\mathrm{C}_{3} * \mathrm{~T}_{\text {ext }}{ }^{2}+\mathrm{C}_{4} * \mathrm{~T}_{\text {torrel_in }}+\mathrm{C}_{5} * \mathrm{~T}_{\text {torre1_in }}{ }^{2}+ \\
& \mathrm{C}_{6} * \mathrm{~T}_{\text {torrel_in }} * \mathrm{~T}_{\text {ext }}+\mathrm{C}_{7} * \mathrm{~T}_{\text {torrel_in }}{ }^{2} * \mathrm{~T}_{\mathrm{ext}}+\mathrm{C}_{8} * \mathrm{~T}_{\text {torrel_in }} * \mathrm{~T}_{\mathrm{ext}}{ }^{2}+ \\
& \mathrm{C}_{9} * \mathrm{~T}_{\text {torrel_in }} 2 * \mathrm{~T}_{\text {ext }}{ }^{2}
\end{aligned}
$$

onde $\mathrm{T}_{\text {torre1_out_aux }}=$ temperatura do fluxo de água na saída da torre em regime permanente;

$\mathrm{T}_{\mathrm{ext}}=$ temperatura do ar exterior;

$\mathrm{T}_{\text {torre1_in }}=$ temperatura do fluxo de água na entrada da torre;

$\mathrm{C}_{1}, \mathrm{C}_{2}, \mathrm{C}_{3}, \mathrm{C}_{4}, \mathrm{C}_{5}, \mathrm{C}_{6}, \mathrm{C}_{7}, \mathrm{C}_{8}$ e $\mathrm{C}_{9}=$ constantes determinadas empiricamente.

Considerou-se, também, que existe um atraso de tempo entre uma variação das variáveis $T_{\text {ext }}$ e $T_{\text {torre1_in }}$ e a correspondente variação em $T_{\text {torre1_out. Este atraso é }}$ representado pela constante de tempo $\tau_{\text {torrel }}$.

O vetor de variáveis e as equações associados a este bloco são:

vetor de variáveis: $\quad \mathrm{X}_{\text {torre1 }}=\left[\mathrm{T}_{\text {torre1_out }}, \mathrm{v}_{\text {torre1_out }}, \mathrm{T}_{\text {torre1_out_aux }}\right]$

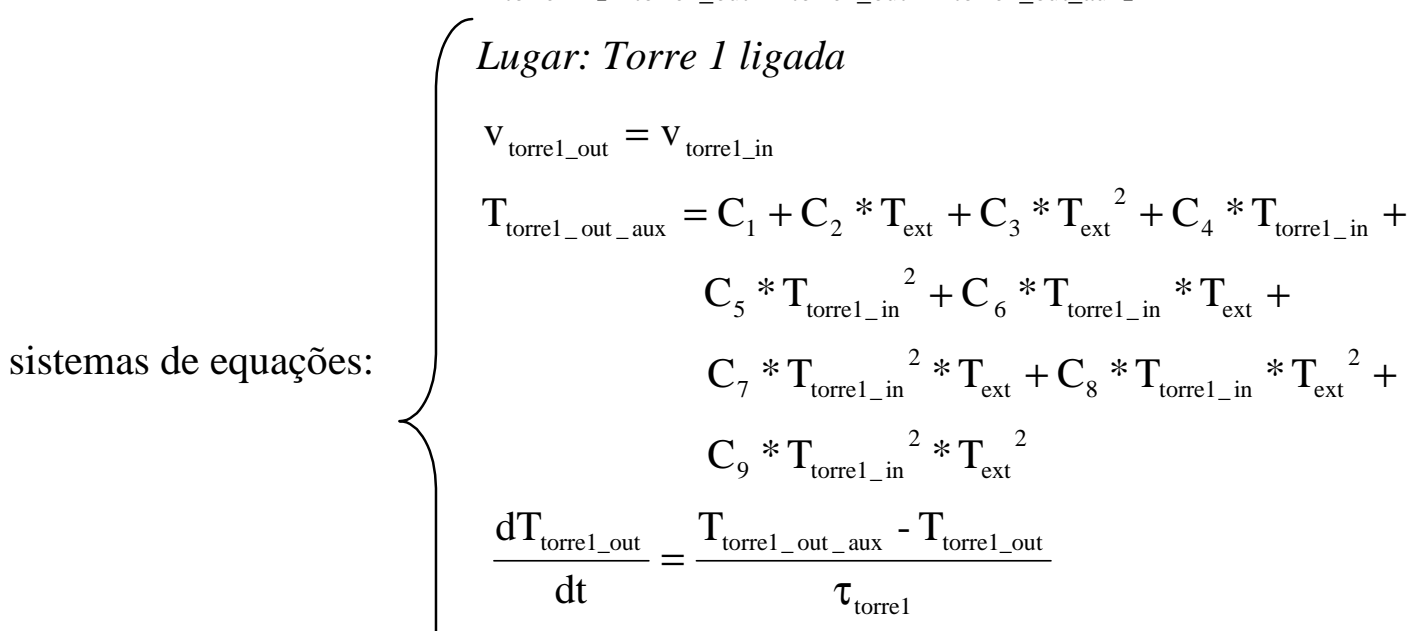

$$
\begin{aligned}
& \text { Lugar: Torrel desligada e Torrel em manutenção } \\
& \begin{aligned}
\mathrm{V}_{\text {torre1_out }} & =\mathrm{V}_{\text {torre1_in }} \\
\mathrm{T}_{\text {torre1_out }} & =\mathrm{T}_{\text {torre1_in }}
\end{aligned}
\end{aligned}
$$

onde $\mathrm{T}_{\text {torre1_out }}, \mathrm{v}_{\text {torre1_out }}=$ temperatura e vazão na saída da torre1;

$\mathrm{T}_{\text {torre1_in }}, \mathrm{v}_{\text {torre1_in }}=$ temperatura e vazão na entrada da torre1;

$\mathrm{T}_{\mathrm{ext}}=$ temperatura do ar exterior;

$\tau_{\text {torre1 }}=$ constante de tempo referente a variação da temperatura. 
Aquecimento da Água no Aquecedor 1(Figura 5.15)

Os aquecedores são responsáveis pelo aquecimento da água. Sua modelagem é semelhante àquela dos “chillers", eles podem assumir três estados discretos: ligado, desligado, em manutenção. A sua modelagem é apresentada na Figura 5.21.

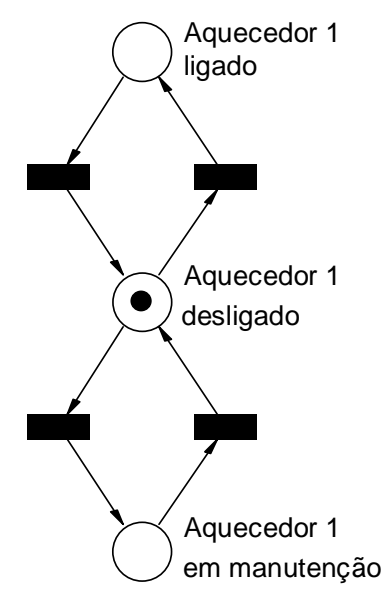

Figura 5.21. Rede PTD - Aquecedor 1.

vetor de variáveis: $\quad \mathrm{X}_{\mathrm{aquecedor} 1}=\left[\mathrm{T}_{\mathrm{aquec1} 1 \mathrm{out}}, \mathrm{V}_{\text {aquec1_out }}, \mathrm{T}_{\mathrm{aquec1} \text { _cond_out }}, \mathrm{V}_{\text {aquec1_cond_out }}\right]$ sistemas de equações: $\left\{\begin{array}{l}\text { Lugar: Aquecedor 1 ligado } \\ \frac{\mathrm{dT}_{\text {aquec1_out }}}{\mathrm{dt}}=\frac{\mathrm{Sp}_{\text {aquecedor1 }}-\mathrm{T}_{\text {aquec1_in }}}{\tau_{\text {aquecedor1 }}} \\ \mathrm{v}_{\text {aquec1_out }}=\mathrm{v}_{\text {aquec1_in }} \\ \text { Lugar: Aquecedor1 desligado e } \text { em manutenção } \\ \mathrm{v}_{\text {aquec1_out }}=\mathrm{v}_{\text {aquec1_in }} \\ \mathrm{T}_{\text {aquec1_out }}=\mathrm{T}_{\text {aquec1_in }}\end{array}\right.$

onde $\mathrm{T}_{\text {aquec1_out }}, \mathrm{v}_{\text {aquec1_out }}=$ temperatura e vazão na saída do aquecedor1;

$\mathrm{T}_{\text {aquec1_in }}, \mathrm{V}_{\text {aquec1_in }}=$ temperatura e vazão na entrada do aquecedor 1;

$\tau_{\text {aquec } 1}=$ constante de tempo referente a variação da temperatura;

Sp $\mathrm{p}_{\text {aquecedor1 }}=$ "set-point" do aquecedor para temperatura de fornecimento da água. 
Imposição de Fluxo no Ventilador 1r (Figura 5.16)

O ventilador de retorno pode assumir quatro estados discretos: ligado em três velocidades diferentes ou desligado. A rede correspondente é apresentada na Figura

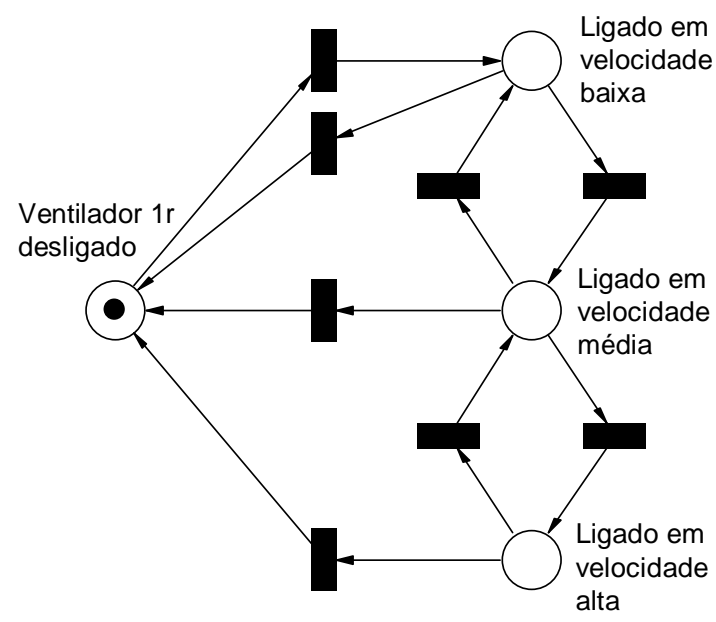

Figura 5.22. Rede PTD - Ventilador de retorno 1r.

Para a modelagem das equações associadas aos lugares, a relação entre a vazão de $\operatorname{ar}\left(\mathrm{v}_{\mathrm{vent1}} \mathrm{r}_{\mathrm{out}}\right)$ e a velocidade do ventilador $\left(\mathrm{N}_{\mathrm{vr}}\right)$ foi considerada constante [ASHRAE, 1996], e onde $\mathrm{K}_{\mathrm{f}}$ é a constante de proporcionalidade.

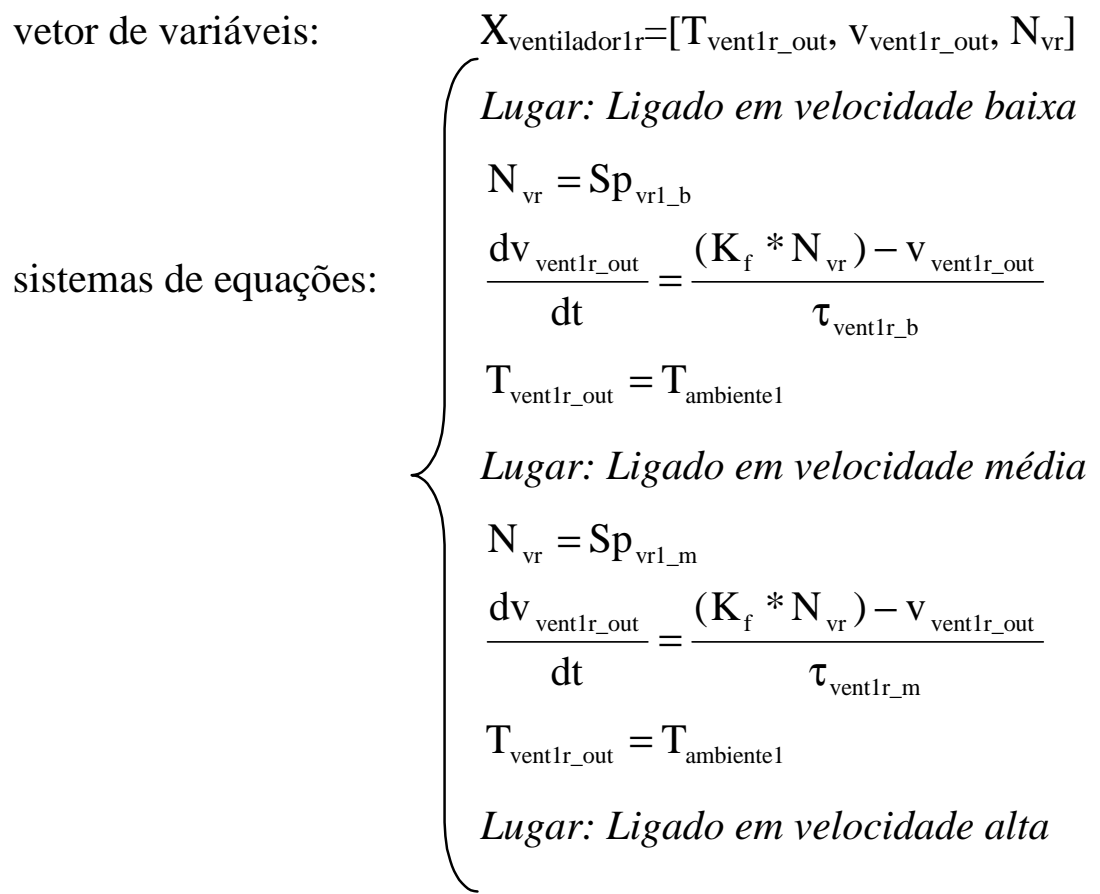




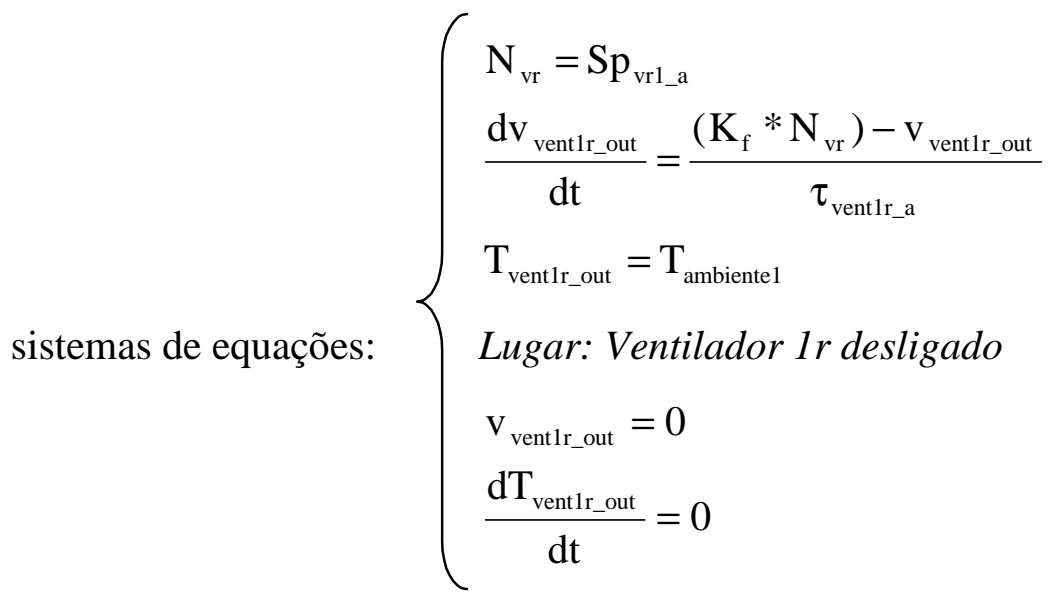

onde $\mathrm{T}_{\text {vent1r_out }}, \mathrm{v}_{\text {vent1r_out }}=$ temperatura e vazão na saída do ventilador;

$\mathrm{T}_{\mathrm{ambiente1}}=$ temperatura no ambiente condicionado;

$\mathrm{Sp}_{\mathrm{vr} 1 \_\mathrm{b}}=$ "set-point" para velocidade baixa do ventilador;

$\mathrm{Sp}_{\mathrm{vr} 1 \_\mathrm{m}}=$ "set-point" para velocidade média do ventilador;

$\mathrm{Sp}_{\mathrm{vr} 1 \_\mathrm{a}}=$ "set-point" para velocidade alta do ventilador;

$\tau_{\mathrm{vr} 1 \_\mathrm{b}}=$ constante de tempo referente a variação da vazão para velocidade baixa do ventilador;

$\tau_{\mathrm{vr} 1 \_\mathrm{m}}=$ constante de tempo referente a variação da vazão para velocidade média do ventilador;

$\tau_{\mathrm{vr} 1 \_\mathrm{a}}=$ constante de tempo referente a variação da vazão para velocidade alta do ventilador;

\section{Mistura de ar na Caixa de Mistura 1 (Figura 5.16)}

A caixa de mistura (Figura 5.23) pode assumir 3 configurações :

- "damper" de exaustão totalmente aberto, "damper" de insuflamento totalmente aberto, “damper" de retorno totalmente fechado: renovação 100\%;

- “damper" de exaustão parcialmente aberto, "damper" de insuflamento parcialmente aberto, "damper" de retorno parcialmente aberto: renovação $S_{\text {caixa1 }}$, correspondente a taxa de renovação definida em projeto; 
- “damper" de exaustão fechado, "damper" de insuflamento fechado, "damper" de retorno aberto: renovação $0 \%$;

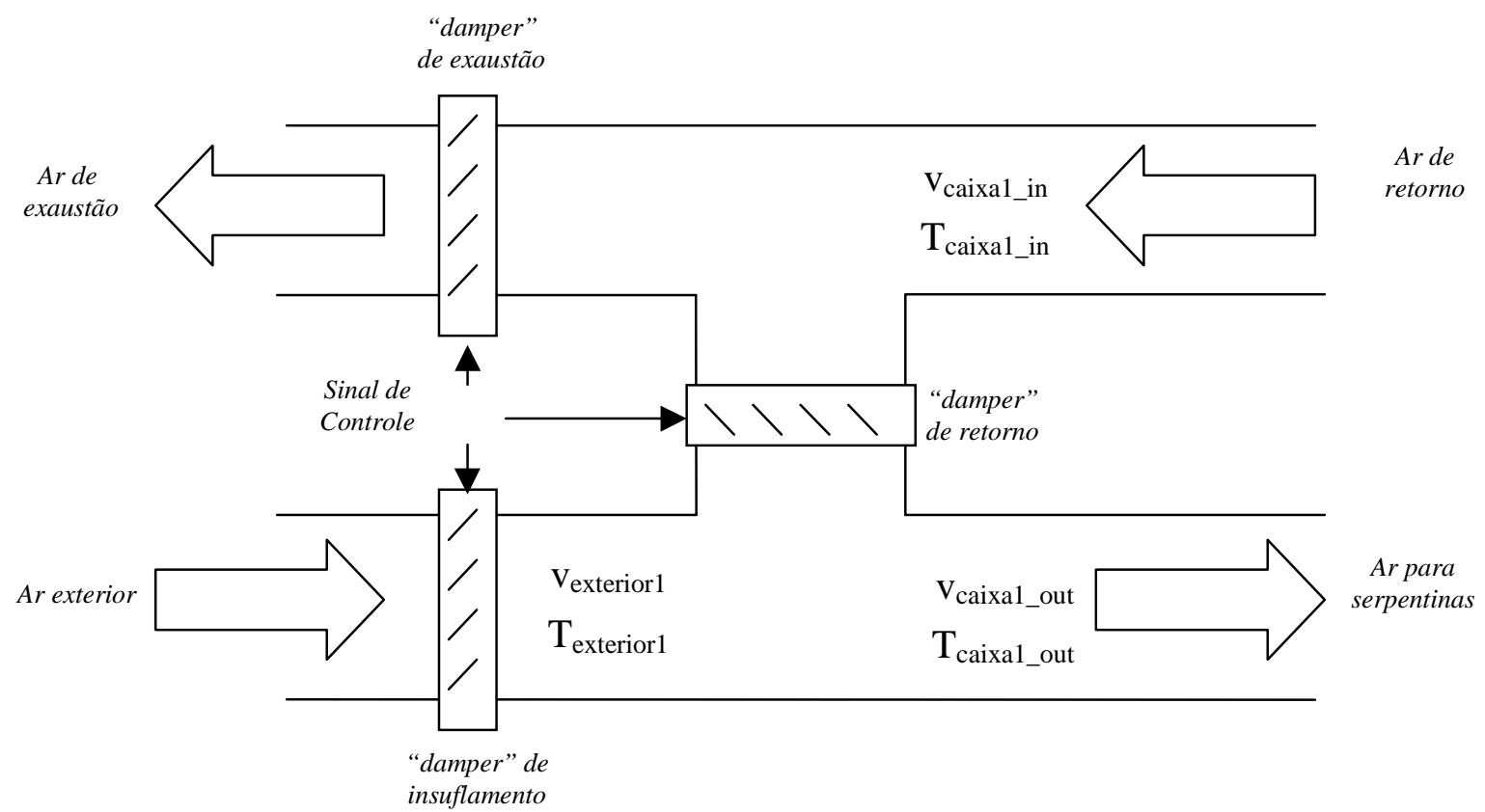

Figura 5.23. Esquema da caixa de mistura1.

A rede discreta para a caixa de mistura 1 é apresentada na Figura 5.24:

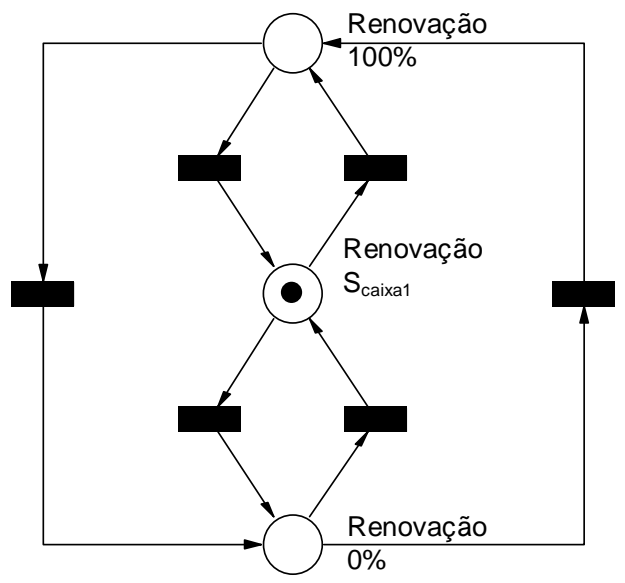

Figura 5.24. Rede PTD - Caixa de mistura1.

Na modelagem da caixa de mistura considerou-se que o fluxo na saída da caixa de mistura é determinado pela velocidade do ventilador de insuflamento.

Considerou-se que, quando não existe renovação de ar, a vazão de ar que é retirado do ambiente é igual a vazão de ar que é insuflado no ambiente, o que deve ser 
garantido pelo sistema de controle do ar condicionado para que não haja problemas de aumento da pressão nos dutos do sistema de ar condicionado.

$\mathrm{Na}$ modelagem das equações associadas aos lugares, para a determinação da temperatura final da mistura no caso de renovação parcial do ar, considerou-se a conservação de energia na caixa de mistura (Equação 21).

$$
\begin{aligned}
& \mathrm{Q}_{\text {trocado }}=\mathrm{S}_{\text {caixa1 }} * \mathrm{v}_{\text {caixa1_out }} * \rho_{\mathrm{ar}} *\left(\mathrm{~h}_{\mathrm{ar}}\left(\mathrm{T}_{\text {caixa1_in }}\right)-\mathrm{h}_{\mathrm{ar}}\left(\mathrm{T}_{\text {caixa1_out }}\right)\right) \\
& =\left(1-\mathrm{S}_{\text {caixa1 } 1}\right) * \mathrm{v}_{\text {caixa1_out }} * \rho_{\mathrm{ar}} *\left(\mathrm{~h}_{\mathrm{ar}}\left(\mathrm{T}_{\text {exterior } 1}\right)-\mathrm{h}_{\text {ar }}\left(\mathrm{T}_{\text {caixa1_out }}\right)\right)
\end{aligned}
$$

Considerando o ar como gás perfeito, isto é, a variação da entalpia é proporcional à variação da temperatura. A Equação 21 é então simplificada para:

$$
\mathrm{T}_{\text {caixa1_out }}=\mathrm{S}_{\text {caixa1 }} * \mathrm{~T}_{\text {caixa1_in }}+\left(1-\mathrm{S}_{\text {caixa1 }}\right) * \mathrm{~T}_{\text {exterior } 1}
$$

O vetor de variáveis e os sistemas de equações associados a esta rede são:

vetor de variáveis: $\quad \mathrm{X}_{\text {caixa1 }}=\left[\mathrm{T}_{\text {caixa1_out }}, \mathrm{V}_{\text {caixa1_out }}\right]$

sistemas de equações: $\left\{\begin{array}{l}\text { Lugar: Renovação } 100 \% \\ \mathrm{~T}_{\text {caixal_out }}=\mathrm{T}_{\text {exterior }} \\ \mathrm{v}_{\text {caixa1_out }}=\mathrm{v}_{\text {ventli_out }} \\ \text { Lugar: Renovação } S_{\text {caixal }} \\ \mathrm{T}_{\text {caixa1_out }}=\mathrm{S}_{\text {caixa1 }} * \mathrm{~T}_{\text {caixa1_in }}+\left(1-\mathrm{S}_{\text {caixa1 }}\right) * \mathrm{~T}_{\text {exterior }} \\ \mathrm{v}_{\text {caixal_out }}=\mathrm{v}_{\text {ventil_out }} \\ \text { Lugar: Renovação } 0 \% \\ \mathrm{~T}_{\text {caixa1_out }}=\mathrm{T}_{\text {caixa1_in }} \\ \mathrm{v}_{\text {caixa1_out }}=\mathrm{v}_{\text {ventli_out }}\end{array}\right.$

onde $\mathrm{T}_{\text {caixa1_out }}, \mathrm{v}_{\text {caixa1_out }}=$ temperatura e vazão na saída da caixa de mistura 1 ;

$\mathrm{T}_{\text {aixa1_in }},=$ temperatura na entrada da caixa de mistura;

$\mathrm{v}_{\text {vent1i_out }}=$ vazão na saída do ventilador $1 \mathrm{i}$;

$\mathrm{T}_{\text {exterior }}=$ temperatura do ar exterior;

$\mathrm{S}_{\text {caixa1 }}=$ "set-point" taxa d renovação parcial do ar; 
Imposição de fluxo no ventilador 1i (Figura 5.16)

A modelagem do ventilador de insuflamento é semelhante a do ventilador de retorno, mas este possui apenas uma velocidade de operação. A rede correspondente ao ventilador de insuflamento 1i é apresentada na Figura 5.25:

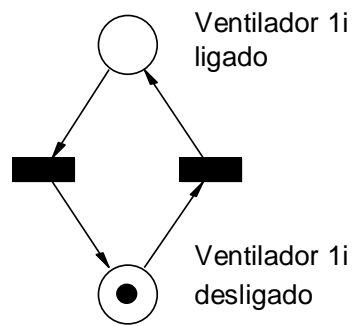

Figura 5.25. Rede PTD - Ventilador 1i.

O vetor de variáveis e os sistemas de equações são apresentados a seguir

vetor de variáveis: $\quad \mathrm{X}_{\text {ventiladorli }}=\left[\mathrm{T}_{\text {vent1i_out }}, \mathrm{V}_{\text {vent1i_out }}, \mathrm{N}_{\mathrm{vi}}\right]$

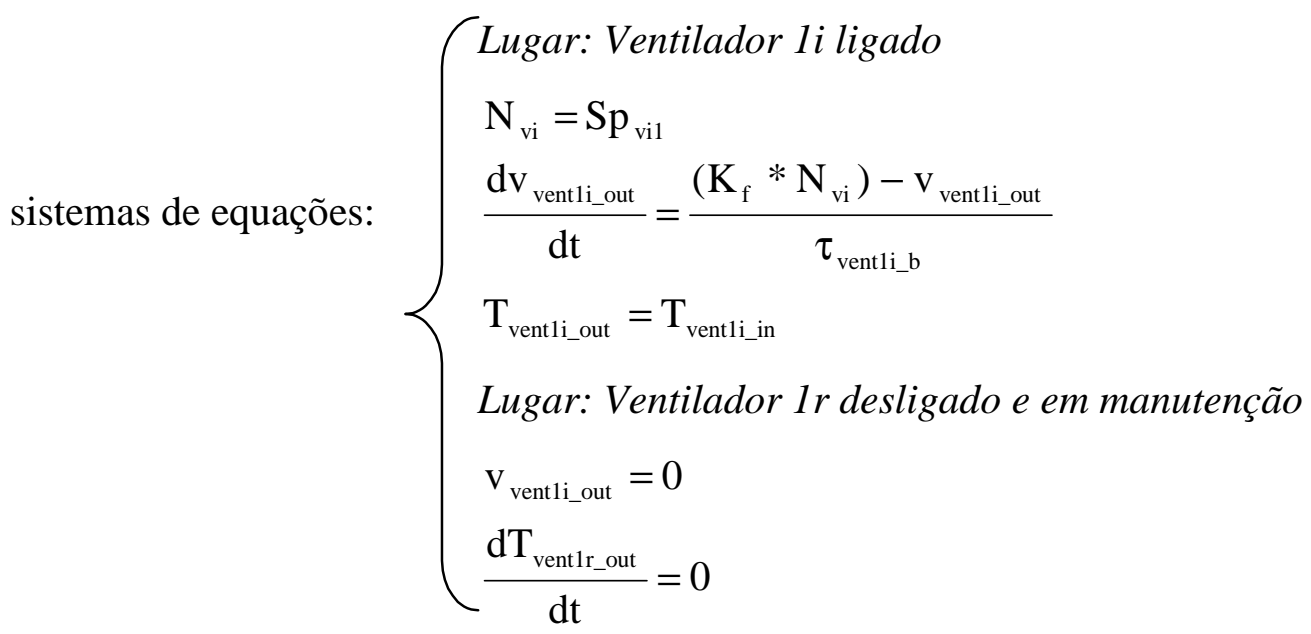

onde $\mathrm{T}_{\text {vent1i_out }}, \mathrm{v}_{\text {vent1i_out }}=$ temperatura e vazão na saída do ventilador;

$S p_{\text {vi1 }}=$ "set-point" para velocidade do ventilador;

$\tau_{\mathrm{vi1}}=$ constante de tempo referente a variação da vazão do ventilador;

Divisão de Fluxo na Válvulalf (Figura 5.16)

A válvula que controla a vazão na serpentina é de 3 vias. Um esquema da válvula é apresentado na Figura 5.26. 


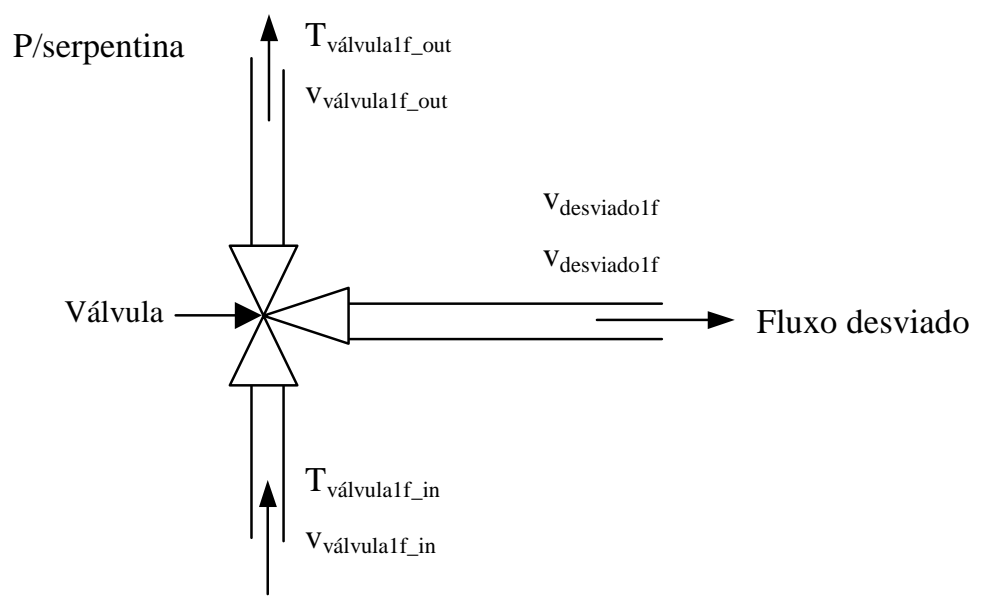

Figura 5.26. Esquema da válvula da serpentina de água fria.

A válvula pode assumir qualquer posição variando entre " 0 " e " 1 ", onde “ 0 " representa a válvula completamente fechada e " 1 " representa a válvula completamente aberta. A relação entre a posição da válvula e o fluxo enviado a serpentina é do tipo exponencial e é fornecida pela Equação 23 [Salsbury, 1996], onde a variável $\mathrm{Ab}_{\mathrm{f} 1}$ indica a abertura da válvula

$$
\frac{\text { fluxo enviado }}{\text { fluxo total }}=\left[\mathrm{L}+(1-\mathrm{L}) \frac{\left(1-\mathrm{e}^{\beta . A b_{\mathrm{f} 1}}\right)}{\left(1-\mathrm{e}^{\beta}\right)}\right]
$$

Os parâmetros $\beta$ e L estão relacionados a curvatura da exponencial e a existência de vazamento na válvula quando totalmente fechada, respectivamente.

As propriedades na saída da válvula são representadas pelo vetor de variáveis e pelo sistema de equações abaixo:

vetor de variáveis: $\quad \mathrm{X}_{\text {válvula1f }}=\left[\mathrm{T}_{\text {válvula1f_out }}, \mathrm{v}_{\text {válvula1f_out }}, \mathrm{T}_{\text {desviadolf }}, \mathrm{v}_{\text {desviadolf }}, \mathrm{Ab}_{\mathrm{f} 1}\right]$ sistemas de equações: $\left\{\begin{array}{l}\mathrm{Ab}_{\mathrm{f} 1}=\mathrm{V}_{\mathrm{V}_{-} \mathrm{f} 1} \\ \mathrm{v}_{\text {válvulalf_out }}=\left[\mathrm{L}+(1-\mathrm{L}) \frac{\left(1-\mathrm{e}^{\beta . A b_{\mathrm{f} 1}}\right)}{\left(1-\mathrm{e}^{\beta}\right)}\right] * \mathrm{v}_{\text {válvulalf_in }} \\ \mathrm{v}_{\text {desviadolf }}=\mathrm{v}_{\text {válvulalf_in }}-\mathrm{v}_{\text {válvulalf_out }} \\ \mathrm{T}_{\text {válvulalf_out }}=\mathrm{T}_{\text {válvulalf_in }} \\ \mathrm{T}_{\text {desviadolf }}=\mathrm{T}_{\text {válvulalf_in }}\end{array}\right.$ 
onde $\mathrm{T}_{\text {válvula1f_out, }} \mathrm{V}_{\text {válvula1f_out }}=$ temperatura e vazão do fluxo de água enviado a serpentina de resfriamento 1 ;

$\mathrm{T}_{\text {desviadolf }}, \mathrm{v}_{\text {desviadolf }}=$ temperatura e vazão do fluxo de água desviado da serpentina de resfriamento 1 ;

$\mathrm{Ab}_{\mathrm{f} 1}=$ posição da válvula $1 \mathrm{f} ;$

$\mathrm{V}_{\mathrm{V}_{-} \mathrm{f} 1}=$ sinal de controle enviado referente a posição da válvula $1 \mathrm{f}$.

\section{Resfriamento do Ar na Serpentina If (Figura 5.16)}

$\mathrm{Na}$ serpentina de resfriamento ocorre a troca de calor entre a água fria e o ar. Um esquema da serpentina de resfriamento é apresentado na Figura 5.27.

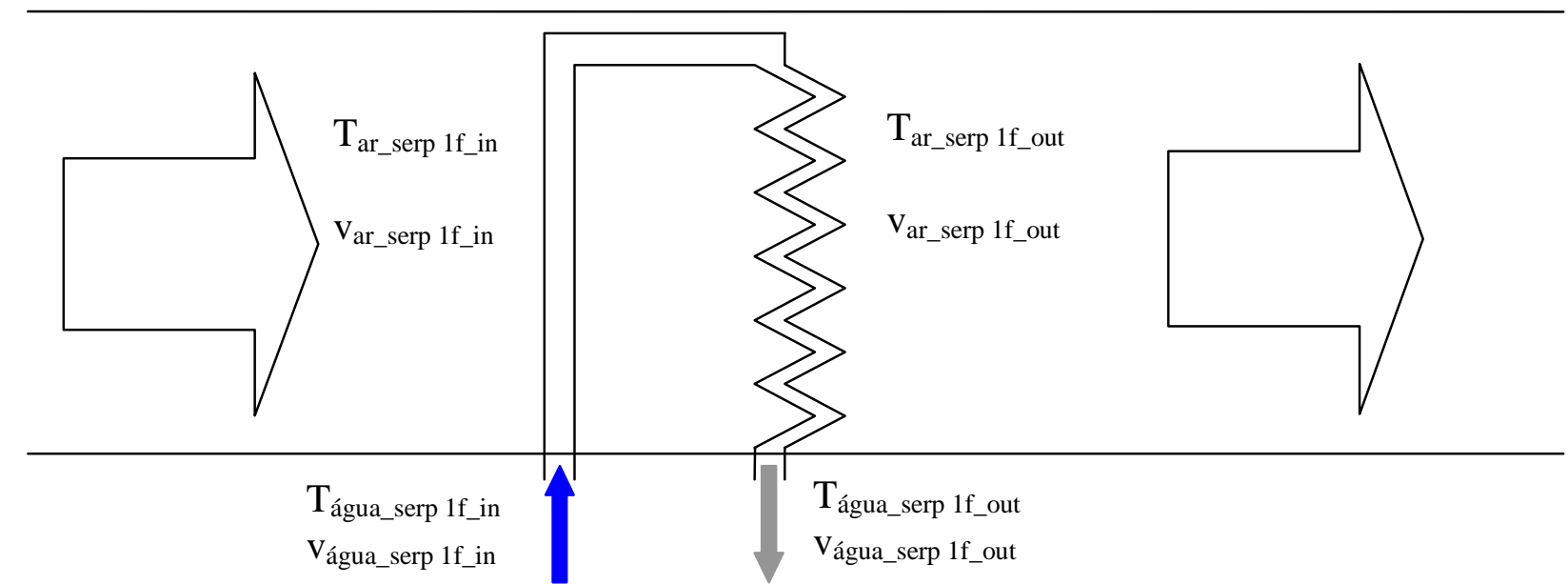

Figura 5.27. Esquema da serpentina de resfriamento.

Para a determinação da temperatura do ar e da água na saída da serpentina adotouse o modelo matemático utilizado por [Salsbury, 1996] que foi desenvolvido baseado no conceito de condutância global, onde a troca de calor é calculada através do coeficiente global de transferência de calor (UA).

Observa-se que este modelo não considera a ocorrência de desumidificação do ar, ou seja, a retirada por condensação de parte do vapor de água contido no fluxo de ar e que corresponde a uma parcela de calor latente. Esta desumidificação ocorre quando o 
ponto de orvalho do ar é superior à temperatura da superfície da serpentina em contato com o fluxo.

Em [Chow,1997] encontra-se uma revisão bibliográfica dos principais modelos de serpentina de resfriamento proposto nas últimas décadas. São apresentados modelos fundamentais, semi-empíricos e empíricos.

O coeficiente global de transferência (UA) de calor é definido em termos da resistência térmica total da serpentina à transferência de calor entre os dois fluidos (Equação 24) [Incropera, 1990]:

$$
\frac{1}{\mathrm{UA}}=\frac{1}{(\eta \cdot r \cdot A)_{\mathrm{a}}}+\mathrm{R}_{\mathrm{s}}+\frac{1}{(\mathrm{r} \cdot \mathrm{A})_{\mathrm{w}}}
$$

onde $r=$ resistência a convecção;

$\mathrm{A}=$ área de troca de calor;

$\eta=$ resistência apresentada pelo material entre a água e o ar;

${ }_{\mathrm{w}} \mathrm{e}_{\mathrm{a}}=$ sub-índices que indicam água e ar, respectivamente;

$\mathrm{R}_{\mathrm{s}}=$ resistência à condução através do material que separa os dois fluidos.

A determinação de UA depende das propriedades dos fluidos, da geometria do trocador de calor e das condições de fluxo.

O grande número de variáveis presentes e a complexidade da modelagem do escoamento em uma geometria complexa fazem com que uma modelagem analítica seja inviável. Optou-se então pelo modelo empírico utilizado por [Salbury, 1996] (Equações 25):

$$
\begin{aligned}
& (\eta \cdot h \cdot A)_{\mathrm{a}}=\mathrm{k}_{\mathrm{a}} \dot{\mathrm{m}}_{\mathrm{a}}{ }^{\mathrm{a} 1} \\
& (\text { h.A })_{\mathrm{w}}=\mathrm{k}_{\mathrm{w}} \dot{\mathrm{m}}_{\mathrm{w}}{ }^{\mathrm{a} 2}
\end{aligned}
$$

onde $\dot{\mathrm{m}}_{\mathrm{a}}=$ vazão em massa de ar; 
$\dot{\mathrm{m}}_{\mathrm{w}}=$ vazão em massa de água.

Os valores de a1 e a2 são sugeridos em [Holmes, 1982]. Quanto à resistência $R_{s}$, esta pode ser desprezada devido ao seu valor insignificante em comparação aos demais termos de UA.

Uma vez que o UA da serpentina é conhecido, o calor transferido entre os fluidos pode ser calculado utilizando o método NTU, também chamado de método da efetividade proposto em [Incropera, 1990].

O vetor de variáveis e o equacionamento para este sistema são então definidos como:

vetor de variáveis:

$\mathrm{X}_{\text {serpentina1f }}=\left[\mathrm{T}_{\text {água_serp1f_out }}, \quad \mathrm{V}_{\text {água_serp1f_out }}, \quad \mathrm{T}_{\text {ar_serp1f_out }}\right.$, $\mathrm{V}_{\text {ar_serp1f_out }}, \mathrm{UA}, \mathrm{C}_{\mathrm{a}}, \mathrm{C}_{\mathrm{w}}, \mathrm{C}_{\min }, \mathrm{C}_{\mathrm{r}}, \mathrm{NTU}, \varepsilon, \mathrm{T}_{\text {água_serp1f_aux }}$, $\left.\mathrm{T}_{\text {ar_serp1f_aux }}\right]$

sistemas de equações:

Lugar: Válvula If aberta

$\mathrm{V}_{\text {água_serp1f_out }}=\mathrm{V}_{\text {aggua_serp1f_in }}$

$\mathrm{V}_{\text {ar_serp1f_out }}=\mathrm{V}_{\text {ar_serplf_in }}$

$\mathrm{UA}=\frac{\mathrm{k}_{\mathrm{a}}\left(\rho_{\mathrm{a}} * \mathrm{v}_{\mathrm{ar} \_ \text {serplf_in }}\right)^{\mathrm{a} 1} * \mathrm{k}_{\mathrm{w}}\left(\rho_{\mathrm{w}} * \mathrm{v}_{\text {água_serplf_in }}\right)^{\mathrm{a} 2}}{\mathrm{k}_{\mathrm{a}}\left(\rho_{\mathrm{a}} * \mathrm{v}_{\text {ar_serplf_in }}\right)^{\mathrm{a} 1}+\mathrm{k}_{\mathrm{w}}\left(\rho_{\mathrm{w}} * \mathrm{v}_{\text {agua_serplf_in }}\right)^{\mathrm{a} 2}}$

$\mathrm{C}_{\mathrm{a}}=\mathrm{c}_{\mathrm{pa}} * \rho_{\mathrm{a}} * \mathrm{v}_{\text {ar_serplf_in }}$

$\mathrm{C}_{\mathrm{w}}=\mathrm{c}_{\mathrm{pw}} * \rho_{\mathrm{w}} * \mathrm{~V}_{\text {água_serplf_in }}$

$\mathrm{C}_{\text {min }}=\min \left(\mathrm{C}_{\mathrm{a}}, \mathrm{C}_{\mathrm{w}}\right)$

$\mathrm{C}_{\max }=\max \left(\mathrm{C}_{\mathrm{a}}, \mathrm{C}_{\mathrm{w}}\right)$

$\mathrm{C}_{\mathrm{r}}=\frac{\mathrm{C}_{\min }}{\mathrm{C}_{\max }}$

$\mathrm{NTU}=\frac{\mathrm{UA}}{\mathrm{C}_{\text {min }}}$

Para $C_{m i n}=C_{a}: \varepsilon=\left(\frac{1}{\mathrm{C}_{\mathrm{r}}}\right)\left(1-\exp \left\{-\mathrm{C}_{\mathrm{r}}[1-\exp (-\mathrm{NTU})]\right\}\right)$

Para $C_{m i n}=C_{w}: \varepsilon=1-\exp \left(-\frac{1}{C_{\mathrm{r}}} \cdot\left\{1-\exp \left[-\mathrm{C}_{\mathrm{r}} \cdot(\mathrm{NTU})\right]\right\}\right)$ 


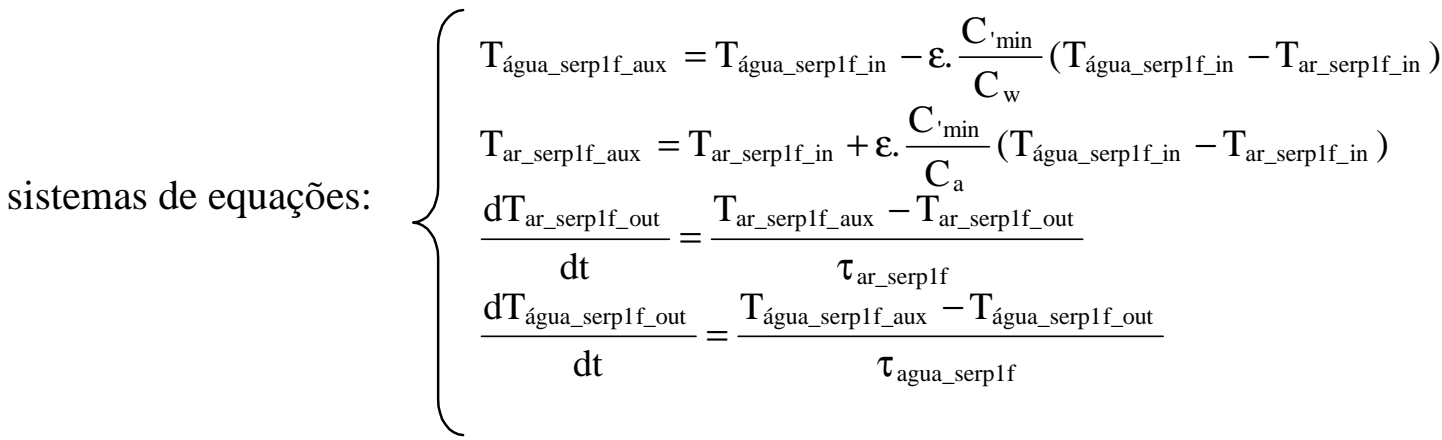

onde $\mathrm{T}_{\text {água_serp1f_out, }}, \mathrm{v}_{\text {água_serp1f_out }}, \mathrm{T}_{\text {ar_serp1f_out }}, \mathrm{v}_{\text {ar_serp1f_out, }},=$ temperatura e vazão dos fluxos de água e ar na saída da serpentina;

$\mathrm{UA}=$ coeficiente global de transferência de calor;

$\mathrm{C}_{\mathrm{a}}, \mathrm{C}_{\mathrm{w}}=$ capacidade térmica do ar e da água, respectivamente;

$\mathrm{C}_{\min }, \mathrm{C}_{\max }, \mathrm{C}_{\mathrm{r}}=$ capacidade térmica mínima, máxima e relativa;

$\mathrm{k}_{\mathrm{a}}, \mathrm{k}_{\mathrm{w}}=$ constantes para $\mathrm{o}$ ar e para água respectivamente;

$\rho_{\mathrm{a}}, \rho_{\mathrm{w}}=$ densidade do ar e da água, respectivamente;

NTU = parâmetro adimensional que representa o número de unidades de tranferência [Incropera, 1990];

$\varepsilon=$ efetividade do trocador de calor;

$\mathrm{T}_{\text {água_serp1f_aux }}, \mathrm{T}_{\text {ar_serp1f_aux }}=$ temperatura na saída da água e do ar para regime permanente.

Aquecimento do ar na Serpentina 1q (Figura 5.16)

A modelagem da serpentina de aquecimento é semelhante à da serpentina de resfriamento.

Aqui também foi adotado o conceito de condutância global e o método de eficiência para determinar o valor da temperatura da água e do ar na saída da serpentina. 


\subsubsection{Modelagem do Sistema de Controle Local}

Conforme apresentado no Capítulo 4, o sistema de controle local é dividido em duas partes: aquela formada por controladores e aquela formada por processadores responsáveis por transformar informações provenientes de sensores sobre os valores das variáveis contínuas em sinais de habilitação e inibição de transições do sistema de gerenciamento.

No PAMB, utilizam-se controladores do tipo PI para controlar a temperatura no ambiente através da abertura da válvula que regula a passagem de água pela serpentina.

O ajuste da temperatura no ambiente é realizado através da variação da temperatura de insuflamento do ar. A determinação da temperatura ideal de insuflamento é realizado segundo um controlador do tipo PI, de acordo com a Equação 26:

$$
\begin{aligned}
\mathrm{T}_{\text {insufl_1f }}= & \mathrm{K}_{\mathrm{P}_{-} \text {insufl_1f }} *\left(\mathrm{~T}_{\text {sensor_zona1 }}-\mathrm{T}_{\text {set_po int 1 }}\right)+ \\
& \mathrm{K}_{\mathrm{I}_{\text {_ insufl_1f }}} \int\left(\mathrm{T}_{\text {sensor_zona1 }}-\mathrm{T}_{\text {set_p p int 1 }}\right) \mathrm{dt}+\mathrm{V}_{0_{-} \text {insufl_1f }}
\end{aligned}
$$

onde $\quad \mathrm{K}_{\mathrm{P} \_ \text {insufl_1f }}, \mathrm{K}_{\mathrm{I} \_ \text {insufl_1f }} \mathrm{e} \mathrm{V}_{0 \_ \text {insufl_1f }}$ são constantes do sistema;

$$
\begin{aligned}
& \mathrm{T}_{\text {sensor_zona1 }}=\text { temperatura medida pelo sensor na zona } 1 ; \\
& \mathrm{T}_{\text {set_point1 }}=\text { temperatura desejada na zona } 1 ; \\
& \mathrm{T}_{\text {insufl_1f }}=\text { sinal de controle enviados referentes a temperatura de insuflamento }
\end{aligned}
$$
do ar.

Considerando que existe um atraso entre a temperatura na zona 1 e a temperatura fornecida pelo sensor, tem-se que:

$$
\dot{\mathrm{T}}_{\text {sensor_zona1 }}=\frac{\mathrm{T}_{\text {zona_1 }}-\mathrm{T}_{\text {sensor_zona1 }}}{\tau_{\text {sensor }}}
$$

onde $\quad \tau_{\text {sensor }}=$ constante de tempo; 
$\mathrm{T}_{\mathrm{zona1}}=$ temperatura na zona $1 ;$

O ajuste da temperatura de insuflamento é realizado através da variação da vazão de água que atravessa a serpentina. Controladores do tipo PI controlam as válvulas que regulam a vazão de água quente e fria nas serpentinas em função da temperatura do ar na saída da serpentina.

Para a válvula 1f tem-se a seguinte equação de controle (Equação 28):

$$
\begin{aligned}
\mathrm{V}_{\mathrm{V}_{-} \text {lf }}= & \mathrm{K}_{\mathrm{P}_{-} \mathrm{V} l \mathrm{f}} *\left(\mathrm{~T}_{\mathrm{ar}_{-} \text {serplf } \_ \text {out }}-\mathrm{T}_{\text {insufl_lf }}\right)+ \\
& \mathrm{K}_{\mathrm{I}_{-} \mathrm{V} l \mathrm{f}} \int\left(\mathrm{T}_{\mathrm{ar}_{-} \text {serplf_out }}-\mathrm{T}_{\text {insufl_lf }}\right)+\mathrm{V}_{0_{-} \mathrm{V}_{1}}
\end{aligned}
$$

onde $\quad K_{P_{-} V 1 f}, K_{I \_V 1 f}$ e $M_{V 1 f}$ são constantes do sistema;

$\mathrm{T}_{\text {ar_serp1f_out }}=$ temperaturas do ar na saída das serpentinas fria e quente;

$\mathrm{T}_{\text {insufl_lf }}=$ temperaturas de insuflamento desejada na saída da serpentina

$\mathrm{V}_{\mathrm{V}_{-} \text {lf }}=$ sinal de controle enviado referente a posições das válvula 1f

A rede PTD da Figura 5.28 representa este controle.

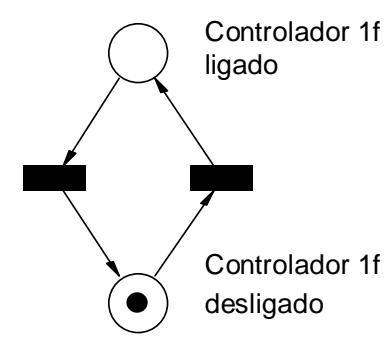

Figura 5.28. Rede PTD do controlador de resfriamento da zona 1.

O vetor de variáveis e o sistema de equações associados a esta rede são:

vetor de variáveis: $\quad \mathrm{X}_{\text {contr_f_zonal }}=\left[\mathrm{T}_{\text {insufl_1f }}, \mathrm{V}_{\mathrm{V}_{-} \text {1f }}, \mathrm{T}_{\text {sensor_zona1 }}\right]$

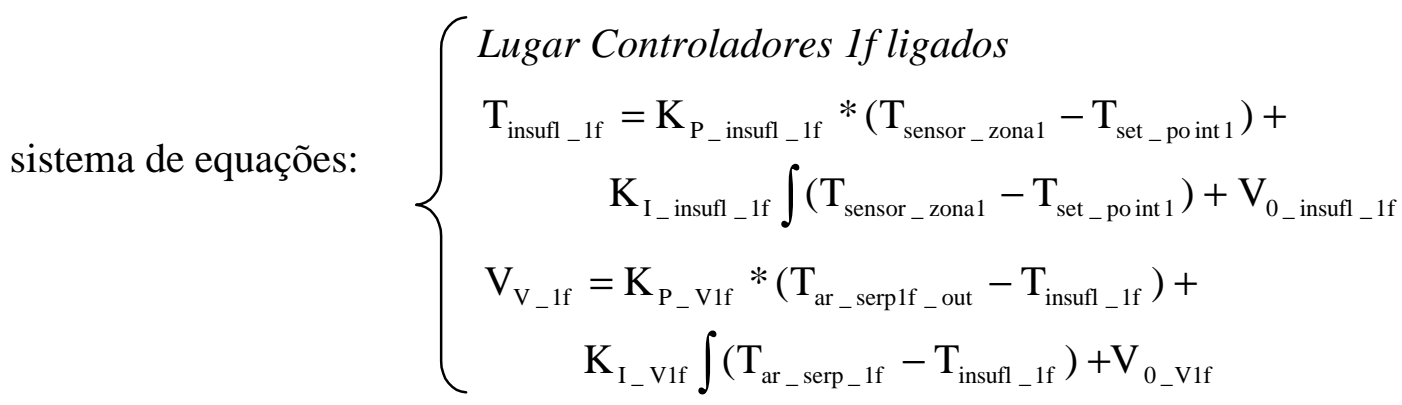


sistema de equações: $\left\{\begin{array}{l}\dot{\mathrm{T}}_{\text {sensor_zona1 }}=\frac{\mathrm{T}_{\text {zona_1 }}-\mathrm{T}_{\text {sensor_zona1 }}}{\tau_{\text {sensor }}} \\ \text { Lugar Controladores 1f desligados } \\ \mathrm{T}_{\text {insufl_lf }}=0 \\ \mathrm{~V}_{\mathrm{V}_{-} \text {If }}=0 \\ \mathrm{~T}_{\text {sensor_zona1 }}=0\end{array}\right.$

Para o aquecimento tem-se um sistema de controle semelhante àquele de resfriamento (Figura 5.29).

Os sinais contínuos processados são a temperatura da água na entrada dos "chillers" e a temperatura do ar na zona.

No caso da temperatura da água na entrada do "chillers", deve-se fornecer ao sistema de gerenciamento a informação relativa a necessidade de desligar ou ligar "chillers" e aquecedores.

A rede PTD da Figura 5.30 é responsável por este controle, onde a decisão é realizada através de funções de habilitação das transições. A esta rede não são associadas equações ou vetor de variáveis.

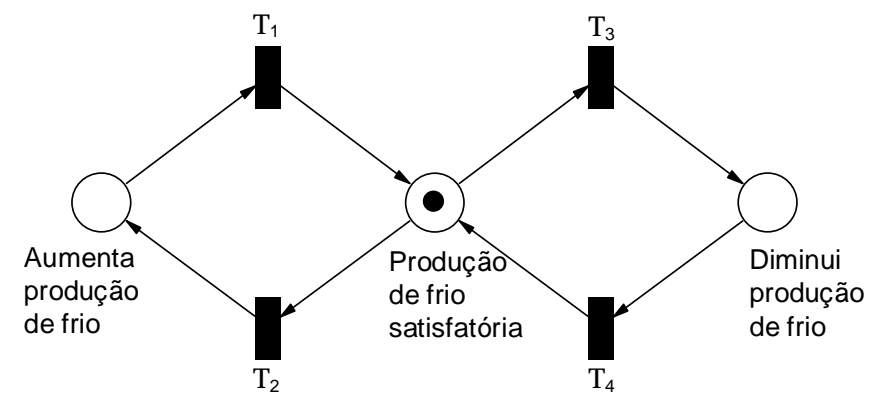

Figura 5.30. Modelo para redução/aumento da retirada de carga térmica.

FUNÇÕES DE HABILITAÇÃO:

$$
\mathrm{HC}_{1}: \mathrm{T}_{\text {chiller1_in }}<\left[\frac{\mathrm{n} * \mathrm{C}_{\text {chiller }}}{\mathrm{v}_{\text {chiller1_in }} * \mathrm{~K}}+\mathrm{T}_{\text {chiller1_out }}\right]
$$


$\mathrm{HC}_{2}: \mathrm{T}_{\text {mist_A_out }}>\left[\frac{\mathrm{n} * \mathrm{C}_{\text {chiller }}}{\mathrm{v}_{\text {mist_A_out }} * \mathrm{~K}}+\mathrm{T}_{\text {mist_B_out }}\right]$

$\mathrm{HC}_{3}: \mathrm{T}_{\text {mist_A_out }}<\left[\frac{(\mathrm{n}-1) * \mathrm{C}_{\text {chiller }}}{\mathrm{V}_{\text {mist_A_out }} * \mathrm{~K}}+\mathrm{T}_{\text {mist_B_out }}\right]$

$H C_{4}: T_{\text {mist_A_out }}>\left[\frac{(n-1) * C_{\text {chiller }}}{\mathrm{v}_{\text {mist_A_out }} * K}+T_{\text {mist_B_out }}\right]$

onde $\quad \mathrm{K}=$ constante;

$\mathrm{v}_{\text {mist_A_out }}=$ vazão da água;

$\mathrm{T}_{\text {mist_A_out }}=$ temperatura da água na entrada dos "chillers";

$\mathrm{T}_{\text {mist_B_out }}=$ temperatura da água na saída dos "chillers";

$\mathrm{n}=$ número de "chillers" em operação;

$\mathrm{C}_{\text {chiller }}=$ capacidade de um "chiller" (considera-se que todos os "chillers" possuem a mesma capacidade).

Esta rede é conectada com a rede da Figura 5.9 através de arcos habilitadores.

Para a temperatura do ambiente, tem-se a seguinte rede PTD responsável pelo chaveamento entre os controladores de aquecimento e resfriamento.

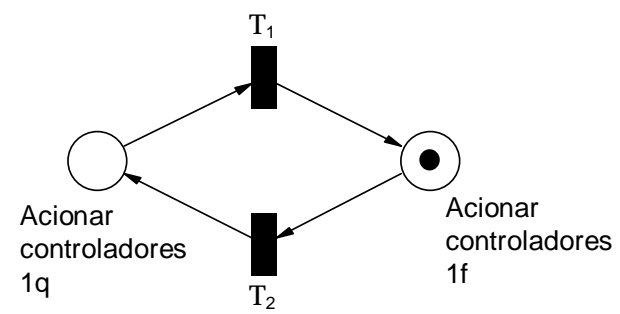

Figura 5.30. Modelo para determinação da necessidade de chavear controladores de aquecimento/resfriamento.

FUNÇÕES DE HABILITAÇÃO:

$\mathrm{HC}_{1}: \mathrm{T}_{\text {zona1 }}>\mathrm{T}_{\text {máx }}$

$\mathrm{HC}_{2}: \mathrm{T}_{\text {zona1 }}<\mathrm{T}_{\text {mín }}$ 
onde $\quad \mathrm{T}_{\text {zona1 }}=$ temperatura na zona 1 ;

$\mathrm{T}_{\text {mín }}=$ set-point para acionamento do aquecimento do ambiente;

$\mathrm{T}_{\text {máx }}=$ set-point para acionamento do resfriamento do ambiente;

\subsubsection{Integração de modelos}

De acordo com o apresentado no item 4.2.5 a integração entre os modelos do sistema de gerenciamento e os modelos do sistema de ar condicionado e do sistema de controle local é realizada através de arcos habilitadores e inibidores.

A Figura 5.31 apresenta a conexão entre a operação "Ligar chiller 1" e o modelo da válvula 1f e do "chiller" 1, e entre os modelos dos controladores 1f e a operação "ligar controladores 1f".

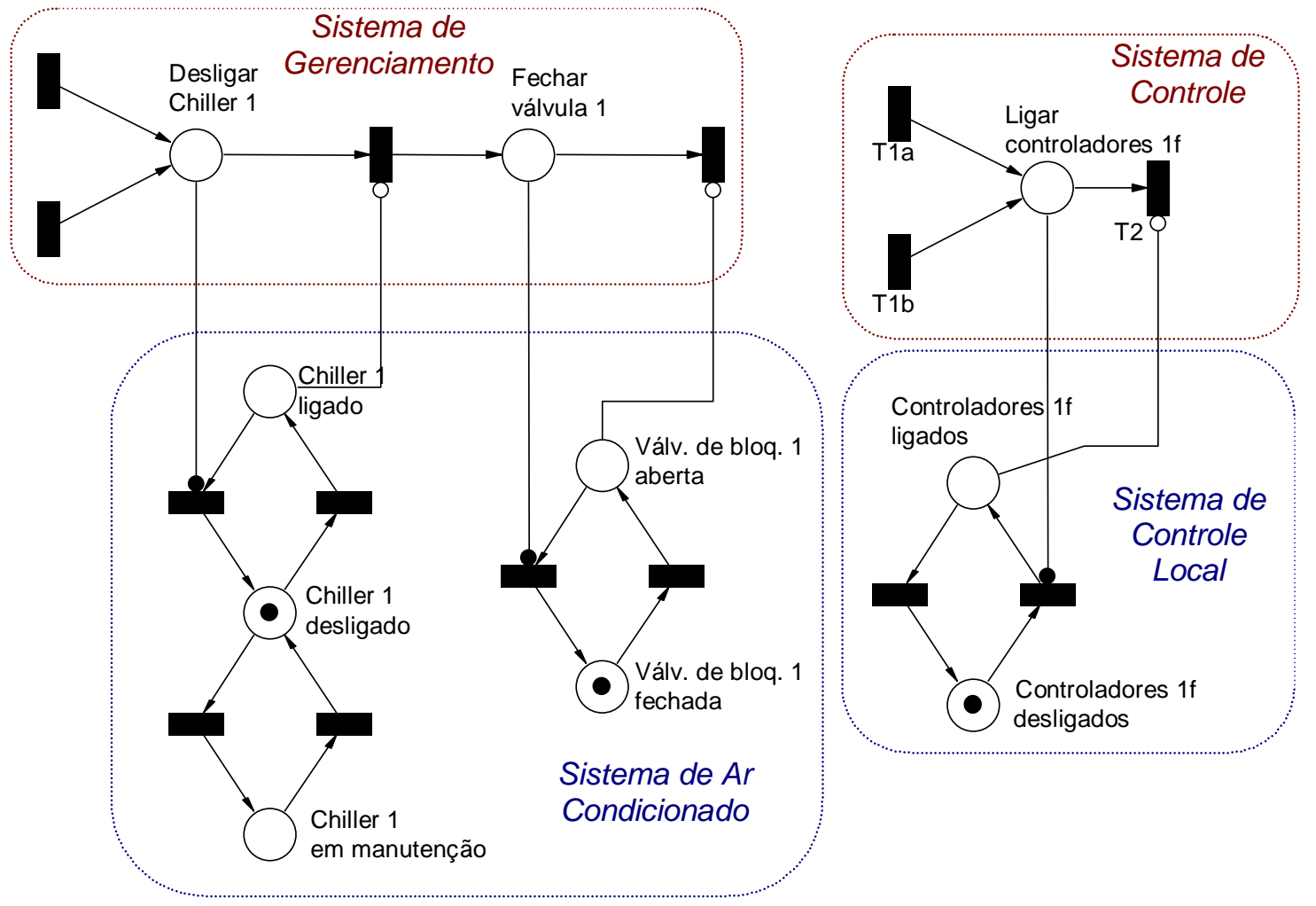

Figura 5.31. Exemplo de conexão entre modelos. 


\subsubsection{Modelo do Ambiente}

O primeiro passo para a modelagem do comportamento dinâmico das propriedades do ambiente a serem controladas é a determinação da quantidade de calor adicionada ou retirada do ambiente a cada instante.

Em um ambiente existem diversas fontes de calor externas e/ou internas. As principais fontes de calor externas são a transferência de calor por convecção e radiação através de janelas, paredes e tetos. $\mathrm{O}$ calor transmitido para as paredes, tetos e janelas não é imediatamente transmitido para o ar do ambiente, esta inércia térmica do edifício depende de diversos fatores como por exemplo, do material utilizado na construção, da espessura de suas paredes, etc.

A modelagem destas fontes de calor pode ser realizada através do equacionamento da troca de calor entre paredes, janelas e tetos com o ambiente exterior e com o ambiente interior.

No presente estudo de caso, utiliza-se o modelo proposto por [Hudson \& Underwood,1999] onde o calor transmitido através das paredes e tetos é dado por:

$$
\begin{aligned}
& \mathrm{Q}_{\text {paredes_int }}=\mathrm{A}_{\text {paredes_int }} * \mathrm{U} *\left(\mathrm{~T}_{\text {paredes_int }}-\mathrm{T}_{\text {zona1 }}\right) \\
& \mathrm{Q}_{\text {paredes_ext }}=\mathrm{A}_{\text {paredes_ext }} * \mathrm{U} *\left(\mathrm{~T}_{\text {paredes_ext }}-\mathrm{T}_{\text {zona1 }}\right) \\
& \mathrm{Q}_{\text {teto }}=\mathrm{A}_{\text {teto }} * \mathrm{U} *\left(\mathrm{~T}_{\text {teto }}-\mathrm{T}_{\text {zonal }}\right) \\
& \mathrm{Q}_{\text {piso }}=\mathrm{A}_{\text {piso }} * \mathrm{U} *\left(\mathrm{~T}_{\text {piso }}-\mathrm{T}_{\text {zona1 }}\right) \\
& \mathrm{Q}_{\text {janela }}=\mathrm{A}_{\text {janela }} * \mathrm{U} *\left(\mathrm{~T}_{\text {janela }}-\mathrm{T}_{\text {zona1 }}\right)
\end{aligned}
$$

onde $\mathrm{Q}_{\text {parede_int }}, \mathrm{Q}_{\text {parede_ext }}, \mathrm{Q}_{\text {teto }}, \mathrm{Q}_{\text {piso }}, \mathrm{Q}_{\text {janela }}=$ carga térmica transmitida ao ambiente através de paredes internas, paredes externas, teto, piso e janela, respectivamente;

$\mathrm{A}_{\text {parede_int, }} \mathrm{A}_{\text {parede_ext }}, \mathrm{A}_{\text {teto }}, \mathrm{A}_{\text {piso }}, \mathrm{A}_{\text {janela }}=$ área de paredes internas, paredes externas, teto, piso e janela, respectivamente;

$\mathrm{U}=$ coeficiente de transferencia de calor por convecção; 
A temperatura de paredes, piso e teto são determinadas através das seguintes expressões:

$$
\begin{aligned}
& \dot{\mathrm{T}}_{\text {paredes_int }}=\frac{\mathrm{A}_{\text {paredes_int }} *\left(\mathrm{U} *\left(\mathrm{~T}_{\text {zona1 }}-\mathrm{T}_{\text {paredes_int }}\right)+\mathrm{U} *\left(\mathrm{~T}_{\text {outras_zonas }}-\mathrm{T}_{\text {paredes_int }}\right)\right)}{\mathrm{Vol}_{\text {paredes_int }} * \rho_{\text {paredes_int }} * \mathrm{c}_{\text {paredes_int }}} \\
& \dot{\mathrm{T}}_{\text {paredes_ext }}=\frac{\mathrm{A}_{\text {paredes_ext }} *\left(\mathrm{U} *\left(\mathrm{~T}_{\text {zonal } 1}-\mathrm{T}_{\text {paredes_ext }}\right)+\mathrm{U} *\left(\mathrm{~T}_{\text {exterior }}-\mathrm{T}_{\text {paredes_ext }}\right)\right)}{\mathrm{vol} \mathrm{l}_{\text {paredes_ext }} * \rho_{\text {paredes_ext }} * \mathrm{c}_{\text {paredes_ext }}} \\
& \dot{\mathrm{T}}_{\text {teto }}=\frac{\mathrm{A}_{\text {teto }} *\left(\mathrm{U} *\left(\mathrm{~T}_{\text {zonal }}-\mathrm{T}_{\text {teto }}\right)+\mathrm{U} *\left(\mathrm{~T}_{\text {exterior }}-\mathrm{T}_{\text {teto }}\right)\right)}{\operatorname{vol}_{\text {teto }} * \rho_{\text {teto }} * \mathrm{c}_{\text {teto }}} \\
& \dot{\mathrm{T}}_{\text {piso }}=\frac{\mathrm{A}_{\text {piso }} *\left(\mathrm{Q}_{\text {radiação }} / \mathrm{A}_{\text {piso }}+\mathrm{U} *\left(\mathrm{~T}_{\text {zona1 }}-\mathrm{T}_{\text {piso }}\right)+\mathrm{U} *\left(\mathrm{~T}_{\text {exterior }}-\mathrm{T}_{\text {piso }}\right)\right)}{\operatorname{vol}_{\text {piso }} * \rho_{\text {piso }} * \mathrm{c}_{\text {piso }}}
\end{aligned}
$$

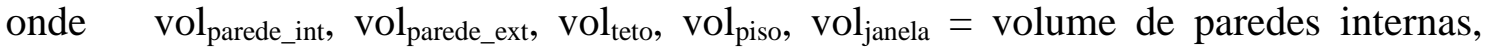
paredes externas, teto, piso e janela, respectivamente;

$\mathrm{T}_{\text {zona1 }}, \quad \mathrm{T}_{\text {outras_zonas }}, \mathrm{T}_{\text {exterior }}=$ temperatura na zona analisada, nas zonas adjacentes e temperatura exterior, respectivamente;

$\mathrm{c}_{\text {parede_int }}, \mathrm{c}_{\text {parede_ext }}, \mathrm{c}_{\text {teto }}, \mathrm{c}_{\text {piso }}, \mathrm{c}_{\text {janela }}=$ calor específico de paredes internas, paredes externas, teto, piso e janela, respectivamente;

$\rho_{\text {parede_int }}, \rho_{\text {parede_ext }}, \rho_{\text {teto }}, \rho_{\text {piso }}, \rho_{\text {janela }}=$ densidade de paredes internas, paredes externas, teto, piso e janela, respectivamente;

Observa-se que este modelo considera que o calor de radiação transmitido através dos vidros é constante e incide sobre o piso.

As principais fontes de calor internas são pessoas, dispositivos de iluminação artificial, equipamentos, entre outras coisas.

A carga térmica produzida por pessoas varia, entre outras coisas, de acordo com a atividade por ela desenvolvida. No presente trabalho, considerou-se que cada pessoa no ambiente a ser condicionado introduz uma quantidade fixa de energia na forma de calor sensível/latente. Alguns valores a serem adotados pode ser encontrado em [ASHRAE, 1996] de acordo com o tipo de atividade. 
Para a carga térmica introduzida por equipamentos também considerou-se que cada equipamento introduz uma quantidade fixa de energia quando ligado. Alguns valores a serem adotados pode ser encontrado em [ASHRAE, 1996] de acordo com o tipo de equipamento.

Para a carga térmica produzida pela iluminação artificial, adotou-se o modelo apresentado em [ASHRAE, 1996] onde considera-se que apenas uma fração da energia liberada se dá na forma convectiva, do que resulta um aumento imediato da temperatura do ambiente. Esta fração é fornecida por:

$$
\mathrm{Q}=\mathrm{W} * \mathrm{~F}_{\mathrm{sa}},
$$

onde $\quad \mathrm{Q}=$ carga térmica dissipada por luminárias (Watts),

$$
\begin{aligned}
& \mathrm{W}=\text { potência (Watts), } \\
& \mathrm{F}_{\mathrm{sa}}=\text { fator de ajuste. }
\end{aligned}
$$

Valores para o fator de ajuste para alguns tipos de lâmpadas podem ser encontrados em [ASHRAE, 1996].

A carga térmica adicionada ou retirada através de pessoas, de iluminação e de equipamentos varia de acordo com o número de pessoas, equipamentos ligados, luzes acesas, etc. Assim, representa-se através de redes de Petri os eventos relacionados a variação discreta desta cargas (Figura 5.32).
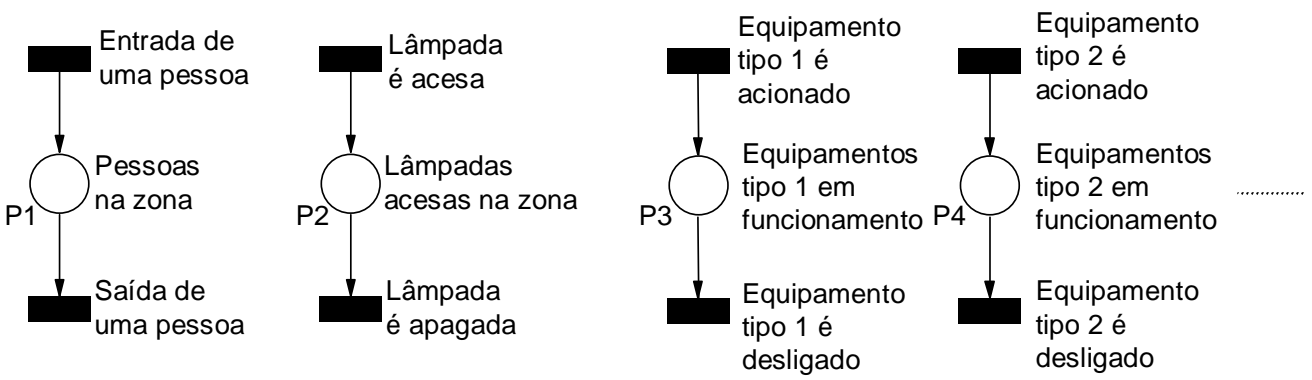

Figura 5.32. Exemplo de modelos em redes de Petri da ocorrência de eventos discretos.

Tem-se então que: 


$$
\begin{aligned}
& \mathrm{Q}_{\text {pessoas_teor }}=\mathrm{m}_{\mathrm{P} 1} * \mathrm{C}_{\text {pessoa }} \\
& \mathrm{Q}_{\text {ilum_teor }}=\mathrm{m}_{\mathrm{P} 2} * \mathrm{~W}^{*} \mathrm{~F}_{\mathrm{sa}} \\
& \mathrm{Q}_{\text {equip_teor }}=\mathrm{m}_{\mathrm{P} 3} * \mathrm{C}_{\text {equip1 }}+\mathrm{m}_{\mathrm{P} 4} * \mathrm{C}_{\text {equip2 }}
\end{aligned}
$$

onde $\quad \mathrm{Q}_{\text {pessoas_teor }}=$ calor introduzido na zona 1 por pessoas;

$\mathrm{Q}_{\text {ilum_teor }}=$ calor introduzido na zona 1 por luminárias;

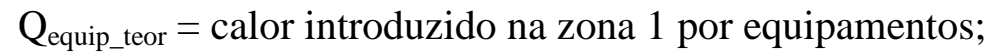

$\mathrm{m}_{\mathrm{P} 1}, \mathrm{~m}_{\mathrm{P} 2}, \mathrm{~m}_{\mathrm{P} 3}$ e $\mathrm{m}_{\mathrm{P} 4}=$ marcação dos lugares P1, P2, P3 e P4 da Figura 5.32;

$\mathrm{W}=$ potência da luminária;

$\mathrm{F}_{\mathrm{sa}}=$ fator de ajuste da luminária;

$\mathrm{C}_{\text {pessoa }}, \mathrm{C}_{\text {equip1 }}$ e $\mathrm{C}_{\text {equip2 }}=$ calor liberado por uma pessoa, por um equipamento do tipo 1 e por um equipamento do tipo 2 , respectivamente.

Observa-se que neste exemplo considerou-se a existência de dois tipos de equipamentos diferentes e de apenas um tipo de luminária.

A carga adicionada ou retirada pelo ar condicionado é dada por:

$$
\begin{aligned}
& \mathrm{Q}_{\mathrm{ar}_{-} \text {cond_teor }}=\mathrm{v}_{\mathrm{ar}} * \rho *\left(\mathrm{~h}\left(\mathrm{~T}_{\mathrm{ar}_{-} \text {insufl }}\right)-\mathrm{h}\left(\mathrm{T}_{\text {zona1 }}\right)\right)+\mathrm{v}_{\mathrm{ar}} * \rho * \mathrm{~h}_{\mathrm{lv}_{\mathrm{v}}}\left(\mathrm{T}_{\mathrm{ar}_{-} \text {insufl }}\right) *\left(\omega_{\mathrm{ar}_{-} \text {insufl }}-\omega_{\text {zona1 }}\right) \\
& =\mathrm{v}_{\mathrm{ar}} * \rho * \mathrm{c}_{\mathrm{p}}\left(\mathrm{T}_{\mathrm{ar} \_ \text {insufl }}-\mathrm{T}_{\mathrm{zona1}}\right)+\mathrm{v}_{\mathrm{ar}} * \rho * \mathrm{~h}_{\mathrm{lv}_{\mathrm{v}}}\left(\mathrm{T}_{\mathrm{ar}_{\_} \text {insufl }}\right) *\left(\omega_{\mathrm{ar}_{\_} \text {insufl }}-\omega_{\text {zonal }}\right)
\end{aligned}
$$

onde $\quad Q_{\text {ar_cond_teor }}=$ carga térmica adicionada ou retirada pelo ar condicionado,

$\mathrm{T}_{\mathrm{ar} \_ \text {insufl }}, \mathrm{T}_{\text {zona1 }}=$ temperatura do ar insuflado e temperatura na zona1;

$\omega_{\text {ar_insufl }}, \omega_{\text {zona1 }}=$ umidade do ar insuflado e temperatura na zona1;

$\rho=$ densidade do ar;

$\mathrm{v}_{\mathrm{ar}}=$ volume de ar insuflado;

$\mathrm{h}_{\mathrm{lv}}=$ entalpia de vaporização da água.

Na equação 33 a entalpia de vaporização é calculada por [Taube, 97]:

$$
\mathrm{h}_{\mathrm{lv}}(\mathrm{T})=-0,8 \cdot 10^{-5} * \mathrm{~T}^{3}-0,2.10^{-3} * \mathrm{~T}^{2}-2,336 * \mathrm{~T}+2501,2
$$


No entanto, a carga térmica introduzida pelo ar condicionado, por pessoas, etc. não é distribuída instantaneamente por todo o ambiente, afetando principalmente a temperatura nas vizinhanças da fonte de calor, como por exemplo ao redor de uma pessoa, na vizinhança da boca de insuflamento, etc. Para considerar este fato introduziuse um atraso de tempo entre a introdução da carga e a influência desta carga no ambiente. Adotou-se, então, as seguintes expressões:

$$
\begin{aligned}
& \dot{\mathrm{Q}}_{\text {pessoas }}=\frac{\mathrm{Q}_{\text {pessoas_teor }}-\mathrm{Q}_{\text {pessoas }}}{\tau_{\text {pessoas }}} \\
& \dot{\mathrm{Q}}_{\text {ilum }}=\frac{\mathrm{Q}_{\text {ilum_teor }}-\mathrm{Q}_{\text {ilum }}}{\tau_{\text {ilum }}} \\
& \dot{\mathrm{Q}}_{\text {equip }}=\frac{\mathrm{Q}_{\text {equip_teor }}-\mathrm{Q}_{\text {equip }}}{\tau_{\text {equip }}} \\
& \dot{\mathrm{Q}}_{\text {ar_cond }}=\frac{\mathrm{Q}_{\text {ar_cond_teor }}-\mathrm{Q}_{\text {ar_cond }}}{\tau_{\text {ar_cond }}}
\end{aligned}
$$

A carga total na zona é dada, então, por:

$$
\begin{aligned}
& \mathrm{Q}_{\text {total }}=\mathrm{Q}_{\text {paredes_int }}+\mathrm{Q}_{\text {paredes_ext }}+\mathrm{Q}_{\text {piso }}+\mathrm{Q}_{\text {teto }}+ \\
& \mathrm{Q}_{\text {janelas }}+\mathrm{Q}_{\text {ilum }}+\mathrm{Q}_{\text {pessoas }}+\mathrm{Q}_{\text {equip }}+\mathrm{Q}_{\text {ar_condicionado }}
\end{aligned}
$$

Fazendo o balanço energético do ambiente, tem-se a seguinte evolução da temperatura:

$$
\begin{aligned}
& \operatorname{vol}_{\text {ar_zona }} * \rho * c_{\mathrm{p}} *\left(\mathrm{~T}_{\text {zonal }}(\mathrm{t})-\mathrm{T}_{\text {zonal }}\left(\mathrm{t}_{0}\right)\right)=\int_{\mathrm{t}_{0}}^{\mathrm{t}} \mathrm{Q}_{\text {total }} \mathrm{dt} \\
& \dot{\mathrm{T}}_{\text {zonal }}=\frac{\mathrm{Q}_{\text {total }}}{\operatorname{vol}_{\text {ar_zona }} * \rho * \mathrm{c}_{\mathrm{p}}}
\end{aligned}
$$

onde $\quad$ vol $_{\text {ar_zona }}=$ volume de ar na zona;

$\rho=$ densidade do ar;

$\mathrm{c}_{\mathrm{p}}=$ calor específico a pressão constante;

$\mathrm{T}_{\text {zona1 }}=$ temperatura do ar na zona $1 ;$

$\mathrm{t}=$ tempo;

$\mathrm{t}_{0}=$ instante inicial. 
O equacionamento acima considera:

- mistura perfeita entre o ar insuflado e o ar no ambiente;

- comportamento de gás perfeito (variação da entalpia proporcional a variação da temperatura);

- processo a pressão constante;

- efeitos de infiltração negligenciável;

\subsection{Simulação dos Modelos}

Uma vez construídos os modelos, a etapa seguinte refere-se a sua simulação, através da qual é possível obter o valor das diversas variáveis contínuas e discretas de acordo com a evolução do tempo e com a ocorrência de eventos discretos.

Como exemplo, apresenta-se a simulação da estratégia [Área utilizada - zona 1] da Figura 5.6.

Para a simulação da parte discreta $^{3}$ do modelo considerou-se como condição inicial os ventiladores e controladores de aquecimento e resfriamento desligados e a caixa de mistura na posição de renovação do ar de $0 \%$.

A Figura 5.33 apresenta o modelo construído em redes de Petri com a marcação inicial. Observa-se que, foram omitidos, por uma questão de espaço e legibilidade do grafo, os modelos relativos aos ventiladores, à caixa de mistura e as respectivas operações do sistema de gerenciamento.

\footnotetext{
3 A ferramenta utilizada na simulação da parte discreta do modelo é o Visual Objekt Net++, versão 2.0, desenvolvido no Department of Automatic Control and Systems Engineering da Ilmenau University of Technology, Alemanha.
} 


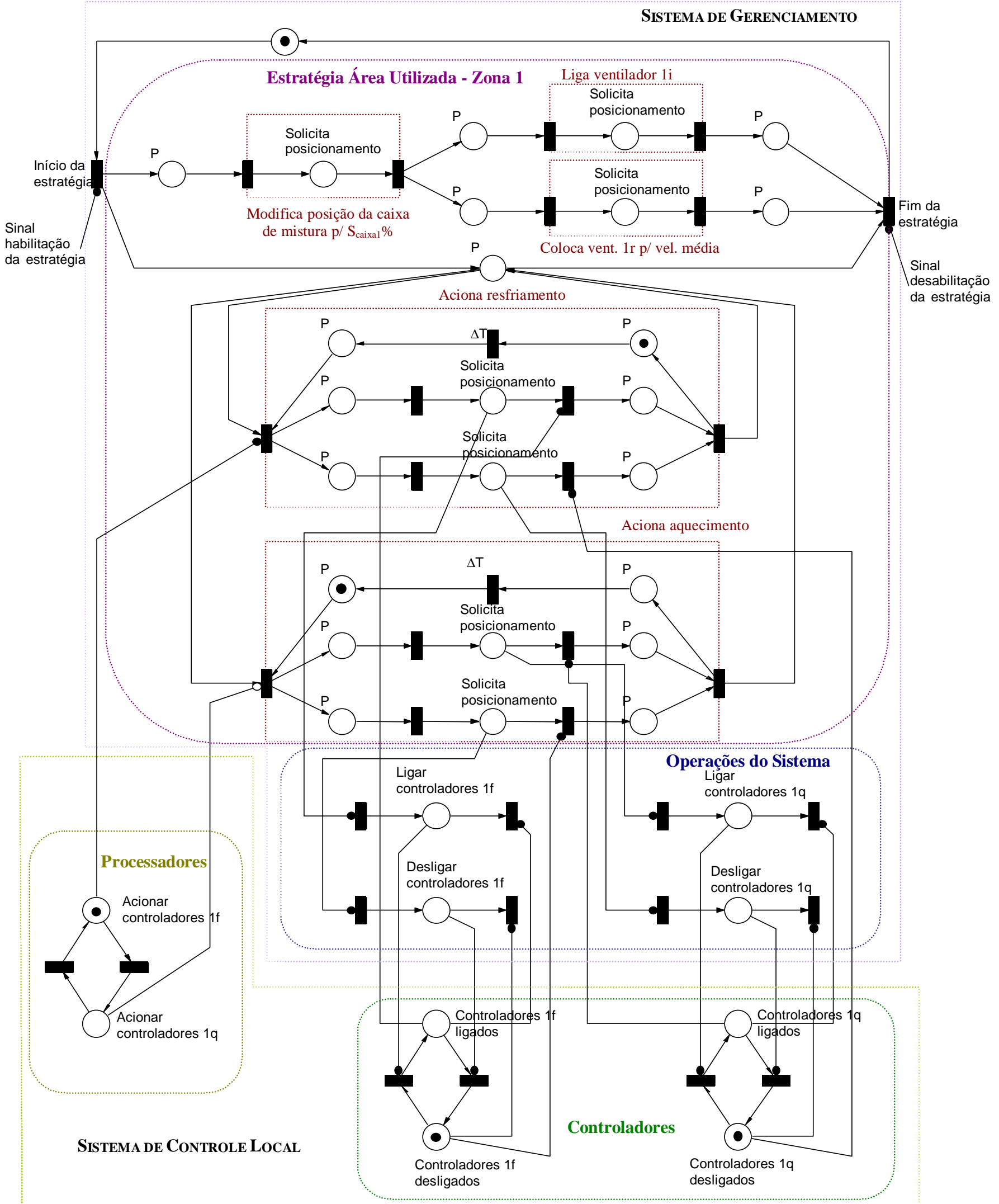

Figura 5.33. Exemplo de modelo construído no simulador de Redes de Petri 
$\mathrm{Na}$ simulação do modelo contínuo ${ }^{4}$ foram utilizados os seguintes valores para constantes dos sistemas ${ }^{5}$ :

- constantes para a serpentina para o modelo apresentado no item 5.3.2.2:
$\diamond \quad \rho_{\mathrm{a}}=1,2928 \mathrm{~kg} / \mathrm{m}^{3}$
$\diamond \quad \mathrm{k}_{\mathrm{a}}=5 \cdot 10^{3} \mathrm{~W} \cdot \mathrm{kg}^{-0,8} \cdot \mathrm{s}^{0,8}$
$\diamond \quad \mathrm{c}_{\mathrm{pa}}=0,24 \cdot 4,186 \cdot 10^{3} \mathrm{~J} /(\mathrm{kg} \cdot \mathrm{K}) ;$
$\diamond \quad \mathrm{a} 1=0,8$
$\diamond \quad \rho_{\mathrm{w}}=1000 \mathrm{~kg} / \mathrm{m}^{3}$
$\diamond \quad \mathrm{k}_{\mathrm{w}}=10 \cdot 10^{3} \mathrm{~W} \cdot \mathrm{kg}^{-0,8} \cdot \mathrm{s}^{0,8}$
$\diamond \quad \mathrm{c}_{\mathrm{pw}}=0,99 \cdot 4,186 \cdot 10^{3} \mathrm{~J} /(\mathrm{kg} \cdot \mathrm{K})$;
$\diamond \quad \mathrm{a} 2=0,8$

- $\quad$ constante da válvula $b=2,75$;

- $\quad$ volume de ar na zona: $500 \mathrm{~m}^{3}$;

- constantes utilizadas para os atrasos de tempo

$\checkmark \quad \mathrm{p} /$ carga do ar condicionado: $300 \mathrm{~s}$;

$\diamond \quad$ p/sensor de temperatura: 180s (para vazão e temperatura);

$\checkmark \quad$ p/ outras cargas: $300 \mathrm{~s}$;

$\diamond \quad$ p/serpentina: 300s (para vazão e temperatura);

- constantes dos controladores PIs:

$\diamond \quad P I 1: K_{P \_ \text {insufl_1f }}=-6,04 ; K_{I \_ \text {insufl_1f }}=-0,002 ; V_{0 \_ \text {insufl_1f }}=15$;

$\diamond \quad$ PI $2: \mathrm{K}_{\mathrm{P}_{-} \mathrm{V} 1 \mathrm{f}}=0,1 ; \mathrm{K}_{\mathrm{I}_{-} \mathrm{V} 1 \mathrm{f}}=0,0001 ; \mathrm{V}_{0 \_\mathrm{V} 1 \mathrm{f}}=0,5$;

\footnotetext{
${ }^{4}$ A simulação contínua foi realizada no software Simulink®

${ }^{5}$ Devido a não disponibilidade de dados referentes a zonas do PAMB, os dados aqui apresentados foram estimados a partir de exemplos presentes na bibliografia.
} 
- $\quad$ set-point para temperatura: $23^{\circ} \mathrm{C}$;

- renovação parcial de ar da caixa de mistura: $40 \%$;

- vazão de ar insuflado para ventilador na posição velocidade média: $0,7 \mathrm{~m}^{3} / \mathrm{s}$.

Considerou-se também como constantes os valores das seguintes variáveis:

- temperatura do ar exterior: $25^{\circ} \mathrm{C}$;

- vazão máxima de água fornecida a serpentina: $6,8.10^{-4} \mathrm{~m}^{3} / \mathrm{s}$;

- temperatura da água fornecida a serpentina: $7^{\circ} \mathrm{C}$.

Como condição inicial para as variáveis contínuas considerou-se:

- temperatura inicial no ambiente: $25^{\circ} \mathrm{C}$;

- temperatura inicial transmitida pelo sensor: $25^{\circ} \mathrm{C}$;

- temperatura nas zonas adjacentes: $25^{\circ} \mathrm{C}$;

- temperatura inicial de paredes, pisos e tetos: $25^{\circ} \mathrm{C}$;

- posição inicial da válvula: fechada;

Para ilustrar a simulação do modelo híbrido construído ${ }^{6}$, foi realizada a simulação da estratégia [Área utilizada - zona 1] para um período de 3 horas. Durante este período considerou-se a ocorrência dos seguintes eventos discretos:

- Evento 1: em $\mathrm{t}=1$ hora, são acionados quatro equipamentos e entram 15 pessoas no ambiente;

- Evento 2: em $\mathrm{t}=2$ horas os equipamento são desligado e as 15 pessoas saem do ambiente;

\footnotetext{
${ }^{6}$ Para a realização da modelagem da parte contínua e discreta simultaneamente, até o presente momento não existem ferramentas que possibilitem a simulação do modelo em redes PTD e redes de Petri para sistemas discretos. O desenvolvimento de uma ferramenta não faz parte do escopo do presente trabalho, assim obtou-se pela adaptação de um modelo desenvolvido no Simulink® para a consideração da ocorrência de eventos discretos.
} 
Considerou-se que cada equipamento ligado libera cerca de $1375 \mathrm{~W}$ e cada pessoa libera cerca de $150 \mathrm{~W}$, totalizando uma variação de 7000W.

A Figura 5.34 apresenta a evolução da temperatura na zona resultante da simulação, a partir do instante $(\mathrm{t}=0)$ em que a estratégia [Área utilizada - zona 1] é executada.

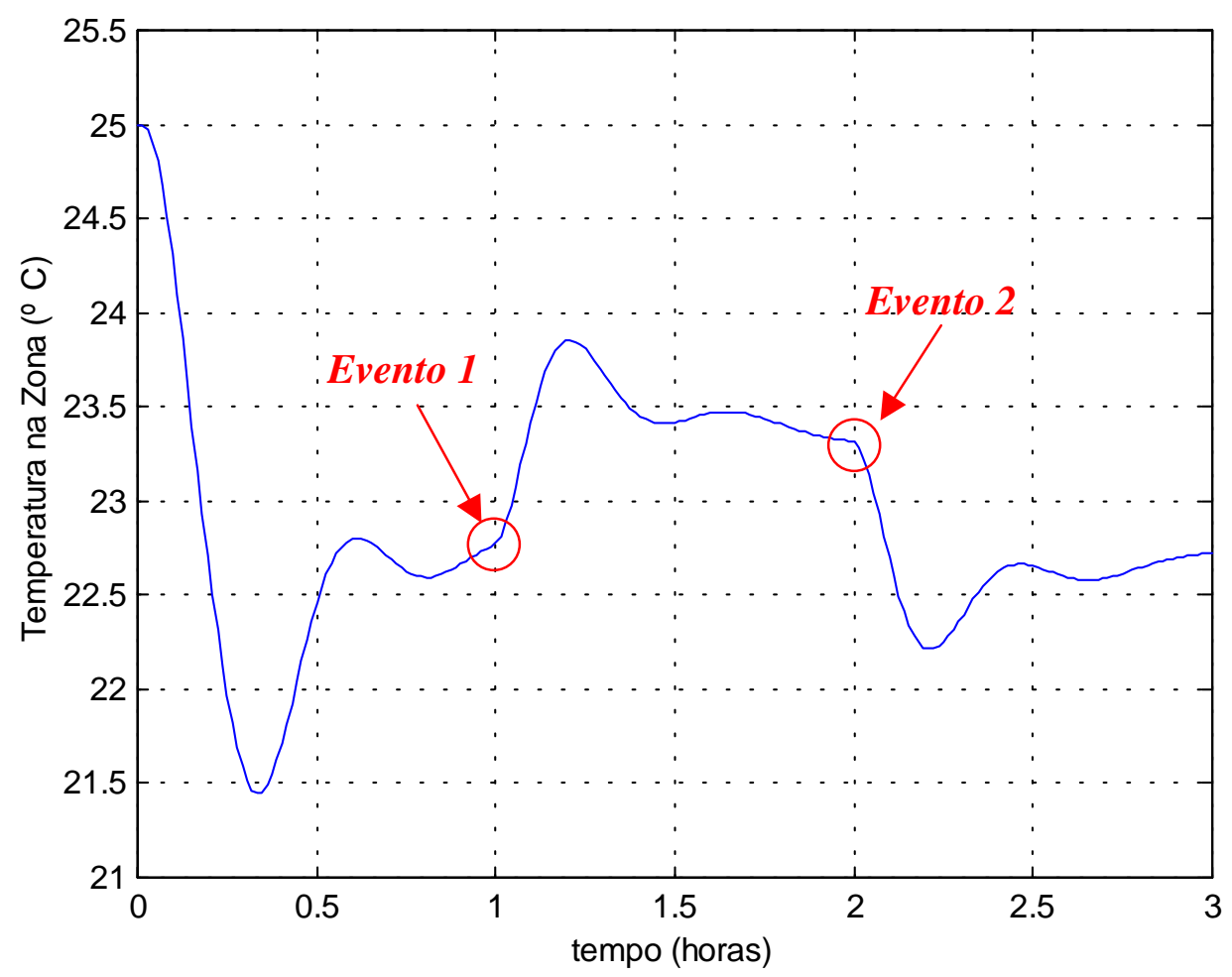

Figura 5.34. Evolução no tempo da temperatura na zona.

Através do modelo construído pode-se obter não só as condições ambientais na zona, mas também as características dos fluxos de água e ar, bem como os estados discretos (ligado, desligado, etc.) dos equipamentos do sistema.

Como exemplo, as Figura 5.35 e Figura 5.36 apresentam a evolução no tempo da temperatura do fluxo de água na saída da serpentina e da posição da válvula de três vias. 


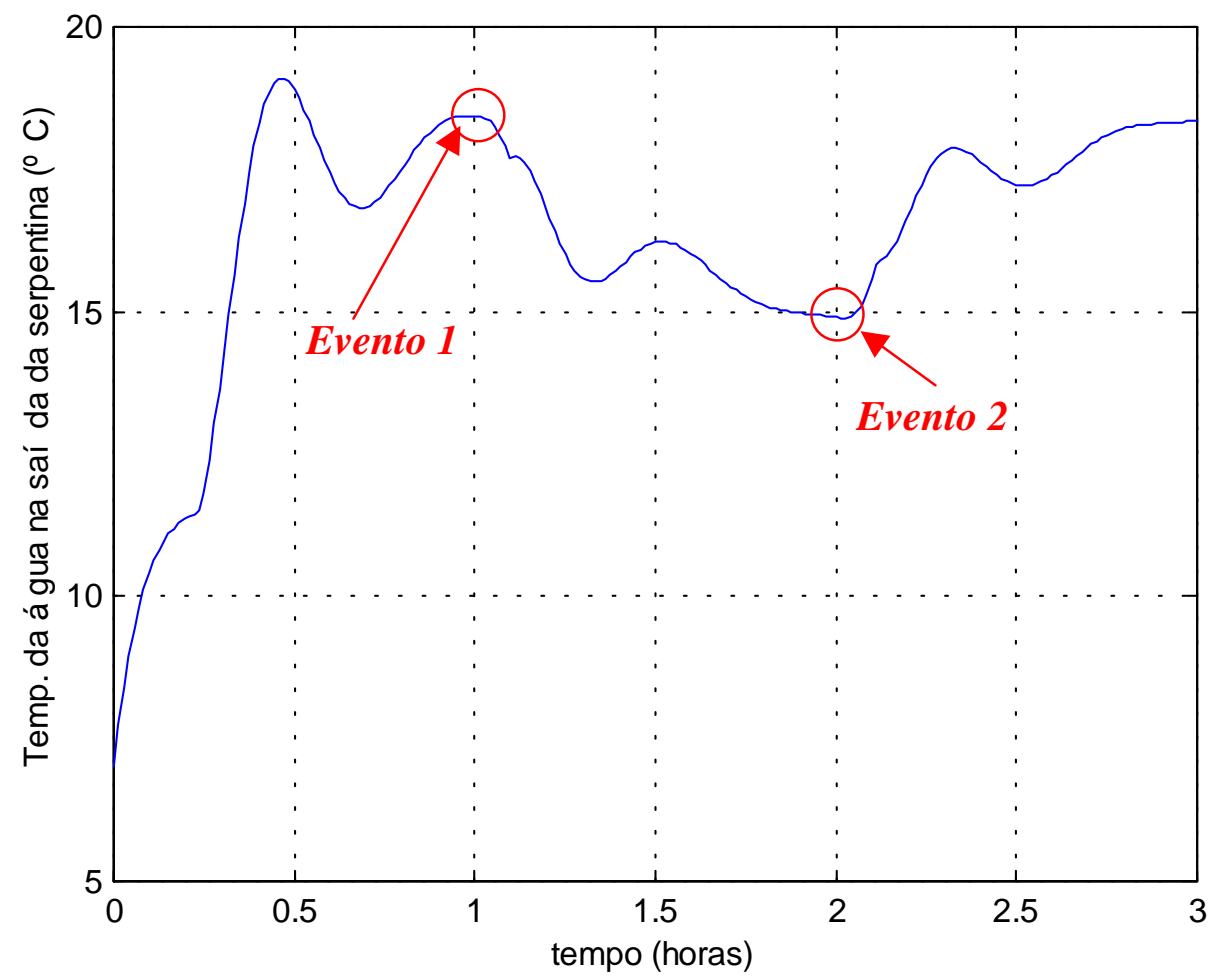

Figura 5.35. Evolução no tempo da temperatura da água na saída da serpentina.

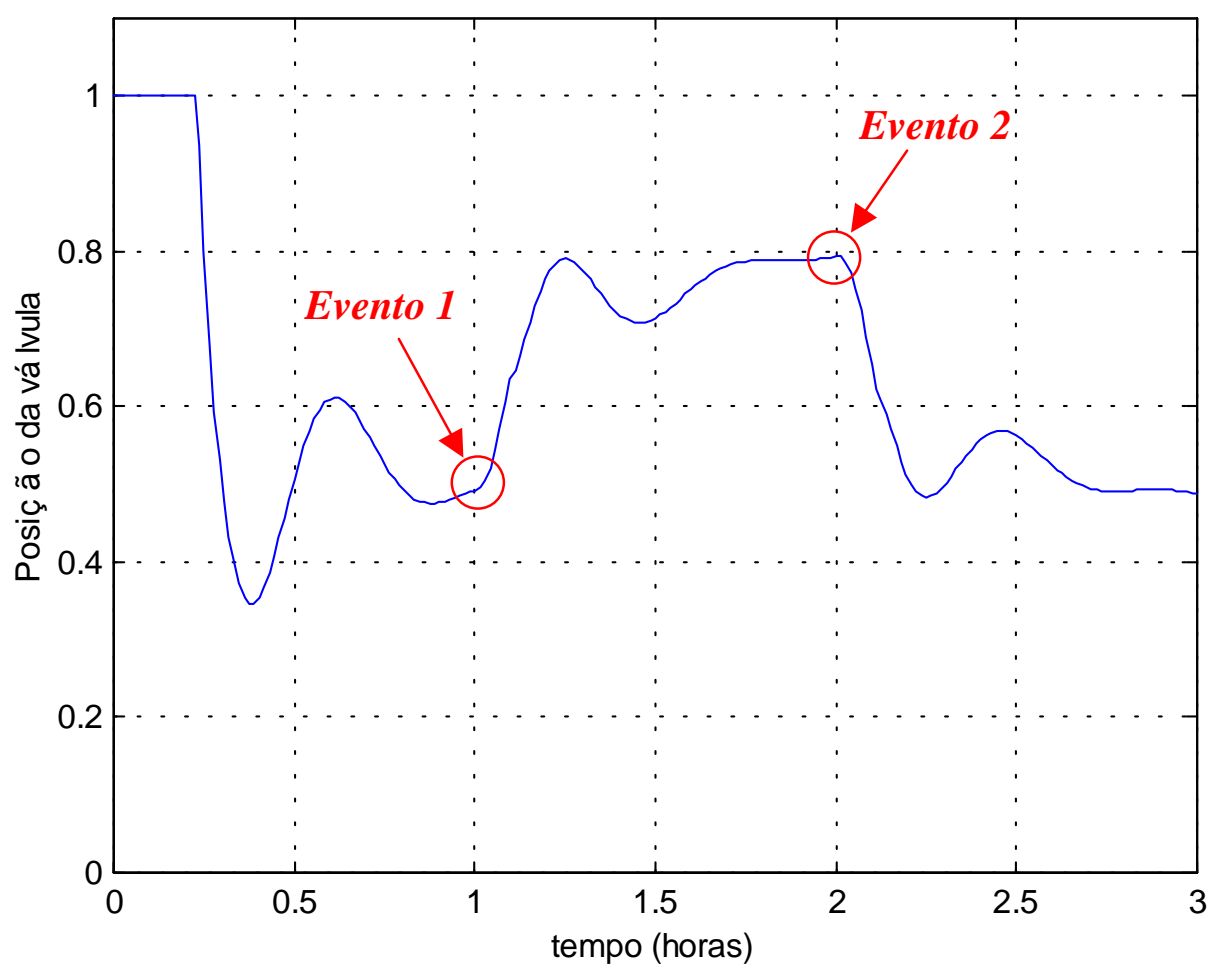

Figura 5.36. Evolução no tempo da posição da válvula. 
Os resultados obtidos a partir das simulações contribuem qualitativamente para a validação da proposta apresentada, uma vez que o sistema apresentou o comportamento esperado diante da ocorrência dos eventos introduzidos. No entanto, não foi realizado um estudo detalhado de validação, uma vez que este implicaria na comparação dos resultados obtidos com medições experimentais realizadas no ambiente e com a simulação do sistema para diversas condições iniciais e para a ocorrência de diversas combinações de eventos.

Observa-se ainda que a validade dos resultados obtidos está diretamente relacionada a precisão dos modelos contínuos adotados para cada parte do sistema. No entanto, existe um compromisso entre o aumento da complexidade dos modelos e o benefício obtido, principalmente no que se refere ao custo de implementação e tempo de simulação. Considerando o escopo do presente trabalho, onde visa-se ilustrar a aplicação da metodologia e não a defender a utilização de um determinado modelo dinâmico, os modelos adotados para o PAMB foram devidamente simplificados.

Uma vez que o objetivo, neste caso, é a análise do conforto térmico dos usuários do edifício, onde uma precisão demasiadamente grande não traz benefícios, visto que os próprios métodos de avaliação do conforto térmico apresentam uma larga margem de imprecisão, os resultados obtidos comprovam o potencial da proposta como uma abordagem efetiva para avaliação do sistema de ar condicionado. 


\section{Tratamento de perturbações}

De acordo com o apresentado no item 2.6, em EI existe a possibilidade do tratamento de grandes variações de carga térmica em curto espaço de tempo, causadas pela ocorrência de eventos discretos detectados por outros sistemas do EI. Confirma-se aqui que o modelo desenvolvido de acordo com a metodologia proposta é efetivo para avaliar se este tratamento pode ser realizado através da interferência no sistema de controle local do ar condicionado.

\subsection{Tipo de Intervenção}

O objetivo da interferência desejada no sistema de controle do ar condicionado é a diminuição do atraso na resposta do sistema de ar condicionado.

Para diminuir a duração e a intensidade da perturbação causada pela introdução de uma nova carga térmica atua-se no sistema de controle de ar condicionado no momento em que esta introdução é sinalizada por outros sistemas prediais. Assim, eventos como a entrada de pessoas, a abertura de portas, o acionamento de equipamentos, etc. devem ocasionar uma modificação no sistema de ar condicionado que possibilite o início imediato da retirada da carga térmica por eles produzida. Eventualmente, para o caso de situações futuras previsíveis, esta modificação pode ser até realizada antes da ocorrência da perturbação.

O tipo de intervenção a ser realizada varia de acordo com o tipo de sistema de ar condicionado. Em sistemas VAV deve-se interferir diretamente na unidade terminal 
VAV da zona onde ocorreu a perturbação, abrindo-se ou fechando-se o "damper" da referida unidade o suficiente para anulação da variação de carga térmica introduzida.

Em sistemas com volume de ar constante, como no caso do PAMB, pode-se interferir diretamente na válvula da serpentina de resfriamento ou aquecimento ou na temperatura de fornecimento do ar para a zona afetada, ocasionando uma rápida variação da carga térmica retirada ou adicionada à zona onde ocorreu a perturbação.

\subsection{Estratégia de Controle}

Dentro do sistema de controle apresentado anteriormente, para o controle das perturbações do sistema de ar condicionado, adota-se a técnica de chaveamento de controladores [Skafidas et al, 1999].

De acordo com os eventos que ocorrem no ambiente a ser condicionado um chaveador é responsável por selecionar qual o controlador (conjunto de parâmetros) que atua sobre o sistema de ar condicionado (Figura 6.1).

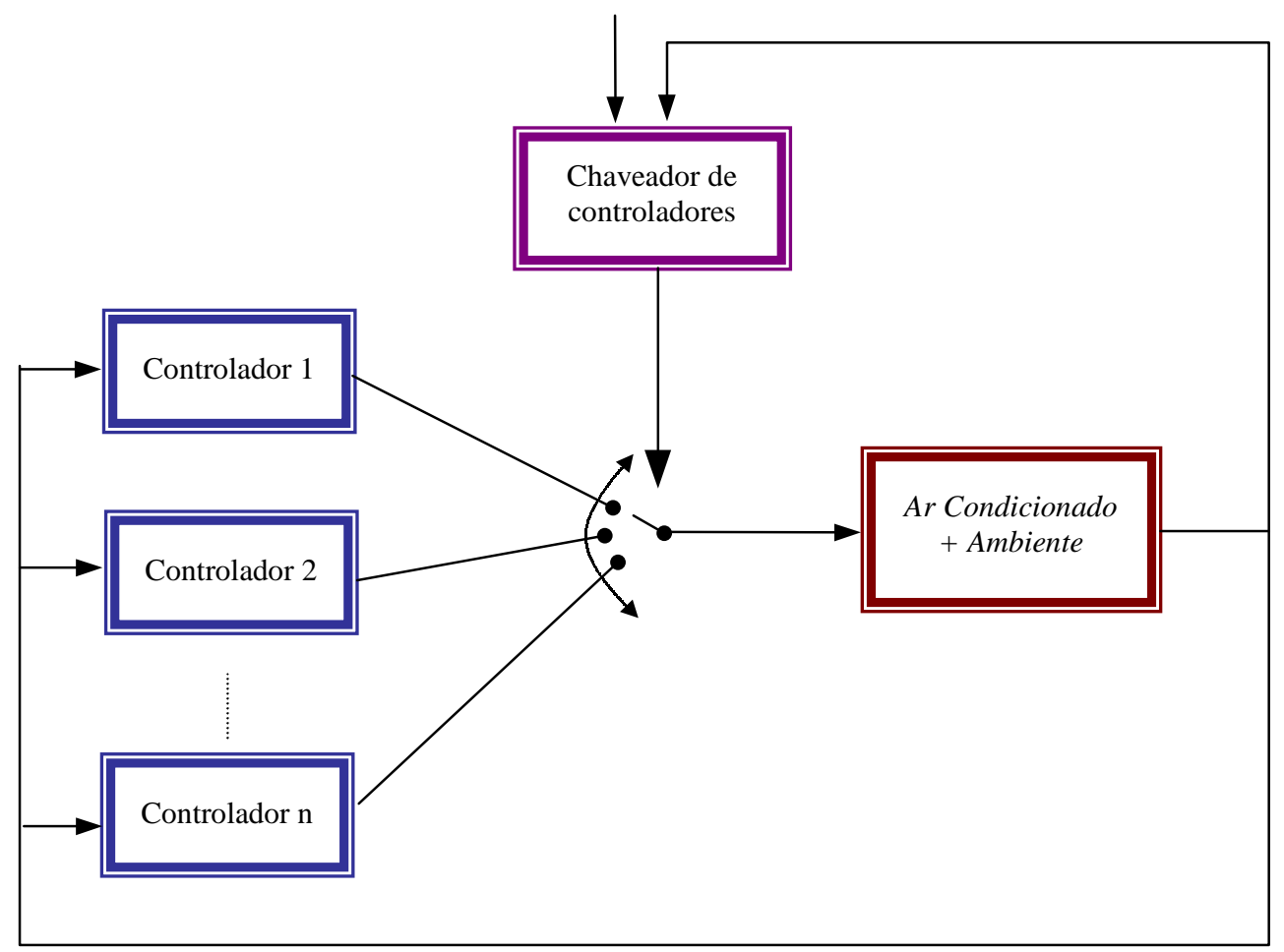

Figura 6.1. Técnica de controle proposta para tratamento de perturbações. 
A partir de interrupções geradas pelo BMS e provenientes originalmente de outros sistemas, contabiliza-se a variação total de carga térmica.

Uma vez detectada a ocorrência e a intensidade de variações da carga térmica, gera-se uma intervenção no sistema de controle local. Esta intervenção só é gerada quando a variação da carga térmica é superior a um determinado limite.

Para o caso em que após um determinado tempo não há ocorrência de variações da carga térmica, as ocorrências anteriores que não foram suficientes para gerar uma intervenção são desconsideradas. Exemplo: se é necessária a entrada de 10 pessoas para gerar uma intervenção, se entrarem 7 e depois de um tempo maior que o intervalo de tempo máximo determinado entrarem mais 4, não será gerada nenhuma intervenção. Esta desconsideração de pequenas cargas depois de um determinado tempo ocorre porque considera-se que durante este tempo o sistema de controle local consegue responder adequadamente a esta perturbação.

O novo controlador selecionado deverá ter parâmetros que corresponderão, por exemplo, a uma maior ou menor abertura da válvula de modo a anular a variação da carga térmica introduzida.

\subsection{Modelagem do Tratamento de Perturbações}

O primeiro passo para a introdução do tratamento de perturbações no modelo construído é a modificação do modelo dos controladores. A partir do modelo em rede PTD desenvolvido inicialmente, são introduzidos novos estados que correspondem ao funcionamento dos controladores com diferentes parâmetros. A Figura 6.2 apresenta este novo modelo para os controladores $1 \mathrm{f}$. 


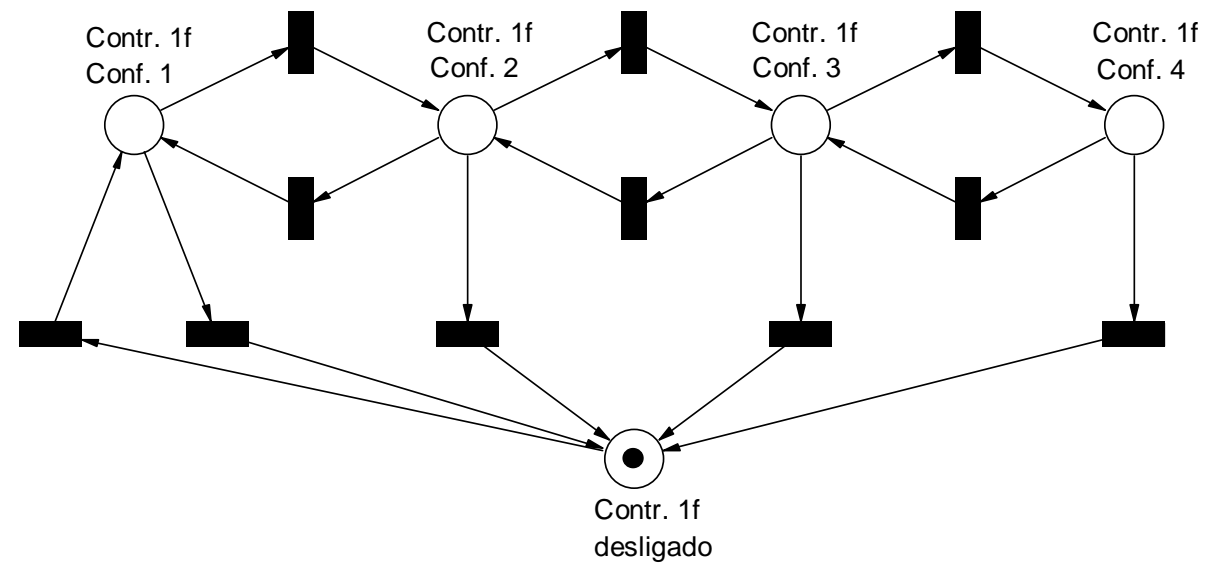

Figura 6.2. Modelo em rede PTD dos controladores considerando tratamento de perturbações.

vetor de variáveis:

sistema de equações:
$\mathrm{X}_{\text {contr_f_zonal }}=\left[\mathrm{T}_{\text {insufl_1f }}, \mathrm{V}_{\mathrm{V}_{-} \text {1f }}, \mathrm{T}_{\text {sensor_zona1 }}\right]$

$$
\begin{aligned}
& \text { (Lugar Controladores If ligados - Configuração } 1 \\
& \mathrm{~T}_{\text {insufl_1f }}=\mathrm{K}_{\mathrm{P}_{-} \text {insufl_lf_cl }} *\left(\mathrm{~T}_{\text {sensor_zona1 }}-\mathrm{T}_{\text {set_po int 1 }}\right)+ \\
& \mathrm{K}_{\mathrm{I}_{-} \text {insufl_lf } \_\mathrm{cl}} \int\left(\mathrm{T}_{\mathrm{ar}_{-} \text {serp_lf }}-\mathrm{T}_{\text {insufl_lf }}\right)+\mathrm{V}_{\mathrm{O}_{-} \text {insufl_1f } \_\mathrm{cl}} \\
& \mathrm{V}_{\mathrm{V}_{-} \text {lf }}=\mathrm{K}_{\mathrm{P}_{-} \mathrm{Vlf}_{-} \mathrm{cl}} *\left(\mathrm{~T}_{\mathrm{ar}_{-} \text {serplf_out }}-\mathrm{T}_{\text {insufl_lf }}\right)+ \\
& \mathrm{K}_{\mathrm{I}_{-} \mathrm{Vlf} \_\mathrm{cl}} \int\left(\mathrm{T}_{\mathrm{ar}_{-} \text {serp_lf }}-\mathrm{T}_{\text {insufl_lf }}\right)+\mathrm{V}_{0_{-} \mathrm{V} l f_{-} \mathrm{cl}} \\
& \dot{\mathrm{T}}_{\text {sensor_zona1 }}=\frac{\mathrm{T}_{\text {zona_1 }}-\mathrm{T}_{\text {sensor_zona1 }}}{\tau_{\text {sensor }}}
\end{aligned}
$$

Lugar Controladores If ligados - Configuração 2

$\mathrm{T}_{\text {insufl_lf }}=\mathrm{K}_{\mathrm{P}_{-} \text {insufl_lf } \_ \text {c2 }} *\left(\mathrm{~T}_{\text {sensor_zonal }}-\mathrm{T}_{\text {set_po int } 1}\right)+$$$
\mathrm{K}_{\mathrm{I}_{-} \text {insufl_lf } \_ \text {c } 2} \int\left(\mathrm{T}_{\mathrm{ar}_{-} \text {serp_-1f }}-\mathrm{T}_{\text {insufl_lf }}\right)+\mathrm{V}_{0_{-} \text {insufl_lf } \_ \text {c } 2}
$$$$
\mathrm{V}_{\mathrm{V}_{-} \text {1f }}=\mathrm{K}_{\mathrm{P}_{-} \mathrm{V}_{1 f}{ }_{-} \mathrm{c} 2} *\left(\mathrm{~T}_{\mathrm{ar}_{-} \text {serplf_out }}-\mathrm{T}_{\text {insufl_lf }}\right)+
$$$$
\mathrm{K}_{\mathrm{I}_{-} \mathrm{V} 1 \mathrm{f} \_\mathrm{c} 2} \int\left(\mathrm{T}_{\mathrm{ar}_{-} \text {serp_lf }}-\mathrm{T}_{\text {insufl_lf }}\right)+\mathrm{V}_{0_{-} \text {Vlf_c } 2}
$$$$
\dot{\mathrm{T}}_{\text {sensor_zonal }}=\frac{\mathrm{T}_{\text {zona_1 }}-\mathrm{T}_{\text {sensor_zona1 }}}{\tau_{\text {sensor }}}
$$

Lugar Controladores If ligados - Configuração 3

$$
\begin{aligned}
& \mathrm{T}_{\text {insufl_lf }}=\mathrm{K}_{\mathrm{P}_{-} \text {insufl_1f } \_ \text {c3 }} *\left(\mathrm{~T}_{\text {sensor_zona1 }}-\mathrm{T}_{\text {set_p point 1 }}\right)+ \\
& \mathrm{K}_{\mathrm{I}_{\_} \text {insufl_1f_c3 }} \int\left(\mathrm{T}_{\text {ar_serp_1f }}-\mathrm{T}_{\text {insufl_1f }}\right)+\mathrm{M}_{\text {insufl_1f_c3 }}
\end{aligned}
$$




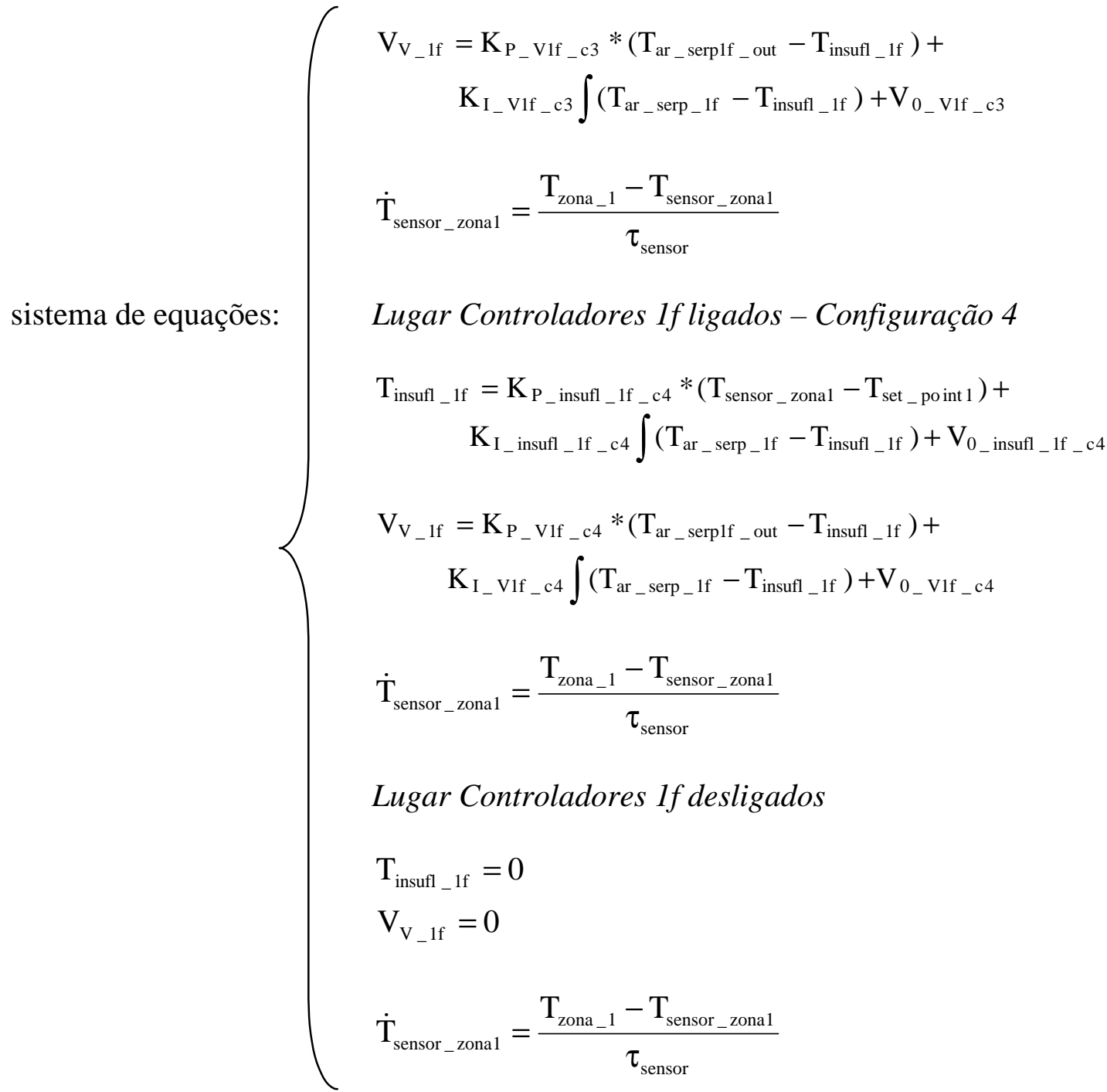

$\mathrm{O}$ passo seguinte refere-se a modificação do sistema de gerenciamento. As operações associadas a este modelo são:

- "Acionar controladores 1";

- "Acionar controladores 2";

- "Acionar controladores 3";

- “Acionar controladores 4";

- "Desligar controladores".

Modifica-se, então, a estratégia de controle “Área utilizada - zona 1" para considerar o tratamento de perturbações. 
A Figura 6.3 apresenta o novo modelo em PFS para esta estratégia.

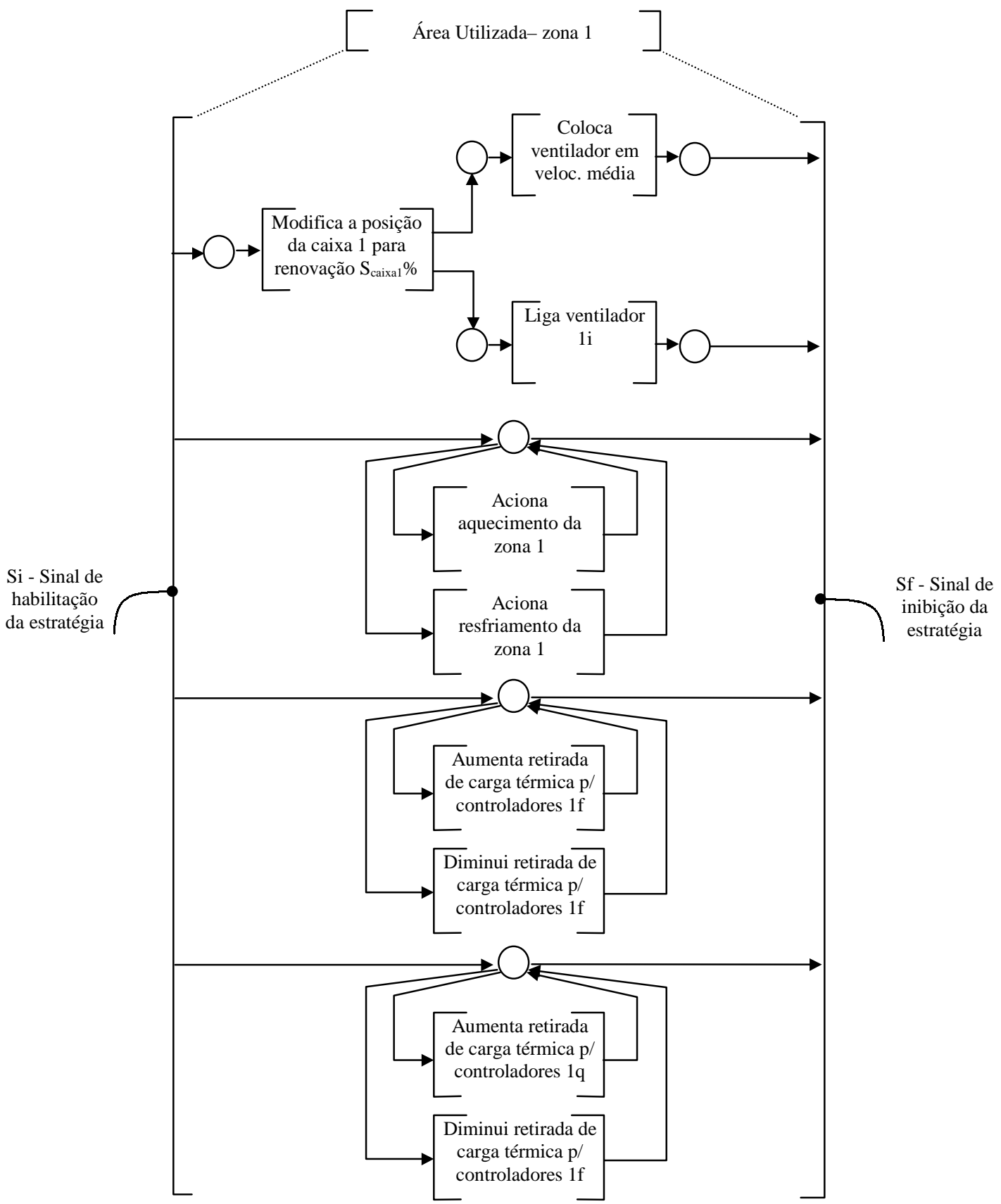

Figura 6.3. Modelo em PFS considerando chaveamento de controladores.

O detalhamento da atividade [Aumenta retirada de carga p/ controladores 1f] é apresentado na Figura 6.4. Esta atividade consiste em chavear os controladores para a próxima configuração (a mais adequada). Observa-se que esta atividade só é iniciada se os controladores 1f já estiverem ligados. 


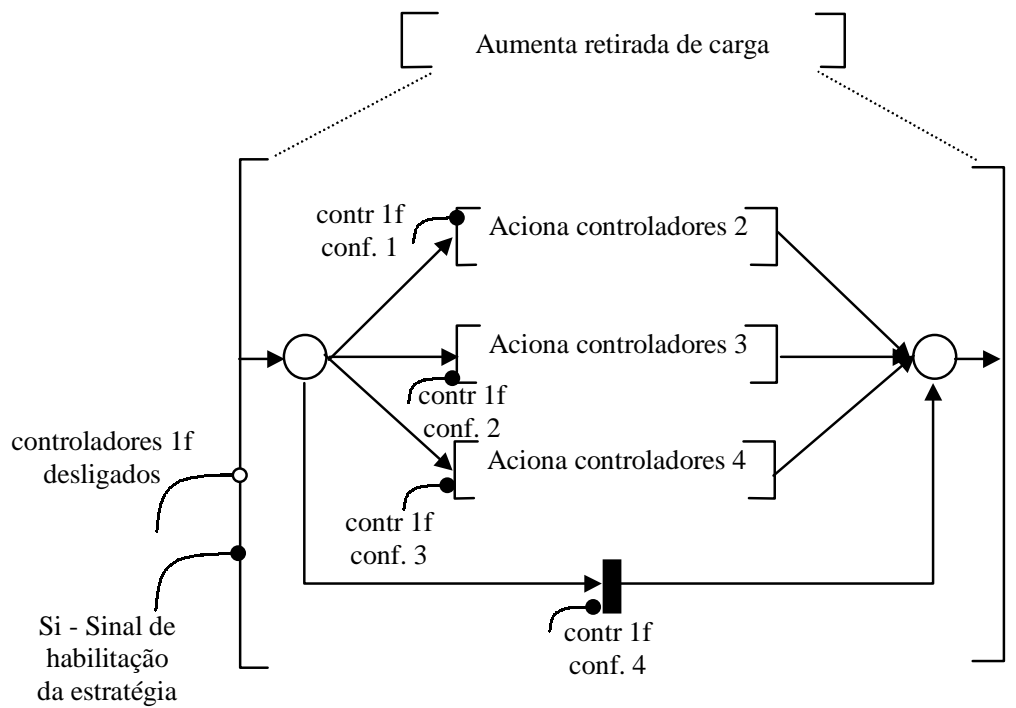

Figura 6.4. Detalhamento da atividade [Aumenta retirada de carga].

O sinal de habilitação da estratégia é gerado por um sistema de controle discreto modelado em redes de Petri que controla a variação da carga térmica discreta no ambiente a partir de sinais recebidos do BMS. A Figura 6.5 ilustra este controle.

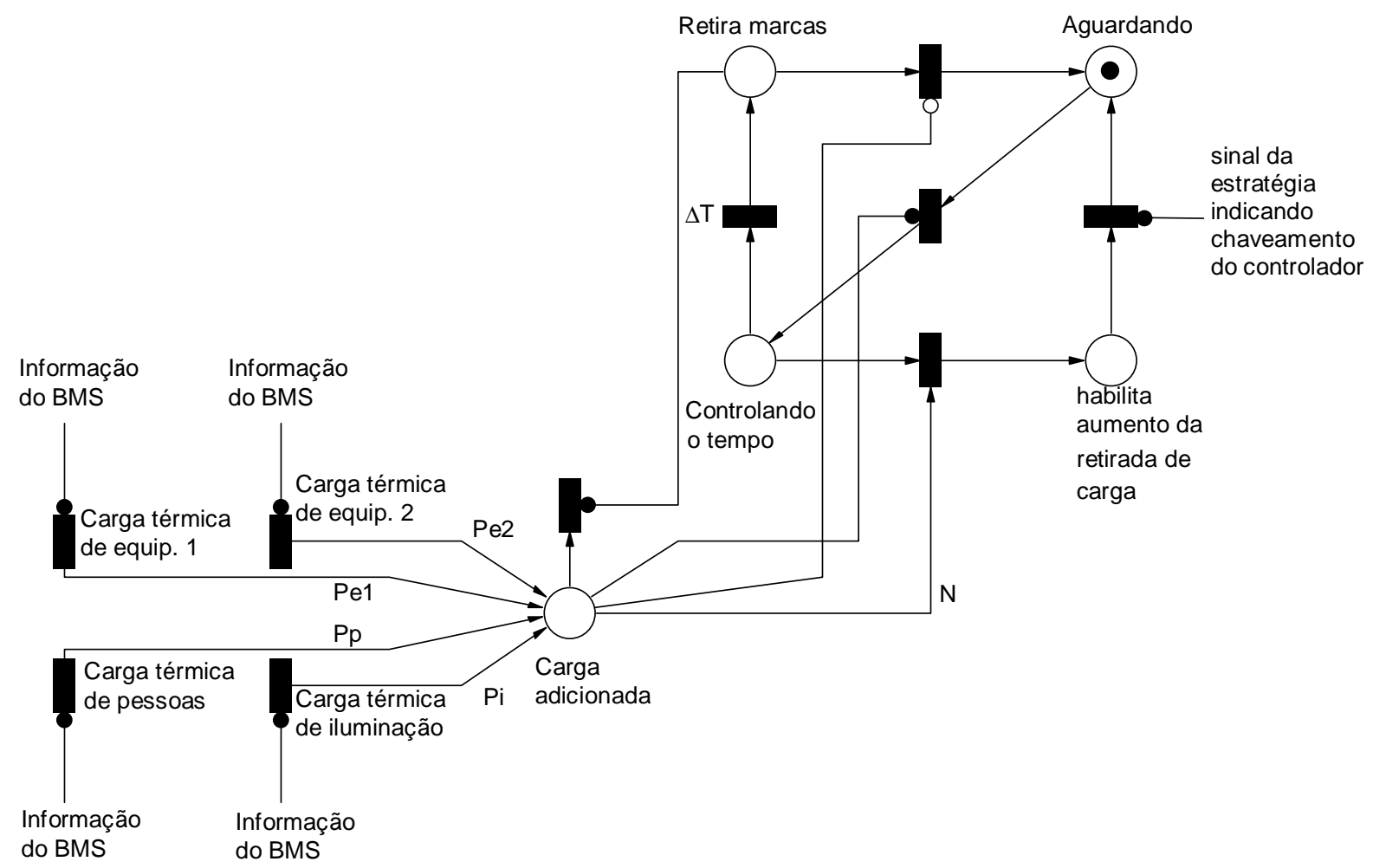

Figura 6.5. Controle de variação da carga térmica. 
$\mathrm{Na}$ parte inferior da rede da Figura 6.5, transições habilitadas pelo BMS informam o aumento de carga térmica. Os arcos associados a estas transições possuem pesos proporcionais a carga térmica introduzida no ambiente por aquele evento. Quando esta carga atinge um determinado valor limite, habilita-se o controlador. Se a carga não atingir o valor limite dentro de um determinado tempo $\Delta \mathrm{T}$, as marcas são retiradas do lugar, pois considera-se que a variação não foi ampla o suficiente para o chaveamento. A contagem do tempo é reiniciada na ocorrência de uma nova introdução de carga no ambiente.

A modificação dos controladores é realizada considerando-se que, quando ocorre uma variação discreta na carga térmica, a mesma variação deve ser provocada na carga insuflada pelo sistema de ar condicionado. Para tanto, deve ser gerada a seguinte variação na temperatura de insuflamento do ar:

$$
\Delta \mathrm{Q}=\Delta \mathrm{T}_{\mathrm{ar} \_ \text {insufl }} * \mathrm{c}_{\mathrm{p}_{-} \text {ar }} * \rho_{\mathrm{ar}} * \mathrm{v}_{\mathrm{ar}_{-} \text {insufl }}
$$

onde $\Delta \mathrm{Q}=$ variação de carga térmica para qual ocorre chaveamento do controlador;

$\Delta \mathrm{T}_{\mathrm{ar} \_ \text {insufl }}=$ variação correspondente na temperatura de insuflamento;

$\mathrm{c}_{\mathrm{p} \_ \text {ar }}=$ calor específico do ar a pressão constante;

$\mathrm{v}_{\mathrm{ar} \_ \text {insufl }}=$ volume de ar insuflado.

Uma vez conhecido $\Delta \mathrm{T}_{\text {ar_insufl, }}$, modifica-se a constante de "off-set" do controlador de modo a obter uma variação discreta na temperatura de insuflamento desejada quando ocorre uma perturbação na carga térmica:

$$
\mathrm{V}_{0_{-} \text {insufl_lf } \_ \text {c } 2}=\mathrm{V}_{0_{-} \text {insufl_lif_cl }}+\Delta \mathrm{T}_{\text {insufl }}
$$

As demais constantes do controlador são recalculadas para operação com maior carga térmica, o que resulta em um melhor controle do sistema uma vez que o sistema de ar condicionado é não linear. 
A estratégia proposta foi simulada para o ambiente apresentado no item 5.4. Para o cálculo das constantes dos controladores foi utilizado o método de Ziegler-Nichols [Åstrom \& Hägglund, 1995]. Considerou-se o chaveamento de controladores para perturbações iguais ou superiores a $7000 \mathrm{~W}$.

No exemplo apresentado o Evento 1 causa o chaveamento para a segunda configuração $(\mathrm{t}=1 \mathrm{~h})$, enquanto o Evento 2 causa o retorno para a primeira configuração. A Figura 6.6 apresenta os resultados obtidos para a evolução no tempo da temperatura no ambiente.

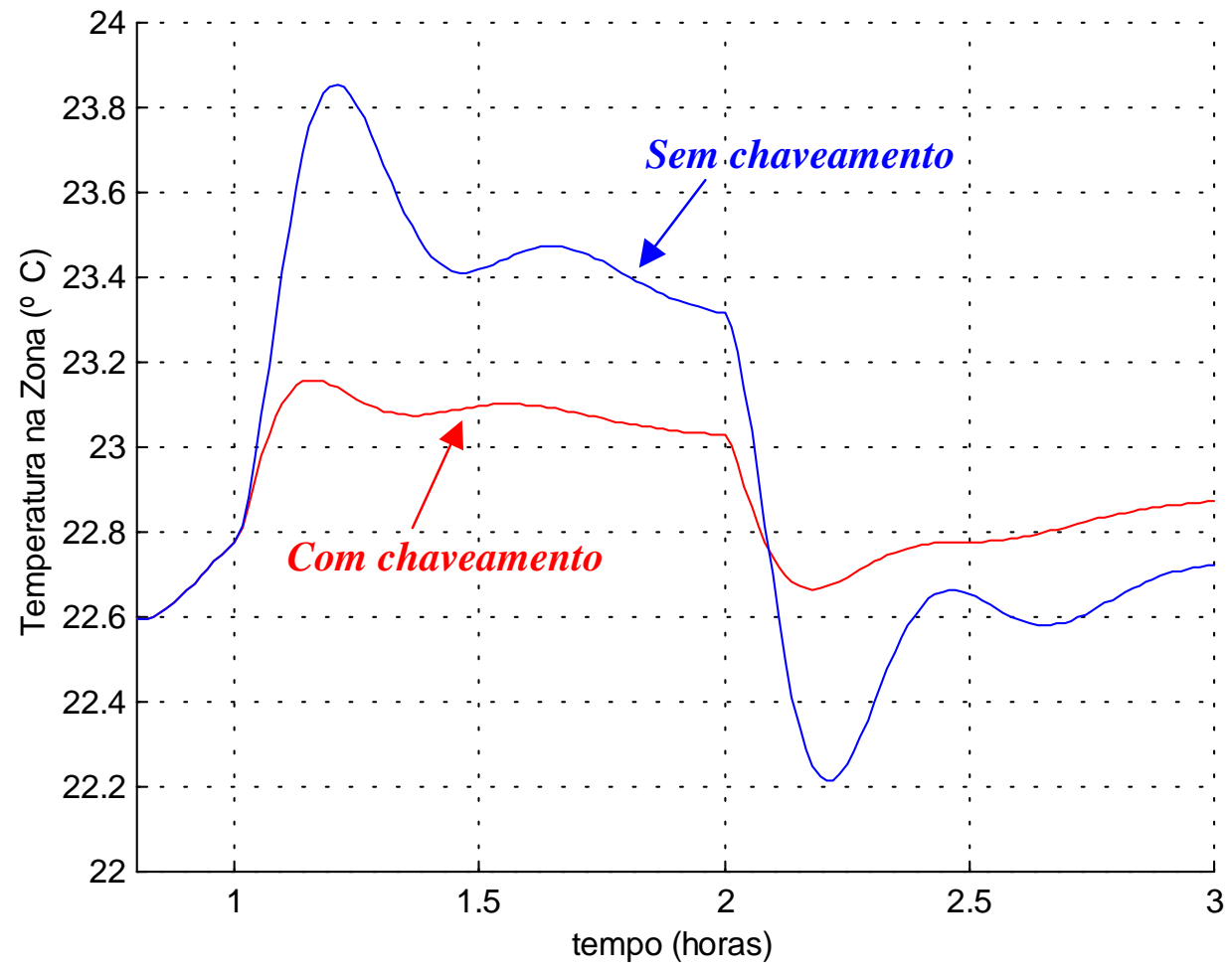

Figura 6.6. Evolução no tempo da temperatura no ambiente com e sem chaveamento.

Como é possível observar, ocorreu uma redução das oscilações provocadas pela perturbação. De acordo com o método para avaliação de ambientes apresentado na [ISO 
7730, 1994], esta redução correspondente a uma redução da porcentagem de pessoas insatisfeitas no ambiente de cerca de $9 \%$ para $5 \%{ }^{7}$.

Observa-se ainda que a eficiência do chaveamento de controladores varia de acordo com as características do sistema de ar condicionado, com o tipo de variação de carga térmica ao qual ele é submetido e com as constantes de tempo do sistema.

Em relação a utilização da estratégia no PAMB, alguns ambientes necessitam particularmente de controle das condições ambientais, como salas de cirurgia, berçários, etc.

Considerando genericamente o contexto de EI, a estratégia proposta apresenta potencial para aplicação em ambientes onde a variação discreta de carga térmica é significativa, como por exemplo em auditórios ou em ambientes com grande número de equipamentos.

\footnotetext{
${ }^{7}$ Considerou, para o cálculo velocidade do ar inferior a $0,10 \mathrm{~m} / \mathrm{s}$, atividade sedentária, umidade relativa
} do ar de $50 \%$ e vestimenta para meia estação $($ clo=1). 


\section{Conclusões e Trabalhos Futuros}

Dentro da abordagem de "Edifícios Inteligentes" (EI), a integração de sistemas é considerada um elemento essencial para a otimização dos serviços do edifício. Entre os diversos sistemas, este trabalho considerou em particular a integração do sistema de ar condicionado, cuja importância é evidenciada, entre outras coisas, pela necessidade de manutenção do conforto térmico dos usuários. Neste contexto, a metodologia apresentada no presente trabalho visa, através da simulação, fornecer dados para a análise do ambiente e do sistema de ar condicionado considerando estratégias de controle cuja evolução é determinada, entre outras coisas, pela ocorrência de eventos em outros sistemas.

Para atingir o objetivo acima foi introduzida uma abordagem híbrida, onde aspectos discretos e contínuos são considerados. Os sistemas híbridos são um tópico de estudo relativamente recente, quando comparado com os sistemas a eventos discretos ou com o sistemas de variáveis contínuas. Existem ainda muitas controvérsias a respeito de definições de conceitos para estes sistemas, a começar da própria definição de sistemas híbridos, e a respeito da adaptação de conceitos utilizados em sistemas discretos para sistemas contínuos e vice-versa. Um exemplo típico refere-se ao problema encontrado no presente trabalho para a definição do que é uma atividade e o que é uma interatividade em um fluxo contínuo de material.

Quanto a modelagem de sistemas híbridos, muitas técnicas já foram propostas. No entanto, estes modelos geralmente são adequados para a modelagem de uma classe 
específica de sistemas. Através dos estudos realizados, conclui-se que para uma ferramenta de modelagem ser aplicável a uma grande gama de tipos de sistemas, ela não deve tentar incorporar em modelos discretos elementos que representem variáveis contínuas (como lugares e transições contínuos para as Redes de Petri) ou tentar incorporar em modelos contínuos elementos que representem eventos discretos (como variáveis discretas em equações), mas sim definir uma interface entre os dois modelos de modo a permitir maior flexibilidade de modelagem tanto da parte contínua quanto da parte discreta. A rede de Petri Predicado-Transição Diferencial utilizada neste trabalho é um exemplo de modelo onde procurou-se conservar as características iniciais dos dois modelos: redes de Petri e sistemas de equações diferenciais e algébricas.

A metodologia proposta é baseada no detalhamento sucessivo do modelo do sistema, de acordo com uma abordagem hierárquica e modelar, que, em comparação a uma abordagem não hierárquica, apresenta maior facilidade de construção, compreensão e utilização.

Neste trabalho focalizou-se a utilização da metodologia para o estudo do conforto térmico nos ambiente. No entanto, observa-se que um campo onde a metodologia apresenta grande potencial de aplicação é na otimização do consumo de energia, sendo que este também é um dos principais objetivos dos EI e que o ar condicionado está entre os sistemas que apresentam maior consumo de energia dentro de um edifício.

No que diz respeito ao tratamento de perturbações proposto, demostrou-se que este tipo de controle pode compensar a inércia do sistema de ar condicionado. No caso proposto, considerou-se que o tempo para a carga térmica se distribuir no ambiente e elevar a temperatura de toda a zona condicionada é aproximadamente equivalente ao tempo de resposta do ar condicionado. Obviamente isto não ocorre em todos os sistemas, podendo variar de acordo com o tamanho da zona, com o tipo de carga 
térmica introduzida, com as características do sistema de ar condicionado, entre outras coisas. Assim, de acordo com as constantes de tempo do sistema deve-se também considerar a realização de intervenções antes e/ou depois da ocorrência dos eventos discretos.

Quanto a sugestões para o desenvolvimento de trabalhos futuros, propõem-se:

- Construção de um simulador de sistemas de equações diferenciais, de redes PTD e de redes de Petri;

- Adaptação da metodologia proposta para outros tipos de sistemas híbridos;

- Adaptação da metodologia para gerar as especificações de sistemas de controle;

- Desenvolvimento de uma metodologia semelhante para outros sistemas do EI, considerando inclusive o BMS (Building Management System).

- Para o tratamento de perturbações, utilização de modelos mais complexos para o ambiente, onde fossem representadas as temperaturas em diversos pontos da zona. 


\section{Anexo 1 - Redes de Petri Híbridas}

A Rede de Petri Contínua foi criada inicialmente para representar SED onde a quantidade de marcas é muito elevada, causando uma explosão no número de estados alcançáveis. Em seguida, sua utilização foi estendida para sistemas contínuos e, sucessivamente, para sistemas híbridos através da definição de Redes de Petri Híbridas, onde coexistem elementos discretos e contínuos.

Similarmente às Redes de Petri discretas, as Redes de Petri Híbridas podem ser divididas em autônoma, onde o tempo não é considerado, e em temporizada, onde associa-se uma velocidade de disparo para cada transição. No presente trabalho será abordada apenas as redes temporizadas, uma vez que os modelos autônomos são utilizados apenas para representar aproximações de sistemas discretos [Alla \& David, 98].

Baseando-se na Rede de Petri Lugar/Transição, aos lugares e transições discretos (Figura A.1.1 a e c) foram adicionados os seguintes elementos, formando, assim, a Rede de Petri Híbrida:

- lugares contínuos: cuja marcação é um número real não negativo (Figura A.1.1b);

- transições contínuas: as quais são associadas velocidades máximas de disparo representando um fluxo contínuo de marcas (Figura A.1.1d);

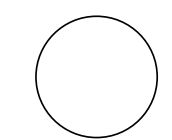

a) Lugar Discreto

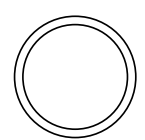

b) Lugar Contínuo

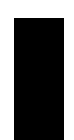

c) Transição Discreta

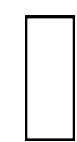

d) Transição Contínua

Figura A.1.1. Elementos discretos e contínuos. 
A velocidade de disparo de uma transição é a velocidade máxima definida para ela enquanto a marcação dos lugares de entrada for suficiente, caso contrário a velocidade de disparo é limitada pela somatória da quantidade de marcas presente nos lugares de entrada e dos fluxos de marcas que estão entrando nestes lugares.

Um exemplo ilustrativo da utilização dos elementos contínuos é apresentado na Figura A.1.2.

No sistema da Figura A.1.2a, um líquido flui do Tanque 1 para o Tanque 2 pela força da gravidade com um fluxo de $0,003 \mathrm{~m}^{3} / \mathrm{s}$. O fluxo do Tanque 2 para o Tanque 1 é realizado através de uma bomba a uma vazão de $0,002 \mathrm{~m}^{3} / \mathrm{s}$. A rede de Petri correspondente é apresentada na Figura A.1.2b. Os volumes iniciais são $0,18 \mathrm{~m}^{3}$ para o Tanque 1 e $0 \mathrm{~m}^{3}$ para o Tanque 2.

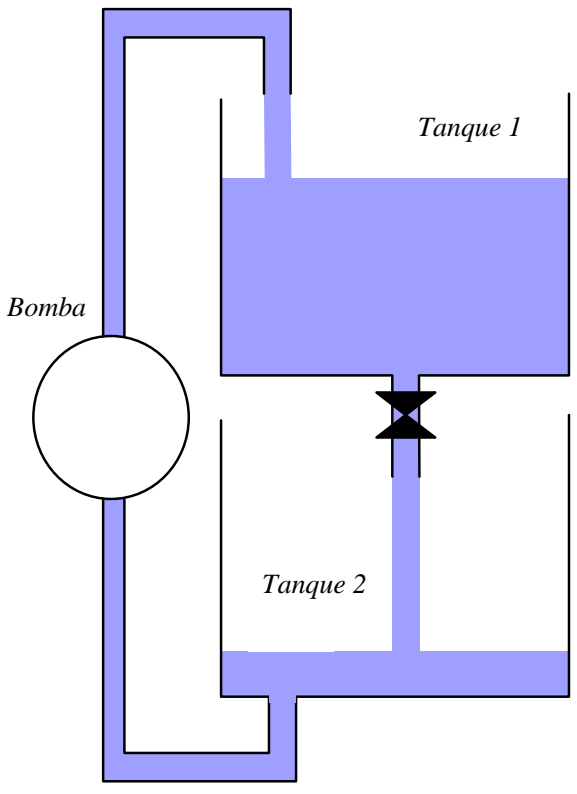

a) Sistema contínuo

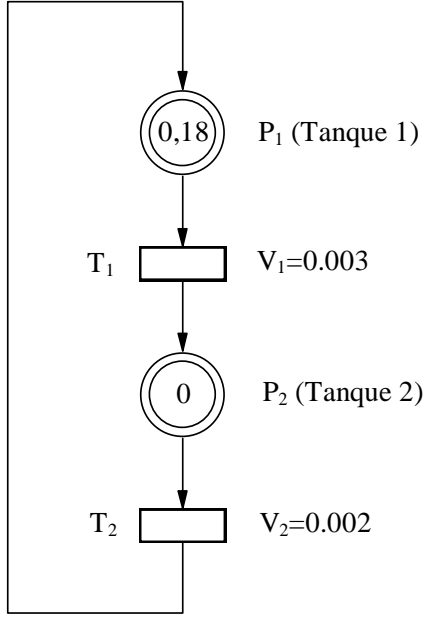

b) Rede de Petri

Figura A.1.2 Exemplo de modelagem de sistema contínuo.

A Figura A.1.3 apresenta a evolução no tempo da marcação de $\mathrm{P}_{1}$ e $\mathrm{P}_{2}$, bem como a velocidade de disparo das transições $\mathrm{T}_{1}$ e $\mathrm{T}_{2}$. 

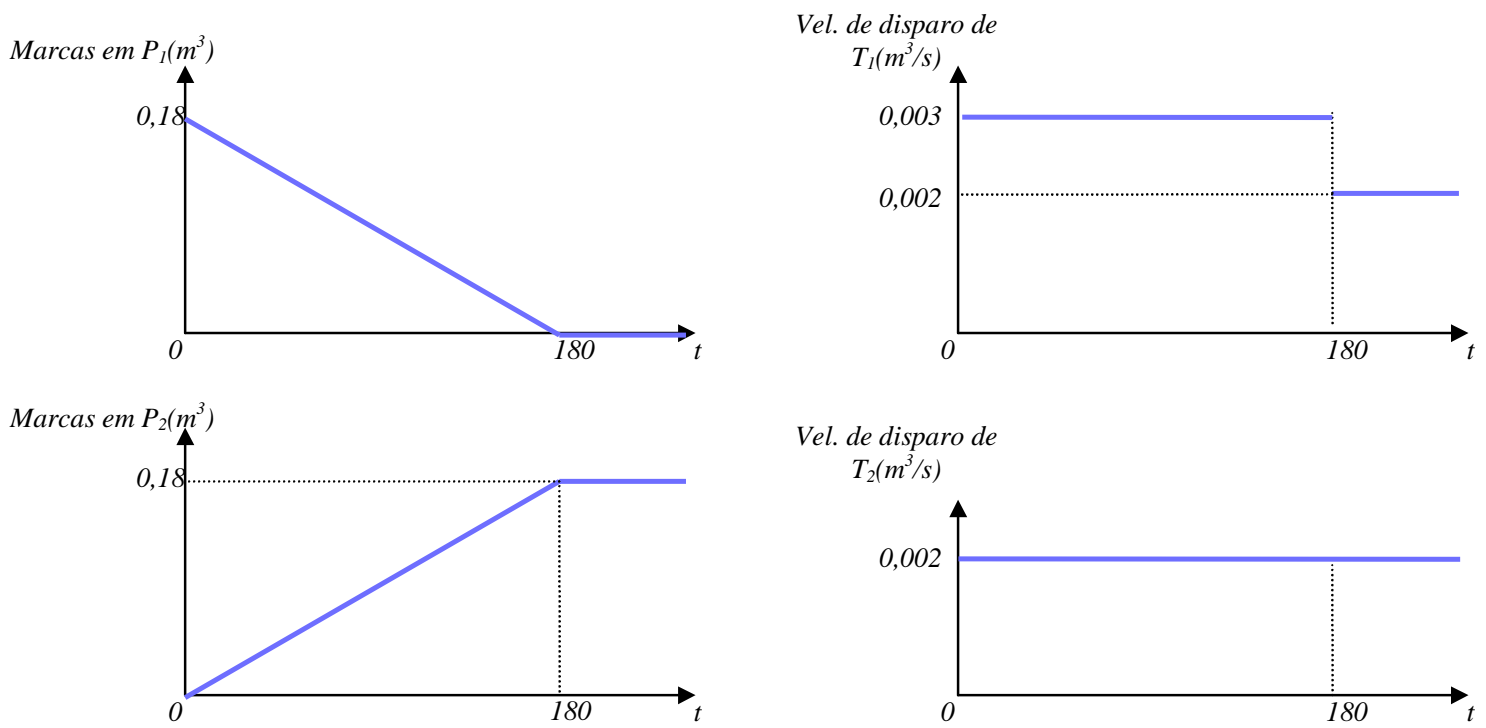

Figura A.1.3. Evolução do sistema no tempo.

Enquanto houver líquido no Tanque 1 a velocidade de disparo de T1 será a velocidade máxima. Durante este intervalo, ou seja, enquanto $t \leq 180$ s, a evolução no tempo da marcação dos lugares contínuos é representada pelas seguintes equações, onde $\mathrm{m}_{1}$ e $\mathrm{m}_{2}$ representam a marcação dos lugares $\mathrm{P}_{1}$ e $\mathrm{P}_{2}$, respectivamente :

$$
\begin{aligned}
& \mathrm{m}_{1}(\mathrm{t}+\mathrm{dt})=\mathrm{m}_{1}(\mathrm{t})-(0,003-0,002) d t \\
& \mathrm{~m}_{2}(\mathrm{t}+\mathrm{dt})=\mathrm{m}_{2}(\mathrm{t})+(0,003-0,002) d t
\end{aligned}
$$

Integrando as equações acima tem-se:

$$
\begin{aligned}
& \mathrm{m}_{1}(\mathrm{t})=\mathrm{m}_{1}\left(\mathrm{t}_{0}\right)+\int_{\mathrm{t}_{0}}^{\mathrm{t}}(-0,003+0,002) \mathrm{dt}=0,180-0,001 * \mathrm{t} \\
& \mathrm{m}_{2}(\mathrm{t})=\mathrm{m}_{2}\left(\mathrm{t}_{0}\right)+\int_{\mathrm{t}_{0}}^{\mathrm{t}}(0,003-0,002) \mathrm{dt}=0,001 * \mathrm{t}
\end{aligned}
$$

Após 180 segundos o Tanque 1 estará vazio. A partir deste instante ( $>180$ s) a velocidade de disparo de T1 será reduzida ao fluxo do líquido que está entrando neste tanque. Tem-se, então, as seguintes equações representando a marcação do sistema: 


$$
\begin{aligned}
& \mathrm{m}_{1}(\mathrm{t})=\mathrm{m}_{1}\left(\mathrm{t}_{180}\right)+\int_{\mathrm{t}_{180}}^{\mathrm{t}}(-0,002+0,002) \mathrm{dt}=0,000 \\
& \mathrm{~m}_{2}(\mathrm{t})=\mathrm{m}_{2}\left(\mathrm{t}_{180}\right)+\int_{\mathrm{t}_{0}}^{\mathrm{t}}(0,002-0,002) \mathrm{dt}=0,180
\end{aligned}
$$

A máxima velocidade de disparo de uma transição pode ser determinada de diversas formas [Alla \& David, 1998]. No exemplo apresentado na Figura A.1.2 esta velocidade é constante. Uma outra opção é a associação a transição de uma velocidade máxima variável dependente da marcação de lugares. A Figura A.1.4 apresenta um exemplo com o respectivo equacionamento.

$$
\begin{aligned}
& \mathrm{v}_{1}(\mathrm{t})=0,250 * \mathrm{~m}_{1} \\
& \mathrm{v}_{2}(\mathrm{t})=0,125 * \mathrm{~m}_{2} \\
& \dot{\mathrm{m}}_{1}(\mathrm{t})=\mathrm{v}_{2}(\mathrm{t})-\mathrm{v}_{1}(\mathrm{t})=0,125 * \mathrm{~m}_{2}-0,250 * \mathrm{~m}_{1} \\
& \dot{\mathrm{m}}_{2}(\mathrm{t})=\mathrm{v}_{1}(\mathrm{t})-\mathrm{v}_{2}(\mathrm{t})=0,250 * \mathrm{~m}_{1}-0,125 * \mathrm{~m}_{2} \\
& \mathrm{~m}_{1}(\mathrm{t})=\mathrm{m}_{1}\left(\mathrm{t}_{0}\right)+\int_{\mathrm{t}_{0}}^{\mathrm{t}} \dot{\mathrm{m}}_{1} \mathrm{dt} \\
& \mathrm{m}_{2}(\mathrm{t})=\mathrm{m}_{2}\left(\mathrm{t}_{0}\right)+\int_{\mathrm{t}_{0}}^{\mathrm{t}} \dot{\mathrm{m}}_{2} \mathrm{dt}
\end{aligned}
$$

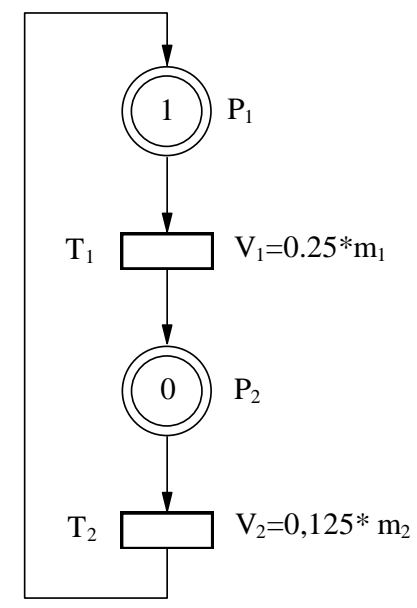

Figura A.1.4. Rede de Petri com velocidade variável.

Outra opção consiste na associação à transição de uma taxa de disparo dependente do tempo.

A Rede de Petri Híbrida apresentada por [Alla \& David, 1998] comporta ainda a associação de pesos aos arcos e a introdução de arcos inibidores.

Quanto a ocorrência de conflitos, o disparo de uma transição discreta tem prioridade sobre o disparo de uma transição contínua. Quando o conflito ocorre entre o disparo de duas transições contínuas não existe uma regra previamente definida, podese estabelecer prioridades para disparo ou divisão da marcação disponível entre os dois lugares. 


\section{Anexo 2 - Redes de Petri Diferenciais}

\section{(rede RPD)}

Este tipo de rede introduz a definição de transição diferencial e de lugar diferencial, onde os lugares diferenciais suportam números negativos. A representação gráfica dos novos elementos é apresentada na Figura A.2.1.
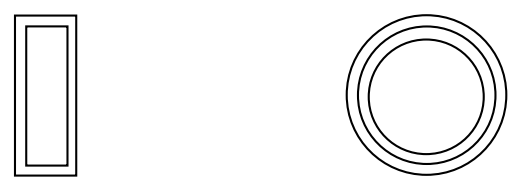

Figura A.2.1. Transição diferencial e lugar diferencial.

Estes elementos podem ser descritos como:

- lugares diferenciais: lugares cuja marcação é um número real (positivo, negativo ou nulo).

- transições diferenciais: transições cuja velocidade de disparo pode ser uma constante, uma combinação linear ou uma função não linear da marcação dos lugares diferenciais conectados a equação diferencial.

Observa-se que, como os lugares podem atingir valores negativos, não existe sentido em definir-se a velocidade associada a transição como velocidade máxima.

Como exemplo apresenta-se a rede correspondente a um sistema cujo comportamento é representado pelo chaveamento dos seguintes equacionamentos:

Caso 1) $\dot{\mathrm{x}}(\mathrm{t})=\mathrm{x}$

Caso 2) $\dot{\mathrm{x}}(\mathrm{t})=-6$

onde x é a variável que se deseja representar. 
Uma rede RPD correspondente é apresentada na Figura A.2. 2. A marcação do lugar P3 representa a variável “x”. Quando P1 está marcado, a transição T3 está habilitada, e sua taxa de disparo $(\dot{\mathrm{x}})$ corresponde a "x". Neste caso, tem-se que o comportamento do sistema é representado pelo equacionamento do Caso 1). Quando T2 dispara, P2 é marcado e T4 passa a estar habilitada no lugar de T3, disparando com taxa correspondente a “-6". Neste caso, tem-se que o comportamento do sistema é representado pelo equacionamento do Caso 2).

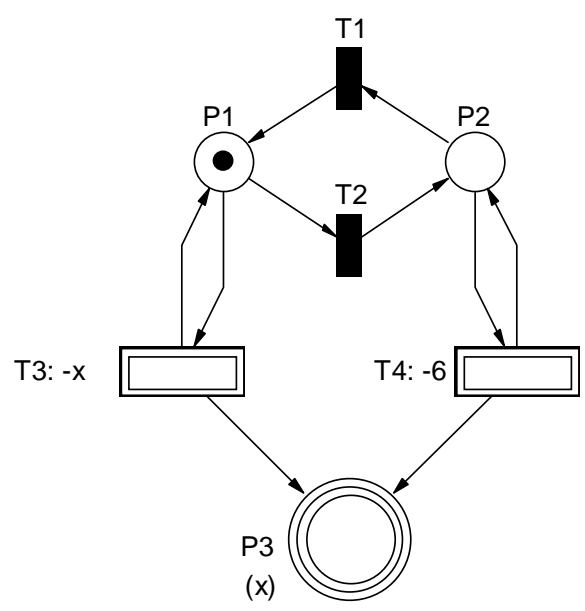

Figura A.2. 2. Exemplo de Rede de Petri Diferencial.

Para a execução da rede, a parte contínua é discretizada. Associa-se então, a cada transição diferencial, uma frequiência de disparo que representa o passo de integração que será utilizado no cálculo da integral da equação da transição. 


\section{Anexo 3 - Rede Híbrida Orientada a}

\section{Objetos (Hybrid Object Net)}

Este tipo de rede baseia-se em uma rede de Petri semelhante as Redes de Petri Diferenciais, observando apenas que a velocidade de disparo da transição pode ser função da marcação de qualquer lugar da rede.

O sistema a ser modelado deve ser decomposto em objetos que interagem entre si. Os conceitos referentes a modelagem orientada a objetos ${ }^{8}$ são aplicados da seguinte forma:

- Atributos: são representados em lugares, o seu conteúdo é representado pela marcação do lugar. Os atributos públicos são aqueles que podem ser acessados por outros objetos.

- Métodos: são representados na forma de estrutura da rede.

- Informações escondidas: é considerado através do encapsulamento de informações sobre a estrutura da rede. Definindo-se a interface do objeto determina-se quais serão os atributos públicos.

- Abstração: consiste em transformar uma estrutura de rede em uma classe.

- Hereditariedade: consiste em criar um objeto a partir de uma classe (instanciamento de uma classe).

- Compartilhamento de dados: é realizado através do fluxo de marcas entre objetos.

\footnotetext{
${ }^{8}$ Conceitos referentes a modelagem orientada a objetos, como atributo, método, classe, etc., podem ser encontrados em [Meyer, 1997]
} 
- Reutilização: é considerada através da hereditariedade e do instanciamento de classes. Objetos derivados podem ser refinados através da adição de lugares, transições e arcos, mas nenhum elemento herdado pode ser apagado.

Um exemplo é apresentado na Figura A.3.1, onde uma rede compara dois valores quaisquer $\mathrm{x}_{1}$ e $\mathrm{x}_{2}$ e indica se $\mathrm{x}_{2}<\mathrm{x}_{1}$, se $\mathrm{x}_{2}=\mathrm{x}_{1}$ ou se $\mathrm{x}_{2}>\mathrm{x}_{1}$. Esta rede é transformada na classe "Comparador", para a qual é definida uma interface. Esta classe é instanciada no objeto "Comparador_1" que compara a posição de um robô com a posição da peça e move o robô de acordo com o resultado.
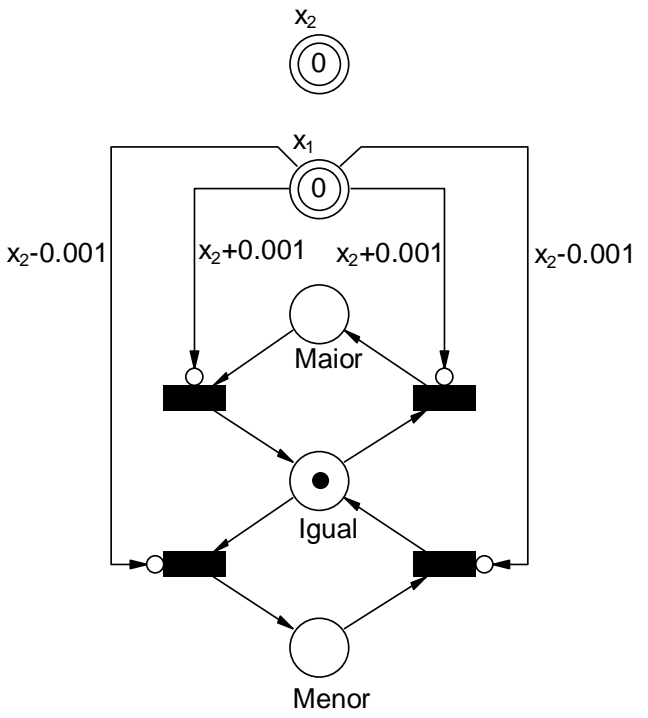

a) Rede de um Comparador

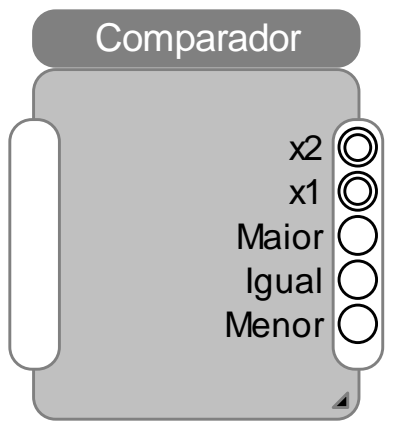

b) Definição da classe "Comparador"
Posiciona o robô
Pega

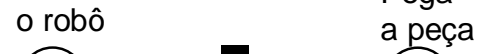
(1) 
Outros exemplos de Rede Híbrida Orientada a Objetos podem ser encontrados em [Drath, Engmann \& Schwuchow, 1998]. 


\section{Anexo 4 - Rede de Petri de Alto Nível}

\section{(HyNets)}

Nesta rede marcas são objetos pertencentes a classe elementares ou a classes definidas. A linguagem utilizada na definição de objetos e classes é baseada em C++. Por classes elementares entende-se as classes já definidas em $\mathrm{C}++$, como "int”, "bool”, “char”, entre outras. A definição de uma nova classe é realizada através da definição de seus atributos e métodos. Os atributos são definidos a partir das classes elementares. Os métodos são definidos através de operações matemáticas. Como exemplo apresenta-se a definição de uma classe para representação de tanques. Para esta classe são definidos como atributos a área $A$, o nível de líquido $l$ e a densidade $d$. São também definidos dois métodos $v()$ e $p()$ onde $v()$ calcula o volume de líquido no tanque e $p()$ a pressão na sua base.

Class Tank \{float A; double d; real $\boldsymbol{l}$; double $\boldsymbol{v}()$; double $\boldsymbol{p ( )}$; \}

Double Tank $:: v()$ \{return $(A * l) ;\}$

Double Tank :: $\boldsymbol{p}()$ \{return $\left.\left(d^{*} l\right) ;\right\}$

Os elementos presentes na rede são transições discretas e contínuas e lugares.

Aos lugares associa-se uma classe e uma capacidade. A classe pode ser uma classe elementar ("int", "char", etc.) ou um classe definida (ex. "Tanque”). A capacidade do lugar indica o número máximo de objetos que ele pode conter.

Arcos têm peso e um nome de variável a ele associado. O peso indica o número de objetos que será retirado ou adicionado ao lugar a ele conectado. O nome é utilizado para referenciar em uma transição os objetos de um lugar. Por exemplo, se um arco é 
nomeado $x$ e tem peso dois, duas variáveis são associadas a ele $x(1)$ e $x(2)$. Os arcos podem ser arcos orientados, arcos contínuos, arcos habilitadores e arcos inibidores.

As transições têm as seguintes características:

- Condição de ativação: é utilizada para impor condições adicionais para o disparo da transição, deve ser definida como uma expressão booleana em função da marcação dos lugares de entrada.

- Ação de disparo: em caso de transições discretas, é constituída por expressões que determinam os objetos introduzidos nos lugares de saída a partir dos objetos retirados dos lugares de entrada. Para transições contínuas a ação de disparo é constituída por um sistema de equações algébricas e diferenciais. Apenas as variáveis do tipo real podem se encontrar do lado esquerdo das expressões.

Para as transições discretas tem-se ainda mais duas inscrições: o tempo de atraso e o tempo de disparo.

Um exemplo de disparo discreto é apresentado na Figura A.4.1.

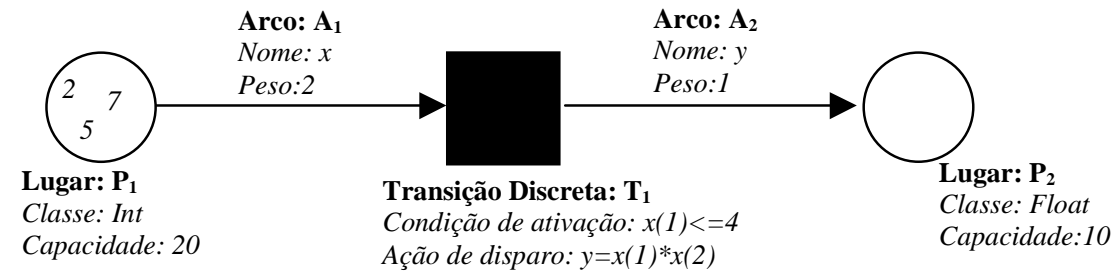

a) Antes do disparo

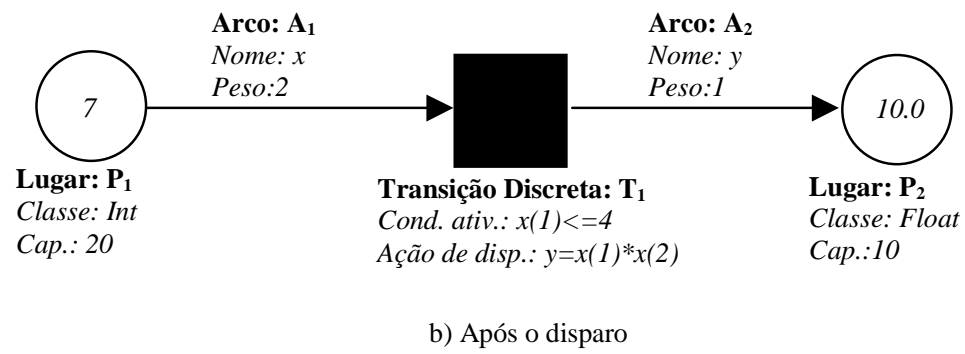

Figura A.4.1. Disparo de transição discreta 
Neste exemplo, o lugar $\mathrm{P}_{1}$ pode conter objetos apenas da classe "int" (números inteiros). Sua capacidade máxima é de 20 elementos. No estado representado na Figura A.4.1 a) ele contém 3 elementos: “2”, "7" e "5". O lugar $\mathrm{P}_{2}$ pode conter até 10 objetos da classe "float" e no estado representado na Figura A.4.1. b) está vazio. O arco $\mathrm{A}_{1}$ tem nome " $\mathrm{x}$ " e peso 2, o que indica que, quando $\mathrm{T}_{1}$ dispara, são retirados dois elementos do lugar $\mathrm{P}_{1}$. Estes elementos, chamados de $\mathrm{x}(1)$ e $\mathrm{x}(2)$, são utilizados nas funções associadas à transição $\mathrm{T}_{1}$. A transição $\mathrm{T}_{1}$ possui como condição de disparo $\mathrm{x}(1) \leq 4$. $\mathrm{O}$ disparo de $\mathrm{T}_{1}$ gera um elemento y que é adicionado ao lugar $\mathrm{P}_{2}$. y é da classe "float" e o seu valor é determinado pela ação de disparo.

No exemplo acima havia duas possibilidades de disparo: a primeira onde $\mathrm{x}(1)=2 \mathrm{e}$ $x(2)=5$, resultando em $y=10,0$, e a segunda onde $x(1)=2$ e $x(2)=7$, resultando em $y=14,0$. A decisão neste caso é tomada aleatoriamente. A Figura A.4.1 b) representa o disparo de $\mathrm{T}_{1}$ utilizando a primeira opção.

Um exemplo de transição contínua é apresentado na Figura A.4.2.

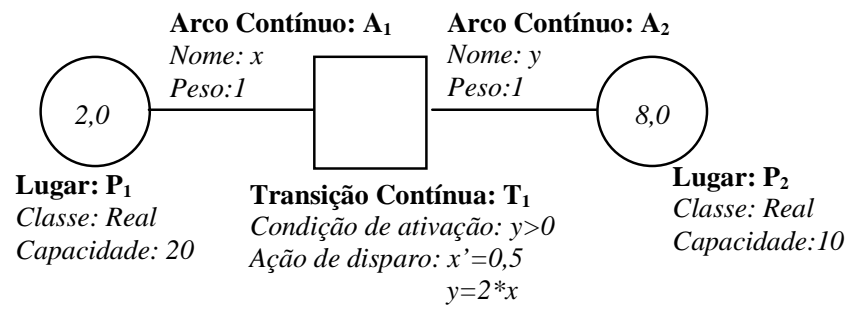

Figura A.4.2. Exemplo de transição contínua

Neste exemplo a transição $\mathrm{T}_{1}$ modifica um elemento $\mathrm{P}_{1}$ e um elemento de $\mathrm{P}_{2}$, chamados de $\mathrm{x}$ e $\mathrm{y}$, de acordo com as expressões da ação de disparo. Observa-se que o arco contínuo não é orientado. As expressões associadas a ação de disparo das transições podem ser algébricas (" $\mathrm{y}=2^{*} \mathrm{x}$ ”) e diferenciais de primeira ordem (“ $\dot{\mathrm{X}}=0,5$ "). 
Outros exemplos e definições formais podem ser encontrados em [Wieting, 1996 a e b]. 


\section{Bibliografia}

Abramson, A. B. (1995) "The Intelligent Building Evolution"; In: Proceedings of IB/IC Intelligent Buildings Congress, Telaviv.

Alla, H. \& DAVID, R (1998) "Continuous and Hybrid Petri Nets" Journal of Circuits, Systems and Computers, vol.8, n.1, pp 159-188.

ANTSAKLIS, P. J. \& Nerode, A. (1998) "Hybrid Control Systems: An Introductory Discussion to the Special Issue" IEEE Transactions on Automatic Control, vol 43, n.4, pp 457-459.

ARKIN, H. \& PACIUK, M.(1995) "Service Systems Integration in Intelligent Buildings "; In: Proceedings of IB/IC Intelligent Buildings Congress", Telaviv.

ARKIN, H. (1997) "Introduction of special issue of intelligent buildings"; In: Automation in Construction, vol. 6 n.5, pp 379-381.

ASHRAE. (1991) ASHRAE Handbook of HVAC Applications. American Society of Heating, New York.

ASHRAE. (1996) ASHRAE Handbook of Guide and Databook Equipment. American Society of Heating, New York.

ASHRAE. (1997) ASHRAE Handbook of Fundamentals. American Society of Heating, New York.

ÅströM, K. \& HÄGGLund, T. (1995) PID Controllers: Theory, Design, and Tuning, $2^{\text {nd }}$ ed., ISA, New York.

BECKER, R. (1995) "What is an "Intelligent Building"; In: Proceedings of IB/IC Intelligent Buildings Congress, Telaviv.

Blanchard, B.S. \& Wolter, J. F. (1981). Systems Engineering and Analysis, Prentice Hall, New York.

CARrIer, W. H. (1950) Modern Air Conditioning, Heating and Ventilating. Pittman publishing corporation, New York.

Champagnat, R. (1998) Supervision des Systèmes Discontinus: Definition d'un Modèle Hybride et Pilotage en Temps-rèel Thèse de Doctorat, Université Paul Sabatier, Toulouse.

Champagnat, R. ET All (1998a). "Petri Net Based Modeling of Hybrid Systems". Computers in Industry, vol. 36, n.1-2, pp 139-146.

Champagnat, R. ET ALl (1998b). "Modelling and Simulation of a Hybrid System through Pr/Tr PN-DAE Model" ADMP'98 $3^{\text {rd }}$ International Conference on Automation of Mixed Processes, Reims.

Champagnat, R. ET ALl (1998c). "A Gas Storage Example as a Benchmark for Hybrid Modeling" ADMP'98 $3^{\text {rd }}$ International Conference on Automation of Mixed Processes, Reims.

Chow, T.T. (1997) "Chilled Water Cooling Models From Empirical to Fundamental" Numerical Heat Transfer, v.32 n.1.

DAvid, R \& Alla, H. (1994) "Petri Nets for Modeling of Dynamic Systems - A Survey" Automática, v.30, n.2, p175-201.

Demongodin, I. \& Koussoulas, N. T. (1998). “ Differential Petri Nets: Representing Continuous Systems in a Discrete-Event World". IEEE Transactions on Automatic Control, vol. 43, n.4, pp 573-579. 
DrATH, R. (1998). "Hybrid Object Nets: An Object Oriented Concept for Modelling Complex Hybrid Systems" ADMP'98 $3^{\text {rd }}$ International Conference on Automation of Mixed Processes, Reims.

Drath R., Engmann U. \& Schwuchow S.(1998). "Hybrid Aspects of Modelling Manufacturing Systems Using Modified Petri Nets", Brasil.

FANGer, P. O. (1970) Thermal Confort. McGraw-Hill, New York.

FAnger, P. O. (1972) "Conditions for Thermal Comfort - A Review"; In: Proceedings of CIB Commission W 45 Symposium, [s. 1.].

FANGER, P. O. (1986) "Radiation and Discomfort"; In: ASHRAE Journal, vol.28 n.2 pp 33-34.

Finley, M. R. \& KAMAE, T. (1993) "Current Trends in Intelligent Buildings: From Materials to Media"; In: IEEE Communications Magazine, pp 18-21, vol. $31 \mathrm{n}$. 10.

Finley, M. R., KARAKURA, A \& NBOGNI, R. (1991) "Survey of Intelligent Buildings Concepts"; In: IEEE Communications Magazine, pp 18-23, vol. 29 n. 4.

FLAX, B. M. (1991) "Intelligent Buildings"; In: IEEE Communications Magazine, pp 24-26, vol. 29 n. 4.

Frota, A. B.\& Schiffer, S. R. (1988) Manual de Conforto Térmico; Nobel, São Paulo.

FujIE, S. \& Mikami, Y.(1991) "Construction Aspects of Intelligent Buildings"; In: IEEE Communications Magazine, pp 50-57, vol. 29 n. 4.

GENRICH, H. J. (1987). "Predicate/transition nets", Lecture Notes in Computer Science, Springer-Verlag, Berlin.

Gotesman, M. \& Benitez, N. L. (1996). "Petri Net-Based Modeling of Hybrid Dynamic Systems" $34^{\text {th }}$ Annual Allerton Conference on Communication, Control and Computing'96, Illinois.

HAnsen, S. J. (1991) Managing Indoor Air Quality. Prentice Hall, Inc., New York.

Ho, Y. C. (1987) "Basic research, manufacturing automation, and putting the cart before the horse". IEEE Transactions on Automatic Control, vol.AC-32, n.12, pp.1042-1043.

Ho, Y. C. (1989) "Scanning the issue - Dynamics of discrete event systems". Proceedings of IEEE, vol.77, n.1, pp.3-6.

Holmes, M. J. (1982) "The simulation of Heating and Cooling Coils for Performance Analysis". Proceedings of the First International Conference on System Simulation in Buildings, Liege.

Honeywell. (1995) Engineering Manual of Automatic Control - HVAC. Honeywell, Minnesota.

Hudson, G \& Underwood, C. P. (1999). “A Simple Building Modelling Procedure for MatLab/Simulink" Proceeding of Sixth International IBPSA Conference (BS'99), Kyoto.

INCROPERA, F. P. (1990) Fundamentals of heat and mass transfer, Wiley, New York .

Iso 7730 (1994) Moderate Thermal Environments - Determination of the PMV and $P P D$ indices and specification of the conditions of thermal comfort, International Organization for Standartization.

JabARdo, J. M. S. (1984) Conforto Térmico das Habitações; Eternit/IPT, São Paulo.

KRONER, W. M. (1997) "An intelligent and responsive architecture"; In: Automation in Construction, pp 381-393, vol. 6 n.5.

Kujuro, A. \& YASUdA, H. (1993) "Systems Evolution in Intelligent Buildings"; In: IEEE Communications Magazine, pp 22-26, vol. 31 n. 10. 
MAEDA, S. (1993) Intelligent Buildings - a Key Solution for the $21^{\text {st }}$ Century Office ; Thesis, Stanford University, Stanford.

Matsusaki, C. T. M. (1998) Redes F-MFG (Functional Mark Flow Graph) e sua aplicação no projeto de sistemas antropocêntricos, Dissertação de Mestrado, Escola Politecnica da Universidade de São Paulo, São Paulo.

MEYER, B. (1997) Object-oriented software construction, Prentice Hall, New York, N.J.

MeYer, M. K. \& EMERY, A. F. (1995) "Optimal control of an HVAC System Using Cold Storage and Building Thermal Capacitance", Energy and Buildings vol. 23, pp 19-31.

MCQuiston \& F. C.; PARKER, J. D. (1994) Heating, Ventilating and Air Conditioning, Analysis and Design. John Wiley \& Sons, Inc, New York.

Miyagi, P.E. (1988) Control System Design, Programming and Implementation for Discrete Event Production Systems by Using Mark Flow Graph, Doctoral Thesis, Tokyo Institute of Technology, Tokyo.

Miyagi, P.E. (1996) Controle Programável - fundamentos do controle de sistemas a eventos discretos; Editora Edgard Blücher Ltda, S. Paulo, SP.

NoRmas, (1985) Normas Para Projeto de Estabelecimentos Assistenciais de Saúde, São Paulo.

Petterson, S. \& Lennartson, B. L. (1996). "Modelling Analysis and Synthesis of Hybrid" Proceedings of Reglermöte'96, Luleå.

SAlSbURY, T. I. (1996) Fault Detection and Diagnosis in HVAC Systems using Analytical Models, Doctoral Thesis, Dep. of Civil and Building Engineering, Loughborough University, Loughbrough.

SchöF, S.; Sonnenschein, M. \& Wieting, R. (1995) "High-Level Modeling with THORns " Proceedings of the $14^{\text {th }}$ International Congress on Cybernetics, Namur.

SKAFIDAS ET ALL, (1999) "Stability Results for Switched Controller Systems" Automatica, vol.35 n.4.

Stiver, J. A., Antsaklis, D. A. \& Lemmon, M. D. (1995) "Interface and Controller Design for Hybrid Control Systems" Lecture in Computer Science 999 Hybrid Systems II, Springer, Berlin.

Stocker, W. F. (1985) Refrigeração e Ar Condicionado. McGraw-Hill do Brasil, São Paulo.

STÖRRLE, H. (1998) "An Evaluation of High End Tools for Petri-Nets", In: http://www.daimi.aau.dk/PetriNets/.

Taube, G \& Barbosa, W. (1997) PSICRO - Programa de Cálculos Psicométricos, Trabalho de Formatura, Depto. Engenharia Mecânica, EPUSP, São Paulo.

VALENTIN-Roubinet (1998). "Modelling of Hybrid Systems: DAE Supervised by Petri Nets" ADMP'98 $3^{\text {rd }}$ International Conference on Automation of Mixed Processes, Reims.

WiETING, R. (1996a) "Modeling and Simulation of Hybrid Systems Using Hybrid HighLevel Nets" Proceedings of the $8^{\text {th }}$ European Simulation Symposium, Genova.

WiETING, R. (1996b) "Hybrid High-Level Nets" Proceedings of the 1996 Winter Simulation Conference, Coronado.

Wieting, R. \& Sonnenschein, M. (1995) "Extending High-Level Petri Nets for Modeling Hybrid Systems" Proceedings of IMACS Symposium on Systems Analysis and Simulation, Berlin.

YANG, Y. Y., Linkens, D. A. \& BANKS, S. P. (1995) "Modeling of Hybrid Systems Based on Extended Coloured Petri Nets" Lecture in Computer Science 999 Hybrid Systems II, Springer, Berlin. 


\section{Apêndice I - Trabalhos Publicados}

Modelagem do Sistema de Controle das Condições de Conforto Térmico em Edíficios Inteligentes

E. Villani, P. E. Miyagi, D. J. Santos Filho, N. Maruyama, J. Arakaki

Anais do XV Congresso Brasileiro de Engenharia Mecânica (COBEM'99), Águas de Lindóia, Brasil, novembro 1999

Análise Funcional do Sistema de Conforto Térmico em Edifícios Inteligentes

E. Villani, P. E. Miyagi

Anais do III Workshop SIntEd de Edifícios Inteligentes, Cancun, México, novembro 1998

Integração de Atividades e Serviços em Edifícios Inteligentes - Aplicação da Metodologia PFS/MFG

J. Arakaki, P. E. Miyagi, E. Villani, G. B. Gustin, M. M. Miyagi, M. Kisil

Anais do XVIII Encontro Nacional de Engenharia de Produção (ENEGEP'98), Rio de Janeiro, Brasil, setembro 1998

Aplicação do PFS/MFG na Modelagem de Atividades e Serviços em Edifícios Inteligentes

P.E. Miyagi, J. Arakaki, G.B. Gustin, E.Villani, M.M. Miyagi, M. Kisil

Anais da $6^{\text {a }}$ Reunião Anual da Sociedade Brasileira de Pesquisadores Nikkeis (SBPN'98), Ilha Solteira, Brasil, agosto 1998 